$\%$ 


\section{EX LIBRIS}

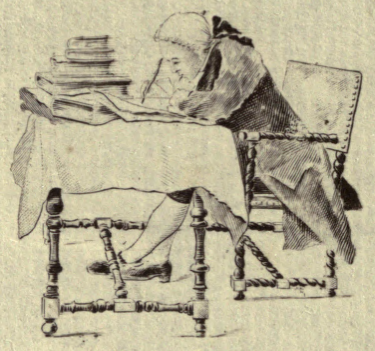

2R. A. $\mathbb{D}$ owning If ullerton

(1) $\frac{1}{1}$ 

TRAINING AND HORSE MANAGEMENT

IN INDIA. 


\section{BY THE SAME AUTHOR.}

\section{VETERINARY NOTES FOR HORSE OWNERS.}

Fourth Edition. Illustrated. Crown 8vo, 12s. 6d.

"We do not think that horse owners in general are likely to find a more reliable book for guidance in an emergency."-THE FIELD.

\section{RIDING : ON THE FLAT \& ACROSS COUNTRY.}

Third Edition. Illustrated. Imperial 16mo, 10s. 6 3.

"His instructions are simply invaluable."-THE TIMEs.

\section{ILLUSTRATED HORSE BREAKING.}

Imperial 16mo, 21s.

"Far and away the best reasoned-out one on bresking under a new sJstem we have seen."-THE FIELD.

\section{SOUNDNESS AND AGE OF HORSES.}

Illustrated. Crown 8ro, 8s. 6d.

"The result of much careful research."-THE FridD.

\section{INDIAN RACING REMINISCENCES.}

$$
\text { Illustrated. Imperial 16mo, 8s. } 6 \mathrm{~d} \text {. }
$$

"The last page comes all too soon."-THE FIELD.

\section{THE POINTS OF THE HORSE.}

Illustrated. 4to. (Nearly ready.)

THE HORSEWOMAN (Companion book to "Riding"). Illustrated. By Mrs. HAYES. Edited by Captain HAYES. 10s. 6d. 


\section{Tratning}

AND

\section{Horse Management}

\section{IN INDIA.}

WITH HINDUSTANEE VOCABULARY AND C. T. C. WEIGHTS FOR AGE AND CLASS.

BY

M. HORACE HAYES, F.R.c.v.S.,

(Late Captain "The Buffs")

AUTHOR OF "RIDING ON THE FLAT AND ACROSS COUNTRY,"

"VETERINARY NOTES FOR HORSE OWNERS," "SOUNDNESS

AND AGE OF HORSES," "ILLUSTRATED HORSE BREAKING," "POINTS OF THE HORSE,"

EDITOR "HORSEWOMAN," ETC.

FIFTH EDITION REVISED.

LONDON :

HURST AND BLACKETT, LIMITED,

13, GREAT MARLBOROUGH STREET. 



\section{SF 285 H45 1892 MAIN}

\section{PREFACE TO THE FIFTH EDITION.}

I HAVE carefully revised the present edition and have made several additions and corrections, which were suggested by the experieuce I had gained during three years' training and horse dealing in Calcutta and four years' travelling through Egypt, India, Ceylon, China, South Africa and other countries on horse breaking expeditions, since the previous edition had appeared. The racing records, weights for age and class, etc., have been brought up to date as far as possible.

Juntor ARMy and Navy Club,

St. Janes' Street, S.W.

October 1, 1892. 



\section{PREFACE TO THE FOURTH EDITION.}

ON returning to England, after bringing out the previous edition of this work, I found so much new material to add to the chapters on Riding, Bitting, Saddlery, and Wasting, that I thought, instead of unduly enlarging the size of the present volume, it would be better to utilise what I had already written as the basis for a systematic treatise on that subject; the result being Riding: on the Flat and Across Country.

In the third edition of my Veterinary Notes for Horse Owners, which was published a few months ago, I have given a chapter on Shoeing, which I treated as fully as the scope of the book would allow, and have, accordingly, limited ny remarks on this subject, here, to a statement of the general principles of the art and to the special points requiring attention in India.

While revising the present edition, I have endeavoured to apply the information I have obtained, during the past five years, in England, and, especially, at Newmarket, for the benefit of owners and trainers in India. I have, also, added a chapter on Teaching Horses to Jump and on Steeplechase Courses; and have rearranged the vocabulary.

M. H. HAYES, M.R.c.v.s.

Rous Road, NeWMaRKet.

November 1, 1884. 



\section{LIST OF CONTENTS.}

PART I.

HORSE MANAGEMENT.

\section{CHAPTER I.}

Stables.

Position and construction of stables-Picketing horsesPoultry near stables-Disinfecting stables

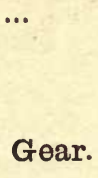

CHAPTER II.

\section{Clothing-Bedding-Stable Gear.}

Clothing - Bandages - Boots - Cloths - Bedding Mangers-Feeding sheets-Nosebags-Fomenting buckets and shoes-Oat-bruising machine-Articles used in $\begin{array}{lllllll}\text { grooming } & \ldots & \ldots & \ldots & \ldots & \ldots & \ldots\end{array}$

\section{CHAPTER III.}

\section{Varieties of Food.}

Oats-Gruel-Gram-Kúlthee-Urud-Moong-MoteBarley - Indian corn-Wheat-Cakes - Bran - LinseedRice-Suttoo-Goor-Carrots and other roots-Grass and hay-Straw and chaff-Oat hay and wheat hay-KurbeeBamboo leaves-Lucern-Milk-Stowage of grain 
CHAPTER IV.

Sketch of the Theory of Food and Nutrition. PAGE

Composition of the body-Waste of tissue-Repair of waste-Analysis of forage-Analysis of the ash of various plants and seeds-Nitrogenous food-Fat, starch, and sugar in food-Heat supply-Mineral substances-Husk of grain -Bulk in food-Selection of food-Hay and grass-Green meat-Variety in food-Salt-Relations of cold, heat, und clothing to food-Mastication and digestion--Functions performed by the blood-Appetite-Influence of an artificial state of life-Preparation of food $\ldots \quad \ldots \quad \ldots \quad$... $\quad$ 44-68

CHAPTER V.

On Watering Horses

CHAPTER VI.

\section{Practical Rules for Feeding and Watering} Horses

\section{CHAPTER VII. \\ Grooming and Stable Routine.}

On the theory of grooming-Washing the horse-Clipping -Grooming-Dressing the mane and tail-TapeeingShedding the coat-Care of the feet and legs-Trimming the mane and tail-Bots-Stable routine

CHAPTER VIII.

Management of Horses on Board Ship

CHAPTER IX.

Servants.

Syces-Grass-cutters-Shoeing-smiths-Riding-lads _. $107-113$

CHAPTER X.

Shoeing.

Shoeing-Plates-Tips-On shoes getting loose 
LIST OF CONTENTS.

CHAPTER XI.

Preparing Ponies for Measurement .

... $118-122$

CHAPTER XII.

Teaching Horses to Jump

... $123-130$

PART II.

\title{
TRAINING IN INDIA.
}

\author{
CHAPTER I. \\ Racing in India.
}

Racing men and horses-On forming a useful stableThe style of race-horse suited to India-The different classes and their respective form-Timing-Records of fast times...

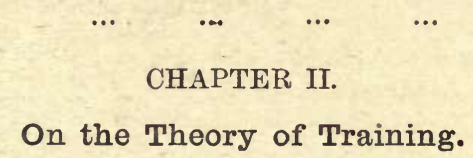

Training-Development of muscle-Effect of exercise on the system-Nature of Exercise-Food-Health-Sweating -Artificial sweating-Physic-Signs of condition

CHAPTER III.

Food during Training ... .. $163-166$

CHAPTER IV.

Daily Routine in Training $\begin{array}{lll}\ldots & \ldots & 167-171\end{array}$

CHAPTER V. 
CHAPTER VI.

\section{Practical Training.}

Remarks on race-horses in India-Training quartersGeneral rules for work during training-Detail of workSweating-Remarks on training continued-Training by short repeated gallops-Remarks on training continued-Trials-Training ponies-Setting-Treatment after running Racehorses travelling by rail

\section{CHAPTER VII, \\ Race-courses.}

On keeping a galloping track in order-Effect of ground on horses-Measuring courses-Lengths of different courses in India$$
\text { ... }
$$

\section{CHAPTER VIII.}

\section{CHAPTER IX.}

\section{Betting.}

Principles of betting and bookmaking-Lotteries-Pari mutucls and totalisators-Race pools

Hindustanee Stable and Veterinary Vocabu. $\begin{array}{lllllllll}\text { lary } . . . & \ldots & \ldots & \ldots & \ldots & \ldots & \ldots & 238-248\end{array}$

Calcutta Turf Club Weights for Age and Class 


\section{HORSE}
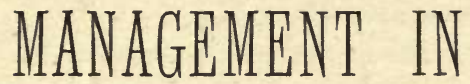

INDIA.

\section{CHAPTER I.}

STABLES.

POSITION AND CONSTRUCTION OF STABLES-PICKETING HORSESPOULTRY NEAR STABLES-DISINFECTING STABLES.

Position and Construction of Stables.-In the plains, stables should, as a rule, be built on high ground, devoid of objects, in their immediate vicinity, which might impede cooling breezes. Their direction should run at right angles to the prevailing winds, so as to obtain free circulation of air through the building; for, in India, our efforts should be directed in providing against the baneful effects of heat, rather than against those of cold, which can, nearly always, be obviated by warm clothing. In this country, experience proves that the chief requisites, for good stables, are airy and dry positions, thick roofs overhead, lofty and spacious stalls, and perfect circulation of air. As long as men or animals are protected from the direct rays of the sun, while the air blows freely through the habitation, whatever it may be, there is little danger from the effects of our tropical sun. The best proof of 
this important principle is afforded by the fact, that however powerful the noonday sun may be, and however fiercely the hot wind may blow, neither man nor beast will suffer much from the high temperature, when out in the open, if they be under the shade of a tree with thick foliage. But if, on the contrary, the current of air be impeded by a wall, screen, or other object, the distressing effects of the heat will be felt in a moment. Stagnation of air, in most cases, is the cause of the many instances of fever which occur during the hot weather, especially in large cities like Calcutta, where houses are crowded together. I have seen, on different occasions, horses that were almost dying from the effects of heat in stables situated on low and confined positions, recover their condition and health, in a very few days, after being removed to others on high and airy ground.

I have tried the experiment of keeping a race-horse - in my own house during the hot weather; but he suffered far more, even under a punkah, from the confined atmosphere inside, than he had done in his stable, which was many degrees hotter, but which had a free current of air through it.

If valuable horses be kept during the hot months in the plains, punkabs may be used with advantage. If they cannot be conveniently fixed, and the horses feel the heat much, a couple of coolies may be told off to each animal, to keep him cool during the mid-day heat with a large hand-punkah.

I have always found that, when proper precautions have been adopted, horses, in dry climates, such as those of the North-West, Oudh, and the Punjab, have 
retained their health and condition during the hot weather, quite as well as they did during the cold months. This is in conformity with the fact that the horse is a native of a dry, hot climate.

In order that the stable should be kept as dry as possible, its walls should be constructed of some material which will not absorb moisture, such as fireburnt bricks, or stone ; the former being, I think, tbe better material. Wood, also, might be employed, though stables made of it are not nearly so cool, during the hot weather, as those constructed of either of the other two. Throughout Eastern Bengal, the walls are made of strong bamboo screens, which serve their purpose admirably. In such a stall, a kicker may be saved from injuring himself, by placing matting (Hind. Chitai), say, three feet high, about six inches from the wall, while the interval may be filled up with dry grass, which will give to the blow, and will act as a padding to the wall.

The floors of the stable should, if possible, be laid down with some material which will not absorb water. The flooring of stables which I prefer to all others, whether in India, England, or elsewhere, is one of thick wooden planks, so arranged that the urine of the horse may drain through the interstices between them, on a waterproof surface. These planks may be about nine inches broad and three inches thick, and should be placed so that they can be readily removed, and the under floor cleansed. I observed in the Durban Tramway Company's stables (Natal) a good arrangement by which a waterproof drain-the width of which was equal to the length of each stall-of slightly curved 
shape, ran underneath each long line of stalls; the planks which formed the flooring being made to fit accurately across it. When the horses were out at work, the planks could be readily removed and the shallow drain washed out. To prevent the absorption of moisture by the wood, it could be tarred over, or soaked with asphalte. The special advantage of wood for the flooring of a stable is that it is a bad conductor of heat, and would consequently act as a preventive of chill and cold. Wood is often employed as a flooring of stables in the Straits Settlement and Far East.

In many parts of India, kunkur may be obtained, and can, then, be applied in the same manner as it is used for metalling roads. In default of it, pounded bricks, which are employed for the same purpose, may be substituted. After these floors are laid down, the stables should not be used until they are thoroughly dry, and the concrete has become hard and solid. Horses stabled in stalls laid down with concrete are, during the prevalence of Loodianah fever and influenza, much less liable to be attaciked by these diseases, than they would be, if the floors of their stalls were capable of retaining moisture.

If it be not practicable to have the floors made of waterproof material, they should be kept covered with five or six inches of sand, the tainted parts of which should be daily removed, and replaced by a fresh supply.

Damp stables are the sources of many serious ailments to the horse, who can keep health and condition alone in a dry habitation. This most important fact should never be lost sight of by the horse-owner. 
The floor of the stable should be made level, so that the horse may have an even "bearing" for his feet. The syce should keep the stall dry and clean, without any provision for the drainage of urine being required. I may remark that this form of construction is in accordance with the practice followed in all the best racing stables at Newmarket, where it has been found unnecessary to drain the stalls and boxes by giving a slope to their floors. The ground around stables, however, should be thoroughly well drained.

The form of stables I prefer is one with a single row of boxes, having a verandah about $12 \mathrm{ft}$. wide, on the outer line of which the roof is supported by a row of pillars, which are the same distance apart, one from another, as are the partition walls of the stalls. The verandah should be protected by bamboo frames covered with thatch (Hind. Jhamp); so that, in the hot weather, the direct rays of the sun may not play on the interior of the building; and, in the cold months, the horses may be protected from draughts.

Loose boxes, to be thoroughly comfortable, should be at least $12 \mathrm{ft}$. by $16 \mathrm{ft}$. In India, $10 \mathrm{ft}$. by $12 \mathrm{ft}$. would be a minimuin. The walls between the boxes should be made about $7 \mathrm{ft}$. high, so as to be just sufficient to prevent the animals smelling each other over them. Stalls, for large horses, should be $6 \mathrm{ft}$. by $12 \mathrm{ft}$. Ponies may be contented with one of $\check{5} \mathrm{ft}$. by $10 \mathrm{ft}$. At Newmarket, stalls are, generally, made $6 \frac{1}{2} \mathrm{ft}$. wide. If narrow stalls are used, the syce, when removing a horse, should back him out, instead of turning him round.

If not more than five or six horses are kept in one 
stable, they will be able to get better rest, than if more animals were present.

The roof of the stable should afford perfect protection from the direct rays of the sun; for which object, thatch will be found to be the best material. Flat masonry roofs may be protected by having earthen vessels (Hind. Gurra), filled with water, placed on them; while tiled roofs may be covered by jhamps. If expense is no object, double roofs may be employed with great advantage. The stable may be admirably ventilated by a space of a few inches being allowed, all round, between the roof and the top of the outside walls.

At the head of each box or stall, there should be a window, say, a yard square and a yard and a half above the ground. The space below the window may be occupied by a movable door, which, during the hot hours, may be taken away, and a thin bamboo screen hung across the opening. If the stable be built of brick, additional ventilation may be obtained by having alternate bricks removed from the first two or three bottom rows of the wall, at the head of the stall, for a distance of six or seven feet. These holes may be stopped up in cold weather. If possible, there should always be a space of a few inches all round, between the roof and the top of the outside walls.

The outside of the stable should be whitewashed, and the walls inside should be dark coloured.

When flies are troublesome, surkunda (a cane-like grass) or split bamboo screens should be placed in front of the doorways and windows, and should be kept down from sunrise to sunset. I may remark that the 
cleaner and darker stables are kept, the freer will they be from flies.

In many stables in India, covered receptacles for urine, which the syces are supposed to bale out every day, are made in the centre of the stalls. This is, obviously, a most objectionable arrangement. Another common trick of these servants is to teach their horses to stale into an earthen pot, which they hold for them, and thus get rid of the fluid without it soiling the bedding. This is, in my opinion, a bad practice; for horses that are accustomed to it, will often, if the syce be not ready to hold the vessel, abstain from staling for a long time, and will, thereby, be rendered uncomfortable. The litter should be taken up twice a day; every soiled particle of it should be removed; and the floor should be thoroughly cleaned and dried. The less tainted portions of the bedding may be dried in the sun for further use.

The doorways of the stalls are usually barred across by two poles - generally bamboos - which are let into the walls at each side, the upper one being fixed about four feet from the ground. These bars are sometimes made to slide through boarded passages in the walls, an arrangement that will save the latter from becoming broken. The best and neatest plan is, I think, to plant two strong upright posts-in which are bored holes for the reception of the horizontal poles-10 or 11 inches from each side of the walls at the doorway. The walls will then be free from injury, and there. will be no occasion to remove the bars, unless, when the horse is taken out or in; for there will be quite sufficient room for a man to pass sideways between the 
walls and the upright posts. The bars are secured by being lashed together with a piece of rope.

Movable half-doors-as well as bars-may be provided, to be used when the nights are cold.

As a rule, hard-worked horses rest and thrive better in boxes than in stalls. Some animals, however, when kept apart from their fellows, pine from want of companionship ; and others, if allowed to be loose, incessantly wander about their box, and, consequently, unduly fatigue themselves. Perhaps, in the majority of cases in England, mares do best in stalls; and horses, in boxes. In India, however, it is not always practicable to keep animals out of doors as long as would be desirable, with regard to their health, were the climate less "trying"; hence, the greater need for boxes in our Eastern Empire than in more temperate climates.

The blood-vessels in the foot of the horse, unlike those in other parts, do not possess valves; because the almost constant movement-except when the animal is lying down or sleeps standing - that he, in a natural state, takes in the search for food, prevents stagnation of blood by gravitation. When the foot is raised, blood rushes into and fills these vessels, which, at the next moment, are emptied, by the effect of pressure, the instant the foot is brought to the ground and weight is thrown on it.

I thoroughly agree with Admiral Rous's remark that, "The windows of a stable ought never to be shut by night or day; in cold weather, add to the clothing, but never deprive them of the first great source of vitality, 'fresh air.'"

In India, during the cold weather, the air is generally 
so dry that precautions to be taken against draughts are not nearly so necessary as in England. Respecting the latter country, Professor Williams writes: "Horses kept in ill-ventilated stables are undoubtedly rendered susceptible to many diseases, and to pneumonia among the rest, but they will bear impure air even better than cold draughts blowing directly upon them. I have repeatedly observed that the slightest cold contracted by a horse kept in a draughty stable has almost invariably been succeeded by pneumonia, and, that if the animal was not removed to a more comfortable situation, the disease tended to a fatal termination."

Ignorant grooms in England have a strong prejudice in favour of warm stables, on account of the good effect they have on the animals' coats. These men, naturally, ignore the increased susceptibility to catching cold, which horses kept in such places acquire, as well as the very marked tendency the legs and feet have of "going to pieces"; for a horse that is laid up with a cough or a filled leg, gives far less trouble to the groom than one which is in full work. In winter, horses undoubtedly thrive better in comfortable stables than in cold bleak ones. The owner, trainer, or groom can personally satisfy himself as to the proper degree of warmth, by regulating it according to what he would consider agreeable to his own feelings, were he to make the stable his own abode; always remembering that its atmosphere should be pure, and free from the slightest suspicion of "closeness."

With hard-worked animals, such as race-horses, I have found the best results attend the practice of 
keeping the stables moderately dark, in order to induce the occupants to lie down, and, during hot weather, to keep the abode cool, by preventing the admission of rays of light, which are always accompanied by rays of heat: I here take for granted that the free circulation of air is not interfered with.

In the cold weather, if horses be not worked to an extent that would render it desirable for them to repose during the day, and, especially, if they be not kept for a considerable time in the cpen air, their stables should not be darkened; for the rays of the sun, when not too powerfui, have a beneficial effect on the general health of animals, by improving the quality of their blood.

On all occasions when the stables are empty, they should be thrown open for the admittance of sunlight, which is a powerful disinfectant.

Picketing Horses.-Head and heel-ropes are admissible only with animals-like those in the Artillery and Cavalry - that may be called upon to camp out at any time. In such cases, if there be any probability of rain, great care should be taken to render the pegs secure; for, if a shower falls, it will make the horses fidgety, and will loosen the hold the pegs have in the ground.

Natives, when they use head and heel-ropes, are very prone to tie up the horses far too tightly.

Horses should not be picketed by a fore-leg; for, then they will be very apt to "screw" themselves by straining at the rope, in the event of being startled; or when jumping about in play.

During the hot weather, in the plains, the horse may, 
with advantage, be picketed, at night, to a pole fixed vertically in the ground, round which his bedding should be spread. The head-rope should be attached to a movable iron ring, which works round the pole. No heel-ropes are, then, necessary.

In hot, close weather, when there is no wind blowing, it is, often, preferable to picket a horse in the open, during the midday heat, under a tree which has thick foliage overhead, than to keep him in the stable, however well ventilated it may be. The leaves of trees exercise a marked cooling effect on the air that passes over their surface : hence, "the grateful shade."

Poultry should never be allowed about a stable, nor should they be kept near it; for the insects that often infest fowl, prove excessively irritating to the horse, when they are allowed to settle on him. Removal of the poultry will soon cure the animal attacked; for these parasites cannot live, beyond two or three days, away from their proper " host."

Disinfecting Stables.-When the floors of stables are formed simply by the surface of the ground, they should be dug up; from time to time-say, once every two months - to the depth of a couple of feet; the tainted soil removed; and fresh, dry mould substituted. This proceeding is particularly necessary after the appearance of Loodianah Fever.

To purify metalled floors and drains, a solution of $1 \mathrm{lb}$. of sulphate iron (Hind. Hurree kussees) to the gallon of water may be used.

Crude carbolic acid may be applied to the iron and woodwork of the stable. 
Carbolized sawdust may be sprinkled here and there in the stable, occasionally, in order to keep it fresh and sweet. This preparation is made by steeping sawdust in as much crude carbolic acid and water-using a solution of equal quantities-as it will take up. 


\section{CHAPTER II.}

CLOTHING-BEDDING-STABLE GEAR.

CLOTIING-BANDAGES-BOOTS - CLOTHS-BEDDING-MANGERS-FEEDING SHEETS-NOSEBAGS-FOMENTING BUCKETS AND SHOES-OAT-BRUISING MACHINE-ARTICLES USED IN GROOMING.

Clothing.-For the maintenance of high condition in the horse, it is requisite that he should be supplied, in the stable, with an ample quantity of warm clothing -short of causing him to perspire. Clothing not alone stimulates the skin, and guards the animal from the ill-effects of chill, but also aids in maintaining the internal temperature of the body, thereby supplementing one of the most important offices of food. To avoid overweighting the horse too much, it is advisable to use only English clothing of close material, and not too heavy. During the cold months, a suit of warm clothing by day, with an extra rug at night, will generally be sufficient. As a rule, hoods may be dispensed with; although, if the animal is suffering from a cough or cold, a "night-cap" may be put on at night. This article is a short hood about a foot long, and is made to fit close round the throat. Ordinary hoods, if buckled to the body-piece, are apt, during the night, to prove uncomfortable to the horse. If unattached, they usually fall over the animal's head, on his lowering his 
neck. The head-collar should be put on over, not under, the hood, or " night-cap."

Horses that are used for rough work in all weathers, should, naturally, be lightly clothed; so that they may not be liable to be affected by change of temperature. On this point, the owner should exercise his own judgment.

Clothing, with the breast and quarter-piece in one, will do for night use, but if it be worn by horses when they are exercised, it will cause the hair to be rubbed off their shoulders, thus giving them the appearance of having been in harness. If hoods be made of country blanketing, they should be lined with cotton cloth, so as to save the manes from being injured by the coarse woollen material.

A suit of warm clothing can be made from an English pattern, for about Rs. 10 .

The use of warm clothing often irritates a horse having a thin delicate skin. In such a case, a light cotton sheet should be placed under the woollen suit.

With well-bred horses, rollers should be furnished with breast-plates to prevent them from working back.

Bandages.-Horses that have done much work, and whose legs are inclined to fill, will generally require the aid of flannel bandages to keep their limbs fine. The uses of these bandages are to encourage insensible perspiration from the skin; to afford support to the tendons and ligaments, and, by pressure, to cause absorption. They should be made of close, thick flannel, similar to that used for cricketing trousers. Serge should not be employed; as its texture is too harsh. They should be about $8 \mathrm{ft}$. long and $4 \frac{1}{2}$ ins. 
broad. "Bandages, specially made, and with a selvage on each side, are supplied by all saddlers. These are, however, often too short, too thin, and too broad. A bandage, to be ready for immediate use, should be wound up with the tapes inside. When putting it on, a few inches of it may be unrolled and laid obliquely across the outside of the leg, close to the knee, with the end reaching to about the centre of that joint, and the rolled-up part turned to the outside and directed downwards and forwards. The bandaging is continued down to, and around, the fetlock and upper part of the pastern, and is brought up close below the knee; the loose end is, then, turned down and the folds of the bandage carried over it. The tapes are tied a little above the centre of the cannon bone. By this method, the folds do not require to be turned or twisted over, as in the ordinary way. Besides this, they lie close and do not bulge out."-(Veterinary Notes for Horse Owners.)

When flannel bandages are used to give support during work, they should not be broader than $3 \frac{1}{2}$ ins. In the book which I have just quoted I have given a drawing to show their mode of adjustment. The description is as follows:- "Commence by laying the loose end diagonally across the fetlock, with its extremity a little below that joint; then take about four turns round the leg, so that the bandage may come close below the knee, take another turn in a downward direction, bring the, loose end up and lay it flat against the bandaged part, and continue the turns over it. The loose end will now be firmly secured between the cloth on both sides. When put on accord- 
ing to this plan, the bandage cannot become undone unless the tape breaks."

A good bandage for giving support is an elastic one, made from the material used for side-spring boots, and of the same form as an ordinary bandage, but somewhat shorter, so as to allow of its stretching. These bandages will not bear being rolled round the fetlock and pastern; for, if this be done, they will work loose.

The following plan may be adopted for putting on a bandage that is intended to be employed as a poultice:-Make a pad of four or five folds of cotton cloth, and large enough to wrap round the leg; wet this pad thoroughly, apply it, wrap over it a piece of oil-silk, and then roll a moderately tight flannel bandage round the whole. In cases of sprain, the application may consist of either plain water, or of a lotion consisting of a wineglassful of the tincture of arrica to a quart of water. Arnica is said to act by stimulating the small blood-vessels of the skin.

A good plan for applying moist heat to horses' legs, is to dip a rolled-up flannel bandage into boiling water, squeeze it as dry as possible, by wringing it in a towel, and then put it on quickly. After hard work, bandages which are thus employed, may be allowed to remain on for two or three hours. As soon as they are removed, the legs should be well hand-rubbed, and dry flannel bandages applied.

Boots are worn to give support like bandages, and also to prevent the horse from hurting himself by "brushing," or by otherwise striking his leg. For the former object, the boot may be made of strong boot 
elastic, and to lace at the side. The laces may be made of whipcord, or, better still, of strong waxed hempen thread. For "brushing," or "speedy-cutting," leather guards should be sewn on to the inner side of the cloth. The same precaution may be used to protect the back tendon with cross country horses, especially, when schooling.

When putting on boots, care should be taken that the upper and lower straps should be buckled looser than the middle one, or pair, according as there are three or four of them.

Bandages are best for support, boots for protection.

Cloths are commonly employed in England instead of bandages; they are formed of stout "box cloth," sewn down the side of the horse's leg, and are not removed. I think bandages, which are properly put on, are much superior to them in every way, especially in the facility they afford for handrubbing, or fomenting the legs. Besides this, irritating substances, picked up from the ground, are apt to get inside the cloth and hurt the leg. This is especially the case when animals are galloped on tan.

Bedding.- Iong wheaten straw furnishes the softest and most comfortable bedding for the horse, especially, if he be without clothing. Oat straw is brittle, so does not last as well as that obtained from wheat. Horses rarely care to eat rice straw, which is far from being economical to use, as it very quickly breaks up. With respect to horses eating their bedding, see page 39 .

If it be desired to prevent a horse from eating his bedding, the straw may be damped, and kept in the 
sun a few days before using, so that it may become too sapless and unpalatable to be chosen in preference to grass, while a layer of old bedding may be kept on the top. Such cases of morbid appetite will generally call for medical treatment, if a full supply of salt and green meat, such as carrots, lucern, etc., fail to correct the habit.

Cheena straw makes excellent bedding, as it is soft, difficult to break, and unpalatable to most horses.

The bedding should be carefully spread, so as to be as comfortable as possible for the horse; and should be banked up around the walls, so that the animal may not hurt himself when lying down, or when rolling. At the entrance of the box or stall, for appearance sake, the bedding should be arranged in a straight line, which may be finished off by a piece of plaited straw being stretched along it.

Hard-worked horses should, if possible, have the bedding under them by day as well as by night, so that they may have every inducement to lie down and rest themselves, when they choose. Besides this, when the horse stands on the bare ground, he will abstain from staling longer than he ought to do, and, may be, to an injurious extent. Most of us old Indians know that a straw mat, expressively called, in Hindustanee, a seetul patee, or cold mat, is the coolest thing on which to lie during the hot weather; so we may infer that straw forms an equally grateful couch for the horse. While he is out at morning and evening work, the bedding should be removed, and dry straw should be substituted for any that may have become soiled or wet. 
A slight additional expense is the only objection to keeping the horse bedded down by day.

I have found that savdust makes a good substitute for straw, though I am inclined to think it takes some of the polish off the coat. "Stonehenge" remarks "that it soon heats when wetted with urine, and ammonia is given off profusely, so that great care must be exercised to change it as soon as it becomes soiled."

When a horse has on a high-heeled shoe-as during treatment for sprain of the back tendons or suspensory ligaments, \&c.--sawdust makes the best bedding; for it will not catch in the long calkins. Alone, without a raised shoe, it enables a horse to assume a comfortable position for the injured limb.

Sand forms a very cool bedding for horses, who generally show by frequently rolling on it that they like having it under them. Its use spoils the look of the coat, for the time being, on account of its absorbing a considerable part of the cil which is secreted by the glands of the skin, and which serves to keep the hair soft and pliable.

Tan is an excellent material to put down in a loose box, for a horse that is at all inclined to inflammation in the feet, provided that the syce is careful to remove the wet portions immediately they become tainted.

Mangers.-Many years ago, Prof. Coleman directed, and with reason, that the feeding-trough should be placed on the ground; as that arrangement makes the borse assume the natural position in which he was intended to feed. I advocate this practice, because it obliges the animal to eat much slower than he would 
do, were the manger in the usual position; hence, he will masticate his food more thoroughly. To carry out this principle 'still further, I would advise the use of a broad feeding-box, in which the grain should be spread in a comparatively thin layer. Some horses, from infirmity, \&c., will require the manger to be slightly raised, say a foot from the ground.

Sheets may be used with advantage instead of mangers. They may be made of sacking (tat), and about a square yard in size. They are laid on the ground, and the grain is spread over them. They cost little, are easily cleaned, and can be packed up in a small compass. I have always employed them with my own horses in India.

Nosebags.-These articles should never be used, except when a proper manger is not obtainable, as on the march, \&c.; because they are uncomfortable to the horse, who, with one on, is apt to bolt his food or chuck it out; and he cannot help tainting his corn with his breath and rejected saliva. Besides this, it is difficult to keep nosebags clean and sweet. When used, they should be made of canvas or sacking, and not of leather; should be deep, not too wide; and should narrow off to the bottom, so as to allow the animal, towards the end of his feed, to readily pick up the remaining grains of corn without having to chuck the bag up.

A common plan for preventing a horse from throwing corn out of his nosebag, is to tie a string at the place where either end of the head-strap is fixed to the bag, and then attach it just above one of the animal's knees, at such a length that he cannot throw up his head. 
When nosebags are employed, horses should have something on which to rest them, for instance, a low wall, or a bundle of hay. Dray horses may often be seen supporting their bags on their companions' quarters. Without such aids, the animal will be liable to spill his corn, in his attempts to get it into his mouth.

Fomenting Buckets and Shoes.-A couple of long narrow leather buckets for applying warm water to horses' legs are useful in cases of accident. They should reach up to the knee, should be made of stout hide, anả should be provided with wooden bottoms to preserve them from injury. I may here mention, in passing, that water, at a temperature higher than that which the band can comfortably bear, should never be used in fomenting the horse's skin. A pair of shoes, with wooden bottoms, made of pliable leather, and reaching only to a little above the fetlock joint, should be kept for poulticing the feet, when required. Each shoe should be provided with a leather thong to close the mouth round the leg. Mashed turnips or carrots form an excellent poultice.

Oat-bruising Machine.-Machines which are provided with circular rollers should be employed for oats. Those made by Turner, of Ipswich, are excellent. A small one, with packing case, which also answers for a stand, will cost about Rs. 80 in India.

Articles used in Grooming.-Each horse should be provided with a brush and curry-comb, a hoofpicker, mane-comb, three or four cotton rubbers, and a couple of wisps made of unprepared hemp. One pair of scrapers will be enough for a small stable. 
English body-brushes should be used in preference to those of country make. The bristles should be closely set, long, and moderately soft, so as not to hurt the skin while cleansing it from scurf. Each rib of a currycomb should be made of wrought iron, and should be riveted at each end to the iron back. The teeth should be blunt, so that they may not unduly wear out the bristles of the brush. An inferior kind has the ribs made in pairs from pieces of sheet iron turned up at the sides. These ribs quickly lose their shape, and, owing to the thinness of the metal, their teeth are much too sharp. Long, thin, copper sweat-scrapers, made with handles at each end, are much to be preferred to those of a semi-circular form, constructed with only one handle; as the latter are hard and unyielding to the skin.

Capital wisps may be made from unprepared hemp (Hind. Sun). 


\section{CHAPTER III.}

VARIETIES OF FOOD.

OATS - GRUEL - GRAM - KÚLTHEE-ÚRUD - MOONG - MOTE - BARLEY INDIAN CORN - WHEAT - CAKES-BRAN - LINSEED - RICE - SUTTOOGOOR-CARROTS AND OTHER ROOTS-GRASS AND HAY - STRAW AND CHAFF - OAT-HAY AND WHEAT-HAY - KURBEE - BAMBOO LEAVES LUCERN-MILK-STOWAGE OF GRAIN.

Oats.-This grain, when grown in India, possesses a far larger proportion of husk to flour than that produced in England; hence its lower value as an article of food. As the measure of the horse's appetite is by bulk, rather than by weight, the heavier the oat, the more valuable, as a rule, does it become. Samples, at $47 \mathrm{lbs}$., $42 \mathrm{lbs}$., and $32 \mathrm{lbs}$. to the bushel, will respectively yield about threefourths, one-half, and one-third flour, which proportions approximately give the nutritive values. Mr. Stewart (Stable Economy) tersely describes sound English corn as follows:-

"Good oats are about one year old, plump, short, hard, rattling when poured into the manger, sweet, clean, free from chaff and dust, and weighing about 40 lbs. per bushel." Although our Indian oats are far below this standard, still they are much superior, as a food for horses, to any other grain which we can procure. This is especially the case with hardworked animals, because they can eat an almost 
unlimited quantity of oats without it disagreeing with them. On the contrary, gram, kuilthee, and barley, given in amounts sufficient to supply the necessary nutriment, almost always upset the digestion, and induce a "heated" state of the system.

In order to make up for the inferior quality of the oats, we may, with great advantage, supplement them by an addition of gram, or kúlthee, which should not exceed a third of the whole amount. This practice is in accordance with that, in England, of adding beans to the corn, and is particularly applicable to old horses whose powers of assimilation are impaired. In England, new oats are rightly considered to be indigestible-an objection which may be removed by having them kiln-dried; but in this country, they do not appear to be injurious to any great extent-a fact which may be accounted for by the extreme heat of our tropical sun. New Indian oats never present the soft, pulpy appearance seen in new English oats.

Oats should be given in a bruised state; for, then, not alone is the possibility of the grain passing through the horse in an undigested state avoided; but, also, the animal is obliged to chew it more thoroughly than if it were given whole.

On the Bengal side, oats are principally grown in Tirhoot, Dehra Doon, and the Meerut district.

Gruel is best made by mixing a pound of oatmeal well up with a quart of cold water, to which should be added three quarts of boiling water; the whole being put to simmer over the fire and occasionally stirred up until it thickens. It should then be removed and ailowed to cool. It should be given to the horse in 
a lukewarm state, and of a consistency a little greater than that of milk. It may be flavoured with salt or sugar, according to the horse's taste.

Gram.-This grain, known as chunna, is very commonly used throughout Northern India and the Bombay Presidency. It is objectionable on account of its tendency to cause diarrhœa, and to induce a "foul" and "heated" state of the system, when given in large amounts, say, anything above $10 \mathrm{lbs}$. daily. It is best used in combination with oats, Indian corn, barley, or rice in husk. Before being used, it should be, at least, seven or eight months old. It should be given in a broken state and always dry. The practice of steeping gram in water is injurious.

Kúlthee is extensively employed throughout Madras and Bombay. It seems superior, as a food for horses, to chunna, when either grain is used alone; and, in limited quantities, has an excellent effect on the general condition and coat. On account of the hardness of the husk, it has to be given in a boiled state. Only just enough water to cook it should be used, so that, when fully done, the fluid which remains over in the pot, may be absorbed on cooling. The steam should be allowed to escape, so that the kúlthee may become as dry as possible. When properly boiled, the interior of the grains should be dry and floury, like that of good and well-cooked potatoes. Kúlthee is very similar in its composition to gram, and may be used in the same combinations with oats, \&c.

In the Bengal Presidency, it is readily procurable at Hajeepore, which is near Patna, and also at different places in the North-West Provinces. Külthee which is 
grown in those parts does not appear to be as good as that produced in Madras.

Urud.-This variety of $d a l$ is a food common among natives in Eastern Bengal, and, more or less so, in other parts of India. It is extremely like kúlthee in composition and qualities, and is prepared in a similar manner.

Both kulthee and úrud are valuable when a change of food is necessary, especially when the animal is in poor condition, and his skin out of order.

Moong, boiled, and given like kílthee, may be used with advantage when a change of food is required. Three or four pounds of it may be mixed with the horse's other grain.

Mote (Phaseolus aconitifolius).-A friend of mine, who has had a long experience among horses in India, tells me that equal quantities of mote and gram, bruised and given raw, forms an excellent food for horses. I would, with confidence, suggest the daily addition of from 2 to $4 \mathrm{lbs}$. of bran to this mixture. I have no personal acquaintance with the value of mote as an article of forage.

Barley.-Next to oats, this grain is, in my opinion, the most suitable one for horses, which should be gradually accustomed to its use; for it is apt to disagree with them at first. It may be given raw and in a bruised state, or parched, which is probably the better plan; as the husk seems to possess an acrid principle, the effects of which appear to be obviated by the process of parching. A native parcher (bhurbhunja) will charge two or three annas a maund (82 lbs.) for parching. Boiled barley may also be 
INDIAN CORN.

used. Barley should not be employed until it is a year old.

A mixture of parched barley and gram, known as ardawa, is commonly sold in India. It is usually made of inferior grain, and is always more or less adulterated with dirt and chaff.

Indian Corn.-This grain, known as mukaee, is very cheap and plentiful in some parts, the Punjab, for instance. In Europe and America, maize is usually regarded as a food that, without the addition of other grain, is not sufficient for the requirements of hardworking horses. The results of experiments conducted on a large scale in France and Austria, as well as observations made by practical men in other countries, prove that, although horses readily take to maize as a food, digest it, and, on it, get fat and acquire glossy coats, they show a marked deficiency in vigour, speed and stamina, to animals fed on oats. Professor Bruchmüller, who conducted a six months' trial of feeding 5,200 horses partly on maize, came to the conclusion that it can be used to advantage only with horses that are not required to move out of a walk.

Hiram Woodruff, the celebrated American trainer, thus writes :- "The grain should be oats of good quality. I do not let colts have corn at all when young; and even to old horses I think it should be fed very sparingly. ..... Above all, avoid Indian corn in all shapes for young colts. . . . Keep the corn for the bullocks and hogs, and give oats to the horses."

The experience, however, of horse owners in South Africa-where Indian corn and oat-hay form the staple food for horses-places the food-value of this grain in 
a more favourable light. The fact remains that the majority of South African mail coach horses, which have to do 10 to 12 mile stages over bad ground at a fair rate of speed, go through their work well and keep in good condition, on nothing but maize and oat or wheat chaff. At the same time, it is well rəcognised by those in charge of these and other horses in that country, that the addition of a few pounds of oats or of oat-hay to the daily allowance of maize and chaff is very useful for imparting additional vigour to these animals. I may mention that these coach horseswhich are hardy, light-built animals of an average height of about $14 \mathrm{hs}$. 2ins. - get about $18 \mathrm{lbs}$. of maize and about $5 \mathrm{lbs}$. of chaff, with an occasional feed of grass on the veldt.

From my own observations made in South Africa, I have come to the conclusion that the quietness and want of spirit shown by the generality of horses in that country, are to a certain extent due to the fact that Indian corn forms a large proportion of their food. Maize mixed with gram and bran (say, in equal parts by weight), or with oats is in every respect better for hardworking horses, than by itself.

Maize may be given either whole, bruised, or soaked. To horses not accustomed to this grain, it is safest to give it bruised and mixed with either chaff or bran. In this state, it might be slightly sprinkled with water in order to keep down the dust which might arise from the finely divided particles; although I do not see any material benefit from this provision. If gradually brought on to its use, the grain may be given whole. 
Eating it in this state, sometimes makes the animal's mouth sore, in which case, bruised maize should be substituted. I have heard of maize in cobb (or husk) being given after having been passed through a particular kind of machine that cut up the head of the corn as well as the grain which it enclosed, and that this combination of grain and husk formed an excellent and easily digested food: it would be certainly an economical one. In South Africa, although the best judges prefer to give the grain dry than damp; still it is frequently used after having been soaked overnight in a minimum of water, and then mixed with chaff. I do not see much objection to this practice; for the chaff takes up so much of the remaining moisture, that there is but little danger of the horse swallowing the grain without first chewing it. I may mention that the danger to be feared from the improper use of maize, is that it might produce colic.

It would be useless to deny that both in Europe and in America, maize, when given as the only grain, has been proved to be an unsuitable food for horses that have to do hard, and, especially, fast work. The question naturally arises : what is the cause of the difference between maize used in those countries and maize in South Africa. The correct answer to this is, I am convinced, that the difference does not lie in the respective values of the Indian corn; but in the material with which it is given. South African chaff is exactly like tibben (see page 40 ), and consequently it forms an admirable vehicle for the mealies, in that it separates the particles one from another, and by its softness allows the animal to thoroughly masticate them, whether the grain be whole or broken. 
Wheat.-This grain is difficult of digestion, probably owing to the viscid nature of the gluten which it contains, preventing the different digestive fluidssaliva, gastric juice, pancreatic juice, \&c.-from permeating through its substance. This objection might be removed by the process of parching. Raw wheat is apt to gripe the horse.

That very reliable authority, Mr. Stewart (Stable Economy) mentions that a quantity of wheat, not exceeding $4 \mathrm{lbs}$., may be substituted for the same, or a slightly larger amount of oats ; that it should always be given mixed with bran or chaff; and that it should be bruised in the same manner as oats. In South Africa, I have known it to be given, without producing any ill effects, three times a day in quantities of $2 \frac{1}{2} \mathrm{lbs}$. and mixed with chaff. For examples of its combinations, see page 76 .

A couple of pounds of boiled wheat, in which a little salt has been mixed, may be given at night when soft food is required.

Cakes (Hind. Chupatee) made from the following constituents are often relished by delicate feeders :-
Flour...
... $1 \mathrm{lb}$.
Goor (see page 34 )... ... 4 oz.
$\begin{array}{lllll}\text { Ghee ... } & \ldots & \ldots & \ldots & 2 \mathrm{oz} .\end{array}$
Garlic... $\quad \ldots \quad \ldots \quad \ldots \quad 10 z$...

Bran.-English bran consists almost entirely of the envelope which surrounds the grains of wheat, the flour being nearly all removed. The outer portion of this envelope is indigestible, and acts, mechanically, as a gentle laxative; while the inner layer (according to Mège Mouriès) has the same property as diastase in 
converting starch into sugar, and consequently aids in the process of digestion. English bran is therefore of itself unsuitable as a food. Indian bran, on the contrary, owing to imperfect manufacture, retains a considerable portion of the flour, which supplies nutriment; so that horses, doing slow work, may be kept in good condition on 10 or $12 \mathrm{lbs}$. of it alone, without other grain. Given even in these quantities, it hardly ever purges a horse. On the contrary, if an animal gets " foul" and "loose " from too much corn, nothing is better than to keep him simply on dry bran and grass for a few days ; after which time his dung will become well formed and healthy-looking.

Dry bran seems to have a binding effect, or, at least, one opposed to a lax condition of the bowels. This is probably owing to a healthy action of the stomach and intestines being induced by bulk being given to the food, without the addition of a large proportion of nutriment which would have a stimulating effect.

Wet bran, in the form of a mash, is a laxative.

I am very partial to the use of bran for hacks and ordinary horses, when oats are not used, and would advise that 3 or $4 \mathrm{lbs}$. of it be given daily in a dry state. If we turn to page 49 , we shall see that bran contains a large amount of mineral matter, of which a comparatively large proportion consists of phosphorus, which is essential to the growth and development of the various tissues.

With race-horses and others, the custom is to give a bran mash every Saturday night, or oftener, as the case may demand. Instead of a simple bran mash, I much prefer one to which linseed has been added. 
Bran Mashes are made as follows :- After scalding a stable bucket with boiling water, put into it about $3 \mathrm{lbs}$. of bran, with an ounce of salt, and pour in as much boiling water as the bran will take up, which will be about equal to the weight of the bran itself, calculating the gallon of water to weigh $10 \mathrm{lbs}$. The mash should then be well covered, so as to keep in the steam, and should be left to stand for a quarter of an hour, or twenty minutes.

Bran and Linseed Mashes.-Boil slowly from 1 to $1 \frac{1}{2} \mathrm{lbs}$. of linseed, for two or three hours, till the grains become soft, allowing only just sufficent water, so that at the end of the time, it may, when the linseed is cooked, soak up a couple of pounds of bran, which is then mixed in and the whole covered up, as before described. The thicker the mash, the readier will the horse eat it.

Linseed.-This grain, which is the seed of the flax plant, containing as it does a large percentage of oil, is very useful for fattening horses that are low in flesh. It improves the condition of the coat in a marked manner, and has a peculiarly soothing effect on the urinary organs. A linseed mash is the usual form in which it is given. If the making of this cause too much trouble, a quarter of a pint of the oil, mixed through the corn daily, may be substituted. Linseed is most beneficial in cases of a disordered state of the skin, difficulty in staling, and diseases of the organs of breathing.

Owing to the careless method of saving which is adopted by cultivators in India, the linseed that is sold in the bazaar, usually, contains a large proportion of 
mustard seed (Hind. Surson), which is a small, round, light-yellow seed, and may be readily recognised by the taste it gives on being chewed. It should be carefully separated from the linseed; for, if it be consumed by the horse, it may have an injurious effect on his digestive and urinary organs. In linseed, are also found rape and hempseed. The former is a black seed of about the same size and shape as mustard seed. The latter is an oval and somewhat flattened seed, about half the size of a grain of wheat; and is of a light brown colour. The consumption of rape and hempseed, to a moderate extent, will cause no ill-effect to the animal.

Linseed Tea may replace water as a drink, when we wish to give linseed, and when the horse will not take it readily in other forms. It may be made by boiling half a pound of linseed in two gallons of water, for a couple of hours. The fluid should then be strained off and allowed to cool.

Rice.-In some parts of India, especially in Eastern Bengal, rice in husk, commonly called paddy (Hind. Dhan), is much used, after it has been kept for one season. It is given raw and in a broken state. It forms a fairly good food. A mixture of one part of gram to two of rice is an excellent one for feeding purposes. Rice, without the husk, is quite unsuitable for horses.

Rice-water (Hind. Kanjee) is most useful in cases of superpurgation, \&c. It may be prepared by boiling a pound of rice in two gallons of water, for a couple of hours. If time be of consequence, and boiled rice be at hand, a sufficient amount may be taken, and well 
macerated between the fingers in warm water, the whole being brought to the boil, and then allowed to cool.

Suttoo.-This, mixed with water, is the Indian substance for gruel. It is usually composed of finelyground parched gram and barley; but is sometimes made from Indian corn alone. It is always given in cold water, $1 \mathrm{lb}$. to half a bucket being the usual proportions. The horse gets his suttoo and water usually before his morning feed. I have never been able to discover any benefit to arise from its constant use. Syces are very partial to the practice of giving it: but more for their own sakes than that of their horses.

Goor.-From one to two pounds of this kind of unrefined sugar, given daily as a bonne bouche, is useful for getting horses into condition, and for tempting the appetite of delicate feeders.

Carrots and other roots contain but a small amount of nutriment compared to their bulk; hence they are inapplicable for forming a large proportion of the food of horses which are called upon to do fast work. They have a good effect on the animal's general health; as they supply the system with certain important salts which tend to preserve the fluidity of the blood and to build up tissue. They are especially useful when the system is in a feverish condition; for then, owing to the increased waste of tissue, the blood becomes loaded with impurities and abnormally thick. They come into season during the autumn, and may, with great benefit, be given in quantities of 6 or $7 \mathrm{lbs}$. daily : 2 or 3 lbs. will be sufficient for race-horses. 
Carrots are the best roots for horses, and, next to them, parsnips. Swedes may also be given. Horses in South Africa often get pumpkins as "green meat." Other roots may be given, in a boiled state, to animals used for slow draught.

"Carrots also improve the state of the skin. They form a good substitute for grass, and an excellent alterative for horses out of condition. To sick and idle horses they render corn unnecessary. They are beneficial in all chronic diseases of the organs connected with breathing, and have a marked influence upon chronic cough and broken wind. They are serviceable in diseases of the skin. In combination with oats, they restore a worn-out horse much sooner than oats alone." (Stewart.)

Dr. Voelcker points out, that the nutritive value of different root-crops depends largely upon their state of maturity; that unripe roots are not alone poor in sugar-hence their decreased value-but also contain a number of organic acids (notably oxalic acid), and imperfectly elaborated nitrogenous substances, which appear to be the cause of their unwholesomeness; that the leaves of their roots contain a far larger proportion of oxalic acid than does the root itself-hence, the scouring effect produced when the leaves are givenand that moderate-sized and well-matured roots are far more wholesome than monster ones.

Grass and Hay.-I am convinced, from long experience, that the maintenance of good condition in the horse is much more dependent on the proper supply of grass than on that of corn.

The following are the best Indian grasses :- 
Doob (Cynodon dactylon), called hurryalee in Madras, is generally regarded as the typical form of good Indian grass. It is that peculiar root-grass which grows on, or rather in, the surface of most sandy soils, and spreads itself as a creeper, so that it has to be rooted up (cheeled) with a sort of trowel, which is called in Hindustanee, a kúrpa. In good soil, when cultivated, it loses its creeping character, and grows like English meadow grass; to which, I think, it is much superior.

"Digitaria sanguinalis (called janowa in Hindustanee, and poliaong in the Punjab) is an excellent forage grass, and makes first-rate hay.

"In the Himalayas the finest of all grasses, superior even to $d h u b$, is a kind called maniara by the natives, and Pennisetum triflorum by English botanists.

"Spear grass (Heteropogon contortus), called lam in the Punjab, is also very common in some parts of the country. The spears are long barbed processes at the end of the seed-covers. It is good fodder if given before the spears form; and even afterwards horses will thrive upon it, if it is well beaten so as to shake them off." (Meyrick.)

When the grass is brought in, it should be opened out; carefully picked; dried in the sun, for a day or two, as may be deemed necessary; and beaten, in order to get rid of the dust and earth that may adhere to its roots, before it is given. The grass-cutters should not be allowed to wash it, as they are inclined to do, before bringing it in, with the object of making it look fresh and green, and, sometimes, to make it weigh heavy; for doing so is apt to dissolve out a portion of the sap, and will render the grass liable to 
ferment, if kept tied up for a few hours. Besides, there is always danger of disease germs being conveyed to the grass, from the water in which it may have been washed; for the filthiest pool will be considered, by the grass-cutters, quite good enough for this purpose. " It should be an invariable rule never to feed horses on grass grown in swamps, on account of the numerous lower forms of animal and vegetable life found in stagnant water. Horned cattle living on swampy land are particularly liable to anthrax; and there is no doubt but that this very fatal disease, called in India Loodianah fever (a form of anthrax), is often caused by horses either drinking stagnant water, or eating grass grown in it. Worm in the eye also appears to be produced in the same way." (Meyrick.)

I have abridged the following remarks on grass and hay, from a paper by M. L. Grandeau, which appeared in the Journal d'Agriculture Pratique :-

Growing grass possesses a waxy envelope, which protects the sugar, albumen, and other soluble compounds contained in it, from being dissolved by moisture and rain. When the grass is cut, this varnish gradually wears away, and if the grass be exposed to wet, it will then lose a considerable portion of its nutritive elements, especially if this envelope be bruised in any way. As long as the plant lives, it cannot be the seat of fermentation, which process is caused by the nitrogenous matters coming in contact with the sugar and water, on the breaking up of the different cells which compose the substance of the grass. During fermentation, the non-nitrogenous matters are turned into sugar, then into alcohol, and 
finally into carbonic acid, which is set free into the atmosphere in the form of gas. Thus, fodder which has been submitted to active fermentation soon loses the most of its nutritive properties. When grass is cut, if the weather is fine and warm, so that desiccation takes place rapidly, the proportion of moisture soon falls so low that fermentation cannot take place. The hay remains upon the ground and cannot easily become heated, even though in reality it contains more water than fodder harvested in bad condition. 'The more rapidly hay is turned to the sun, the less it will be bruised; and the greener it is, the better it will resist fermentation when it is stored. Nevertheless, it often happens that a too rapid preparation injures fodder, and in a good year hay appears to be saved in fine condition, when in reality it is not. If hay be completely dried in the sun it will not heat. A slight fermentation, far from being deleterious, is often very useful; in fact, we know that, in such a case, certain aromatic principles are produced which render fodder more sapid, and perhaps even more nourishing. As long as the green colour remains, the hay has lost none of its quality. When it is much heated, it turns brown. Some cultivators prefer brown to green hay, and it is certain that the former frequently has more flavour and smell than the latter. Although horses may prefer brown hay, it is not at all desirable to have sufficient moisture in the fodder at the time it is housed to turn it brown; because the loss resulting from fermentation is not counterbalanced by the slight aromatic smell it requires.

Grass lands, unless of exceptional richness, require 
to be manured in order to keep up the quality, as well as the quantity of the grass produced. Poor and impoverished land produces but very inferior fodder. On the other hand, as pointed out by Mr. H. S. Thompson (Journal of the Royal Agricultural Society, 1872), if land be treated with an excess of manure rich in nitrogenous matters, as guano and nitrate of soda, the luxuriant grass thus produced will be of inferior quality, and will prove unwholesome. The same remark applies to carrots and other roots.

Straw and Chaff.-When horses are fed in the ordinary way, on corn and hay, or on corn and grass, there is no objection to allowing them to eat wheat or oat straw, which, if they be that way inclined, they will generally select from their bedding. Wheat and oat straw are more easily digested than barley straw; all three kinds being better than rice straw. I have noticed that in England, some horses will not thrive unless they are allowed to eat a portion of their straw bedding. This is, probably, owing to the fact that, for the digestion of the highly-nutritious food upon which they are fed, they require an additional amount of bulk, which the straw supplies. In India, sufficient bulk will generally be obtained from the grass which the animal consumes. Although "long straw" may be a useful adjunct to grass or hay, as a food, I do not think it advisable to give it alone and in large quantities, with the corn; for it will then be liable to produce obstinate constipation. Its consumption, to the exclusion of hay or grass, is supposed to be a fruitful cause of roaring among Scotch cart-horses. The breaking up or cutting up of straw into small pieces seems to 
greatly increase its food value when given with grain; apparently, on account of the "chaff" facilitating the more thorough mastication of the corn by separating the grains or particles of the corn one from another, and by more evenly distributing the pressure of the teeth on them. We may readily see that for the performance of this work, it is better to have the different pieces of chaff soft than hard; although the softness should be obtained by bruising or tearing, and not by the application of moisture. In Egypt, Syria, Arabia, and other Asiatic countries, the chaff is formed from wheat or barley straw, which is broken up into small pieces and is thoroughly bruised by the native threshing machine (Arabic, noraj), and is then called tibben. A mixture of barley and tibben forms the staple food of vast numbers of Eastern horses, which, except on rare occasions, get no other forage, and which keep in excellent condition on it. Horses would not thrive as well on ordinary chopped straw, thus given, as on tibben. A similar practice is carried on in South Africa, where the chaff is made principally from wheat straw, which is bruised and broken up into small pieces during the process of threshing, which is performed by horses and mules trampling upon the stalks of corn. In places where this bruised chaff could not be obtained, it would be very useful to have a special machine which could bruise and break up the straw in this manner, were it desired to use straw as a food for horses.

Oat Hay and Wheat Hay.-Oat hay is largely used in the Australasian Colonies and in South Africa, where it is called "forage," either as an addition to, or as a substitute for, ordinary hay or grass. The oats 
for this purpose are cut when the grain has just lost its milkiness, and when the green stalk is beginning to turn in colour; the object being to get as much flour in the grain as possible, without allowing the stalk to become hard and dry. We must remember that if the grain be allowed to ripen, the sheaves would bear transport badly; for even a moderate degree of shaking would then cause a large proportion of the grain to fall out of the ears. In South Africa, oat hay frequently replaces hay and grass entirely in the feeding of horses-and with good results. Race-horses in that country are fed entirely on "forage" (as a substitute for hay) and oats, in which case, about six inches of the lower end of the stalks of the oat hay are cut off. I must, however, say, from personal experience, that I do not think that race-horses trained on this food, show as good condition as those which are prepared in India on doob grass and oat; notwithstanding that the Indian oats are inferior in quality to those grown in South Africa. I am therefore of opinion that although oat hay is a valuable adjunct (as I have often proved it to be) to doob grass, it is not altogether a satisfactory substitute.

Wheat hay, prepared like oat hay, though not as good, can be used in place of it. Green oats or green wheat may be used as "green meat" for horses, in the same way as we would employ lucern, etc.

Kurbee-Kurbee, which is the stalks of Indian millet, called in Hindustanee, ju'war (Holcus sorghum, or Sorghum vulgare), or bajra (Panicum spicatum), may be given, without being prepared in any way, in quantities of about $25 \mathrm{lbs}$. daily, as a substitute for 
grass for feeding and bedding, when grass is scarce. $J u$ 'war is known in Madras as cholum.

Bamboo Leaves.-In some parts of Eastern Bengal, these leaves are used as a substitute for grass; which purpose they answer fairly well; although, sometimes, they have too laxative an effect.

Lucern.-Lucern forms the best green crop for use during the hot weather. The seeds are readily procur- able, and the plant, as a rule, grows well in India, provided it gets a sufficiency of water. When out of work, 8 or 9 lbs. of it will be a good allowance for each horse: half to be given after the morning feed, the rest during the afternoon. It is advisable to dry it, for half an hour or so in the sun, before the horse eats it.

Milk.-For sick or delicate horses, milk is often most valuable, and they will seldom refuse it. Sweet skim-milk is preferable to new milk, which, from being too rich, it very apt to purge the horse. A couple of gallons may be given daily. To correct any tendency it might have to produce diarrhcea, the milk might be boiled in a clean vessel, care being taken that it be not smoked during the process. Sugar or salt may be added.

Stowage of Grain.-Grain may be kept sweet, and free from the attacks of rats and mice, in large earthen jars (Hind. Mutka). They will hold about 600 lbs., are very cheap, and can be easily procured.

Bags, capable of holding about a ton, may be employed. Each bag will cost about 7 or 8 rupees, and should be placed on a wooden stand. There is gene- 
rally some difficulty about protecting them from the attacks of vermin.

Native grain-sellers generally use receptacles (Hind. Kothee) made of thin bamboo wicker-work plastered over with clay, or with clay and cow-dung.

If a large quantity of grain has to be stowed away, a granary may be constructed as follows:-T'race on the ground a circle of about 16 feet in diameter, and build on its circumference twelve or thirteen brick pillars, say 18 inches square and $2 \frac{1}{2}$ feet high, and, at its centre, a circular pillar of the same height, and about 3 feet in diameter. On these pillars construct a boarded floor, and build on it a strong barnboo wicker-work house, 9 or 10 feet high. This is plastered over, a small door is left at the top, and a light thatched roof is put over the whole. A house, such as I have described, would cost, say 25 rupees, and would hold about 25 tons of oats.

Measures and Weights of Grain.-A Bengal mun (Anglice maund) is about $82 \mathrm{lbs}$. In England the following measures are used :-
$\begin{array}{lllll}4 & \text { quarterns (quarts) } & \ldots & \ldots & 1 \text { gallon. }\end{array}$
$\begin{array}{llllll}4 \text { gallons } & \ldots & \ldots & \ldots & 1 \text { bushel. }\end{array}$
8 bushels : $\quad . . \quad \ldots \quad \ldots \quad 1$ quarter.

A quartern or feed of oats weighs about $2 \frac{1}{2}$ lbs. 


\section{CHAPTER IV.}

SKETCH OF THE THEORY OF FOOD AND NUTRITION.

COMPOSITION OF THE BODY-WASTE OF TISSUE-REPAIR OF WASTE-

ANALYSIS OF FORAGE-ANALYSIS OF THE ASH OF VARIOUS PLANTS AND SEEDS-NITROGENOUS FOOD-FAT, STARCH, AND SUGAR IN FOOD-HEAT SUPPLY-MINERAL SUBSTANCES-HUSK OF GRAINBULK IN FOOD-SELECTION OF FOOD-HAY AND GRASS-GREEN MEAT-VARIETY IN FOOD-SALT-RELATIONS OF COLD, HEAT, AND CLOTHING TO FOOD - MASTICATION AND DIGESTION-FUNCTIONS PERFORMED BY THE BLOOD - APPETITE - INLUENCE OF AN ARTIFICIAL STATE OF LIFE-PREPARATION OF FOOD.

Composition of the Body-Nearly four-fifths of the body of the horse is composed of water, the remainder being made up of various organic and inorganic compounds. The former may be subdivided into substances containing nitrogen-a gas, which when mixed with oxygen, forms atmospheric air-and substances which are wanting in that element. The latter comprise the different mineral matters of the system, such as common salt, the carbonate and phosphate of lime, and carbonic acid, with traces of ammonia. The non-nitrogenous compounds may be put under two classes; namely, fats, and saccharine substances, such as milk and sugar.

Every tissue of the body which is employed in the performance of labour-such as the muscles, tendons, nerves, glands, \&c.-is composed of substances that 
come under the nitrogenous group; "even the noncellular liquids passing out into the alimentary canal at various points-which have so great an action in preparing the food in different ways-are not only nitrogenous, but the constancy of this implies the necessity of the nitrogen, in order that these actions shall be performed." (Parkes.) White of egg is a familiar example of this group. These nitrogenous substances consist of carbon-of which charcoal is a well-known form-hydrogen and oxygen-the two constituents of water-combined in various propotions with nitrogen, and, in the case of albuminous substances, with a small amount of sulphur.

Both the fats and saccharine matters are composed of certain combinations of carbon, hydrogen and oxygen. In the latter, the two last-mentioned elements are united in the proportion that forms water, so that sugar and starch may be regarded as a combination of carbon with that fluid; but in the former, there is a smaller amount of oxygen. The fat, which is deposited as a layer immediately under the skin, serves to maintain the internal temperature of the body, by the fact of its being a bad conductor of heat. Fat also acts as a natural elastic cushion to various parts of the system, as, for instance, at the back of the eyeball, above the horny frog, and around the joints.

Dr. Carpenter remarks, that "the muscular, nervous, and glandular tissues are not composed of albuminous substances alone; they contain, as an essential constituent of their structure, a certain portion of fat, without which their composition would be imperfect, and the performance of their functions impossible." 
Such fat, he points out, must, therefore, be regarded as a tissue former, and not alone a supplier of heat, although it will serve in the latter capacity on becoming broken up.

Waste of Tissue.-Every tissue of the body has a certain limited time for existence (a period which is directly shortened by exercise), after which it becomes broken up, and is absorbed into the blood. In order to remove these effete and deleterious matters, the system is provided with various excretory organs, such as the lungs, kidneys, \&c. During respiration, the oxygen, which is absorbed from the air by the blood-vessels in the air-cells of the lungs, is carried through the various parts of the body, so that it may break up the effete tissue by combining with the carbon to form carbonic acid, which the blood, at the completion of its circuit, conveys to the lungs, to be by them expelled into the atmosphere.

A small amount of carbonic acid is eliminated by the skin.

We may roughly express the oxidation of the various tissues as follows :

1. Fat + oxygen $=$ carbon + hydrogen + oxygen toxygen $=$ carbonic acid + water .

2. Sugar + oxygen $=$ carbon + water + oxygen $=$ carbonic acid + water.

3. Albumen + oxygen $=$ carbon + hydrogen + nitrogen + oxygen + oxygen $=$ carbonic acid + water + degraded nitrogenous matters, such as urea, \&c.

The carbonic acid, as we have already seen, is got rid of by means of the lungs, which, together with the 
kidneys and skin eliminate water; the degraded nitrogenous matters, and broken-up mineral substances being excreted by the kidneys.

Repair of Waste.-In order to supply material for the repair of the constant waste experienced by the system, the animal must have food which shall answer the following conditions :-

1. It must contain a proper proportion of the elements necessary for the building up of the new tissue.

2. It must be digestible.

3. It must be of sufficient bulk for the stomach and intestines to act on it.

4. It must be palatable.

Grain, grasses, and roots, used in suitable proportions, answer the above conditions. As chemistry enables us to analyse these foods, we may, by its aid, approximately judge of their respective nutritive values. The following tables may serve as a guide to the reader :- 


\section{ANALYSIS OF FORAGE.}

Compiled from the writings of Drs. Voelcker, Parkes, Letheby, and Professors Wolff and Knop.

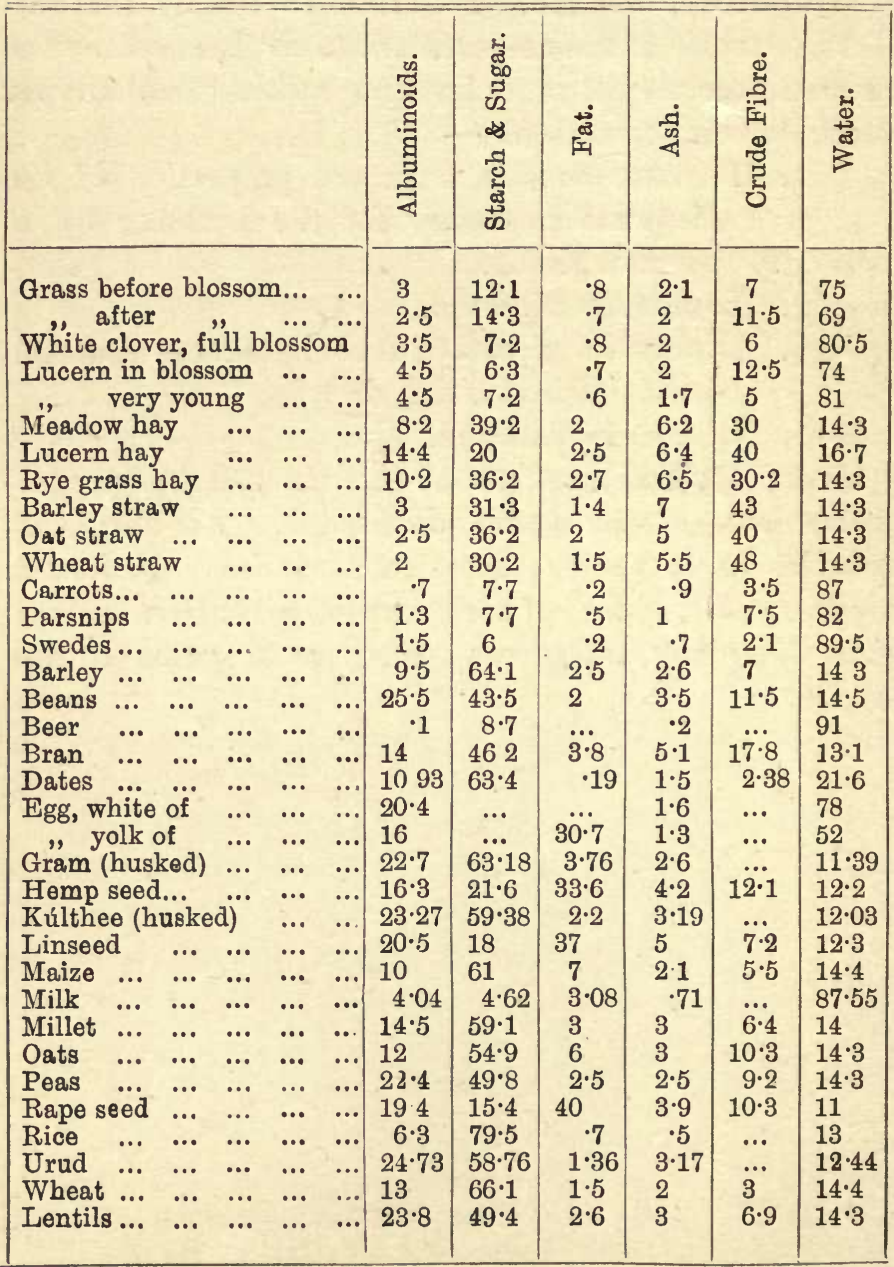


THEORY OF FOOD AND NUTRITION.

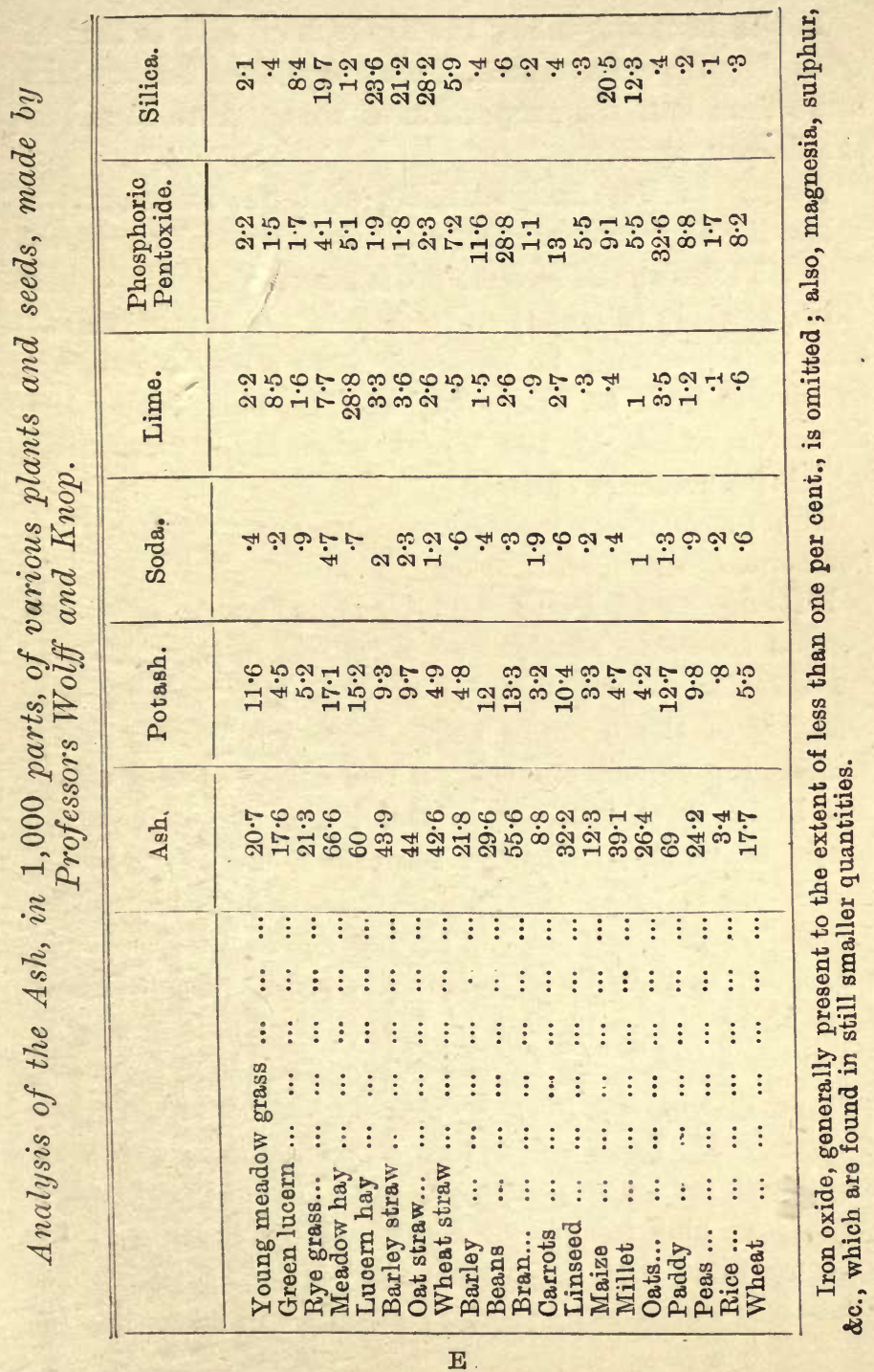


In the foregoing table, the analysis of oats is that of good English corn, which, I may say, does not contain more than half the proportion of woody fibre found in the Indian variety.

Owing to the indigestibility of bran, its nutritive value is not in accordance with its chemical composition. This want of agreement is also apparent in other foods, notably in wheat and potatoes. The portions of bran which cannot be digested serve a useful purpose in giving bulk to the food, and in stimulating the digestive canal by the slight mechanical irritation which its presence causes.

The nitrogenous matters contain from $15 \cdot 4$ to 16.5 per cent. of nitrogen (Parkes).

Nitrogenous Food.-The natural waste of nitrogenous tissue is accelerated by exertion, though to a far smaller extent than is that of fat. From the analysis of the urine of men, taken while they were undergoing violent exertion, it was observed that there was but a small increase in the waste of nitrogenous products, which, as before remarked, are excreted by the kidneys. Experience, however, demonstrates the necessity, in such cases, of an adequate supply of nitrogen, as may be seen by the good results obtained from the addition to oats of beans-in England-or of gram, or kúlthee-in Inäia-especially, when, from old age, or illness, the horse's powers of assimilation were diminished. Such a diet, however, should be carefully regulated, for an over-supply is apt to upset the animal's digestion, and to poison his blood by causing it to become filled with an excess of deleterious nitrogenous products, which the excretory organs will be unable to 
eliminate with sufficient rapidity. We may often witness the baneful effects-in the form of diarrhœa, filled legs, and a general "heated" state of the system -of the consumption of too much gram, or kulthee.

An excess of nitrogenous food, such as gram, or kúlthee, seems to hasten the oxidation of fat, probably, by inducing a fevered state of the system, in which the temperature of the body is raised above its normal degree. Hence we find that an excess of such food retards the process of getting an animal into a fat condition.

Fat, Starch, and Sugar in Food.-These constituents are, by the process of digestion, utilized in the formation of fat; the first named being directly absorbed, without undergoing any organic change. Its excess is apt, especially during idleness, to cause derangement of the liver, from its accumulating to an injurious extent in the cells of that organ; and also tends to produce fatty infiltration and degeneration of various tissues, rendering them unable to bear the strain of violent exertion. Too large a supply of sugar also acts in a similar, but in a less energetic manner. An excess of starch appears to exert little or no injurious effect ; for what is not required, seems to be harmlessly expelled with the dung. Thus, we see that the bad results of an excess of either fat, sugar, or starch are in a direct proportion to the ease with which they are assimilated. When an animal is in poor condition, the value of these foods is in the same ratio.

Nitrogenous matters are also capable of forming fat; for in them we find the necessary carbon, hydrogen, and oxygen. This process of obtaining fat from nitro- 
genous food, probably, takes place to a far slighter degree among the herbivora, than among the carnivora, whose bodily weight and internal temperature can be sustained on a diet of lean meat alone.

When long-distance walking and swimming came into vogue a few years ago, it was thought that concentrated food, of a highly nitrogenous nature, was the most suitable for the athlete while attempting such feats. The fallacy of this was proved by experience; for it was found that incomparably greater trials of endurance were performed under a regimen rich in fat, than under the old system of training on lean meat and dry bread. This was notably shown in the case of Gale, while walking 1,500 miles in 1,000 hours; for his diet consisted of ordinary meat, buttered toast and bread, eggs, \&c. Gale, it must be remembered, while performing his remarkable feat, walked $1 \frac{1}{2}$ miles at the commencement of each consecutive hour. In the days of our forefathers, Captain Barclay astonished the athletic world by walking 1,000 miles in 1,000 hours. He, however, by having been allowed to do a mile at the end of one hour, and another at the commencement of the next hour, was able to procure, between his tasks, more than double the length of rest which was given to the Cardiff man. Weston, the pedestrian, was, I believe, one of the first to demonstrate, in England, the advantages of this system. Webb, the Channel swimmer, too, was another instance. Indian wrestlers, who always train on a diet rich in fat, have for ages worked on true physiological principles which European scientists are only just beginning to understand. I am thoroughly convinced that the fact of modern feats 
of endurance, totally eclipsing the performances done in former days, is mainly owing to a larger supply of fat and starch having been introduced into the diet of athletes. This lesson we should utilize in the case of hard-worked horses. Unfortunately our choice in the matter of food is here but small, when we are limited in the matter of expense, except in the case of linseed, which is a thoroughly suitable article. We might, however, in some cases, supplement it with milk, eggs, ghee (clarified butter), and goor (unrefined sugar).

We find that, for the maintenance of health, a man requires, in his food, a supply of fat as well as of starch, and that the former cannot be replaced altogether by the latter. The horse, it appears, is far more independent of a supply of fat in his diet, than is man; but whether it can be dispensed with altogether or not, is a question I am unable to answer. The fact, however, of the existence of a certain, though varying proportion of fat, in the natural food of the animal, indicates its value, if not its absolute necessity. In the daily diet, given by Dr. Parkes, for a man performing very laborious work, we find that the fat is to the starch and sugar, as one is to four. The proportion for a horse, on a full supply of oats and hay, is about one to sixty.

In food for horses, it appears that sugar may be entirely replaced by starch, though the converse of this does not hold good.

Heat Supply.-The constant oxidation of carbon and hydrogen-attended by the formation of carbonic acid and water-in the various tissues, is accompanied by the evolution of heat, which serves to sustain the internal temperature of the body of the horse at about 
100.5 F. During exercise, there is a proportionate increase in the amount of tissue broken up by these chemical combinations taking place; but the greater portion of the excess of heat appears to be utilized by its becoming, converted into motion; for we find that after rapid movement, which is necessarily accompanied by considerable waste of tissue, there is but a very slight increase in the temperature of the body. This is in accordance with the fact that heat and motion are but modifications, though under different forms, of force.

Mineral Substances.-These, with the exception of common salt, are obtained in ample sufficiency from the various grasses. Corn contains them in a far smaller proportion (see page 49): hence the necessity of the former food. We may observe, as before remarked, that bran contains a large proportion of phosphorus, which is an indispensable factor in all the functions of life.

The phosphates of lime and magnesia, the carbonate of lime, and silica are the chief agents that give solidity to the bony skeleton. The phosphate and carbonate of soda "would seem to have as their chief purpose the maintenance of the alkalinity of the blood, on which depends not merely the solubility of its albumen, but the facility of its passage through the capillaries, and the readiness with which its combustive materials are oxidized, whilst they also increase the absorptive power of the serum for gases, and thus play an important part in the respiratory process. The salts of potash appear to be specially required for the nutrition of the muscles and nerves, since they are largely present in 
the fluids and ashes of these tissues, but they probably exert the same general influence as those of soda... The presence of the earthy salts, on the other hand, would seem to have reference almost exclusively to the composition of the tissues, into which some of them enter very largely." (Carpenter.) Iron is principally found in the red corpuscles of the blood, in the muscles, and in the hair.

Husk of Grain.-The office of the husk of grain appears to be that of furnishing mineral matters, and of giving bulk to the food. It also seems, by mechanical irritation, to increase the wormlike motion of the bowels, which tends to obviate the ill-consequences which might arise from the decomposition, in the intestines, of the unassimilated nitrogenous matters of the corn; a possibility likely to occur owing to the unstable nature of the compounds of nitrogen. Both from theory and practice we may safely conclude, that the husk should not be removed from the grain which the horse is to consume.

We may see, from the foregoing observations, that the working parts of the animal machine are formed of nitrogenous and mineral substances, with a small amount of fat; the motor power being obtained from heat generated by the oxidation of fat, and also of the component parts of the machine itself.

Bulk in Food.-The fact of the horse's intestines being of large capacity, indicates that his food should be of a bulky nature. The intestines have a wormlike motion, which causes the food to become thoroughly mixed with the intestinal juices, its various particles to be presented to the absorbents-which take up the 
nutritive matter-and the remainder to be expelled onwards. They possess this power of motion from the fact of one of their coats being a layer of muscle which contracts when it is stimulated by the presence of food. The more bulk the food has, speaking generally, the less have the intestines to contract in order to move it about. If this condition of bulk be not complied with, the digestive apparatus will get out of order, however accurately materials for building up tissue be supplied. Indigestible woody fibre-contained in large quantities in the various grasses - and unassimilated starch, chiefly serve the required purpose. The fact that, within certain limits, the measure of a horse's appetite is by bulk and not by weight, is evidently due to the necessity the animal feels of having his intestines filled. We see the same craving for bulk evinced by human beings. "The Kamschatdales, for example, are in the habit of mixing earth or saw-dust with the trainoil, on which alone they are frequently reduced to live. The Veddahs, or wild hunters of Ceylon, on the same principle, mingle the pounded fibres of soft and decayed wood with the honey on which they feed when meat is not to be had; and on one of them being asked the reason of the practice, he replied, 'I cannot tell you, but I know that the belly must be filled." "(Carpenter.)

Selection of Food.-For all practical purposes, we need not consider grain beyond its use as a former of fat, and of nitrogenous tissues, such as the various muscular and nervous structures. To give bulk to the food (except in the case of horses getting as much oats as they can eat), and to supply the required mineral matters, we must principally depend on grass. As 
exercise directly increases the waste of tissue, we must add to the amount of grain according to the degree of labour, though, at the same time, allowing an unlimited supply of hay, in order to comply with the conditions just stated. The exceptions to this rule will be: when the horse is in a state of enforced idleness; when his appetite is in a depraved or abnormal condition; and when he is required for immediate work. When a horse's powers are fully taxed, he should be allowed as much hay and suitable corn as he chooses to consume. This now leads us to the pertinent question, "what proportion should the nitrogenous matter in grain bear to the starchy constituents?" From the teaching of experience, which here can alone direct us, we may learn that, for moderate work, it should not exceed that which is contained in oats, namely, 10 to 47 (about). To find the maximum, we may assume a diet of four parts of oats and one part of beans (as given in England to hardworked animals), which will give us the proportion of 10 to 38 (about).

To determine the maximum amount of nitrogenous food, I think we may safely assume it to be about that contained in $20 \mathrm{lbs}$. of oats, namely, $2 \frac{1}{4} \mathrm{lbs}$. (about). If we are forced, by circumstances, to use a grain, such as gram, or kúlthee, which is too rich in nitrogen, we should do so at the expense of the starch, but should, on no account, exceed the amount of nitrogen already laid down; for if we do so, the excess will tend to produce the derangements of the system which have been already mentioned.

Respecting the supply of fat, I am unable to say anything more definite than I have done in the previous 
pages of this chapter. Dr. Parkes' proposition, that " if men are undergoing great exertion, they take more food, and if they can obtain it, the increase is especially in the classes of albuminates and fats," holds equally well with regard to horses.

Hay and Grass.-We may consider these two to be, nearly, the same kind of food, except that the former contains a less proportion of water than the latter.

I have previously argued that a horse should get a full supply of hay under all circumstances, except when he is unable to take sufficient exercise.

A horse, omitting exceptional cases, evinces a marked preference for corn compared to hay; hence we may assume that, when he turns from the former to the latter, he does so from the prompting of an instinct which is intended by nature to guide him in the selection of the food most suitable for the requirements of his system. We need hardly dwell on the not uncommon folly of stinting a horse of his hay, when the object is to get him to eat as much corn as possible, in order to enable him to sustain violent and continued exertion, such as that demanded during the training of race-horses. I have always found that such animals eat more corn and digest it better when their supply of hay is unlimited at all times, than when it is curtailed, and especially so when they are deprived of it during feeding hours. The idea that a groom, trainer, or owner, can tell to a pound, how much hay his hardworked horse should eat, is palpably absurd. The case of corn is very different; for a horse, unless his powers are fully taxed, is almost always prone to eat 
too much of it, and its bad effects are patent to the most careless observer. General Sir F. Fitzwygram justly remarks that, "practically it will be found that horses, which are not limited as regards oats, will not usually consume above $6 \mathrm{lbs}$. of hay per diem." Surely no one could say that this was an inordinate amount? As regards training, I have often been met with the objection that horses would gorge themselves, and would even eat their bedding, unless muzzled; but I have never found this to occur when a full supply of oats has been given, although I have had several horses in training that came to me with the character of being insatiable gluttons.

I desire to lay considerable stress on the subject of allowing horses hay during feeding hours, as I have always found this practice to be attended with the best results, for not alone is the condition of bulk complied with, but also irritation to the alimentary canal, resulting from the presence of stimulating food, is avoided, as much as possible, by the corm becoming diluted by the hay. To see how reasonable this practice is, we need but apply the case to ourselves with respect to the meat and vegetables we consume at our meals.

Green Meat.-Although the necessity of a supply of fresh vegetables, as a part of human food, is clearly recognised; still, up to the present time, physiologists have been unable to explain the rationale of the fact, and have been obliged to accept it simply as a result of experience. In the same manner we find that "green meat" is almost equally as indispensable for horses. This is especially the case when the hay which is used, has been subjected to a process of fermentation, which 
gives it a brown appearance, and often increases its sweetness, although it diminishes its value. This method of curing hay is seldom adopted in India, where an ample supply of doob grass will fairly fulfil the conditions supplied by "green meat" and ordinary hay.

Variety in Food.-As far as my experience goes, I have been unable to notice any marked good arising from a change of food, unless when the new article of diet contained elements of nutrition deficient in the other

Salt is the only necessary food that is not supplied in sufficient quantity by the grain and grass consumed by the animal. A moderate excess of it can, in nowise, prove injurious; for it will be speedily eliminated by the kidneys, after the system has taken up sufficient for its own requirements. It furnishes the elements for the supply of the hydrochloric acid which is a constituent of the gastric juice. It also plays a most important part in the whole nutrition of the body. "It was demonstrated by Boussingault, that when, of two sets of oxen, one was allowed the unrestricted use of salt, whilst the other was as far as possible deprived of its use, a marked contrast was observable in the course of a few weeks between them, and manifestly to the advantage of the former. The desire for common salt on the part of animals and man is extremely powerful, leading the former, especially if they be vegetable feeders, to traverse great distances to reach saline deposits." (Carpenter.)

Relations of Cold, Heat, and Clothing to Food. -When the temperature of the surrounding air falls much below its normal degree, a proportionate increase of starch and fat, to keep up the natural temperature 
of the body, should be made to the food of the animal, if it be unsupplied with warm clothing, which, by preventing radiation, supplements the action of the fatty layer which lies immediately underneath the skin. Hence a judicious addition of clothing may be practically regarded as an addition to the food; so that, when it cannot be made, more corn ought to be given. In hot weather, the animal will, naturally, require less food.

Mastication and Digestion.-The long hairs about the horse's muzzle serve him as feelers in the selection of the food which his lips convey into his mouth, aided, when the fodder offers some resistance, by the front teeth (nippers, or incisor teeth). The muuthful is then conveyed to the grinders, and is ground by them into a pulp. During this operation it becomes mixed with saliva, which, under the stimulus of the food, flows into the mouth from the different salivary glands. This secretion contains the active principle ptyalin - a species of ferment-the office of which is to convert starch into dextrine (a kind of mucilaginous starch) and subsequently into grape sugar, in which form it is absorbed by the system. "A large proportion of this albuminous principle is present in the saliva of the horse, but only traces of it exist in that of man." (Carpenter.) The amount of saliva secreted during mastication is proportional to the hardness and dryness of the fodder. Lassaigne gives, from experiment, the following results :-

100 parts of dry hay requires 406 parts of saliva.

$\begin{array}{llrrr}" & \text { barley } & \text { " } & 186 & , \\ " & \text { oats } & \text { " } & 113 & \text { ", }\end{array}$


"Bernard was led to suggest that the submaxillary gland ministers to the sense of taste, whilst the parotid is connected with mastication, and the sublingual with deglutition. The size of the parotid in animals is proportionate to the degree in which the mastication of their food is performed. It is large in the horse, which lives on comparatively dry food, less in carnivora, and still less in the aquatic mammals, as the seal. It is absent in birds which swallow their food whole." (Carpenter.) The salivary glands of the horse are larger than those of all other animals, except ruminants

The presence of saliva in the food materially aids its digestion in the stomach. "Among the experiments are those of Spallanzani and Reamur, who found that food inclosed in the perforated tubes, and introduced into the stomach of an animal, was more quickly digested when it had been previously impregnated with saliva than when it was moistened with water. Dr. Wright also found that if the osophagus [gullet] of a dog is tied, and food mixed with water alone is placed in the stomach, the food will remain undigested though the stomach may secrete abundant acid fluid, but if the same fluid is mixed with saliva, and the rest of the experiment similarly performed, the food is readily digested." (Kirkes.)

Saliva is alkaline, and gastric juice acid. Pancreatic juice and bile are both alkaline. This alternate character seems to have been given to these fluids, so as to regulate their action.

The chief part of the starch contained in the horse's food passes unchanged into his stomach; and the action of the alkaline saliva, as a ferment in converting 
this starch into sugar, ceases on being neutralised by coming into contact with the acid gastric juice. Hence, it would appear that the chief office of the saliva is to check undue acidity in the stomach.

The frothy nature of saliva seems to aid digestion. "The numerous air-bubles for which saliva is remarkable have their special purpose; since the presence of atmospheric air in the stomach is accessory to digestion." (Leared.)

I submit that the foregoing observations indicate, as a general rule, the advisability of giving grain in a dry state.

The presence of salt in the food excites the flow of saliva in the mouth; hence, if boiled or steeped food be used, it should be given mixed with that condiment; because, owing to the moist and soft state of the grain, a deficient amount of saliva will be secreted.

Having reached the stomach-the capacity of which is from 3 to $3 \frac{1}{2}$ gallons - the food becomes mixed with the gastric juice, which flows slowly at first. This secretion is liable to become checked by violent exercise, or by the stomach becoming unduly distended. If it be largely diluted with water, its action will be arrested, until the excess of that fluid be absorbed. Cold also stops the performance of its functions; for it will not act at a temperature much below blood heat. A moderate supply of hot spices stimulates its secretion. When the supply or action of the gastric juice-which is a natural antiseptic-is checked, the food that is in the stomach at the time is apt to become decomposed with the probable result of indigestion, flatulent colic, and even rupture of the stomach, caused by the evolu- 
tion of gas. Hence we may conclude that horses ought not to be watered soon after being fed, and that they should not be given large supplies of boiled food which is very bulky in comparison to the amount of nutriment it contains, and can also be rapidly swallowed. Besides, exciting but a small secretion of saliva, it arrives in the stomach in an unprepared state, and is consequently liable to become decomposed before the gastric juice can act on it.

The antiseptic properties of gastric juice is well shown by the immunity with which many races of men eat putrid flesh and fish.

The active principle of gastric juice-pepsine- converts the nitrogenous matters of the food into a soluble form-peptone-and also serve to split up the fat into a state of fine division, by dissolving the nitrogenous envelopes, which enclose the globules. When the food-now called chyme-leaves the stomach and enters into the small intestine, it becomes mixed with bile and pancreatic juice which flow from a common duct. The action of the fluid which comes from the pancreas (sweetbread) is very similar in its nature to, though much more energetic, than that of the saliva, the work of which in converting starch and cane sugar into grape sugar it completes. It also, like gastric juice, dissolves albumen. By virtue of its alkaline nature, it makes an emulsion, or soap, with the fat contained in the chyme, which consequertly assumes a white appearance, and is then termed chyle. The particles of fat are thus split up into a very fine state of division, so as to be readily absorbed in an unchanged state, as none of the digestive fluids produce any effect on their com- 
position. The bile acts as a natural purge, the bowels becoming constipated when it is deficient in quantity. It also, by reason of its antiseptic properties, prevents decomposition of the ingesta, prior to their being expelled. In the absence of bile, deleterious gases are evolved in the intestines, and are absorbed into the system, to the detriment of the health of the animal; in which case the dung has a foul smell. Bile is constantly being excreted by the liver. We find that certain of the higher animals, such as man, are provided with a gall-bladder, into which this fluid collects, to be poured out into the intestines during the process of digestion, which is, in these cases, intended by nature to take place at certain intervals. The horse, however, possesses no gall-bladder, which fact clearly indicates that he should be, more or less, constantly supplied with food. The fact of his stomach being of small capacity, and his intestines of large size, points to the same conclusion.

On leaving the small intestine, which is about 72 feet long, the food becomes collected into a capacious cul-de-sac-the cæcum-formed by the large intestine, the length of which is about 20 feet. The cæcum appears to be a kind of supplementary stomach, in which is collected the pulpy mass of water and unassimilated food, which the stomach and small intestines have failed to take up. Here the remaining nutritive particles are dissolved out and absorbed. The cæcum can contain about 6 gallons of fluid.

Functions performed by the Blood.-As the nutritive part of the food becomes changed into forms capable of being assimilated, it becomes gradually 
taken up by the minute vessels, called absorbents, that line the interior of the stomach and intestines, and is conveyed into the blood, which ramifies through the various tissues of the body, and which supplies them with materials for repair. Thus, we see that the blood acts as the vehicle for removing the products resulting from the waste of tissue, and also for furnishing the elements required in the building up of new structures.

Appetite.-Appetite serves two purposes-(1) When the system requires new elements for repair, it prompts the animal to eat, so as to obtain them from his food. But, in order to avoid excess, the process of feeding should be carried on slowly. On this subject, Dr. Carpenter remarks:- "To eat when we are hungry, is an evidently natural disposition; but to eat as long as we are hungry, may not always be prudent. Since the feeling of hunger does not depend so much upon the state of fulness or emptiness of the stomach, as upon the condition of the general system, it appears evident that the ingestion of food cannot at once produce the effect of dissipating it, though it will do so after a short time; so that, if we eat with undue rapidity, we may continue swallowing food long after we have taken as much as will really be required for the wants of the system; and every superfluous particle is not merely useless, but injurious." These observations apply equally well to horses as they do to ourselves." (2) Appetite guides the animal in the selection of food suitable for the repair of the waste that is going on at the time. As a general rule, when a horse's powers are fully taxed, he should be allowed as much corn and hay as he chooses to eat, provided always, they are both of 
a suitable nature. The instinctive selection of food is well seen in the case of men who have to work hard, such as navvies and sailors; for they will eat, with benefit, a quantity of animal food and fat, from which a sedentary person will turn with loathing.

Influence of an artificial state of Life. - The horse is intended by nature to travel considerable distances when grazing; and his natural food is one of large bulk, and containing a comparatively small amount of nourishment; his digestive organs being specially adapted for its consumption. The requirements of civilization, however, interfere most materially with these conditions. At times, long protracted rest deprives the animal of the exercise which is essential to his health, and which he, in a state of nature, would be obliged to take in the pursuit of food. On the other hand, in order to develop his physical system to its utmost extent, he is supplied with forage of a far more concentrated form than he was naturally intended to consume. Hence, being unable to trust to the animal's appetite alone as a sure guide in the selection of food, in all cases, we must regulate it according to the indications afforded us by the study of the anatomy and functions of his system.

Preparation of Food.-Oats, gram, Indian corm, barley, wheat, and rice in husk (Hind. dhan) should be bruised or broken before being given to the horse, in order to oblige him to masticate them properly, so that the grain may become thoroughly saturated with saliva. If given in a whole state, it is liable to be swallowed, as soon as its outer surface becomes moistened.

Heat, whether by the process of boiling or parching 
causes the grains of starch in corn to burst, and the albumen to coagulate, so that the different digestive fluids are then able to penetrate easily through its substance. The objection to boiling is that it causes the food to become saturated with water, which decreases its digestibility, and greatly increases its bulk. Parching, however, is free from any such drawback, and may be advantageously applied to the preparation of barley and wheat. The husk of the first-mentioned grain often has a more or less irritating effect on the intestines of the horse. The process of parching not alone renders the grain porous, but also deprives the husk of its objectionable properties. The husk of linseed, kúlthee, and urud is so hard that they require to be boiled before being given. 


\section{CHAPTER Y.}

\section{ON WATERING HORSES.}

THE blood being the source from which the different tissues obtain materials for repair and development, and the vehicle which conveys away the effete products resulting from the constant waste that goes on in the animal economy ; the whole question of nutrition depends on supplying the system with materials suitable for preserving that fluid in a normal and healthy condition.

The proportion of water in the blood is about 750 parts in 1,000 ; the variation being dependent on the nature of the animal's work, food, state of health, etc. Its presence is essential to the performance of the various functions. If its supply be curtailed, the secretions that are indispensable to the process of digestion are checked either wholly or in part; because the glands are unable to obtain a sufficiency of water from the blood. If, on the contrary, more water be drunk than is needed for the requirements of the system, the excess is quickly eliminated by the kidneys, skin, and lungs, without doing any harm. We may conclude, therefore, that a full supply of water, given a short time before feeding, is essential for the proper digestion of food.

The office of the sensation of thirst is to cause the 
animal to desire to drink water, when there is a deficiency of that fluid in his blood.

The stomach is furnished with a vast number of blood vessels, the office of which is to absorb water for the supply of the glands that secrete the gastric juice. As the amount of the secretion, necessary for digestion, varies from 10 to 20 gallons daily (Brinton), and as about 99 per cent. of it is composed of water, we find that the process of digestion, during the day, demands the outpouring, for the formation of gastric juice, of double or treble as much water, as there is blood in the whole body. Now, as this water is derived directly from the blood, its adequate supply can only be obtained by the constant reabsorption, in the stomach, of the watery portion of the effete gastric juice, as well as of that of other fluids which may be present. Considering the enormous quantity of water required for the secretion of the gastric juice, we may accept the fact that drinking a small quantity of water with the food is not alone free from objection, but may be actually beneficial. On this point we may safely trust to the instinct of the animal, and may consequently leave a supply of water before him while he is eating; provided always that he has had a full opportunity of drinking shortly before being fed.

If (as we have seen in the preceding chapter), while digestion be going on, a large amount of water be taken into the stomach, it will dilute the gastric juice to an extent that will probably arrest its action, until the excess of water becomes absorbed. During this interval, decomposition of the food, with consequent derangement of the digestion, may ensue; followed, perhaps, 
by colic, or even by rupture of the stomach, owing to the pressure exerted by the evolved gas. Hence, we may conclude that the horse should be watered before being fed. But if, as in case of want of time, this precaution has not been observed, only small quantities, with reasonable intervals to allow of its absorption, should be allowed; say 10 "go downs" at intervals of five minutes, assuming 20 "go downs" to the gallon. Considering the quickness with which a horse digests his food, I think we may assume that he may be watered $2 \frac{1}{2}$ hours after being fed, without any ill consequences. The reason that soft is better than hard water for horses-a fact known to every careful stableman-is that the freer this fluid is of impurities which possess astringent properties, the more readily will it become absorbed into the blood.

Respecting the celerity with which water is assimilated, I cannot do better than quote the following extract from Seller and Stephens' Physiology of the Farm:- "That water passes with extreme rapidity from the stomach of the horse, as from that of mammals in general, is apparent from the well known fact that a horse will drink within a few minutes a much greater quantity than his stomach can contain. It is commonly supposed that the excess passes at once into the highest part of the small intestines, namely, the duodenum. But this supposition is hardly necessary, for it is proved that absorption of thin fluids takes place from the inner surface of the stomach with an almost incredible rapidity. This fact is established by many experiments; and moreover, that substances dissolved in the water taken in have been found in the urine 
within an incredibly brief period." The obvious lesson these considerations teach us is, that we should not be chary in allowing a horse to drink when he wants to do so, except indeed after feeding.

One of the popular errors about watering horses is, that they should be stinted of water for several hours before doing fast work, on the plea that it affects their wind. As the water which becomes part and parcel of the blood, cannot by any possibility impede the organs of breathing, it follows that its unabsorbed portion alone can affect them; but we have just seen that the whole of the water is taken up with extreme rapidity, so that, after a short time, there is none left in the stomach or intestines to cause any impediment. On the contrary, stinting a horse with water will directly affect his wind, for the blood will then gradually become thickened, and, if the animal be put to violent exertion, will fail to circulate through the lungs with requisite freedom; besides that, the action of the heart will become impeded, and the nutrition of the system more or less arrested.

If a horse has been deprived of water for a considerable time, we should exercise some caution in watering him, lest he may drink a larger quantity than can readily be taken up; for the unabsorbed portion-especially if the fluid be given cold - may cause serious derangement. When a horse is heated by exercise, his system will absorb water far more readily than when he is cool; hence, under the former condition, there is far less risk in giving a liberal supply, than under the latter, always supposing that the water is not very cold: in which case, there would be danger of injury 
from nervous shock. General Sir F. Fitzwygram remarks :- "It is a somewhat singular fact that horses may be watered with safety almost immediately after their return from work, even though somewhat heated." And he points out that there is then far less risk of chill from such horses drinking cold water, than when the system has begun to flag; and that, in the latter case, the water should be made slightly tepid, or a bucket of gruel should be substituted for it. As the application of cold causes contraction of the muscular coats of the blood-vessels, so does it retard the absorption of water which is taken into the stomach.

When a horse goes through violent and continued exertion without drinking, the amount of water in his blood falls below its normal quantity. If this loss is considerable, the thickened blood will be unable to circulate throngh the lungs with its wonted facility; in fact, more or less congestion will take place, and the action of the heart will become laboured in its efforts to pump this abnormally dense fluid through the system. If a horse, in this state, be given, say, a couple of gallons of water, they will be absorbed at once into the blood, and will restore it, more or less completely, to its normal fluidity; the action of the lungs and heart will be almost instantaneously relieved, and the feelings of distress will rapidly subside. Had the water, on the contrary, been withheld until the horse had cooled down, the prolonged distress, even if the congestion had passed off with no bad results, would undoubtedly have injuriously affected the animal's condition and spirits. In accordance with this principle, I have adopted, with the best results, the practice of giving 
half a bucket of water to race-horses I bave had in training, immediately after their gallops.

Persons who have had to ride long distances, in hot countries, are well aware of the advisability of allowing their mounts to drink frequently during a journey, of any good water near which they may pass, even when the horse is bathed in perspiration.

In Nortbern India, the ecka (a small two-wheeled trap) ponies, which average about 13 hands 1 inch in height, frequently travel 50 to 60 miles a day over unmetalled roads during the hottest weather, when the noontide heat often exceede $115^{\circ}$ in the shade. Such performances can only be accomplished by watering the ponies every 7 or 8 miles: the system pursued being that they get at each bait from 1 to $2 \mathrm{lbs}$. of suttoo mixed in a couple of quarts of water. This is in accordance with the practice-generally adopted by stokers and firemen on board steamers-of mixing oatmeal with the water they drink; a practice from which these men, who are often exposed to intense heat, and who are consequently obliged at such times to drink large quantities of water, experience great advantage. In the stable, I think the best system is to allow a constant supply of water; a plan which is not alone beneficial to "washy" horses that scour easily, to roarers, and to broken-winded animals, but also is particularly well calculated to prevent and to cure the pernicious habits of crib-biting and wind-sucking. 


\section{CHAPTER VI.}

PRACTICAL RULES FOR FEEDING AND WATERING HORSES.

From the theoretical considerations detailed in the two preceding chapters, and from the results of experience, we may draw the following conclusions:-

1. The horse's corn should be given dry; except when the grain-such as linseed, kulthee, \&c.-is too hard, in its natural condition, to be properly masticated; when, from old age and other causes, the animal's powers of chewing are impaired; and when the appetite has to be humoured in sickness.

The only way I can account for the Indian practicenow happily falling into disuse-of steeping gram in water, before giving it to the horse, is that it is done with the idea of causing the gram to swell, as much as possible, before entering the stomach, in order that it may not do so after arriving there, especially, if the animal be, subsequently, supplied with water. Those who adopt such a precaution, entirely ignore the fact that it is the evolution of gas-resulting from the decomposition of the food-which produces flatulent colic and rupture of the stomach, and not any swelling of the gram, which, if it be given dry-as we have previously seen-will become saturated with a greater quantity of saliva than that of its own bulk, before it 
even reaches the stomach. The danger of a horse choking himself-if the stableman takes the most ordinary precautions-is purely imaginary.

2. The different grains before being given to the horse may be prepared as follows:-Oats and wheat, bruised. Gram, Indian corn, and rice in husk, roughly broken. Barley, parched and roughly broken. If the parching be dispensed with, barley should at first be cautiously given to the animal, so that it may not "scour" him.

3. The following forms a list of Indian foods, calculated to maximum amounts :-

1. Gram or kúlthee ... 10lbs.

2. Gram

Bran...

3. Barley

4. Barley

Gram...

5. Oats ...

... $\quad \ldots 7$,

6. Oats ..

Gram, kúlth... or úrud

7. Indian corn...

Gram

8. Indian corn

Gram

Bran...

9. Gram

Indian corn... $\quad . .5$,

Bran

... 4 ,
10. Oats ... $\quad \ldots \quad$... 6 6lbs.

Gram ... $\quad \ldots \quad \ldots \quad 5$,

Bran ... $\quad \ldots \quad$... 2 ,

Linseed $\quad . . \quad$... llb.

11. Gram ... ... ... 6lbs.

Rice, in husk ... 10 ,

12. Gram ... ... ... 5 ,

Rice, in husk ... 8 ,

Bran ... ... ... 4 ,

13. Wheat... ... ... 8 ,,

Chaff, a sufficiency, say 4 ,,

14. Wheat ... ... 4 ,

Gram ... $\quad \ldots \quad \ldots \quad 7$,

15. Wheat $\ldots$... $^{4}$,

Indian corn $\ldots . \quad \ldots \quad 4$,

Bran ... $\quad \ldots . \quad \ldots .4$,

Gram ... $\quad \ldots \quad \ldots \quad 4$,

16. Mote $\ldots$... $^{. . .} \quad \ldots, 6$,,

Gram .. $\quad \ldots \quad \ldots 6$,

I have assumed Indian oats to contain about a quarter less nutriment than English corn.

Bearing in mind the difficulty there often is in procuring certain grains in many parts of India, I have varied the proportions, so as to suit horse owners who have but a limited supply of particular grains; such as oats, for instance. 
The reader may rely on these foods being suitable in practice, as well as correct in theory. Nos. 5, 6, 8, 9, and 10 are those $I$ would specially recommend. No. 5 is the best for ordinary animals ; No. 6, hard-worked horses, such as those used in racing; No. 10, for similar animals when low in condition. The other two can almost always be procured, and usually at a cheap rate. The amounts are intended for a fullsized Australian, or English horse. During ordinary work we may give from two-thirds to three-fourths of them. One-half will be sufficient during idleness.

4. A 13-hand pony will eat about half as much as a large horse. An Arab will, as a rule, require about $4 \mathrm{lbs}$. less than a full-sized Australian or English horse.

5. The amount of grain, given to the animal, should be proportionate to the work he is called upon to perform, remembering, always, that there is a constant waste of tissue going on which demands repair by food.

6. When a horse is comparatively idle, his food may consist of one-third to one-half of bran, and two-thirds to one-half of oats, Indian corn, barley, or paddy-in preference to gram or kúlthee-say 8 or $10 \mathrm{lbs}$. altogether. The same practice may, with advantage, be observed during the hot weather.

7. Horses should not be allowed to run down in condition, even when out of work; for, especially in India, it takes a long time to put flesh on them again.

8. When a horse's powers are fully taxed, he should get as much suitable corn as he may choose to eat.

9. The corn should not be given in such quantities as will cause irritation of the intestines, which will be evinced by a loose and sticky condition of the dung, 
which should, on the contrary, be fairly formed, brittle, and devoid of bad smell. When gram and kúlthee alone are used, these conditions cannot be properly complied with. When diarrhoa is thus set up, it is the result of an effort of the system to expel an excess of nutritive matter, which is deleterious to the health. In such cases, withdrawal of the corn, bran mashes and, may be, a mild purgative, are indicated.

10. When the amount of grain is limited, say to 8 or $9 \mathrm{lbs}$., and when the animal has to do hard work, gram, or killthee, are more suitable than other grains that contain less nitrogen.

11. Foods rich in fat and sugar, such as linseed, Indian corn, milk, goor, \&c., are the best for putting a lean horse into lusty condition.

12. Horses that get a full amount of corn should, as a rule, have a bran, or a bran and linseed mash once or twice a week-say on Wednesday and Saturday nights. It will tend to remove any irritation of the intestines caused by the grain.

13. In cold weather, if horses be not warmly clad, they should have an increase to the amount of their corn.

14. A horse should have a constant supply of salt, say two ounces daily; or he may be allowed a lump of rock salt in his stall.

15. If boiled food be used, salt should be mixed with it, before giving it to the horse.

16. A horse's corn should be given at frequent and regular intervals. Say as follows, supposing $9 \mathrm{lbs}$. to be the daily amount: 
RULES FOR FEEDING AND WATERING HORSES. 79

\begin{tabular}{|c|c|c|c|c|}
\hline 5 & A.M. & $\ldots$ & $\ldots$ & 1 lb. \\
\hline 8.30 & $"$ & ... & .. & $2 \mathrm{lbs}$. \\
\hline 12.30 & P.M. & .. & $\ldots$ & 2, \\
\hline 4 & ,, & $\ldots$ & $\ldots$ & $1 \mathrm{lb}$. \\
\hline 8 & , & $\ldots$ & $\ldots$ & $3 \mathrm{lbs}$. \\
\hline & & Total & & $9 \mathrm{lbs}$. \\
\hline
\end{tabular}

17. When the animal's powers of digestion are impaired, spices or condiments may be given, in order to stimulate the system to take up an increased amount of nutriment from the food. Such articles have little or no dietetic value of their own.

18. In order to induce the horse to eat slowly, it is desirable to feed him from a broad box, or trough, placed not much above the level of the ground. On the bottom of the box, the corn may be spread out in a thin layer.

19. Greedy feeders may have a quantity of chopped hay mixed through their corn.

20. A horse should not be worked for at least an hour and a half after feeding.

21. A horse should always have a supply of hay, or dried grass before him while he is eating his corn, so that, by inducing him to vary his food, he may not consume it in too concentrated a form.

22. Horses, that are inclined to "scour," should have some hay given to them before they get their corn.

23. Unless in cases of enforced idleness, depraved appetite, \&c., a horse should have as much hay, or dried grass as he may choose to eat.

24. If procurable, the grass which is called doob in 
Bengal, and hurryalee in Madras, should be used in preference to all other kinds. It ought to be dried a day or two in the sun, before being given.

25. If possible, a horse should get daily, at least 2 , or $3 \mathrm{lbs}$. of green food, such as lucern, carrots, \&c., as the time of the year may permit.

26. On a journey, a horse should be baited about every two hours, giving him, say, a gallon or two of water-if he chooses to drink it--followed by about $2 \mathrm{lb}$. of corn, with a little grass each time; or he may get a couple of pounds of suttoo mixed in his water, and a little grass after it. The hotter the weather and the harder the work, the more frequent should be the baits. If he be given a larger feed than $2 \mathrm{lbs}$. of corn, he should be rested for at least an hour, or he will be apt to tire quickly and be inclined to scour. Suttoo and water is the best bait when the halts are of short duration.

27. On long journeys, a horse should be allowed to drink very frequently; in fact, whenever he wants to do so. Taking an immoderate amount, at one time, should of course be guarded against.

28. Some horses are inclined to purge if they be put to work soon after being either fed or watered. If the services of such animals be required in the morning, they should get neither corn nor water until after their work.

29. The best plan, regarding the water of horses in the stable, is to allow them a constant supply of it in their stalls.

30. If this cannot be done, they ought to be watered before each feed, or, at least, twice a day in cold weather, and three times in hot. 
RULES FOR FEEDING AND WATERING HORSES. 81

31. Immediately after violent exertion, a horse should have a moderate amount of water to drink, say, one gallon, and, if he be thirsty, another gallon in five or six minutes.

32. However hot and perspiring a horse may be, he should get this water at once, before he cools down; but if he cannot get it until he is cool, he should be given a smaller amount, and some more at intervals of five minutes or so.

33. The " chill" need not be taken off water, except when the horse is very thirsty, and the water unusually cold.

34. Soft water is generally considered preferable to hard, although I have never known any bad results accrue to horses in India from the use of well water that was good for human consumption. The hard water of some limestone districts in England, being loaded with mineral matter, is apt to cause colic when taken cold and in large quantities, especially, when the stomach is full, or weakened by long fasting. I prefer well water, in India, to that obtained from rivers. Water from swamps or stagnant pools should not be used. (See page 37.) 


\section{CHAPTER VII.}

GROOMING AND STABLE ROUTINE.

ON THE THEORY OF GROOMING-WASHING THE HORSE-CLIPPINGGROOMING-DRESSING THE MANE AND TAIL-TAPEEING-SHEDDING THE COAT-CARE OF THE FEET AND LEGS-TRIMMING THE MANE AND TAIL-BOTS-STABLE ROUTINE.

On the Theory of Grooming.-The skin of the horse is composed of two layers. The inner layer, or true skin, is tough and elastic, and is provided with nerves and blood-vessels. In it exist a vast number of narrow, minute depressions-hair follicles-which secrete the hair that covers the body; and, also, an innumerable number of sweat.glands and oil-glands, both of which possess minute tubes to convey their respective secretions to the surface. The oil-glands are specially connected with the hair, as their tubes open either into the hair follicles, or close to the hairs. The action of the oil is to keep the skin and hair soft and pliable, and, also, to protect the skin from chill; while that of the watery fluid is chiefly employed in carrying off, by evaporation, any excess of heat beyond the standard temperature of health. The sweat of the horse is compused of a mixture of these two secretions, the former giving it a greasy character when he is fat ; the preponderance of the latter, a watery appearance, 
when he is in poor condition, or when "drawn fine." The effect of friction applied to the skin, is to draw to the surface an increased amount of blood, from which the glands in question obtain materials for forming their respective fluids.

The inner layer, or true skin, secretes the outer skin in the form of scales, more or less glued together, according to their distance from the surface. This outer skin lines the openings of the oil and sweat tubes, and surrounds each hair. Its presence affords protection to the skin, and checks the outpouring of the oil and perspiration. Hence, when horses are turned out in the open, without adequate clothing, they should on no account be groomed, which process is intended to remove as much of the outer or scarf-skin as possible, and, by friction, to stimulate the secretion of oil and perspiration. The oil, I may remark, protects the skin from the injurious action of water, and also assists in maintaining the internal temperature of the body by rendering the coat bright and glossy-a condition that checks the radiation, as well as the absorption, of heat. Consequently, a horse with a polished skin will not be as liable to be chilled by wet or cold, nor to be as unduly heated by the rays of the sun, as he would be, were his coat dull. This immunity, however, will only last for a few hours, or until the weather affects the hair.

The skin acts as an assistant to the lungs in giving off carbonic acid gas, and thus aids in purifying the blood. The cold produced by the evaporation of perspiration materially assists in lowering the temperature of the body to its normal degree, when it has been 
raised beyond it by exercise. Hence the necessity of the free secretion of perspiration by the skin of hardworked horses.

Apart from the foregoing considerations, we may see that the fact of the skin being in a healthy state will tend to induce a like condition of the stomach, intestines, and air passages; for the skin is continuous with the mucous membranes which line these organs. Owing, therefore, to the sympathy which exists between the various portions of these respective surfaces, we find that, in cases of derangement of the stomach, $\& c .$, the coat becomes dull and unthrifty. In like manner, a return to health will be marked by an improvement in the state of the skin, affections of which are more or less followed by an impaired condition of the digestive apparatus. Experience, as well as physiology, teaches us that the horse's general wellbeing is greatly dependent on his skin being clean, well polished, and healthy.

From these considerations, we may readily see how important the process of grooming is to the maintenance of high condition in the horse.

I may briefly sum up the objects, sought to be obtained by good grooming, as follows:-1, to remove the scaly part of the outer skin, in order to allow of ready exit to the fluids that flow from the oil and sweat-glands; 2 , to stimulate, by friction, these glands to increased activity; 3 , to determine blood to the surface of the body, so as to relieve the internal organs ; 4 , to remove all superfluous hair, the presence of which would tend to check evaporation from the skin; 5 , to induce a healthy state of the skin itself, in which the mucous 
membranes of the digestive and respiratory organs will tend to participate.

The skin of the well-groomed horse will be in the best possible condition to play its allotted part, when the system is called upon to perform violent exertion; but not to resist the continued effect of cold during a state of inactivity. Hence, such an animal should, when he is at rest, be provided with an adequate supply of warm clothing to make up for the loss of the protection which was afforded by the scaly part of the outer skin, and by the increased amount of hair possessed by him in an ungroomed condition.

Washing the Horse.-This practice is, as a rule, injurious; for it not alone removes the natural oil from the skin, thereby rendering the coat dull, but is also apt to produce chill, which, I need hardly say, is the fruitful source of many equine ailments. In a warm atmosphere, a horse that is heated and perspiring, can take no harm from being washed, provided he is quickly dried. Owing, however, to the large surface of the body, and the presence of hair over it, it is difficult to dry a horse thoroughly in time to prevent the chance of his catching cold; and, then, to apply sufficient friction to stimulate the oil-glands to renew the gloss his coat lost from the washing. If it is imperative to wash, and there is not sufficient assistance to have the animal rubbed dry without loss of time, we may, after scraping and rubbing him over, put on a good supply of warm clothing, bandage his legs, and leave him, thus, to dry under his rugs, which he will do in an hour or less. He should, after that, be exercised, or warmly stabled, so as to prevent him becoming chilled. 
Water has no power to remove the scaly part of the outer skin, its effect being confined alone to any dust or mud that may have fallen on the coat. Our best authorities are unanimous in condemning the custom of washing the animal. Both cracked heels and mudfever-a form of inflammation of the skin, which extends more or less over the legs, and sometimes over the lower surface of the abdomen - are often caused by this practice. Mud-fever is a.common complaint in England, though rare in India.

We find from experience, that the external application of warm water, especially to the legs and feet, is still more objectionable than that of cold. This is chiefly due to the fact that it more readily removes the oil which keeps the skin soft, and is more efficient in loosening the layers of scales which serve to protect the true skin from irritation by external objects. The heat of the warm water may, also, stimulate the oilglands which lie deep in the true skin, to an abnormal degree of activity. Subsequent cold, brought on by evaporation, or by a current of air, may cause contraction of the superficial extremities of the oil tubes, so that the exit of the fluid may become obstructed; a state that will probably be followed by inflammation, as may be evinced by "cracked heels," "grease," or "mud-fever."

Clipping.-The presence of a thick covering of hair is analagous, in the case of a man, to the wearing of a warm overcoat, which, however suitable it would be to protect the body, while in a state of comparative rest, from the inclemency of the weather, would be a distressing burden to one who had to undergo severe 
muscular exertion. Applying the simile of a man taking off his great coat when he has to, say, run, row, or cycle, and putting it on so as to avoid the ill effects of chill when the exercise is at an end; we may see how reasonable it is to have hard-worked horses clipped, and to protect their systems by adequate clothing as soon as they have cocled down. If a horse is not at work, there is no necessity for clipping him, unless the presence of long hair distresses him. I have frequently remarked in India, that the mere fact of clipping a horse caused a marked improvement in his condition. As the seasons of the year in the Antipodes are the reverse of those in countries North of the Equator, newly imported Australasian horses will, unless relieved of it, carry during the hot weather an abnormally long coat, which should be clipped off as occasion demands. Such animals cannot be considered to have become acclimatised until the functions of their skin have accommodated themselves to the conditions under which they are called upon to act.

"With reference to the clipping of horses, I am of opinion that it is a great advantage; they work betterafter being clipped; thrive on less food; are less liable to disease ; are stronger, healthier, and more cheerful ; and when sick, recover in a much shorter time. It is not my intention to discuss the question ; I merely wish to counteract a ridiculous idea propounded by $\mathrm{Mr}$. Gamgee, that clipping is injurious to the horse.

"I strongly recommend the Irish method of clipping, namely, clipping all parts of the body except the legs. The hair that is left on the legs protects them from the irritation of wet and dirt; and, when horses are 
used for hunting purposes, from the penetration of thorns, \&c." (Williams.)

Horses in India, that are thoroughly groomed, wellfed, and warmly clothed, will rarely have a coat long enough to require clipping.

As the bristles that grow about a horse's muzzle, eyes and chin, act as feelers-replacing to some extent the want of hands-they should not be cut or pulled out. The hair which lines the external ear should also be allowed to remain untouched.

Grooming.-Before grooming, the horse may be tied up by side reins running from rings fixed, about six feet high, at each side of the doorway of the stall, and attached to the rings of the watering bridle.

If he kicks badly, his hind legs may be confined by a short hobble, called in Hindustanee, mujuma, placed on his hind pasterns. The use of heel ropes is apt to strain him.

When the horse returns from exercise in clothing, he should be tied up, his hood removed, and his neck and throat scraped, if there be any sweat visible.

The space between his jaws should be carefully dried with a dry cotton rubber. A man on each side, with a fresh straw or hemp wisp, should go thoroughly over the exposed parts, working the wisp backwards and forwards well into his coat. The breast and body pieces are successively removed, and his chest, forearms, shoulders, back, loins, belly, quarters, thighs, \&c., quickly rubbed down and dried in a similar manner. This done, the syces should set to and hand-rub him, beginning at his ears and ending at his hocks. The ears should be pulled gently between the fingers several 
times: a process that always seems to refresh the animal. When hand-rubbing, the stroke should be commenced by bringing the flat of the hand-each one to be used alternately-well under the belly, down the fore-hand, thigh or gaskin, or between the fore-legs, as the case may be, and it should then be drawn up with a steady pressure. As the hand is raised, the elbow should be turned out, and the under part of the bared forearm should be brought into play against the grain of the coat. In doing this, the weight of the body and strength of the arm should be utilised.

With a valuable horse, one should put two men on the legs, and two on the rest of the body. The quicker the hand-rubbing is done, the more effectual will it prove.

On an average, the wisping down will take about ten minutes ; the hand-rubbing, somewhat longer.

If only two men be available, the legs below the knees and hocks should be left untouched until a later period of the grooming.

The hand-rubbing being finished, a syce on each side should go over the coat with the body brush, for the cleaning of which, only, should the curry-comb be employed.

The brush should have long and rather soft bristles, and should be used only in the direction in which the hair lies, and not against it; as, with the grain, it will most effectually remove the dandruff, which is thrown off by the skin in the form of scales that are pierced by the hairs. The syce should place the brush lightly on the coat, so as to avoid hurting the skin, and should then press on it, as he makes his stroke downwards. 
The chief object of brushing the coat is to remove the scaly dandruff; that of wisping and hand-rubbing, to dry and stimulate it.

English trainers usually teach their stable lads to make on their horses' quarters, when the grooming is finished, "quarter marks," of which the most common is the "diamond." This mark is made by brushing the quarter with the body brush, from front to rear, in the direction the hair lies; then drawing a stroke with the brush down the centre of the quarter, in a perpendicular direction, so as to ruffle the hair; and, finally, smoothening, with the brush, the upper and lower portion of the quarter, so as to leave a "diamond," or rather a rhombus; of, say, about 4 inches side. The rough hair of the quarter mark will, naturally, enhance by contrast, the brilliancy of the remainder of the coat of that part. The pattern may be varied at pleasure. Some trainers affect one ; some, another kind of distinctive quarter mark; while others pay no attention to them.

Dressing the Mane and Tail.-The brushing of the body being finished, the syce should brush out the forelock, mane, and tail, taking care, first of all, to commence at the ends of the hair, and to proceed upwards as each kink or knot becomes opened out. The hairs, by small locks at a time, should be brushed from their roots downwards, so as to remove all dandruff. The mane-comb should be used only when it is desired to keep the mane or tail thin.

It is the custom to make the mane lie to the off side; for, as we usually look at a horse from the near side, his neck and shoulders-if they be good-will then 
appear to greater advantage, than if the lines were broken by the mane.

The off-horse of a carriage pair may have his mane groomed to the near side.

Wetting the hair of the mane and tail will tend to make it grow fast.

If the mane does not hang properly down, it may be daily wetted, and plaited, while small weights may be attached to its ends. A thick paste of flour and water plastered over the mane and tied down with a cloth, will make the hair, in a few days, lie flat. The paste should be allowed to remain on during the day, if the animal's services are not required.

If a horse be inclined to rub his tail against the walls of the stable, a light leather sheath, to lace on, may, with advantage, be used to protect the part. In such a case, the cause should be removed by appropriate medicinal treatment, for which see Veterinary Notes for Horse Owners.

Some syces have a habit of washing horses' tails by means of a wet towel, which they rub with and against the grain of the hair. This practice should not be allowed, as it breaks the hair, and disarranges its set, thereby disfiguring the animal.

After the mane and tail bave been adjusted, the syce should wipe out the horse's eyes, nostrils, sheath, and dock with a damp towel or sponge; and then smooth down the coat with a dry wash-leather or cotton rubber. After this, the clothing is put on, care being taken to throw the quarter-piece a little way in front of the withers, and then to draw it back, so that the coat may not be ruffled. 
The feet should then be picked out and cleaned with a dry brush and rubber, the legs hand-rubbed, and bandages put on, if they be employed. If bandages be used during exercise, they should be allowed to remain on until the syce proceeds to hand-rub the legs.

The foregoing completes the description of ordinary gro oming, to which, I think, the following process may, with advantage, be added.

Tapeeing.-This Indian practice is a species of shampooing done with broad circular pads, called tapees, each one of which is about 9 inches in diameter and three inches thick. They are stuffed with horse hair and are covered with leather. A strap is placed at the back of this pad to admit the hand placed flatwise. They are used one on each hand, and are brought down in quick succession, with the whole force of the arm, on the spot intended to be shampooed. The neck shoulders, barrel, and hind quarters are thus gone over by a syce on each side of the animal. The loins and flanks are avoided. The usual method is to strike first with the left hand, then with the right, and again with the left, and then to bring the pads sharply together so as to knock out the dust. Tapeeing has an excellent effect on the skin and coat; and is much relished by the horse when he gets accustomed to it. If put into practice, it should be performed immediately after the animal is brushed down.

In all cases, when there is sufficient help and time, the grooming should be such as I have described in the foregoing pages.

When a horse comes in heated, and there is only one man to attend to him, the girths, if a saddle be on, 
should be slackened, and he should be walked about until he cools down, and then the wisp should be applied, beginning first of all at the part und er the saddle.

I have never found the slightest ill-effect accrue from removing the saddle immediately the horse comes in, however heated he might be; provided always the skin under it was thoroughly well dried without delay.

Shedding the Coat.-The horse sheds his coat twice in the year-in the autumn and in the spring. At the former time, his fine summer hair falls out, to be replaced by a thicker and longer covering, which, in its turn, gives place to the other. If, while the coat is changing in the spring, the brush, or other means, be employed to hasten the process, the hair-follicles will become prematurely exposed to the action of the air, and, consequently, will become stimulated to secrete a coarser form of hair than they would have done, had their natural protection remained on for its allotted period. Hence, the new summer coat will be rougher than it ought to be, and its appearance will, consequently, be more or less spoiled. On this account, when the coat is being shed during that time, the brush should not be applied to it, nor should it be handrubbed. The wisp and rubber will then be sufficient for grooming purposes.

In India, the skedding of the coat of horses that are well groomed and warmly clothed, takes place to a far less extent than in England.

Care of the Feet and Legs.-The horse's feet should neither be washed nor "stopped;" for the 
former practice is the fruitful cause of " cracked heels;" and the latter induces thrush, and softens and weakens the sole, frog, and crust. The old ideas of "thinning" the sole, and kecping the feet soft by stoppings of cowdung and clay, are antiquated fallacies that hardly require being combated in the present day. In India, especially, we require the feet to be as hard and tough as possible, so that the horse may neither flinch, nor go short over hard or broken ground, nor become lame if he casts a shoe, and has to proceed for a few miles bare-foot. Water applied to the feet renders them soft and weak, on account of the capillary attraction exerted by the fibres of the horn on any liquid with which it may come in contact. It is a significant fact that the drier the climate is, in which horses are bred and reared, the stronger and better able to stand work will their feet be.

No benefit is obtained by applying hoof ointment to the crust; unless, perhaps, to those parts from which the hard and varnished covering of the wall may have been rasped away by a careless or ignorant shoeingsmith. The growth of the wall of the hoof can alone be hastened by stimulating the coronet which secretes it; hence, any hoof ointment, used as such, is powerless to effect this end.

Although the employment of greasy applications may have a temporary effect in tending to render dry horn tough; still, their constant use will, as a rule, cause the feet to become far more brittle than they were before; if, by any chance, these dressings are discontinued. They should, therefore, not be employed with horses, like those in the army, that may be sent on 
work, the circumstances of which may prevent the use of such applications.

In this chapter I have already dwelt upon the evils of washing the legs of the horse; hence, I need not further allude to the subject, beyond saying that, if the animal returns to the stable with his legs wet, or covered with the mud, they should be dried by means of the scraper, wisp, and rubber, as the case may be, and hand-rubbed when dry.

One should avoid hand-rubbing the legs when they are wet; as doing so will tend to remove the hair.

Hand-rubbing the legs is a beneficial practice with the generality of stabled horses; for it not alone tends to prevent stagnation of blood in the legs and feet, but also, by the pressure exerted, promotes the absorption of any effusions that may be present about the back tendons and suspensory ligaments.

Trimming the Mane and; Tail.-The mane may be trimmed by pulling out the longest locks, a little at a time, having previously twisted them round the forefinger or a stick. If this annoys the horse, the long ends may be divided by running a half-shut scissors backwards and forwards across them, in the same manner as hair-dressers trim ladies' hair. The ends are held in the left hand, while the right uses the scissors.

A space of about an inch and a half broad should be cut out of the mane, just behind the ears, for the passage of the head-stall of the bridle.

When hogging the mane of a pony, it is customary, in order to help the rider in mounting, to leave a lock of hair. This, to be effective, should be about half way up the neck. The easiest and neatest way to hog the 
mane, is to cut it close, running the clipping machine along the top of the crest, and then on each side, so as to make the hair level. The old plan of hogging the mane, so as to leave a bristling ridge of hair, is tedious in execution and has a bad effect, in that, instead of preserving the natural outline of the neck, it gave the part an abnormally thick and high-crested appearance.

A switch tail may be trimmed in the same manner as the mane.

It is not the fashion to bang the tails of Arabs; a fine, thin tail being considered to be a mark of high caste among them.

Horses' tails ought not to be shortened after the beginning of April, as their powers then will become fully taxed in keeping off flies. They should not be again trimmed before the month of October.

The object of banging a horse's tail is to add to the appearance of strength in his hind-quarters. The usual length at which a horse's tail is banged, is such that will enable the end of the tail, when pulled down, to reach the point of the hock. The more "cobby" the animal, the shorter may be the bang.

The following are three methods for banging the tail :

1st.-Get an assistant to place his hand under the dock, and to hold the tail in a position, similar to that which it would assume were the animal walking; then, with a strong pair of scissors, cut the hair level at the desired length.

$2 n d$.- Bind the tail round with a piece of cord, about six inches above the point at which it is to be divided. 
Then, with a sharp knife, cut so as to give the ends of the hair the required slope.

$3 r d$.-Lay the tail, at the desired length, across the edge of a broad adze (Hind. Busoola), and divide the hair by a smart blow with a flat billet of wood. The adze should be held steady, the handle to the rear, the edge horizontal, and the blade sloped, so that the horse may carry his tail level at a walk. Any loose hairs may then be trimmed with the scissors. This is an admirable plan for troopers, with which dispatch and uniformity are matters of consideration. For use with a number of horses, a blade, resembling that of an adze, but broader, may be let into a block of wood 4 or $5 \mathrm{lbs}$. in weight.

Bots.-During the autumn months, the bot-fly will endeavour to lay its eggs on the chest and forelegs of horses, especially if the animals be kept much in the open, as when on the march. These eggs adhere to the hair, and, though very minute, may readily be recognised by their bright yellow colour, and by their position, which is chosen by the fly, so that the horse may easily lick them off, and thus convey them into his stomach. During these months, syces should be careful to examine their horses after they come in from exercise, and pick off any of those eggs they may detect.

Stable Routine.-The system which is applicable to race-horses, should be the one pursued with all valuable animals, under the modifications that necessity or convenience may require. I may describe it as follows :-

At daybreak, the horse is given about half a gallon of water, and after that a feed of about a pound of corn, 
his clothing is taken off, and he is groomed lightly over. The whole of the bedding should now be put outside, to be aired and dried, and the dung and fouled litter should be removed. The stable should be opened out for the admittance of air and sunshine. The floor should be well swept, and any portion of it which may have become wet with urine should, if the floor be of waterproof material, be strewn over with dry earth, and then swept dry and clean with a broom. If the floor be of earth, the soiled parts should be scraped up and replaced by dry soil. On the horse's return from work or exercise, say about 8 or 9 o'clock, he is watered, groomed, and clothed according to the season. His bedding is now neatly put down; and he is fed, and given a full allowance of grass or hay, at the same time as he gets his corn. The'stable is then darkened, and the animal is left to himself for three or four hours. Between twelve and one he is watered, lightly groomed, and fed as before ; and is not again disturbed until about four o'clock, at which time he gets a little water, a small feed of corn, and a thorough grooming. 'The bedding should again be removed, dried, and selected. On the horse's return to the stable in the evening, he is watered and lightly groomed over. His bedding is now arranged, he is fed, given his grass or hay, clothed, and left for the night.

The syce should remove, without delay, all dung, urine, and soiled litter from the stall ; for the presence of dirt is not alone injurious to the horse's health, but it, also, attracts flies, which are extremely annoying to the animal, especially during the hot weather.

Strict supervision must be exercised in order to 
prevent syces taking the clothing off their horses, on cold nights, and using it themselves for bedding.

For hours of feeding and division of food, see page 79 .

Instead of watering the horse at fixed times, he may, with great advantage, have a constant supply of water at all times in his stall.

It is better to have horses groomed in the afternoon than in the evening, for then the syces will have plenty of light by which to do their work; and the owner will probably be able to superintend it, to some extent at least, without its interfering with his dinner.

To economise the bedding, it may be put down only at night.

I strongly advocate the system of feeding which I have described. 


\section{CHAPTER VIII.}

MANAGEMENT OF HORSES ON BOARD SHIP.

As my experience extends only to the transport of single horses on board ship, and not to that of large numbers, I shall confine my remarks to the former.

The frogs and soles of a horse's feet, before he is embarked, should be hard, strong, and as fully developed as possible. Hence, it is advisable to let him go barefoot for a couple of months beforehand, or to shoe him it la Charlier, or with tips, while the crust and heels are kept low, and to forbid all paring of the soles and frogs with the drawing knife, as well as " stopping" with cow-dung, \&c. If thrush be present, the animal's feet should be treated for it without delay. Shortly before being put on board, the shoes (if they be used) should be taken off, and the heels and walls of the hoofs should again be lowered, so as to obtain frog and sole pressure. These precautions are necessary in order to lessen the possibility of the animal getting irsflammation of the feet (laminitis) from long standing.

For ten days or so before sailing, the horse should be put on laxative food, if he be at all gross, so as to pro- 
MANAGEMENT OF HORSES ON BOARD SHIP. 101

tect his system as much as possible from the attacks of any kind of inflammation. With this object in view, I would advise a bran mash every night, and carrots and green fodder, with very little corn.

The amount of food to be laid in for a voyage can be calculated on the following allowance :-

$$
\begin{aligned}
& \text { Amount of Forage, etc., per day. } \\
& \text { Hay } \ldots . \quad \ldots 18 \mathrm{lbs} \text {. } \\
& \text { Oats } \quad . . \quad \ldots \quad 3 \text {, } \\
& \text { Bran ... ... } 5 \text {, } \\
& \text { linseed ... } \quad \ldots \quad 3 \mathrm{oz} \text {. } \\
& \text { Salt } \quad \ldots \quad \ldots 2 \text {, } \\
& \text { Water ... ... } 6 \text { gallons. } \\
& \text { Straw (for bedding) } 5 \text { lbs. }
\end{aligned}
$$

The linseed may be given as a mash, from time to time.

Besides this, a bag and a half of sand per week may be allowed for the animal to stand on.

The following articles of clothing, \&c., will be necessary :-

A suit of warm clothing complete.

A couple of horse rugs.

A waterproof sheet

A large fly-net to fit over the head and neck.

A pair of knee-caps.

Head collar and side reins.

Watering bridle.

Brush and curry-comb.

Hoof-pricker.

Half-a-dozen cotton rubbers.
A sponge. 


\section{A large pot for boiling linseed, \&c. \\ Slings.}

A set of felt hoof-covers, for applying warm or cold water.

The rugs may, with advantage, be covered with canvas.

For a voyage of a month or two, it is advisable to lay in a few medicines, \&c., as follows :-

Six physic balls (containing $4 \frac{1}{2}$ drachms of aloes)

Nitrate of potash (nitre) $\quad \ldots . \quad \ldots-4 \mathrm{oz}$.

Sweet spirits of nitre $\quad \ldots \quad \ldots \quad 1$ pint

Tincture of opium

Oil of turpentine...

Camphor

... $12 \mathrm{oz}$.

Alum ...

Linseed oil

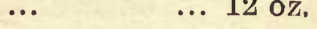

Tincture of myrrh and aloes (for abrasions) $8 \mathrm{oz}$.

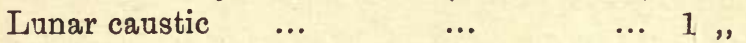

Bicarbonate of soda $\quad$... $\quad \ldots 1 \mathrm{lb}$.

A rasp.

A searcher.

A pair of leather shoes for fomenting the feet.

The horse should be provided with a box in which to remain while he is on board. The best form of box for a valuable animal is one $7 \frac{1}{2} \mathrm{ft}$. long by $5 \frac{1}{2} \mathrm{ft}$. wide. It may be provided with sliding bars, by which the width of the box may be reduced one-half ; so that, if need be, support by them may be given during rough weather. Such a box can carry two horses, who will be far more comfortable in it than if they were in separate ones of $3 \mathrm{ft}$. wide. The ordinary form of box is about $6 \frac{1}{2} \mathrm{ft}$. long, inside, and about $2 \mathrm{ft} .9 \mathrm{in}$. broad. In a large box, like the one described, the horse can lie 
MANAGEMENT OF HORSES ON BOARD SHIP. 103

down with perfect ease, even, during comparatively rough weather, and can take some exercise; but in a short, narrow box, he will be obliged to keep on his feet the whole time.

The box should be provided with doors at both ends, so that the animal may be able to go in or out of it, whichever way it is turned. It should have massive iron rings, placed in convenient positions so as to enable it to be hoisted over the side by means of the crane ; and there should be placed semi-circular iron bars, -over the top, to give it stability, and to afford support to tarpaulins, during wet weather; or to a canvas awning when fine. Strong iron rings should be let into the deck to enable the box to be securely lashed down.

The inside of the box should be thoroughly well padded thronghout its entire extent. Straw padding, covered with canvas, as is generally used, proves very ineffective ; for it soon gets hard and works downward, leaving the upper portion of the woodwork unprotected. I would strongly advise the use of large pieces of felt, to be secured by being laced through holes bored in the planking, so as to dispense with the employment of nails of any sort, next the horse.

The floor of the box should be laid down with thick, rough cocoanut matting, having a long, thick "pile" or "nap," into the upstanding fibres of which the feet of the animal may sink, and thus obtain secure foothold. Six ordinary door-mats made of this material, if sufficiently long, will do for a box : five to cover the floor, and one extra, so that the rearmost mat may be taken out and dried, and the others pushed down in succes- 
sion. If only smooth matting be procurable, it should be kept covered with about three inches of sand. If possible, battens should not be fixed on the floor of the box; for horses are apt to injure their feet by persistently standing with their heels on these slips of wood. I cannot explain why they adopt this procedure, instead of using the battens as a fixed point for their toes, in the manner intended by man. With their heels on the battens, and their toes on the floor, they adopt a position which is eminently calculated to induce laminitis.

Straw should not be put under the horse in rough weather; as it is very slippery. A little of it, however, may be shaken, a couple of times a day, under the animal, for him to stale on; so that his legs may not become wet. Straw may, also, be used for preventing the horse from knocking himself about, or from being injured in bad weather. With this object, it is well to have four or five bags filled with straw, to be used as occasion may demand.

The box should be placed on deck as much amidships as possible, and athwart ships; but not fore and aft. On long tacks, the horse should face to windward; the box being turned round, if necessary. In placing the box, advantage should be taken of any cover that may afford protection from seas bjeaking over the vessel.

Steamers with flush decks and little shear, are by far the worst on which to convey horses on deck. Those provided with high bulwarks are the best. A ship that is light, and is consequently high out of the water, will naturally be safer for horses on deck than if she were deep. 
The box should be opened morning and evening to enable the attendant to clean it out. On other occasions, it should be kept closed.

During fine weather, slings should be placed under the animal ; so loose as not to press against his belly, when he stands up, but tight enough to enable him to rest his weight on them if he chooses. If it gets at all rough, the slings should be at once removed.

If the horse be quiet, he may be taken out, from time to time, when the sea is very smoorh. On no account, should he be allowed to walk on the deck, if it be at all wet or greasy. There is no need to groom the horse beyond sponging out his eyes, nostrils, dock, \&c., and picking out his feet, except when the weather is so fine that he can be taken out on deck; for, accidents with horses, on board ship, are very liable to occur. The horse's head should be secured by means of side ropes attached to the head collar.

During hot weather, the horse should be kept principally on bran and hay, with very little corn. A stock of carrots should, if possible, be laid in.

After a horse has been on board three weeks, his heels and the walls of his hoofs should again be lowered.

An owner should make arrangements with the captain of the ship, for help to be given by some of the crew, in the event of its being required, during bad weather. "Paying one's footing" on the forecastle, with liber. ality, will have a good effect.

"After landing horses from a sea voyage, it is advisable to keep them for a few days in loose boxes so that they may recover the use of their feet before they 
are, even gradually, brought on to work; for a walk, even of a few miles, immediately after coming off ship, is very apt to set up laminitis; although, previously, no symptoms of that disease might have been apparent." (Veterinary Notes for Horse Owners.) 


\section{CHAPTER IX.}

STABLE SERVANTS.

SYCES-GRASS-CUTTERS-SHOEING-SMITHS-RIDING LADS.

Syces.-Although remarks on the management of native stable servants hardly come within the scope of this work, still the subject so nearly concerns the welfare of the noble animal about which I am writing, that I cannot refrain from offering the following hints for the use of inexperienced horse owners.

I may state that the great art of getting on well with one's servants, and, consequently, keeping them up to their work, is to treat them in a uniformly just and sympathetic manner, while always maintaining, towards them, one's proper position as master. One should never swear at, beat, or fine them. The first-mentioned practice is degrading to oneself; the second is cowardly and illegal ; and the third is as silly as the proverbial one of cutting off one's nose to spite one's face ; for the syce will, in the large majority of cases, if fined, scamp his work, or "take it out" of his horse, so as to make up for the loss he has sustained. From a long experience among stable servants, both in India and England, I can say with confidence, that, as a rule, those of the former are as trustworthy, hardworking and intelligent as those of the latter country: and that, too, on, say, Rs. 7 a month instead of 18 
shillings a week. The masters who have most trouble with their native servants, and whose horses get worst looked after, are, generally, young "griffs" who know little or nothing of the language of the country, and are always abusing their syces for being fools; as if, forsooth, "the boot was not on the other leg." Horse owners may observe the following rules with advantage :

Endeavour to give orders concerning the horses as clearly as possible, so that there may be no chance of their being misunderstood.

Pay the servants liberally and regularly.

Insist on the practice of the syce, in case anything goes wrong with his horse, instantly reporting the matter.

On no account allow a syce, on his own responsibility, to treat any ailment his horse may get, such as cracked heels, cuts, etc.; to have any voice in the shoeing of the animal; or to make any arrangement about getting corn from the grain merchant (bunnyah).

If any of the servants are not amenable to kind treatment, they should be dismissed at once; for a master who is known to be good to his men, will never be in want of a choice of applicants for employment. One should not, if possible, keep a discontented servant.

Make certain that the syce can live on his pay; for if he cannot do so, he will assuredly steal his horse's grain.

Before the cold weather comes on, supply each syce and grass-cutter with warm clothing and a blanket, so that they may not be induced to take off the horse's rugs at night, to use as bedding for themselves. 
I may remark that, in racing stables, syces are generally given a month's pay for each race their horses win.

It is the custom to allow each syce a bottle of oil and a pound of country soap, for their respective horses, every month.

If an owner suspects that his syce steals the horse's grain, he may have it sprinkled, by a sweeper, with water before it is given; for then the syce will regard it as polluted and will not eat it.

The old adage about the master's eye making the horse fat, applies particularly well to India.

A native shoeing-smith usually gives a syce four annas for each time his horse is shod.

It is usual in large stables to make the steadiest syce headman over the others, and to have him responsible in case anything goes wrong. He is called a jemadar syce, and gets an increase of one or two rupees a month.

Grass-cutters.-When a grass-cutter goes out to cut grass, he should bring back a double supply, say $28 \mathrm{lbs}$., so that half the number of these servants may remain present to help the syces.

Grass-cutters are sometimes expected to provide bedding for the horses. I would advise that, instead of this being done, the owner should allow a rupee a month per horse for straw, requiring in return that the grass-cutter should assist in grooming.

When marching horses by road, each grass-cutter should accompany his horse, and should carry a feed or two of corn, four or five pounds of grass, a brush and currycomb, a hoof-picker, a rubber, picketing ropes, and 
any odds and ends required, so that the horses may not be inconvenienced by the carts which carry the corn, gear, etc., being delayed on the road. One bucket between two or three horses will be sufficient.

Shouing-Smiths. - Native shoeing-smiths generally charge from Rs. 1-4 to Rs. 1-8 for shoeing, and 12 annas for removing.

With a large stable, it is a good plan to employ a shoeing-smith on a fixed salary. As a rule, they are neat workmen, and will readily learn if properly taught. Their pay will vary from Rs. 10 to Rs. 16, for which they will shoe and plate their master's horses, and, if attached to a racing stable, will accompany them from one meeting to another. They expect permission to shoe during spare hours on their own account.

Riding Lads.-Having got horses to train, the next thing is to find some one to ride them in their gallops; for owners are hardly ever light enough to do this. Besides this, a man can generally train better by superintending work, than by riding gallops himself. If possible, no one over 8 st. 7 lbs., at the very outside, should be put up; for any more weight will certainly tend to shorten the stride of a horse, especially that of small ones like Arabs. On the other hand, too light a lad, say one of seven stone, may not be strong enough to hold a big horse together; and it is always better to put up a little extra weight in the shape of muscle, than to allow a horse, particularly a young one, to sprawl all over the place. When a horse has once learned to gallop, unless he be a determined puller, an eight stone lad will generally be able to do all that is wanted, and with such an one up-if he be at all a 
"workman"- - a horse's legs will stand far longer than under a heavier weight, and the owner need not fear fast work to the same degree, as he should do the other. One may sometimes chance on an English jockey that is light, does not drink, and is a good race rider. Such a man is indeed a treasure, and will be cheap at Rs. 150 a month, Rs. 100 for winning, and Rs. 50 for losing a mount, if an owner keeps four or five horses. But anything short of the genuine article should be shunned; for one of the nondescript lot would take more looking after than a stable of twenty horses. In default of a regular English jockey, an owner's only safety is in employing quiet native lads. Probably, he will have to make a selection from his scyces and grasscutters, or from their sons, and be obliged to teach them himself to ride. As the British nondescript is to be avoided, so is the genuine " coachwan," who delights in gold laced caps, and in sticking out his toes in front of his horse's nose. The best native riding lads I have met have been syces' sons, whom their masters taught, and succeeded in keeping in order. From Rs. 6 to Rs. 10-the "coachwan" will require Rs. 30-a month will be quite enough for such boys, with a small present, say Rs. 5, when any of the horses win. The master should be most careful in keeping them in their place, and should always insist on their helping the syces when grooming. Treat them fairly, and a little liberally at times, but never "give them their heads," nor allow them to gallop a horse, or take one out of the stable, without being present oneself. The three great faults of native boys are, that they ride with too long stirrups, stick their toes out too much in front, and do 
not " ride a horse up to his bridle;" a fatal failing in race riding. Besides this, when silk is donned, they almost all lose their heads when it comes to a finish with English jockeys.

After a native boy has been taught to ride with a fair seat and good hands, the next thing is to give him some idea of pace, which is usually taught by employing the "anna-system." As there are sixteen annas in a rupee, a four-anna gallop is made to stand for quarter; eight annas, for half; twelve annas, for three quarters ; and sixteen annas, for full speed.

Each quarter of a mile being clearly marked by a post or pillar on the course where horses are galloped, the trainer, when instructing native boys, should tell them, before each gallop is given, how many annas' speed he wants, and then may accurately time each quarter of a mile with his stop watch; so that, after the gallop, he may be able to correct the boy, and point out where the latter went too fast, or too slow, as the case may be. The eye alone is not sufficient to detect slight variations of pace; besides this, if the master holds the watch, the boy will more readily believe that he is being told correctly. If the lad be willing and intelligent under this system, and be given instructions as to holding his hands, keeping the proper position of his leg and foot, judging the right length of stirrup, etc., he ought to learn to ride a training gallop fairly, in, say, three months. The trainer may teach the lad the rates of speed by a conventional standard (see page 192); or by the exact division of time; as take, for instance, that the length of the race-course is $1 \frac{1}{2}$ miles, that the horse in question can do this, with the boy up, at full speed 
in $2 \mathrm{~m} .45 \mathrm{~s}$, and that the order for the training gallop is "once round at eight annas;" then the time the horse should take would be $5 \mathrm{~m} .30 \mathrm{~s}$. This I know is slower than the accepted idea of what half speed should be ; but if a faster pace be required, it is just as easy, and perhaps tends less to confuse the lad, to increase the number of annas ordered. Here I take for granted that the race-course is level, like almost all our Indian ones. At Poona, Bangalore, and Dehra Doon, for instance, further directions would be requisite to teach the lad to slightly vary the pace, as the nature of the ground might require. 


\title{
CHAPTER X.
}

\author{
SHOEING.
}

SHOEING-PLATES-TIPS-ON SHOES GETTING LOOSE.

As I have discussed at some length, in my Veterinary Notes for Horse Owners, the principles and practice of shoeing, I need not, here, do more than recapitulate what I have already written on that subject; while adding a few observations that are specially applicable to India.

Shoeing.-In preparing the ordinary healthy foot, it shculd be lowered so that the frog, wall and a portion of the sole should bear weight; while maintaining the part at a proper slope-about 50 degrees for the fore, and 60 degrees for the hind hoofs, viewing them in profile. In doing this, the sole should be left untouched with the knife; except, perhaps, to ease off " the seat of corn" a little. Broken or diseased portions of the frog should be removed. The clenches of the old shoe ought to be cut off by the buffer, without the use of the rasp.

The shoe should be as thin as possible consistent with its standing wear; and should be perfectly flat on the foot surface.

The nail-holes should be punched "coarse" (well away from the edge), so that the nails may take a firm hold, when the outer edge of the shoe is made to 
coincide, as it ought to do, with that of the ground surface of the foot.

It is well to fit on the shoes hot; although this cannot always be done in India.

The shoeing-smith should refrain, as much as possible, from rasping the external surface of the hoof. He should not "spring" the heels of the shoe, i.e., he sbould not leave a space between them and the horny heels; and he should, on no account, be allowed to hammer down the heels of the shoe on to the heels of the hoof, after the nails have been driven; for this practice is a fruitful cause of corns; as it gives rise to undue pressure on the "seat of corn."

Native shoeing-smiths, to save themselves trouble, will, almost always, if ordered to supply thick heeled shoes, bring ordinary ones, the heels of which they have thickened by simply reducing the width of the web by hammering, instead of getting shoes made expressly for the purpose required. As they manufacture neither shoes nor nails, but obtain them ready made from the mistree (blacksmith), there is, usually, some difficulty in inducing them to adopt any new ideas concerning the shape of shoes.

Plates are simply very light shoes, which are intended to last for only one or two races. They are, generally, fixed on the morning of the day before the race, and, to see that all is right, the horse is then sent for a short gallop, which constitutes that day's work. A light plate for an Arab will weigh about $2 \frac{3}{4}$ oz., and be about half an inch broad. But as most horses, out here, have to run at different meetings that follow each other in quick succession, I much prefer using a stouter 
plate ; in fact, a compromise between the plate and shoe used in training. Such an one for an Arab will weigh about $3 \frac{1}{2}$ oz., and ought to last through three weeks' work, and may be made five-eighths of an inch broad all round. Plates and light shoes may have a clip in front for the fore-feet, to give them additional hold. Nails for plates should be much lighter than those for ordinary shoes. An English plate, such as those used at Newmarket, weighs about 3 oz. ; is about $\frac{1}{2}$ inch broad; $\frac{1}{5}$ inch thick; and is fullered. They are made out of specially prepared bars of iron. The hind, as well as the fore plates, have, usually, clips in front.

Mr. Darvell recommends, "if a horse's feet are weak and low, and he has to run on hard ground, it would be advisable to let him run in his shoes."

Tips.-We may briefly sum up the chief evils resulting from the use of shoes as follows:-They tend to deprive the sole and frog of pressure, which, as a rule, is conducive to the health of the foot; the nails are liable to break away the wall; and the weight of the shoes tends to spoil the action of race-horses, by making them go "higher" than they ought to do in the gallop. For these reasons, and on account of the fact that the hoof wears away principally at the toe; "tips," say, about three inches in length, may often be employed, with advantage, instead of ordinary shoes, and, especially, for animals that are not required to work on metalled roads. Mr. Tom Jennings, the celebrated trainer, was accustomed, for many years, to use only very short tips-just sufficient to protect the toes-for his horses, both in training and racing. He was forced, however, to discontinue this very sensible practice, on 
account of the continued opposition offered by the shoeing-smiths he had to employ, to this supposed innovation. I may remark that if tips are to be put on, they should be applied so as not to interfere with the proper slope of the foot.

On Shoes getting loose.-We may ascertain if a shoe is loose, however slightly, by, after taking up the foot, gently tapping the ground surface of the shoe with the fingers. The nature of the sound thus made, will serve to confirm or dissipate our suspicions. As long as the nails have a firm hold, so long will the heels of the hoof be protected from undue wear; but when the shoes become loose, they soon get knocked to pieces, and the proper slope of the hoof will be destroyed for the time being. 


\section{CHAPTER XI.}

PREPARING PONIES FOR MEASUREMLNT.

As in India certificates of height are granted to ponies that need not be either in racing or even robust condition, preparation for measurement has become in that country an established practice. Knowing that such an ordeal will reduce the height of a pony, for the time being, from one to two inches, which is equivalent to 12 to 24 lbs., I need hardly point out that an owner must adopt this means of getting the weight off, if he wishes to run his ponies on equal terms with those of other men. It would be idle to deny that this practice inflicts cruelty on ponies, and is a potent incentive to deceit on the part of their owners. It is, however, only fair to say that the present rule is a great boon to owners, who, in former times, had to get their ponies measured before every race for which they ran. At the same time, its evil consequences might wholly, or to a great extent, be obviated, if it were enacted that a pony not holding a certificate of height should be measured on the day of, and before, each race for which he was going to start; but that his owner could claim a certificate for him in any such event at the height for which he was measured for it, if the measuring authorities were satisfied by the pony's running that he was in 
racing condition. It is, of course, evident that to be in such condition the animal could neither be "faked" nor drugged.

As I am in no way responsible for the moral or immoral tendencies of rules of racing in India, I shall leave the subject alone, and shall now proceed to describe the methods generally adopted under existing requirements to get ponies to measure as low as possible.

I may first of all explain that in the position which a pony has to adopt when he is being measured, the line of his fore-arms and front cannon bones has to be as nearly vertical as practicable; his fore-feet must not be unduly separated; his head must not be lowered beyond what will bring the upper line of his neck horizontal; no pulling down of the skin at the withers is allowed; and the hocks must be pretty well under him. As a rule, every chance is given to the animal to "settle down," so that he may measure as low as he can fairly do: before the record is decided upon. No allowance is made for shoes. The height taken is (or, at least, ought to be) the vertical distance of the highest point of the withers from the ground.

Apart from the actual length of the bones, the height of a horse is affected chiefly by :-

1. The condition of the muscles which connect the fore limbs to the trunk ; for the more they become relaxed by debility - whether from fatigue, ill health, or the action of drugs-the more will the body and, consequently, the withers sink between the fore legs.

2 . The angles made by the bones, respectively, at the shoulder, elbow, and fetlock joints. This is 
especially noticeable by the descent of the fetlock joints.

3. Approximation of the ends of the bones which form the shoulder, elbow, fetlock, and the two postern joints. We may see this settling down of the bones in the joints illustrated in our own cases; for if we have ourselves measured in the morning and also in the evening, we shall find that we were taller in the former time than in the latter.

Agreeably to these principles we find that long continued standing, fatigue, starvation, deprivation of water, and the administration of purgatives and sedatives will tend to cause a marked diminution of a pony's height. The production of a maximum effect will require a course of two or three months, during which time the animal, when he is in the stall, would be tied up, so that he might not lie down. Some operators advise that while the pony is tied up, the ground upon which his fore-feet rest should be somewhat lower than that upon which the hind feet are placed. He is also walked a long distance every day. The food he gets is only just sufficient to keep him on his legs. Some give the patient a quarter of a pound of Epsom salts every day, in order to keep him in a nauseated and debilitated condition. It is considered advisable to walk the pony all night before bringing him up for measurement, and to give him about an ounce of chloral hydrate not less than half-an-hour before he is to be placed under the standard. Prior to doing this, it is well to keep him standing for at least half-an-hour, so that he may "settle down." The final touches have to be given with a considerable amount 
of discrimination, lest the measuring authorities might reject the animal on the score of its being too sick. The able practitioner will, from previous experience, accurately determine the extreme point to which he can go in playing his game with the members of the measuring committee.

As animals at sea get but little sleep and usually have to stand all the time they are on board, it is often advisable, especially if they have suffered much in condition from the passage, to bring up for measurement ponies that have just been landed from a long voyage.

Some ponies measure lower when their head is held up than when the poll is kept on a level with the withers. As the owner or his representative is usually allowed to hold the pony's head, he will generally be allowed to use his own discretion in keeping it up or down, so long as the poll is not brought below the level of the withers. The measuring authorities, as a rule, will take under their own direction the placing of the animal's legs. It is almost needless to say that if the limbs are stretched out of the perpendicular, or if the fore-feet are unduly separated from each other in a lateral direction, the pony will measure lower than he would do, were his position more in accordance with the rules for measuring.

Lowering the heels, within certain limits, will, by increasing the obliquity of the pasterns, decrease the height more than reducing the toes to the same extent. If, however, the heels are so much pared down that the animal cannot stand firmly on them, the rasping or cutting will, as a rule, produce the undesirable effect of making the pony add to his height by causing him 
to bring his pasterns more upright than usual, with the object of relieving his heels of some of the painful pressure. It is thought by some, that in order to get a pony to measure low, it is better, after having reduced the heels as far as is safely practicable, to leave the toes long, with a view of bringing down the fetlock joints, than to pare them. In fact, I have seen shoes with very thin heels and thick toes used with this object. 


\section{CHAPTER XII.}

\section{TEACHING HORSES TO JUMP.}

THE great secret of "making" good jumpers, is to begin early enough with them; for, after a horse has been thoroughly " broken," the sooner he is taught the special work required in leaping, the more accomplished fencer will he become. Too Good, the winner of the Grand Steeplechase de Paris, as a four-year old, and who was one of the cleverest performers " between the flags" we have ever seen, received his name from H.I.M. the Empress of Austria, on account of the perfect manner in which he negotiated, as a two-year old, the difficult country over which his trainer, Mr. Linde, schools his cross-country animals. He was only one of many instances of horses in Ireland, which is the home of steeplechasing, having thoroughly mastered the art of jumping, before they were three years old. The action of the muscles of the hind quarters and shoulders, in leaping, is so different to what it is in galloping, that early instruction, so as to impart the necessary knack, is of the greatest advantage. The fact of getting over the obstacles safely, without losing ground, is not sufficient for success; for we often find that the winner of a steeplechase fairly beats on his merits others which could "lose" him on the flat, even when they do not make a "mistake." That famous 
chaser, the Lamb, was a case in point; for, in the Grand National, he easily defeated Pearl Diver, who was, at least, two stone better than him on an ordinary race-course. By learning young, the jumping muscles are stimulated during the special period of development; and the action itself becomes almost automatic, and, consequently, as nearly perfect as possible. When the art is acquired later on, the effort will be more or less laboured, and the muscles may be inadequate in strength for this new kind of labour. Of course, there are exceptions to this rule, one of the most notable being Voluptuary, who, as a six-year old, won the Grand National of 1884. This son of Cremorne and Miss Evelyn was kept, till he was five years old, on the flat, where he performed very indifferently. He-was, then, taken in hand by that accomplished horseman, Mr. E. P. Wilson, who soon taught him to negotiate the Aintree style of country, and won on his pupil with great ease. I may remark that the Liverpool fences are all of the "flying" sort, and consist chiefly of hedges with a ditch on the taking off or landing side. Being of a uniform character, they do not demand the same amount of cleverness that is required in a more cramped country. Besides this, almost all the Cremornes are natural jumpers. I am aware that it is a very common idea among racing men both in England and in India, that the way to obtain a good maiden chaser is to pick up a hirse that has shown his ability to gallop, stay, and carry weight on the flat; and to teach him to jump. Following the opinion of the best judges on the subject, in Ireland, I maintain that, as a rule, such animals will turn out failures; and that far 
better results, for the same amount of money, will ensue from buying "likely" young ones and teaching them their cross-country business, when two-year olds, if in Great Britain; or, as three-year olds, in India.

As I have thoroughly discussed, in another work, the subject of riding, I need not dwell on it further than to repeat "that the art of riding well over a country, chiefly consists in making as little as possible of the jumps, and that the fact of the rider treating fences and level ground with equal indifference, will inspire his horse with confidence to take things in the same spirit." Horses, like boys, delight in a scamper in the country; and both detest their ramble being converted into a sort of "punishment drill,". consisting of marching backwards and forwards over the same ground. Horses, also, being gregarious, love to follow their leader. Hence, we should take a fresh line of country as often as practicable; avoid making the horses jump the same fence twice consecutively; treat the obstacles as if they were things that were only accidentally met with during the stroll ; endeavour to make the animals enjoy their outing as much as possible; and stimulate the yourg ones to go forward by the lead of one of their companions, or, when obtainable, by the music of the hounds in front. In order to furnish a good idea of the kind of training for jumping which young ones get in Ireland, I give the following extract from a letter I received on this subject from Mr. Betagh, who has had great experience with hunters and race-horses in Ireland :-

"My system of teaching horses to jump is to avoid the whip and all harsh treatment in the preliminary 
lessons. I generally ride an old hunter out with the young one, and take a few easy fences, while the groom follows, leading the pupil with a long rein and cavesson. As a rule, the young one readily follows the other, especially if they have been companions at exercise. For the first few trials, a man with a whip may go behind the youngster and crack it after him; but he should seldom do more than give him a slight touch on the quarters if he does not go over freely. If a young horse is punished severely in his early lessons, he will for ever remember it, and will, probably, learn to refuse; from associating in his mind the cruelty he suffered, with the sight of a fence. I seldom make the animal jump the same fence more than once; then, move on to another, and so on. By varying the exercise, the young one will be induced to tak? pleasure in his work, which he will generally do, if treated kindly, though firmly. After a very few lessons, the colt may be ridden over his fences; but he should, always, until he is fairly proficient, have a steady true jumper to give him a lead. When a young horse is handy at his fences, the sooner he is schooled with hounds the better; for there is nothing that makes a horse jump with such freedom and goodwill, as following them. A short time ago, after teaching a colt of mine-a half brother to Cosmos-to jump, I put a stable lad on him and took him to the Wards. At the very first fence, the crowd, at the only practicable spot, shut him out; and as the hounds were soon out of sight, he lagged behind, and I saw no more of him until I went home. The boy then told me that he had turned back, as he was not able to get over the big 
fences. A few days after that, I had the same colt and boy out with my own harriers, and gave the lad strict orders to stick to the hounds. The result was that the colt never turned his head from anything. I had hardly landed over one enormous bank with a grip on the taking off side, which was almost too big for my liking, although I was on one of the boldest hunters in Ireland, when, to my surprise, the young one was at my girths, sailing away in high delight at the fun.

"It will not take long to make a young horse a good jumper, provided he is treated with kindness, firmness, and common sense. As soon as he gets confidence in himself, he will be fit to go over any steeplechase course; and, then, the pace may be increased at the fences. He should, if possible, always be ridden in company; sometimes, getting a lead, at other times taking it, or going all abreast."

The preliminary practice I would pursue in "making" a jumper, is first to give him a good mouth by driving him on foot in the manner described in Illustrated Horse Breaking, and then teach him to leap without anyone on his back. The great advantages of this method are that the horse which is broken according to it, acquires a perfect mouth, is under absolute control, and is free from the ill effects which too frequently result from the punishment and "jobbing" in the mouth that are inflicted on "green" horses by bad tempered and incompetent riders. After a horse has learnt to leap well, when driven over jumps with a rider who does not hold the reins, on his back (see Illustrated Horse Breaking), he will be far less liable to 
become spoiled by a rider of but moderate skill, than he would be, had he not received his first lessons with the "long reins" and "leading rein crupper."

"A very safe way for teaching horses to jump, is to make a circular course of not less than five yards broad and about 150 yards in circumference, and enclose it with high palings, while four or five fences of different kinds-say, a hurdle topped with brushwood, an Irish kank, a stone wall, a water jump, and a post and rails - may be placed at intervals round it. The horse is then turned loose in this kind of circus, either with or without a leader, and is made to jump with a little persuasion. This plan should be used only as an introduction to schooling." (Riding on the Flat and Across Country.)

After a horse has become perfect in his preliminary work, he should be gradually brought on to the negotiation, if possible, of a " natural" line of country, or, failing it, by one of "made" fences. At first the best kind of obstacle for a young or unschooled horse, is low hedges or fences made up of thorns ; as they will make the animal see the necessity of clearing them, without, at the same time, frightening him by bringing him down. The height, of course, should be gradually increased. Special attention should be paid to getting him clever at water and fences that have a ditch in front of them; as they are, of all others, the ones which horses, as a rule, are most liable to refuse. "Artificial water," which is used on many training courses in England, and which consists of a white sheet or whitewashed strip of ground of the required length and breadth, with a bushed fence of a couple of 
feet high in front, may be employed, with great advantage, in India, where suitable brooks are generally difficult to find. It has the immense merit of causing to the rider who goes at it, the smallest possible amount of trepidation; as he will know full well that it cannot bring him to grief. Artificial water arranged as I have described, is, usually, taken by horses, in al! good faith, as the real article.

In India, a capital plan for teaching horses to become clever over walls, without running any undue risk, is to practise them over ones made up to the proper height with single rows of sun-dried bricks, which will come down if the animal "chances" them, but will hurt his shins sufficiently to render him more careful in the future. For making a horse clever over posts and rails, one should employ a very thick log or trunk of a tree, so that the animal will understand that it is no use attempting to knock it down. In my opinion, the bar ought not to be made to fall down, if the horse strikes it. If the breaker or his helper be not prepared to mount and take the necessary risk, they may put the animal over by means of the driving reins and leading rein, in the manner before described. The bar may be bushed over with thorns. A bar, which should be gradually raised, may be placed across the stable-yard gateway, or other convenient passage, so that the horses may get accustomed to jump it when going to, and returning from exercise. Similar expedients with other kinds of fences may be adopted, as the trainer sees fit. I need only add, that "made" fences should be as long, from side to side, as possible, and have wings if necessary. 
Horses that are being trained for steeplechasing, should be taught to take their fences fast and in company. One great secret of success in this form of sport, is to accustom the horses to the exact style of ccuntry over which they have got to travel. 


\section{PART II. \\ TRAINING AND RACING.}

\section{CHAPTER I.}

RACING IN INDIA.

RACING MEN AND HORSES-ON FORMING A USEFUL STABLE-THE STYLE OF RACE-HORSE SUITED TO INDIA-THE DIFFERENT CLASSES AND THEIR RESPECTIVE FORM-TIMING-RECORDS OF FAST TIMES.

IN England, racing is almost entirely confined to professionals, and to a few moneyed men, who can afford to ruil horses for amusement, just as others go in for yachting, hunting, or shooting, caring little for the cost, as long as they get sufficient excitement out of the particular sport they pursue. There, racing is such a complete business, and its attendant expenses are so heavy, that a man of moderate means cannot, with any safety, follow it, unless he adopts it as his profession. In India, the small amount of public money and limited speculation render the turf, as a rule, too precarious a means of living, except in the case of jockeys and trainers. Few of the latter find training pays, unless they be light enough to earn their winning and losing mounts on the horses of which they have charge. 
There are not many representatives of the moneyed section of the racing public in India, which is, above all others, the country for a comparatively poor man to do a little racing in, without it costing him much, provided he kncws something about horses; for stable expenses are very moderate (say forty rupees a month for each horse, including everything), and none but first-class animals cost extravagant sums. But the fact which enables men of small means to race in Tndia, is the system that divides the majority of races among different classes of horses. These events serve both to fill up prospectuses, and to accommodate owners. Except at the few centres of racing, it is difficult to collect sufficient money to attract first-class animals, even were there more of them in this country, so that handicaps have to be resorted to in order to bring the one or two of them, which ever appear at a small meeting, together with the second-raters. On this account, stewards of race meetings, in order to get fields together, are obliged to add to handicaps, races for "all horses," and selling races, those for Arabs, country-breds, galloways, ponies, and for maidens of the different classes, not to mention still more minute divisions. Thus, an owner would have bad luck indeed, were he not able to find some event or the other suitable to his horses, even if he had nothing better than a country-bred pony, a half-miler, and a jumping nag; although their united value might not exceed two thousand rupees. It may be objected that this is not racing, which it certainly is not in the English sense of the word; yet for all that, a man, who is sufficiently fond of horses to look after and manage them himself, 
can get good sport with a few moderate ones. Personally I would take more interest in training an inferior animal, and, by skill and work, winning races with him in moderate company, than in owning (as many do at home) first-class horses which were entirely in the hands of a trainer, on whom I would have to be solely dependent for information as to their form and pretensions.

Six or seven horses will be found a large enough string for up-country meetings, if the owner intends to look after them himself, and expects them to win enough to cover their expenses. To accomplish this, one should have horses of an useful class, that would be certain to fird races to run for, at the different meetings to which they might go, with a fair chance of pulling off an event now and then. Keeping horses too good for one's line of country, is hardly more paying than owning animals too bad for it. The presence of first-class horses (if their form be known) deters owners from entering against them ; the races do not fill; and even if they do so on an odd occasion, it is simply "buying money" to back them; while in handicaps, a good horse, amollg moderate ones, gets so much weight piled on, that it is almost certain, either to break hirn down, or to spoil his action. An owner should remember that knowledge of the best manner in which to "place" his horses, is the great secret of success in racing.

A first-class steeplechaser does not come under these objections ; for " between the flags," one's money being "in the air," men will usually enter on the outside chance of a fall or refusal. Besides this, the added 
money alone is generally worth running for, even without speculation.

One or two good second-class Australians which can stay up to a mile and a half, a couple of Arabsespecially if one or both be galloways, and are at the same time good enough to run among the big ones, like what Chieftain, Caliph, Abdool Rayman, and Rex were-a fast 13-2 Arab, or country-bred pony, a halfmiler for selling races, and a good chaser. would form the beau idéal of an useful stable for up-country meetings.

A good maiden is a real Eldorado, whether Australian, Arab, or chaser; but they are particularly hard to get, and uncertain to back, unless one lias first-rate trying tackle with which to test their powers. I may here remark that maidens in India take, to some extent, the place which two and three-year-olds occupy in England ; for many of the most important races are confined to horses that have never won during any previous season, irrespective of their age ; though, of course, allowance of weight for it is always given.

Speaking generally, no weight within reason can bring Arabs together with even second-rate Colonials.

For the last twenty years, we have not had a single Cape horse that could hold his own against Australians. As quite as high prices can be obtained for good horses in South Africa as in India, it evidently would not pay to export them from the former to the latter country.

Speaking from my own experience of South African racing during the year 1892, I would say that the best "Cape" horses, like Prosecutor for instance, although 
quite as good as the average English horses imported, such as Savile, Earl Godwin, or Vichy, are fully $7 \mathrm{lbs}$. inferior to the English horses, Metal, Blanchland, and Presto, and to the Australians, Kingcraft, Statesman, Myall King, Moorhouse, and Little Prince, when fit and over their own respective distances. With the increase of railways and of the gold "nutput" at the "Rand," the future of racing in South Africa looks bright. At the same time, I must say that it will have no chance, for many years to come, of successfully competing against Australasia in the Indian horse market, whether with blood stock, or remounts. Although there are some fair horses bred in South Africa, strange to say there are hardly any smart ponies produced there. The only exception I saw was that brilliant chasing pony, Coachman.

I may mention that the old Cape Town hero, the ch. c.h. Echo, 9 st., at Calcutta, December, 1871, won the Stand Plate, 1 mile in $1 \mathrm{~m}$. $48 \mathrm{~s}$, when he was about thirteen years old.

There is a sort of fatality about English horses in India; for few out of the many that are imported, prove, either as racers, or as ordinary riding horses, to be worth their passage-money out to this country. Their feet and legs are far more liable " to go to pieces," on our hard ground, than those of Australia, New Zealand, or the Cape. The chief reason for this, as far as I can judge is, that the drier climate of our Southern colonies is more favourable to the development of soundness in wind and limb, as regards horses, than is the moister one of Great Britain. I am inclined to go so far as to think that horses bred in a dry climate, 
and, consequently, on hard soil, will, after a few generations, have legs and feet of a much better shape to stand work on hard ground than those of animals that are natives of a damp country. In this respect, the horses of Australia and the Cape can compare very favourably with those bred in England, a large proportion of which possess those upright pasterns that are entirely unsuited to work on Indian soil.

The majority of Indian race-courses are so hard that they tend to make horses, which are trained on them, go short and "stilty." Even when the track happens to be soft, the "going" is simply heavy without any elasticity, so that the horse is taught to "dwell on his stride." We hardly ever obtain the happy medium afforded by the light springy turf in England. Good legs and feet are the first considerations, and then comes the power of carrying weight and being able to stay. An English horse, or Australian, should be able to race under $10 \mathrm{st} .7 \mathrm{lbs}$, one and a half miles. If a sound game horse can do all this, his being a little "troubled with the slows" will not prevent him from paying his way. A flashy thorough-bred that could stagger home in extraordinary good time over 5 furlongs with 6 st. up, would be out of place in India, except, perhaps, for a coup at Calcutta.

With the exception of Reputation and Oberon, neither of whom stood training in India, there have been no English horses imported into this country that were up to good handicap form in the land of their birth. Metal, by his running with Althorp at Goodwood, was a fair second-rater. In India he was the best of his time when fit. Blanchland, who was 
a roarer, was probably the fastest five furlong horse we have seen in India. Presto, who was a smart selling plater in England, was nearly first-class in India. In olden days, the English mares, Morning Star and Bridesmaid were, at their own distance, unapproachable by their Australian rivals, who, it must be confessed, had but little pretensions to racing form. Australian horses, such as Myall King, Moorhouse, and Little Prince in recent times, and Kingcraft in former years, have certainly held their own against all comers. I may mention that the only first-class Australian which has run in India, was Bravo, the Melbourne Cup winner, who, from unsoundness, was unable to show in this country anything like his true form. The prominent running in England of the Australian second-rater, Ringmaster, goes to prove that there is not much to choose, from a racing point of view, between Australian and English horses. In India, honours seem to have been fairly divided between them, taking into consideration that of the former there have been far more runners than of the latter. As regards price and the capability of standing work in India, I think the balance is all in favour of Australians, of which there are many well-bred specimens imported every year into India. English horses, owing to their high price, are never sent out on sale to this counts y.

Country-breds sometimes hold their own in hack selling races-winner to be sold for from $\mathrm{Rs} .200$ to 500 - when not beyond $\frac{3}{4}$ mile. Those that do so have almost always a strong dash of English blood, from which they generally derive their turn of speed, as well as some of their inherited infirmities, which doom them 
to running for such minor events. A useful horse for such races-winner to be sold for Rs. 500 or Rs. 600 ought to be able to do with 10 st. up, $\frac{1}{2}$ mile, in 52 s., or $\frac{3}{4}$ mile in $1 \mathrm{~m} .19 \mathrm{~s}$, , on an ordinary race-course.

Without wishing in the slightest to attempt to discourage those who desire to improve the breed of horses in India, I am convinced the fact remains, that racing stock of even the most moderate pretensions cannot be bred in India without the blood being constantly renewed by suitable importations, whether from Europe, the Colonies, or America. The effect of the climate, which is manifest in the indigenous equine type, will not allow, without constant foreign aid, the production of animals fit either for the turf or for heavy saddle work. The country produce bred by General Parrott from nearly pure English blood, although incapable of holding their own against Australians, have been, at weight for age and class, capable of defeating Arabs at all distances. As a rule, however, the sons of the Desert have "the pull" in races of a mile and a quarter and upwards, against other Country-breds. Among the best have been-Pretender, who belonged to Mr. George Plowden, Meg Merrilies, who won the Governor-General's Cup in 1858, and, also, in 1859, Annandale, the black mare Gipsy, Deception, M. T., late Mermaid, Kathleen, Geraldine, Surprise, May Queen, Engadine, Tangree, and Minden.

To judge by Predominant, Sylvia, Lord Clyde, Labby, Mike, Maythorne, Bustle, Marquise, and others, we must regard English ponies as a good deal better than those of all other classes. Next to them come Australasian ponies, like Little Wonder and Achieve- 
ment. Then Arabs, and lastly country-breds. As exceptions, I may mention the Arabs, Rex and Blitz, who, for their respective heights, were as good as anything that ever carried silk in India.

Though there have been many instances of $13-2$ ponies running successfully among galloways ( 14 hands and under) at the usual allowance of $3 \mathrm{lbs}$. the quarter inch, it is rare indeed to meet with a pony lower than that which can do so.

At most meetings, the following classes are those for which races are generally made, with the distances usually run :-

\begin{tabular}{|c|c|c|}
\hline & All horses & ... 1 to 2 miles \\
\hline & Arabs $\ldots$ & $1 \frac{1}{4}$ to 2 \\
\hline & Arabs and country-breds & 1 to 2 \\
\hline & Country-breds $\quad \ldots$ & \\
\hline & Ponies (14 hands and under) & to 1 \\
\hline & Ponies (13-2 and under) & \\
\hline & Ponies (13 hands and under) & $\frac{1}{2} \mathrm{mil}$ \\
\hline & Selling Racehorses ... & 1, \\
\hline
\end{tabular}

In discussing the "form" of horses, I have been obliged to bring in the subject of timing, as it is so universally used and regarded out here. I am quite aware how fallible a test it is, and how much it varies according to the state of the course and the way in which a race is run. The great majority of Indian courses are so level, and the "going" so very much the same on all, that there cannot be the same objection to timing in this country as in England, where every course varies in severity; especially if rain falls. Nevertheless, in races in England, where several horses start, and in which the running is certain to be 
cut out by some of them, the timing of similar horses is singularly close, on the same courses, considering how variable the English climate is. For instance, take that of the great three-year old races, from year to year.

We find timing is a perfectly reliable test in pedestrianism, and can pronounce with certainty that a man who can do his 100 yards in 10 seconds, or his mile under $4 \mathrm{~m} .16 \mathrm{~s}$. on level ground, is undoubtedly a firstclass runner; and so would be a horse which could, with weight for age and class, do his mile in $1 \mathrm{~m} .43 \mathrm{~s}$, or two miles in $3 \mathrm{~m} .39 \mathrm{~s}$. on the Calcutta Course for instance, if he will but try in public; for herein lies the source of nine-tenths of the disappointments timing leads to. The "going" on most Indian race-courses, except at Bangalore, Hyderabzd, Poonah, and Dehra Doon, is very similar, being almost quite level and pretty hard. As it is impossible to get all horses to run the same in public as in private, I would strongly advise the young turfite to limit the use of the stop watch to public performances, and to regulating the pace of training gallops. If one wishes to test the powers of a young one, it should be done, not by "putting him against the watch," but by trying him with some horse that has recently run well in public, and is at the time of the trial in racing condition. Then, if the young one beats the trial horse, and does the distance in really good time, it is all the more to his credit. No exact infurmation as to a horse's form can be obtained by timing his gallops when he takes them alone; for not one horse in ten will run the same by himself as in company ; and it would only 
lead to disappointment to allow for an error that, for all the owner knows, may be either for or against his horse's powers.

I believe that, even with the greatest care and under the most favourable circumstances, the time test alone cannot be relied upon, with a smaller margin for error than $10 \mathrm{lbs}$. in 1 mile, which, allowing for difference in horses, and for the different way races are run, we may assume would be equivalent to from 20 to 30 yards in that distance, or from $1 \frac{1}{4}$ to 2 seconds, which does not say very much for timing, beyond affording an approximate idea of a horse's powers.

On a heavy conrse, a horse will take 4 or 5 seconds longer to do a mile, than on a light one.

Another thing to be considered is, that we must allow at least half a second for the timer's own individual error; while there is still more to be allowed for the way in which horses get off, whether from a flying start, or from a walk.

It does not at all follow that because a horse cannot be got to do good time in private, he is, on that account, a moderate animal ; for many-particularly stayers-require the stimulus of company to make them extend themselves.

When timing in private, the trainer should be most careful to observe how his horses finish ; for an animal who finishes strong, will always-provided he runs honest-beat another that can do even slightly better time, but is "all out" on nearing the winning-post.

The following tables furnish instances of first-class timing. For uniformity sake, and because distances and time are carefully measured there, I have given 
only Calcutta records. I have rejected several which have official sanction; some, because they were "too good" ; others, because owing to the nature of the course, the exact moment of starting could not have been obtained. Such instances (vide Appendix, C. T. C. Book Racing Calendar, 1891-2) as, b. a. gal. Turkish Flag, 10st., 2 miles, 3 m. 46 s., and b. a. p. Minton, 8 st. $4 \mathrm{lbs}, \frac{3}{4}$ mile, $1 \mathrm{~m} .19 \mathrm{~s}$, both at Bombay, are manifestly absurd. 
GOOD PERFORMANCES BY AUSTRALIANS.

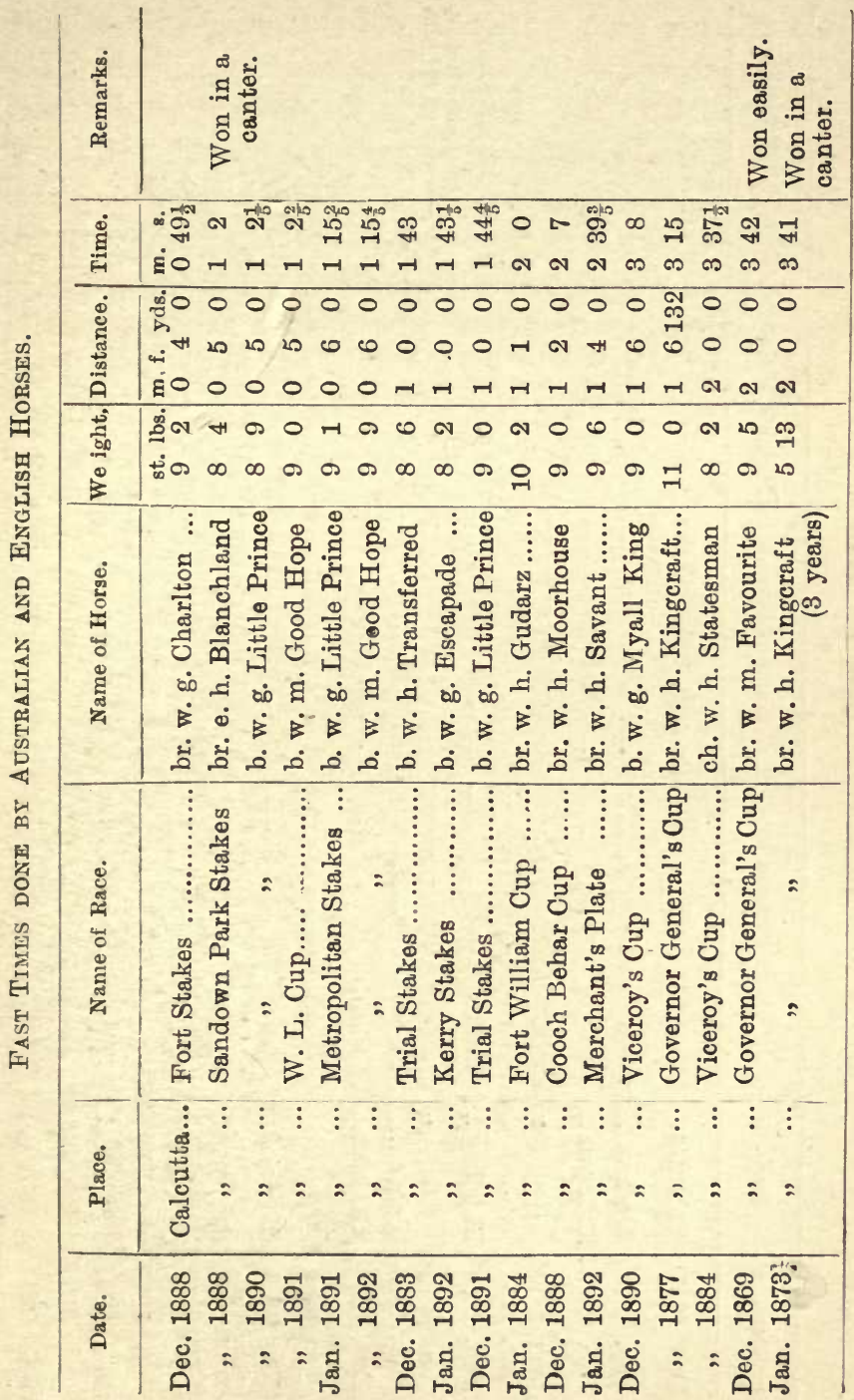




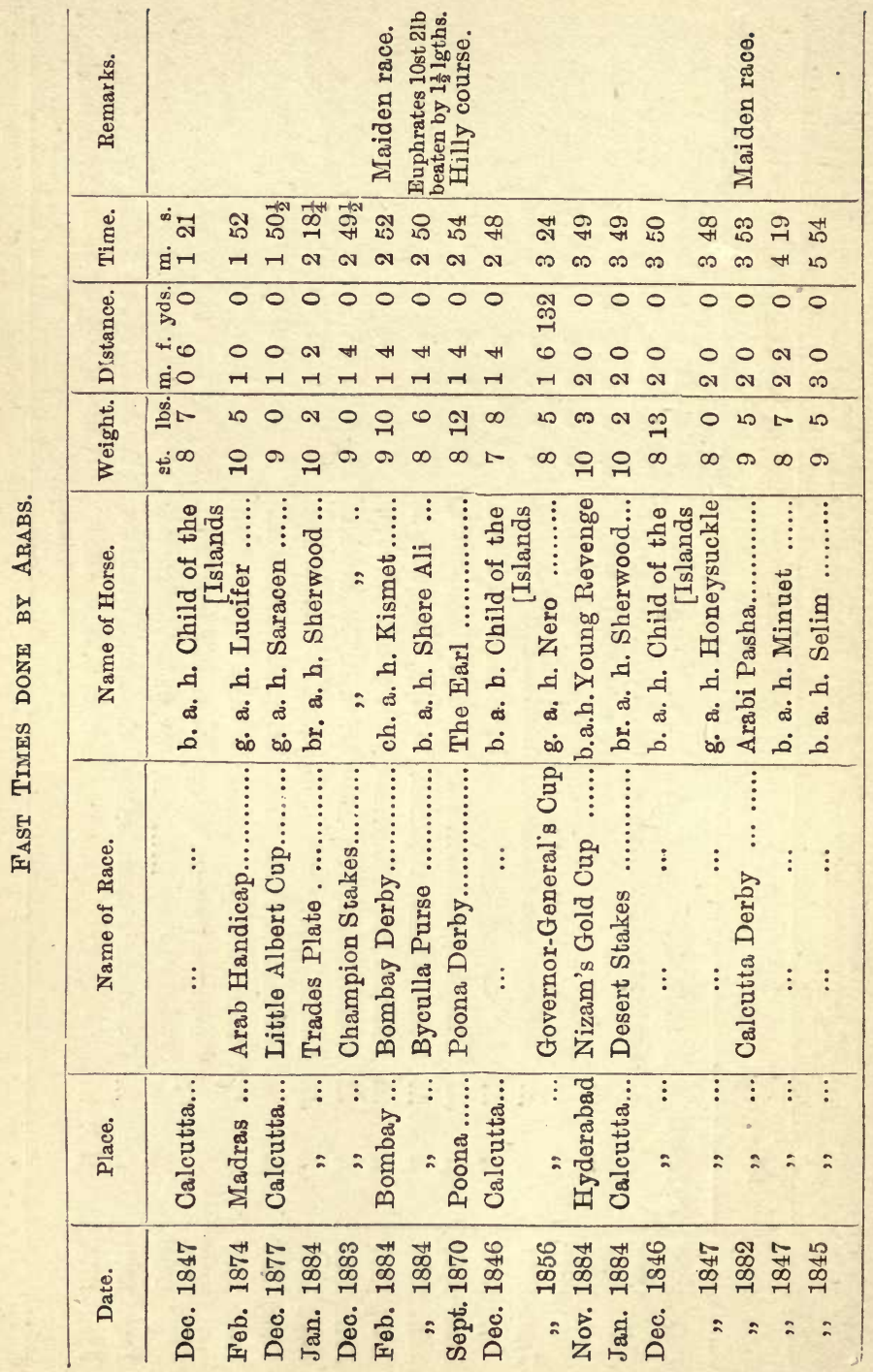




\begin{tabular}{|c|c|c|c|c|c|}
\hline हैं & & " & & 离 & 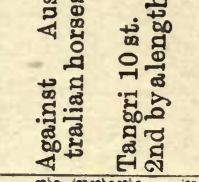 \\
\hline \&્ & 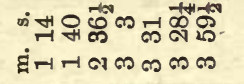 & ๙ै & & 㟧 & 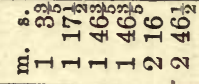 \\
\hline 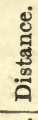 & 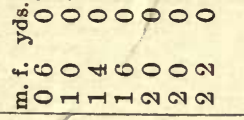 & $\begin{array}{c}0 \\
0 \\
\infty\end{array}$ & & 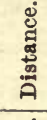 & 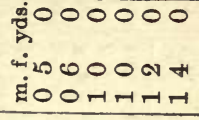 \\
\hline$\frac{\mathscr{a}^{\circ}}{80}$ & 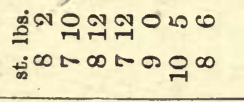 & 0 & 兽 & $\frac{\frac{d}{4}}{\frac{c}{0}}$ & 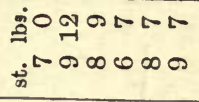 \\
\hline 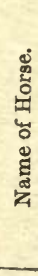 & 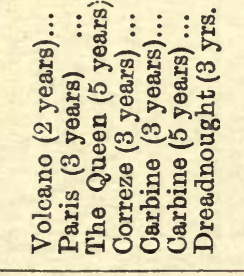 & 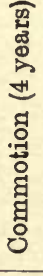 & m & 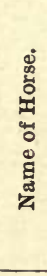 & 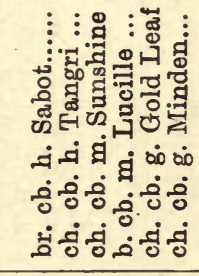 \\
\hline 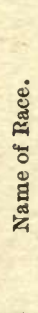 & 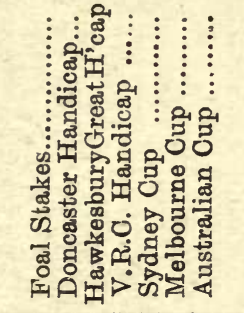 & 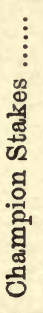 & E्ञ & 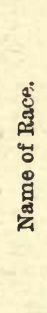 & 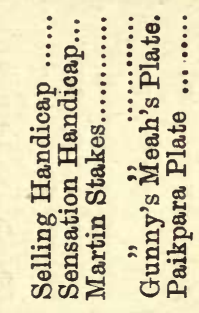 \\
\hline 这 & 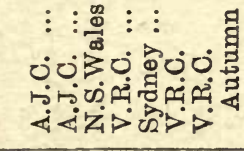 & a & & : & 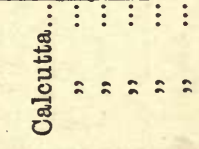 \\
\hline ڤัઁ & 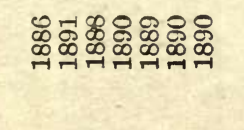 & 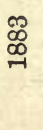 & & 范 & 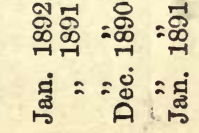 \\
\hline
\end{tabular}




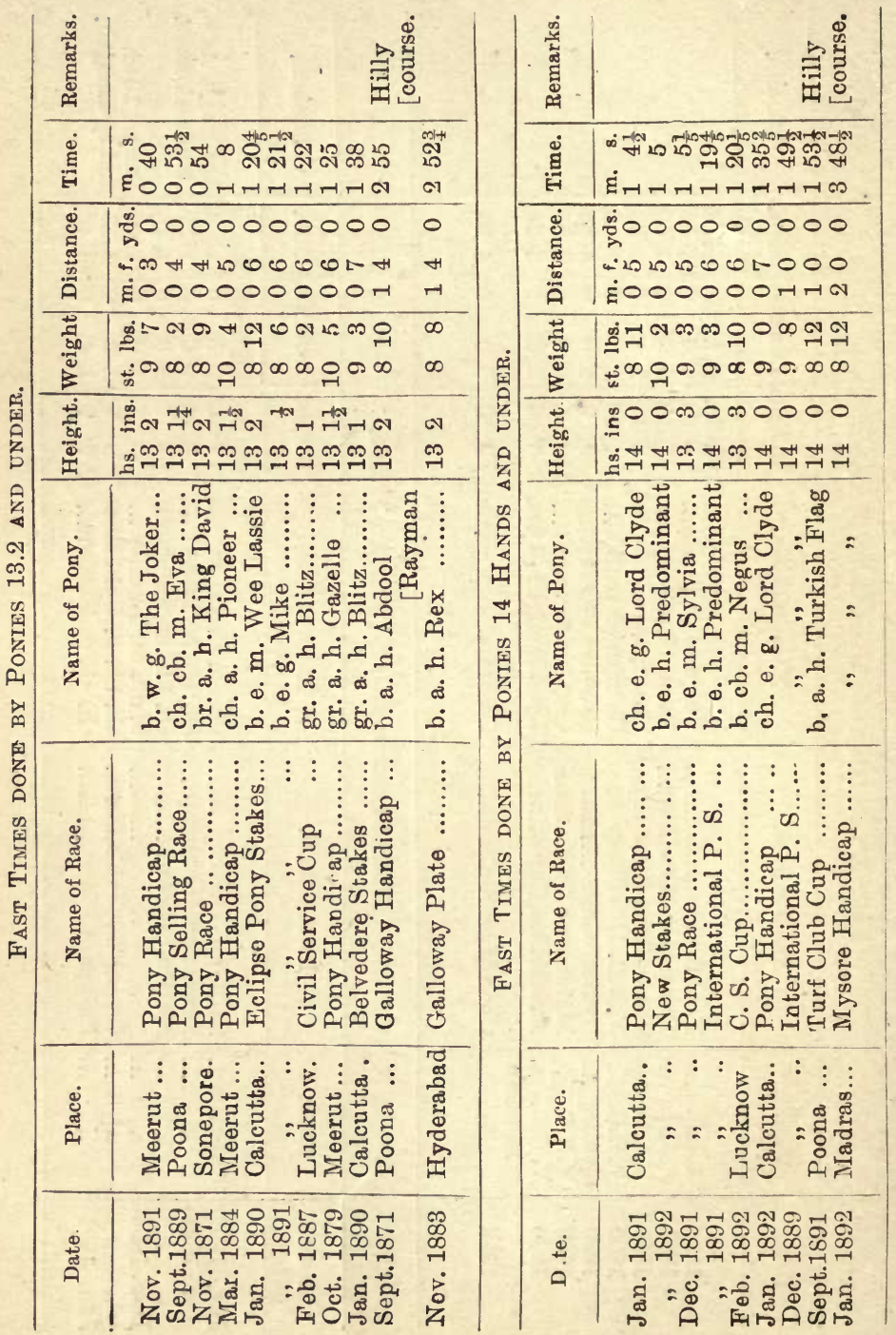




\section{CHAPTER II. \\ ON THE THEORY OF TRAINING.}

TRAINING-DEVELOPMENT OF MUSCLE-EFFECT OF EXERCISE ON THE SYSTEM - NATURE OF EXERCISE-FOOD-HEALTH - SWEATINGARTIFICIAL SWEATING-PHYSIC-SIGNS OF CONDITION.

Training is the art of preparing a horse to gallop a certain distance at the greatest possible speed.

In order to accomplish this, the following conditions are necessary:-

1st.-That the muscles which are used in galloping be developed to the highest extent for the object in view.

2nd-That the whole system, both nervous, muscular, and functional, be in a healthy state.

3rd. - That the organs of breathing be in the best possible condition to sustain the system in its required effort.

4th. - That the muscles be accustomed to the nature of the action they will be called upon to perform.

5th.-That there be a minimum of fat in the system, compatible with health; so that the animal may not be retarded by useless weight, nor his muscles impeded by its presence. 
Development of Muscle.-On this subject Dr. Carpenter (Human Physiology) remarks that "the frequently renewed exercise of muscles, by producing a determination of blood towards them, oocasions an increase in the nutrition; so that a large amount of new tissue is developed, and the muscles augment in size and vigour. This is true, not only of the whole muscular system when equally exercised, but also of any particular set of muscles which is more used than another. Of the former, we have an example in those who practise a system of gymnastics adapted to call the various muscles alike into play; and of the latter, in the limbs of individuals who follow any calling that habitually requires the exertion of either pair, to the partial exclusion of the other, as the arms of the smith, or the legs of the opera-dancer. But this increased nutrition cannot take place unless an adequate supply of food be afforded; and if the amount of nutritive material be insufficient, the result will be a progressive diminution in the size and power of the muscles, which will manifest itself the more rapidly as the amount of exertion, and consequently the degree of waste is greater. Nor can it be effected if the exercise be incessant, for it is during the intervals of repose that the reparation of the muscular tissue occurs; and the muscular system, like the nervous, may be worn out by incessant use. The more violent the action, the longer will be the period of subsequent repose required for the reparation of the tissue."

From this we see that, while giving the horse the exercise necessary to develop those muscles which are used in galloping, nee should attend to his proper 
feeding; should afford him the rest indispensable for the repair of tissue, and should preserve around him the conditions that are most conducive to health.

Effect of Exercise on the System. - The various tissues of the body have but a limited time for existence, which period is directly influenced by the amount of exercise taken by the animal. Apart from the necessity there is for exercise to develop muscle, to reduce fat, and to maintain health, experience also teaches us that tissue which is formed under conditions of rapid waste and repair, is stronger and of better quality than that subjected to more gradual change; and anatomical investigation proves that the former, from being more vascular, is redder and healthier-looking than the latter. Hence, to improve the quality of the muscular and nervous tissues, we should give as much exercise as is compatible with the individual capabilities of the animal trained.

Exercise purifies the blood, by quickening the action of the lungs, which supply oxygen to the vital fluid for the breaking up of effete matters contained in it. By quickening the circulation, it stimulates the processes of nutrition for the building up of new tissue; and, of excretion, for the removal of effete and deleterious substances. It also strengthens the action of the heart and lungs.

Nature of Exercise.-We may conclude that this should gradually conform to that of the race for which the animal is being trained, so that, speaking generally, only the muscles which are particularly used in galloping may be specially developed; for, were other muscles, also, called into abnormal play, their 
extra nutrition would but tend to deprive the muscles used in galloping, of material for repair, and would add unnecessary weight to be carried. No amount of trotting or walking can prove an efficient substitute for galloping, of which exercise the trainer should endeavour to give his horses as much as possible, under certain reservations, to which I shall presently allude.

In o:der that fast work may be given with safety, the horse should be gradually accustomed to it; the golden rule here being, that the length of a horse's gallop should never exceed the distance which he can go - at the time being-without his muscles becoming fatigued, or-which is the same thing-without his becoming "blown ;" for neither man or horse are ever so "beat" as when they are "out of wind." In fast work, the suspensory ligaments are particularly liable to sprain. In my Veterinary Notes for Horse Owners I have alluded to this point as follows-" When the horse is fresh and untired, the muscles to which the perforans and perforatus tendons are attached, contract with suc's precision that the foot is 'picked' up (flexed) before undue strain can fall on the suspensory ligament; in fact, these tendons act as assistant braces to it. But if the pace be continued, the horse will ' dwell' more and more in his stride, and as the two muscles which move the tendons become gradually fatigued, they also become unable to contract with sufficient quickness to save the suspensory ligament from undue strain. Besides this, the muscles get tired, but the ligament does not experience the sensation of fatigue; hence the horse throws weight on the latter to save the former. We may easily imagine how great 
this strain must be in the case of a race-horse struggling home during a desperate finish. When the muscles which flex the fore-legs become tired, a considerable portion of the weight of the horse and his rider, which is propelled forward by the hind, has to be borne by the suspensory ligaments of the fore-legs. No wonder then that race-horses, as a rule, break down within the 'distance,' especially if the ligament has been previously injured. We also may readily see why they are more apt to break down when out of work than when in condition."

Fast work should be very sparingly given on hard ground, owing to the great danger there is of horses exercised on it spraining their suspensory ligaments, and injuring the bones of their legs and feet.

It is most important that the trainer should recognise the fact that he can greatly increase a horse's speed by practice. We find, as a rule, that a pedestrian who has been put into regular training for the first time, will, after a year's constant practice, do his 100 yards, say, 1 sec. faster, or his mile, say, $20 \mathrm{sec}$. better than he could have done before, even when in condition. The same holds good at boxing, fencing, and other kindred sports; and, undoubtedly, does so with horses, whose muscles obey the same laws as those of our own bodies. The benefit, however, which may be derived from practice, in this respect, will be more or less lost if the work be continued after the muscles have become fatigued; for the simple reason that, as soon as they get into this condition, the speed at which they first moved will become decreased, and what was, at starting, fast work, ends by becoming 
slow. Hence, the trainer, speaking generally, should rigidly limit the distance over which he sends an animal at a fast pace, to one which the horse can cover without having to slacken off at the finish.

Experience teaches us that we must be very careful in applying the fact that speed can be greatly increased by practice, to horses; because, if we push it to an undue extent, they will be apt to become disgusted with their work, and may refuse to "try" ; a proceeding which will nullify any calculation made on the basis of the horse being a machine. For this reason, we should, as a rule, never fully extend an animal in a training gallop. If we have to do this in a trial or in a race, so much the worse for the horse in the great majority of cases ; for, unless he is exceptionally "game," the fact of his knowing the utmost extent of his own powers, will prevent him from struggling as resolutely as he would do, were his self-knowledge less extended. How often do we find that, even winning, after a severe finish, converts, for the remainder of his life, a good horse into a worthless brute, as far as racing is concerned; and that the effect of losing, under similar circumstances, is still more liable to ruin an animal. Horses vary so much in the manner they stand fast work that it is impossible to lay down any detailed rules for guidance on the subject. Sluggish horses are, as a rule, far better in this respect than are impetuous ones ; and thorough-breds, than "cocktails." Pedestrians can stand more training than horses, and will often bear being extended day after day without losing their "turn of speed." This fact is probably to be accounted for by the higher development of their nervous system. 
When a horse is restricted for some time to slow gallops, his style, however good it may have been originally, will gradually accommodate itself to this pace, and will, in course of time, become permanently altered, or take a long period to recover. The reason for this is that the muscles which are called into play, obeying a beneficent law of nature, gradually acquire a style of action which will enable them to perform their accustomed task with the least possible exertion to themselves. Thus, when they have become habituated to a slow gallop, they will be unable to act at a fast pace to the best advantage, simply because they are unused to it. This law is well proved by the fact that training horses for long distances has a very prejudicial effect on their speed for short races. Most men, who have sparred much, know how slow the use of heavy dumb-bells makes them.

Continued slow work spoils the action of the horse, in that it accustoms him to move his muscles slowly and to take short strides. Besides this, as it does not call into play his muscles of forced respiration (see page 161), which are greatly used at fast paces, it is entirely inadequate to render him "fit" to race. Work on deep ground causes a horse to shorten his stride and to " dwell" on it. The practice of carrying heavy weights makes the animal go short. Training a horse on a hilly course, when he has got to race on level ground, is a great mistake-always supposing that he is sound-for, from constantly going up hill, he soon learns to "go high ;" as he finds, by doing so, that he lengthens his stride. I need hardly say that although some really good horses, like Lecturer, the Cesarewitch 
winner of 1866 , have high action, we must acknowledge that they would be still better animals, if they possessed more of a "daisy-cutting " style ; for any undue bending of the knees must tend to shorten the stride. Of course, the converse of all this, also, holds good ; as we saw in 18:1, when Colonel Macpherson's g. a. h. Malabar won the Dehra Doon Derby, from a field which contained two or three horses which could have given him, at least, a stone on the flat; his excellence up the hill being due to the fact that he had been trained on it for a couple of years. When he was, subsequently, taken to run on the level course at Umballa, he was found to be incapable of acting to advantage on it. During the lengthy preparation which Scot Free, the winner of the Two Thousand Guineas in 1884, received for the St. Leger, he was given almost all his gallops on Side Hill or on Long Hill, both of which Newmarket training courses form comparatively steep gradients. I saw him do some of his last gallops before going to Doncaster; and although his muscular development was perfect, I could not help being impressed with the fact that his action was much " higher" than when he won The Guineas, beating Harvester, Superba, and others. He started first favourite for the St. Leger, at 11 to 4 , and was never once "in it." I maintain that galloping a horse constantly up hill is not sufficient even for getting his wind in good order for a race on the flat. We knowto take an extreme case-that no amount of practice which a sailor might have in running up ard down the rigging of his ship, would enable him to " stay " even 150 yards on the cinder path; and that mountaineers, 
however good their wind night be for facing a steep hillside, are soon "blown," if they have to run fast on level ground; the reason being that both find the action a novel one to their muscles.

We may safely conclude that a horse should very rarely be fully " extended " over a distance equal to that of the race for which he is being trained, and only then towards the latter end of his preparation. "Getting the distance into them " is too often synonymous with "taking the speed and life out of them."

Repeated fast work, for comparatively short distances, with intervals of rest between, will be found to be accompanied by less risk of accident, and less danger of making a horse slow, than long fast gallops.

Fast work is not alone requisite for preserving and improving the speed of the limbs; but is equally essential for bringing the respiratory muscles into such a condition that they can maintain their action under high pressure. We may rest assured that if a horse be thoroughly fit and well, has had lots of work, and has had his speed developed and his wind made clear by plenty of short spins, with a few fast gallops for nearly the length of the race for which he is going to run, he will, in nineteen cases out of twenty; stay the distance, unless, indeed, it be beyond that of which he is naturally capable.

From the foregoing remarks we may see that in order to bring a horse " fit to the post," we must give him a large amount of exercise, which should not be at a long, slow gallop. Hence, the exercise which we are unable to give at a fast pace, should be at one which will be as little prejudicial to his speed as possible, such 
as the walk, trot, and canter, which are totally different in their action to the gallop.

Food.-The old writers on training were accustomed to lay considerable stress on the necessity of "hard" food, and a restricted allowance of water, in order to reduce the size of a horse's stomach and intestines, and to harden his muscles. At first sight, the former consideration seems to be a most important one ; because, if these organs be distended by the bulky nature of the food, the diaphragm will be impeded in its effort to afford room for the action of the lungs. As the question of food is entirely dependent on conditions of health and nutrition; the trainer may rest assured that if they be duly maintained, the animal's organs will accommodate themselves, in the best possible manner, to the work which he is called upon to perform.

When a horse's powers are fully taxed, we may safely rely on his appetite being the best guide for determining the amount of his hay, corn, and water ; for he will instinctively choose the proportion best calculated to furnish material for the repair of tissue, always supposing that he shows no signs of ill-health, and is sound on his legs.

Health.-As the due nutrition of the system is dependent on the state of the general health, we should endeavour to secure the former by maintaining the latter in the best possible condition; thus avoiding the too common error of neglecting the cause for the effect. Hence, if the slightest symptom of indisposition can be traced to the effects of the food, its nature or amount, as the case may be, should be at once changed. 
The usual symptoms of derangement, caused by errors in diet, are feverishness, with quickened pulse, and hot, dry skin; looseness or constipation of the bowels; the presence of flakes of mucus mixed with the dung, indicating irritation of the intestines; sour smell from the mouth; the practices of grinding the teeth and licking whitewashed walls, \&c., which show acidity of the stomach; dark-coloured urine, evincing that the - animal is fed on food of a too highly nitrogenous nature; yellowness of the gums and lining membrane of the eyelids, pointing to derangement of the liver; a disordered state of the skin; abnormal appetite, \&c.

Sweating.-The result of my own observationsthrough a long experience in several branches of training-on drawing either man or horse "fine," is that it is entirely a question of the state of the nerves of the individual trained; for, as Stonehenge justly remarks, "the nervous system cannot respond to the calls of its great centre without having a due supply of fatty matter." Horses, like men, vary, one with another, in regard to the amount of fat which their systems can lose without their becoming "stale." Most men who have trained hard for pedestrianism, rowing, race running, \&c., will practically understand the meaning of staleness, the causes of which, we may safely infer, are the same both in men and horses. When a man gets much below his ordinary healthy weight, whether by excessive exercise, physic, sweating, or Banting, and continues hard work, he will, as a rule, soon become nervous and shaky; a state which can be cured only by rest, and by discontinuing the means taken to get 
thin; and, then, as his weight rises, his nerves will regain their tone.

I do not, for a moment, mean to say that the disturbance of the equilibrium of the system, due to an abnormal loss of fat, is the sole cause of a horse becoming stale; for I know well that the effects of over-work and the feverishness induced by excitement and high feeding, also tend to bring about that condition. But I wish, simply, to impress on my readers the fact that. a certain amount of fat, in the body of the horse, is indispensable to the continued healthy action of his nervous system, on which is dependent the exhibition of all muscular force. Hence, we should avoid the mistake of drawing a horse fine too soon, and should endeavour to apportion his work in such a manner that he will be "trained to the hour," knowing well that it is impossible to keep him "wound up to concert pitch," beyond a few days.

When a horse, under ordinary conditions, is well fed and little worked, there is not alone a quantity of adipose tissue deposited in his system ; but also a certain amount of infiltration of fat, in the form of distinct drops, takes place in the cells of the different tissues, and particularly in those of the liver. This fat, by distending the cells, renders the muscles, liver, and other involved structures, unfit to bear the strain of violent and continued exertion. The object of training is not alone to get rid of the retarding weight of a quantity of useless fat, but also to eliminate the infiltrated fat from tissues that are called into action during work; hence, when we sweat a horse, we do so in order to remove from his system a certain amount of fat, 
some of which is broken up by the oxidation of its carbon by the agency of respiration, while the greater part of the remainder is carried out, in the form of oily matter, along with the perspiration, which fluid is directly abstracted from the blood. For the maintenance of health, the blood must contain a certain proportion of water, which varies, under special conditions, such as violent exercise, purging, deprivation of water, excessive perspiration, \&c., from 700 to 800 parts in a thousand. If, in case of loss, the normal proportion of water be not speedily restored, the animal's bealth will suffer. Thus we may see that the proper object of sweating a horse is to reduce the amount of fat, and not the amount of water there is in his system; and that as soon as we fail to find that oily matter is given off, to any appreciable extent, with his perspiration, so soon should we stop giving him any more sweats. I need hardly point out how opposed to common sense and to physiological teaching, is the practice of stinting a horse of water after sweating him. In fact, want of a due supply of water interferes with the whole process of nutrition. "The activity of absorption by the bloodvessels depends upon the due fluidity of the materials to be absorbed, for it is well known that no fluids quickly penetrate the vessels, but such as are of lesser density than the blood." (Williams.)

From the foregoing remarks we may draw the practical conclusion, that we may take, during training, the state of the perspiration as a guide by which to judge of the amount of fat in the horse's system, and that we should regulate his work so that the sweat, after his gallops, may not completely lose its greasy 
feel, until within a few days of the race for which he is being trained. This is, of course, supposing that he is one of the sort that will stand being "drawn fine."

Artificial Sweating.-By this term I mean any process of sweating which is accomplished without the aid of exercise, such as that by the Turkish bath, or by clothing the horse very heavily in a warm, closed-up stable, \&c. Such sweating, I think, is most objectionable, unless, indeed, the state of the animal's limbs precludes exertion. When perspiration is thus artificially induced, the increased excretory action is confined to the pores of the skin, so that the blood rapidly becomes charged with effete matter which the lungs fail to eliminate with due promptness; as the respiration is not accelerated by exertion. Hence, the lungs become gorged with insufficiently aerated blood, which causes the breathing to become laboured, and the action of the heart tumultuous. These abnormal conditions cause general distress, and tend to injure the healthy working of the heart; results that speedily -if oft repeated-upset the nervous system, and render the animal stale and incapable of prolonged and vigorous exertion.

Physic.-Before commencing training, it is generally advisable to give a moderate dose of physic, in order to eliminate from the system an excess of the products resulting from the waste of tissue, which are not excreted with sufficient rapidity for the requirements of hard exercise, and to get rid of the superabundant nutritive material absorbed from the chyle. The diseases known as azoturia and lymphangitis are respectively brought on when these two conditions exist to a highly 
injurious extent. In both, the administration of a purgative is advisable. Although we may not have either complaint developed; still feverishness, "filled" legs, dark-coloured urine, \&c., often result from similar causes, when the precaution of giving a horse a dose of physic is not observed before putting him into training.

Signs of Condition.-When a horse is in perfect condition, his coat will be soft and glossy like satin; his eye bright, but tranquil ; his sweat scanty, will dry readily, and will be free from oily matter; his legs and feet cool; his muscles hard, prominent, and distinct from each other; those extending along each side of his spine will be full and massive; while those over his quarters will swell up to a certain convexity. The ribs will be defined, although covered with a powerful sheet of muscle, which, as well as the muscles that cover the belly, will have become developed by the forced respiration necessitated by fast work. The fact of these muscles being in this condition is manifested by the presence of their raised though irregular border, which runs in a more or less diagonal direction down each side of the abdomen towards the groin. The "quarter mark"-division between the biceps rotator tibialis and triceps abductor femoris muscles-is well defined. The space round the anus should be prominent and filled up; the thighs so developed that they should meet for a considerable way down. The crest should be full and hard; and the large caput muscles which lie just above the fore arm, should form a distinct lump. "Who can fail to see in a well-trained racehorse the muscles, standing, as it were, prominently 
one from another about the quarter and thighs, ' hard as iron to the touch,' and giving the animal an appearance of being thin and poor? The appearance of thinness is the result of the great prominence of each individual muscle, of increase in their volume and weight, and an extraordinary healthy tonicity." (Williams.) 


\section{CHAPTER III.}

FOOD DURING TRAINING.

As the suhject of food has been fully discussed in Part I. on Horse Management, I shall treat on it, here, only as far as it relates to training for racing. If oats can be procured heavy enough, they are by far the best grain on which to train. In England, old horses whose powers of assimilation are somewhat impaired are often allowed, with good results, a small proportion of beans, or half beans and half peas, with their corn, in order to increase the nutrient value of the food; as the measure of a horse's appetite is more by bulk than by weight. With our light Indian oats, one part of gram to three of corn will be found to be a good general division. The same proportion of kúlthee and oats may be used. Boiled úrud may be substituted for kúlthee. If oats be not procurable, parched barley and gram. may be given.

I may here remark that beans, peas, gram, kúlthee, and urud are very similar in their composition; and that barley closely resembles oats. These grains differ however, in their action on the digestive organs, beans, having a constipating tendency, while both gram and barley have the opposite effect.

The dung of a healthy horse should be fairly formed, 
brittle, friable, and devoid of any adherent slime. As health is, above all others, the one essential condition, without which it is impossible to get a horse fit, the trainer should so regulate the food that the dung should present a normal appearance, which is comparatively easy to obtain in England where sound, heavy oats are procurable; but in India, where gram or barley often has to be used, the task is much more difficult, always considering the large amount of hard food that is requisite for the utmost development of a horse's powers. In cases where the digestion begins to become upset by too highly stimulating a diet, the trainer should diminish the quantity, and should further use means to restore the functions to a healthy condition. With this object in view, he may mix chopped hay through the corn, or use, instead of it, from 1 to $2 \mathrm{lbs}$. of dry bran daily; or give a few bran or bran and linseed mashes.

As a rule, as soon as a horse gets gradually into strong work, he ought to have as much corn as he can eat, provided the chief part of it be oats. $10 \mathrm{lbs}$. will be enough to commence on with an Australian, which quantity may gradually be increased by $1 \mathrm{lb}$. a week. A full average amount will be : gram 4 lbs., oats 14 lbs.; or gram $6 \mathrm{lbs}$, parched barley $10 \mathrm{lbs}$. In either case, $1 \mathrm{lb}$. of suttoo may be given in the animal's drinking water, as described on page 34 .

An Arab will eat from 2 lbs. to 4 lbs. less corn than an Australian.

Oats, gram, and barley should always be given quite dry; the first should be bruised, and the other two broken. I found the following food suited an old 
FOOD DURING TRAINING.

Arab that I trained very successfully, better than any other:-

\begin{tabular}{|c|c|c|c|c|}
\hline Oats & $\ldots$ & ... & $\ldots$ & \\
\hline Gram & $\ldots$ & . & $\ldots$ & 4 \\
\hline Bran & ... & $\ldots$ & . & 2 \\
\hline Linseed & ... & $\ldots$ & $\ldots$ & 1 \\
\hline
\end{tabular}

At night, the two last-mentioned ingredients-the linseed having been previously kept boiling for two or three hours-were given mixed with $1 \mathrm{lb}$. of corn.

My experience is, that even with Indian oats, a horse can be got at least 7 lbs. "fitter" than with any other grain.

Horses in training should get a bran, or bran and linseed, mash once, and in some cases twice a week, as they may seem to require it. Saturday and Wednesday nights are generally the most convenient times at which to give it.

Through the cold weather, a couple of pounds of carrots may be allowed, with great advantage, to each horse. In case they be not available, some green food may be substituted. The roots, or green fodder, may be stopped a week or ten days before running.

Linseed or hay tea may be given from time to time.

It is impossible to train a horse properly without good grass, on the quality of which quite as much, if not more, depends than on that of the corn. For this purpose, only the best picked doob grass (Madrasee Hurryalee) should be used, after having been dried in the sun for a day. As a rule, the horse should be allowed as much of it as he will eat; unless, indeed, he is a very gross feeder; the time of his preparation is limited; or he is fat, while his legs are infirm. An 
animal on a full allowance of corn will eat far less hay than what is commonly supposed. General Fitzwygram states that "practically it will be found that horses which are not limited in regard to oats, will not usually consume above six pounds of hay per diem."

In concluding this subject, I may remark that the trainer, while supplying the horse with food suitable for the requirements of his system, when undergoing severe work, should never lose sight of the fact that the proper assimilation of such food can only be ensured as long as the functions of digestion are in a healthy state. To maintain this all-important condition, he should study the general question of diet, and the various peculiarities of each individual horse; should preserve a sufficient variety in the food, so that the animal be not disgusted by a never-ending monotony; and should supplement the hard fare, from time to time, with a handful of carrots or parsnips, a bunch of lucern, of freshly-picked green grass, or of young oats or wheat, a piece of sugar-cane, a linseed mash; anything, in fact, to keep the appetite from palling on corn, which is, after all, the chief source from which to obtain muscle. 


\section{CHAPTER IV.}

\section{DAILY ROUTINE IN TRAINING.}

DuRING the training months, the syces should be up nearly an hour before daylight, and should give each of the horses a little water, say, two or three pints, and from one to one and a half pounds of corn, which quantity may be increased to two pounds, if the animals are to be kept out longer than three hours. When this is eaten, the clothing worn at night should be taken off, the coats wisped over, and smoothened down with a towel, the manes and tails set straight, the eyes, muzzles, and docks sponged out, and fresh clothing put on according to the weather. The horses are now taken to the exercising ground, and are kept walking for fully an hour, so that they may empty themselves, and then they get their work, fast or slow, as the case may be. In some racing stables in England, the horses that go out early in the morning, say, at six o'clock, during the hot days of summer, get nothing before starting; while in others, they have a very small feed. The advocates of the former system aver that their animals, being empty, are in the best possible condition for getting work, and that nothing is gained by feeding them at that time. If we may reason from our own cases, we may assume that the horse in India finds his chhotee haziree both agresable and 
"sustaining" before his morning work. On the other hand, it is certain that this practice of giving horses an early feed causes them, in many instances, to "scour" when taken out to work. We should, in such cases, omit this light repast. The diarrhœa which is set up in this manner, is due to the food, the digestion of which was checked by exercise, asting as an irritant to the alimentary canal.

When a horse has finished his exercise, he may be either walked home to his stable, or rubbed down on the spot. If the latter plan be adopted, he may be walked or trotted to the rubbing-down shed, or to the lee of any favourable cover. The girths should be slackened, and, if he be worked in clothing, his hood should be quickly removed, and if there be any sweat visible on his neck, it should be scraped off with the copper scrapers that are made for this purpose. Above all things, the hollow between the jaws should be carefully dried with a towel ; for neglect of this precaution has often been the cause of subsequent cough, or sorethroat. The bridle should now be changed for a common watering one, as horses are apt to spoil the reins by biting them whilst being groomed. If the animal be restless, a man may stand in front with a rein in each hand, and hold his head up; while one or two syces, at each side, rub him down with a wisp of dry straw, or of sun (unprepared hemp). The wisps should be rubbed well into the coat, and should not be used as fans. If he be inclined to bite, the syce who holds the reins may keep a stick in one hand pointing across the horse's face, so as to keep him in order, or a muzzle may be put on. The breastpiece is next removed; the 
base of the neck and chest scraped and dried; and, lastly, the body clothing is taken off, and the barrel, loins, and quarters finished. Dry, light clothing is put on, and he should get half a bucket of water, say, about a gallon. This rubbing down should not take more than five or six minutes, and after it, the animal should be started home at a walk, without further delay.

Though the horse, on leaving his stable, should be ridden at a walk before his work commences, he had better be led home; for then he will return cooler, and will not be so liable to break out into a sweat again, as he would be were he ridden back. If the horse is to be ridden on his way home, the felt saddle-cloth, if it has been used, should be put on inside out, so that the portion of it which has become wet from sweat, may not come in contact with the skin of the animal's back; for, if it did so, it would act, more or less, as a poultice, and render the part soft and tender. Besides this, a dry surface next the skin is more comfortable than a damp one.

Having arrived at the stable, he may get as much water as he chooses to drink, with or without suttoo mixed through it, as the trainer sees fit; and then he is tied up, his clothing removed, and the grooming begun.

The practice of rubbing a horse down immediately after his gallop is specially applicable to an animal which has been worked in clothing, and which, in consequence of the presence of the damp material next its skin, would, were it not removed, be liable to become enervated and chilled during the walk home. When, 
on the contrary, a horse is worked without clothing, which as a rule is much the best plan, it is advisable to walk him, or, if he be at all excitable, to have him led back to his stable. In this case, also, I would give him half a bucket of water to drink immediately after his work.

I may here remark that, if a horse's coat is long, a considerable amount of hair can be got off by handrubbing him completely over, immediately after his gallop, in place of wisping him down. For this, the help of four men is imperative, lest any one part of his body be allowed to cool faster than another. While hand-rubbing, the syces may keep their hands damp with water, so as to get more hair off.

The grooming being finished, the horse gets the remainder of his water-as much as he will drink-or water and suttoo, as the case may be. He may have a handful of dried doob grass to amuse himself with, until he gets his feed. The syce now tidies up the stable, lays down the bedding, prepares and gives the corn. He should not spend more than a quarter of an hour over these preparations.

I strongly advocate the practice of putting dried grass before the horse at the same time that he gets his corn. A supply of fresh water may, with advantage, be always left in the stall.

The stables are now closed till twelve or half-past, and the horses are allowed to rest undisturbed.

At noon, the animal is lightly groomed, fed, and is left again to himself till four or half-past, at which time he is watered, groomed, and gets half a feed. After that, he is taken out and walked for an hour to 
an hour and a half. On returning, he is fed, clothed for the night, the bedding, \&c., is put in order, and he is then left to enjoy his well-earned repose.

When a horse is galloped in the evening instead of the morning, the same routine should be observed; except that the afternoon's grooming should be commenced half an hour earlier. In this case, only a few go-downs of water should be given before it. Here, instead of being watered in the afternoon, he should be watered at mid-day, and then should have no more water, except the few go-downs already mentioned, till after work. When taken out, he should have, at the very least, an hour's walking exercise before his gallop, and after that he should get half a bucket of water, with a full allowance on his return to the stable. He is then groomed, fed, and bedded down for the night.

Supposing that a horse in training gets $16 \mathrm{lbs}$. of corn a day, it may be divided into feeds in the following manner :-

$\left.\begin{array}{lccccc}\multicolumn{2}{l}{\text { Early morning feed }} & \ldots & \ldots & 1 \mathrm{lb} . & \\ \text { Morning } & " & \ldots & \ldots & 4 \mathrm{lbs} . \\ \text { Mid-day } & " & \ldots & \ldots & 4 \mathrm{lbs} . & - \\ \text { Afternoon } & , & \ldots & \ldots & 2 \mathrm{lbs} . \\ \text { Evening } & , & \ldots & \ldots & 5 \mathrm{lbs} .\end{array}\right\} \begin{gathered}4 \\ 4 \\ 2 \\ 6\end{gathered}$ 


\section{CHAPTER V.}

MANAGEMENT DURING THE HOT WEATHER.

IN India the hot weather stops racing in the same manner as the winter does in England. - During the months of April, May, and June, in fact until the rains commence, the trainer-if he be in the plains-should not do more with his horses than to keep them in healthy exercise; for the climate of itself will cause a considerable strain on their systems.

I am much averse to the plan of throwing sound, healthy horses altogether out of training during the summer, when they are required for the following season's racing; for hard condition, once lost, takes a long time to regain; and the abrupt changes in the Indian seasons do not allow of a long period for strict training. Thus, if a horse be permitted to get gross or poor, and his muscles flaccid from want of exercise, and he be not put to work before the middle of July, it will be impossible to get him at all "fit" before November or December. I would, on the contrary, advise that a sound horse should get, all through the hot weather, a fair amount of healthy work, which, when it consists of cantering and trotting, should be given in the early mornings.

Through these slack months, any injuries that the horse's feet and legs may have sustained during the 
previous season should be carefully treated. On this subject it is sufficient to remark, that time and rest are the best means to obtain repair of injured structures; and I would advise my readers to avoid heroic methods of treatment, such as blistering, firing, bleeding, and giving strong purgatives, except under competent veterinary advice.

During the hot weather, horses should get a less quantity of food than when in training, though they should on no account be kept low; for if they be not liberally fed, their systems will be unable to resist the debilitating effects of the climate. It is not from theory, but from what I have seen in practice, that I speak positively on this subject. An Arab may get eight, and an Australian ten pounds of corn-three parts oats, one part gram-with a couple of pounds of bran; and twice a week, at night, a bran and linseed mash; or, every second night, a feed of boiled barley mixed with a pound of bran. A liberal supply of any green food which is obtainable, should be given.

The chief point to be considered is that the dung should be properly formed-though that of some horses which have been trained a good deal, always remains abnormally loose-brittle, devoid of all stickiness and bad odour, and should be of a healthy yellow colour. When oats are used, the dung is much more yellow than with any other grain.

During the hot weather, the horses should have an hour and a half's walking exercise in the morning, and a little less in the evening. It is preferable to have horses ridden at walking exercise than led. Alnost every syce can ride well enough for this. Horses should 
be made to walk smartly. Nothing looks slacker or causes an animal to walk in a more slovenly manner, than the way syces often lead horses, with a long rein or rope over their shoulder, while they hobble along in front, at the rate of about two miles an hour. 


\section{CHAPTER VI.}

PRACTICAL TRAINING.

REMARKS ON RACE-HORSES IN INDIA-TRAINING QUARTERS-GENERAL RULES FOR WORK DURING TRAINING-DETAIL OF WORK-SWEATING - REMARKS ON TRAINING CONTINUED-TRAINING BY SHORT REPEATED GALLOPS-REMARKS ON TRAINING CONTINUED-TRIALSTRAINING PONIES-SETTING-TRFATMENT AFTER RUNNING-RACEHORSES TRAVELLIYG BY RAIL.

Race-horses ir India.-It is an old and true turf maxim, that the better bred a horse is, the more training will he stand. In this country, "blood" is rather an uncertain guide for the trainer; for many of our horses are "cocktails" in the strict English sense of the word. At the same time I must admit that the type of horse which Australia sends us, is improving yearly in quality and breeding, and that cases of giving "salt-water pedigrees" are becoming of rare occurrence.

The subject of pure blood and high caste in the Arab is one on which I have never been able to gain any exact information; nor do I think that any distinct rules, as to external appearance, can be laid down, that would not equally apply to any other breed of horses intended to gallop fast, and "stay," with a fair weight up. Many young Arabs which look unpromising at first, to our eyes, often turn out the best in the end. T'hese horses take a long time to mature; their powers 
rarely becoming fully developed before they are eight or nine years old, and until they have been raced for two or three seasons. On this account, one should not lose heart because a likely-looking son of the Desert does not answer one's expectations at an early date. I may mention that Arabs can stand more work in India than any other class, and that their forte is undoubtedly distance.

A young Australian-say a three-year-old-appears to be-allowing for the difference between the dates from which they respectively take their age-nearly a year; a Country-bred, a year and a half; and an Arab two, if not three, years, more backward than an English horse of the same age. Many three-year-old English horses (like St. Gatien who, at that age, with 8st. $10 \mathrm{lbs}$. up, won the Cæsarwitch in a common canter against a good field) are in their prime at the "back end" of the season.

Young Arabs especially, and indeed all young horses, may, with great advantage, be trained and taught to gallop, without being brought to the post, the season before they are actually run. We generally find a horse that has been raced the first year he has been trained, to become in the next season from $10 \mathrm{lbs}$. to 1 st. better (not allowing for age) than he was during the preceding one. If horses are run the first year they are put to work, they will rarely be able to successfully contend against platers, even when receiving, as maidens, from $7 \mathrm{lbs}$. to 1 st.; simply because they have not had time to learn their business. We seldom see maidens which have been run thus, come out in anything like their subsequent form, until, perhaps, towards 
the end of the season, when there is little to be won with them, on account of the most important maiden races having been already decided. In England, a young one can be kept at work for six months before he runs for the first two or three-year-old events, but out here, the hot weather allows but little more than three months, during which to prepare a maiden, without suffering many of the best stakes, which are reserved for his class, to pass by uncontended for. We should not lose sight of the fact, that it often takes more time to teach a horse to gallop, than to get him into condition.

As it requires at least two years' conditioning to enable a horse to live amongst the first flight in " the Shires;" it will, certainly, require no shorter period to bring a young one-probably fresh off the ship-fit to race over a distance in India.

Small, compact horses mature earlier than those of a larger and looser frame, and consequently may be run at an earlier age. Sluggish horses can almost always both stand work better and stay longer than impetuous ones. Old horses require usually less work to get into galloping condition than young ones do, though they take more time to put up muscle.

In India, horses are rarely trained specially-as in England-for one particular race, as there are few events worth an owner's undivided attention. The usual practice is to give horses, within certain limits, more of a general than of a particular preparation. However, one should never sacrifice the speed of a flyer by giving him long work, when it has been proved that, fit and well, he is unable to stay a distance. 
Ponies, 13 hands and under, had best be trained for from a quarter to half a mile. Although there have been many instances-take Chieftain and Rex-of Arah galloways being able to hold their own, at even weights, with Arabs of all sizes; still, in ninety-nine cases out of a hundred, allowance for height-3 lb. the $\frac{1}{4}$ inch-will not bring a 13 and 13-2 pony together, nor the latter with one of 14 hands, provided the galloway has any pretensions to racing form. But if an owner happens to possess such a rarity, like what Abdool Rayman and Rex were, he had better train him for distances at which he will meet the class bigger than himself; for if the animal can succeed with them, he will have little difficulty in beating those of his own size, even in races shorter than those for which he was prepared.

For "all Arabs," $1 \frac{1}{2}$ miles will be a fair average distance over which to train them. Half a mile less will usually answer for Australians and English horses.

Quite as much, if not more, depends on a horse's stable management, as on the work he gets, in bringing him fit to the starting-post. Many horses have been got into good condition, and have won important races, by being simply hacked, with, now and then perhaps, a canter on a soft bit of turf; or even by doing nothing more than trotting work in a very light trap, when their legs have been particularly infirm. But I doubt whether a horse has ever been brought within a stone of his proper form when he has been but indifferently looked after in the stable.

Training Quarters.-The worst of the hot weather being over by the beginning of July, the horses may 
be put into steady work from that date. Before this, the owner should have made up his mind as to what he intends doing with them during the ensuing season; whether to run them early; to wait for some particular meeting later on; or to gradually gallop them into condition, as they work down country from one meeting to another, which is the usual plan adopted; as the different meetings are fixed to suit this arrangement.

To perform well on a hilly course a horse that has been accustomed to flat courses, ought, as a rule, have at least a month's work on it, so as to "get the hill" into him. An instance of the beneficial effect of this practice was strikingly shown by the moderate Malabar (see page 154). I need hardly remind those of my readers who have had long experience in training, that a horse with naturally high action will require far less time to learn how to climb a hill, than a "daisy cutter." At Newmarket, many horses are spoiled for races on level ground, on account of having been given too much of their work up a hill (see page 154).

Perhaps the best thing to do with valuable horses is to send them at the close of the racing season (the end_of March) to some semi-hill station, where, after a month or six weeks' rest, they may be hacked about with a light weight up, and got into good working order, before being put into regular training. In this way they may be healthier and fresher than had they remained in the plains.

The practice of sending horses which have spent the hot weather and rains in the plains, as late in the year as September, to places close to the hills, is often accompanied by some risk, as the nights there are 
then getting cold-especially towards the end of that month-and animals whose livers are more or less deranged by the effects of the preceding hot weather, are very liable to get congestion of that organ from the sudden change of climate. (See Veterinary Notes for Horse Owners.) If an owner intends sending his horses to such places, I would advise him to do so before the hot weather commences.

It appears that the worst kind of climate for a horse to live in is a damp hot one, like that of Bengal, for instance. A damp, cold climate, like that of Scotland, is not incompatible with the breeding of good cattle, provided they be treated more or less as exotics. But the best of all is a dry warm one. During the excessive heat of several hot weathers at Meean Meer and at Cawnpore, both of which places possess a very dry climate, I have never found that the horses I kept suffered in any way from the great heat, as long as they were well protected from the direct rays of the sun, and had a free circulation of air through their stables. Although I do not say that horses will thrive quite as well during the hot weather and rains in the plains, as in cooler climates, such as Dehra and Bangalore; still I do not think that the balance is very much in favour of them, especially when we take the cases of horses that it would be injudicions to train on a hilly course. In making these remarks, I again except all hot, damp climates, in which it would be most unwise to keep valuable horses during the trying months of the year.

Mozufferpore, possessing, as it does, a race-course covered with soft and elastic turf, offers many advan- 
tages; but I question much if its climate is not too damp, in which to summer horses. The same objection may, with still greater force, be urged against the Sonthal Hills.

\section{General Rules for Work during Training.-} Before a horse is put into training, he should, if possible, be in a sound state of health, and his muscles should be well developed by quiet, slow work and hacking.

If practicable, gallop only in the morning, and get the horses back early to their stables, not later, during the cold weather, than half-past eight o'clock. Apart from the fact that evening work, by exciting a horse, is apt to prevent him from having a good night's rest, we should remember that the ground, on account of the presence of the dew, is softest in the early morning.

I think, however, it is a mistake, as some do, to gallop horses too early in the morning when it is all but dark; for by this practice, accidents are liable to occur, especially from horses putting their feet into holes that are made by rats, which rodents burrow very rapidly on many of our Indian courses. Besides this, too early rising deprives horses of a part of their valuable night's rest, and is apt to induce coughs and colds. I am rather inclined to think that galloping in the twilight is apt to make them "go higher" than they would do were they worked at a time when they could clearly see where they were going.

However backward in condition horses may be, they should not, except in very rare cases, be worked twice a day. Here I do not take into account their evening walk.

They should not get their gallop until they have 
walked for at least an hour, and cleared themselves out.

Horses which become much excited when brought on a race-course, should have their work away from it as much as possible; and the place for their gallops should be frequently changed. When such animals have to be worked on a race-course, they should be sent for their spin as soon as they arrive on the track, and should then be taken home without delay.

When training for a Monsoon Meeting, it is often desirable to gallop one's horses in the evening instead of the morning; for flies, which are fearfully annoying during the rains, are much less so in the former than in the latter time. Besides this, if the course be far from the stable, the horses can rarely return before the morning sun is well up. A sweat, however, should never be given in the evening, if it can possibly be avoided.

Before sending a horse a gallop, his legs and feet should be examined, and if there be anything wrong, or the slightest heat present, he should be sent back to the stable. As a rule, unless a horse which is suffering from some injury, actually goes lame, a syce will rarely inform his master of the accident.

A horse should be given a preliminary canter before sending him a sharp gallop, unless he be a very excitable animal.

The heavier topped a horse is, especially if he have a thick neck and coarse shoulders, the more careful should the trainer be about giving him fast work, particularly down any incline.

Horses should not be kept too long on hard food, 
GENERAL RULES FOR WORK DURING TRAINING. 183

and the trainer should never be afraid of giving them a bunch of lucern, or a few carrots.

If a horse in strong work, begins to leave much of his corn untouched, say, anything over half a pound at each feed, the chances are that he is getting too much work, which should be lessened, or altogether stopped, as the case may require, and he should have two or three bran mashes at successive feeding hours, some green meat, or even an alterative ball, if he be at all "over-marked." The time a horse takes to eat his allowance of corn may be used as a measure of his appetite. Thus, say a certain horse, who, after work, usually consumes his morning feed of $4 \mathrm{lbs}$. in 25 minutes, takes on a particular day half an hour to get through the same amount, the owner may reasonably conclude that he is a little off his feed. By observing such indications in time, the chances of over-working a horse will be materially lessened.

"It is well known to horsemen who are close observers, that, though a horse cannot make a great race when decidedly off the feed, some of the finest efforts that ever were made, and some of the greatest successes that ever were won, came just as the horse was beginning to get dainty, and to pick and nibble at the oats." (Hiram Woodruf.)

A horse should never be fully extended earlier than a fortnight before the day on which he has to run for if if this done, he will be apt to get slow. Yet for all that, he should be sent along pretty fast, occasionally, during the latter part of his training, in order to vary the monotony of the work, "and to get the pace into him.' 
Avoid trying your horses against each other, or against the watch.

"When a horse gets to know his speed in his exercise, it is seldom he can afterwards be got to struggle well in a severe contested race." (Darvill.)

On finishing a gallop, always turn round towards the inside of the curve on which you are galloping. If the direction be in a straight line, turn in preference to the right about, as you would on a right-handed course. This practice will tend to prevent horses learning to bolt off the course; for when they do so, they almost invariably go off towards the outside, and not to the inside of it.

On a race-course, finish the gallop a couple of hundred yards beyond the winning-post, and then gradually pull up.

If a rubbing-down shed be used, it should be placed beyond the winning-post, and on the inside of the course.

One should avoid galloping horses in clothing; as it cramps their action, and the extra weight tends to shorten their stride, and strain their legs.

I cannot help condemning the practice many adopt, of having their horses galloped constantly in beavy clothing. An English jockey, whose lowest riding weight is say 8 st., will, when not wasting, and when wearing warm clothes on a cold morning, weigh close upon, if not quite, 9 st. ; to this add 7 or $8 \mathrm{lbs}$. for the saddle, 2 to $3 \mathrm{lbs}$. for the bridle and martingale, and from 14 to $21 \mathrm{lbs}$. for the clothing, and we will have the animal carrying about 11 st., which is a truly preposterous weight for a training gallop; and then men 
GENERAL RULES FOR WORK DURING TRAINING. 185

who allow this, will, when their horses become lame or get slow, wonder how in the world it occurred! If a trainer wants to get the fat off a horse, by all means let him put clothing on, and give the animal his sweat a little later than usual in the morning, at a trot, or at alternate trots and canters, so that he may not spoil his action, or risk his legs. When the horse is pulled up, let him be well covered over with rugs till the sweat trickles down his pasterns; and repeat, every week or ten days, this process, which will take the "beef" off the grossest horse quite quick enough. A trainer should consider the feelings of his horses, and it is only reasonable to suppose that an animal which is constantly exercised in heavy clothing, must feel his movements cramped both by the weight he carries, and by the presence of the rugs, and that he will consequently lose heart for the want of the exhilaration of spirits produced by a free and untrammelled gallop. The mind of the horse has undoubtedly a great deal to say to the quick, elastic stride, and the lightning dash of speed at the finish, exhibited by a well-trained racehorse.

Admiral Rous, in his book on "Horse-racing," states that "generally speaking, race-horses ought to be galloped stripped all the year round, but comfortably clothed indoors suitable to the temperature."

One should have as light riding boys as possible compatible with their being able to hold their horses together. Even with a screw, it is generally better to put up a stone or so extra, than to be obliged to employ a curb instead of a snaffle for his mouth, in order to enable a light lad to hold him. 
If a horse can be held with a snaffle, never employ any other bit for him. Never use whip or spur in a training gallop, unless with a very sluggish horse, with one that is apt to bolt off the course, or with young animals that go awkwardly and require a deal of collecting.

The longer distance a horse has to go, the finer should he be drawn.

As a rule, do not have a less interval than ten days between each sweat. Rarely sweat later than ten days before a race; for a horse should have just enough time before running, to be eased off, so as to get a little "above himself; " sufficient, in fact, to allow his nerves to regain their tone.

A horse should never scrape quite clean and watery sooner than the last ten days of his final preparation; for if he does so, he is almost certain to become stale.

Assuming that a horse, in training, continues in good health and spirits, with his legs cool and fine, that he is never off his feed, and that his dung is in good order ; we may safely be guided. by the way he scrapes, after his morning gallop, in judging of the manner in which his condition is progressing, and whether he requires a sweat, or more or less work, so that his sweat may be gradually reduced down to the desired consistency. When a horse is gross, his sweat is thick and greasy to touch; but when he is in perfect condition, it is generally scanty, comes off as clear as water, and dries almost as soon as the scrapers have passed over the surface of the skin. He will then have the smailest amount of fat in his system compatible with his nerves remaining for but a very few days in good orảer. Of 
course, he should be wound up to this concert pitch, only just before his race. I am, here, taking for granted that the animal is of the sort which bears being drawn fine.

When a horse, after slight exertion, breaks out into a watery and copious sweat, and dries slowly, we may be pretty certain that he does so through weakness, and that he is in a most unfit state in which to continue training. In fact, what such an animal would require would, as a rule, be a few linseed and bran mashes, some green food, and several days' rest.

Many excitable horses, when in perfect condition, will break out into a profuse sweat if brought on to a race-course. This should not be confounded with sweating from weakness, or grossness.

The great thing to avoid is getting a horse fit too soon. Condition is only relative; for a horse may be in perfect training, although showing little muscle. What we want, however, is quantity as well as quality of muscle, with clean "pipes," and the "faculty of going "thoroughly developed. This desired state can only be obtained by work, which cannot be continued, if the horse be prematurely brought too fine; for the consequent strain on his nervous system will be more than it can bear, and he will, consequently, soon become stale.

I think experience will bear me out in saying that Country-breds, during training, can very rarely stand being galloped oftener than every second day. They should, also, be run " bigger" than any other class.

Horses differ so much in the way they stand work, that it is impossible to lay down fixed rules on this 
subject. A writer on training can only give illustrative work and general rules, just as a whist authority may point out the proper leads, and how to play certain hands. In both cases, the inferences to be drawn, and lessons to be learned, will be only for general application.

In the following pages I shall consider the training of the average style of Australian we have in India; taking for granted that he continues sound and in good health. If a horse in training has a soft constitution, or has infirm legs, I must leave the trainer to exercise his own common sense to provide for the varying circumstances under which the uncertainty of horse-flesh may place him.

Detail of Work.-To proceed to the routine of training, one should first consider what length of time the horse has to get fit in before running. If there be five or six months, they may be divided into two periods; namely, preparatory work for about a couple of months, and the remainder actual training.

Before commencing any work, the horse may get the following alterative ball :-

Barbadoes aloes ... . 2 drachms.

Nitre . . . . . 3

Tartar emetic . . . 1drachm.

Treacle enough to make a ball.

But if he be gross, or with not the best of forelegs to stand the work necessary to reduce his system, a physic ball (of four drachms of aloes and two of ginger) should be given. Before administering the medicine, the corn should be stopped, and bran mashes substituted for a couple of days. 
I think the morning, say about nine o'clock, is the safest time to give a ball to a horse, and that there is then, little chance of his becoming over-purged during the night, when help cannot be readily obtained.

The first month's exercise may consist of walking for a longer distance than the horse has done during the summer, say; eight miles in the morning and four in the evening, varied every second day or so by a couple of miles trotting, or a slow canter for half a mile now and then. In fact, the work should not exceed gentle hacking. On commencing the second month, the trotting may be stopped, and slow cantering, up to one mile, substituted. This work ought only to take place in the morning, and should be gradually lengthened. The speed of the canter ought only to be just sufficient to keep the horse out of trot, or perhaps a very little more. During this month, no clothing should be put on at exercise; for the weather will be still very warm. On no account should the horse do more work than, in the morning, a slow canter after an hour's walking; and in the evening, nothing more than a four or five-mile walk. The morning work should be completed, and the horse back in his stable, before the sun is well up.

On finishing the canter, the horse should be pulled up very gradually, so as not to strain his forelegs or hocks, and not until he has gone a couple of hundred yards beyond the winning-post-if on a race-course. He may then be turned round towards the inside, and trotted to the rubbing-down shed, where he is scraped and rubbed down (see page 168); or he may be walked home. 
These canters may be given two or three times a week. On two other days, the monotony of the work may be broken, by taking the horse out in the country, and then trotting, cantering, and walking him by turns for eight or nine miles. This will keep him fresh, and in good spirits; for he appreciates an "outing" and change of scene, just as much as we do ourselves.

After these two months of preparatory work, the horse's muscles and sinews will have begun to harden, and he may now be put to regular galloping.

Want of preparatory work, before giving horses regular gallops, is but the too frequent cause of breakdowns.

The work I shall now consider, is that which would be suitable for an ordinary Australian. An Arab's gallops might be a quarter longer. With him, a long slow gallop for two and a half or three miles might from time to time be substituted for the short "spurts." In timing, allowance should be made for the fact of the Arab's comparative slowness. Thus, for instance, a second-class Arab that could do at weight for age a mile in $1 \mathrm{~m}$. $57 \mathrm{~s}$., i.e., say $9 \mathrm{~s}$. worse than a second-class Colonial, ought in a gallop, at conventional half speed, over that distance, to take about $15 \mathrm{~s}$. longer than would the Australian under similar conditions ; for, of course, the difference of time between the two, at half speed, would be nearly double that between them when fully extended, the distance being the same in both cases.

It is not without considerable hesitation that I give illustrative timing; for I know well what a large margin must be allowed under varying conditions de- 
pendent on the style of horse, the weight he carries, and the state of the galloping track. I, therefore, crave the indulgence of my readers in the attempt which I make to furnish inexperienced amateur trainers who are unable to obtain practical assistance, with a sound general idea of the nature of the work required to bring an ordinary race-borse in India fit to the starting-post.

At first, the work should commence with slow canters, which may gradually be improved, say, after a couple of months, up to a little better than half speed. An ordinary Australian,-unless, indeed, he be wanted for some particular distance, may commence at three furlongs every morning and increase it up to a mile by the end of two months. Further than this may make him slow. But if he is to be trained for races of only a certain length, then a third of that may be begun with, and he should gradually go up to three-quarters of the full distance. This may be varied once a week by a half-mile spin, somewhat quicker than the usual pace, in order to keep up the horse's " faculty of going." An off-day's hacking in the country will be of great service, as well as a slow gallop once a week for a couple of miles. For instance, the week's work might be divided in the following way, after the horse has been in regular training for a month and a half :-

Monday

Tuesday

Wednesday .

Thursday .

Friday

Saturday

Sunday $\frac{3}{4}$ mile, half speed.

hacking in the country. $\frac{1}{2}$ mile, three-quarter speed. $\frac{3}{4}$ mile, half speed, or walking. $\frac{3}{4}$ mile, half speed. $1 \frac{1}{2}$ to 2 miles, slow. rest. 
Besides the rest on Sundays, I would advise the trainer to give the ordinary Arab or Australian an extra day's rest once a fortnight in the middle of the week; and a bran, or linseed and bran, mash may be substituted for the usual feed of corn on the evening of the preceding day, just as if it were a Saturday. Horses that are at all shy feeders, or are easily upset by work, should have this extra day's rest every week.

What we call half speed is considerably faster than if the distance were done in twice as long a time as the horse could do it at full speed. A similar remark applies to conventional three-quarter and quarter speed. The latter is in reality about seven annas, half speed somewhat better than ten annas, and three-quarter speed about fourteen annas (adopting the custom of counting pace by annas: see page 112). Thus, for a horse that can do his mile in $1 \mathrm{~m} .48 \mathrm{~s}$, the time that he would take to do that distance at the different rates would be about as follows :-

Quarter speed

Half speed

Three-quarter speed

Full speed
. 3 mins. 50 secs.

$$
\begin{aligned}
& .2 \text {, } 45 \text {, } \\
& \text {. } 2 \text { " } 5 \text { " } \\
& \text {. } 1 \text { min. } 48 \text {,, }
\end{aligned}
$$

As a rule, a uniform pace should be maintained during each gallop; for nothing upsets a horse's style of going, and temper, more than "putting on the steam" the moment he enters the straight run in. Horses accustomed to this practice, often refuse to extend themselves, until their " heads are turned home," and then either bolt, or run away. This, of course, would be fatal in a race.

The speed and distance of the weekly work which I 
have detailed, should be gradually increased as the preparation proceeds. Thus, a second-class Australian, say one who could cover his mile with weight for age up in $1 \mathrm{~m} .48 \mathrm{~s}$, might commence doing his half mile gallops in $1 \mathrm{~m} .45 \mathrm{~s}$, and towards the end of two months might do the three-quarters of a mile in $1 \mathrm{~m} .50 \mathrm{~s}$.

During regular training, a horse should travel about twelve miles a day, including every kind of exercise. For instance, four miles before the morning gallop, which might be for one and a half miles, a one-and-ahalf mile walk back to stable, and a five-mile walk in the evening: an amount which should be rarely exceeded; for long continued walking makes horses stale and leg-weary. On days of rest, a five-mile walk in the morning, and a four mile one in the evening will generally be enough. If a horse be gross, and have at the same time doubtful legs, I would prefer to trust to a mild dose of physic, say once a month, and a sweat, say once a week, given at a trot and a walk, alternately, late in the morning, than too long-continued walking exercise.

At Newmarket, horses in training are usually kept out in the morning about two hours and a half; a period which is sometimes extended to three hours, Some trainers give them also a walk in the evening; while others take them out only once.

I may remark that the usual practice at Newmarket is, after the horse has been walked for about three quarters of an hour, to give him two canters of about three-quarters of a mile each, and then to send him his gallop. Between the canters, and between the last canter and the gallop, the hor'se is walked back to the 
spot from which he first started. As in other details of training in England, no invariable routine is observed.

I have previously pointed out, that the trainer must be guided by the manner a horse scrapes, in deciding as to the advisability of giving him a sweat; for at this stage of his work he will not be sent fast enough to try his lungs, so as to judge by their condition. During this time, the sweat will be gradualiy losing its greasy feel, though it will still come off pretty thick. As it is impossible to give minute advice on this subject, I must leave the tyro to be guided by his own common sense, and by the general principles on which I have touched.

Sweating.-Before describing the process of sweating a horse, I would beg my readers to remember that the grosser and more unfit the animal is, the slower the pace of the sweat, and the less severe should it be.

If time be limited, a stout, lusty horse will probably require a sweat, given at a slow pace, once a fortnight. English blankets, and not country ones, should be used; for the texture of the former is much closer and softer than that of the latter. The clothes and distance may be arranged as follows:-

Put a thick rug over the horse's back in the ordinary manner; then take a long blanket, fold it lengthwise in two or three folds, so that it may not be too broad, pass one end under the horse's belly to a man on the off side, make him draw it towards himself till it be properly divided, and pass the ends one above the other, over the horse's back, so that the rug and blanket may be tightly wrapped round his body. A long blanket folded like a shawl, is passed in front of the horse's chest, and well up his neck-so that it may not 
interfere with the action of his forelegs-the ends are crossed over his neck, chest, and withers, and are brought down on each side, under the place for the saddle, which is now put on, and which will keep his chest rug in its place. A couple of hoods-the underneath one having the ears cut off-will complete the clothing. The horse may now be sent on his journey, the length of which, as well as the amount of clothing, will depend on the style of the animal and on the heat of the weather. If the sweat be given in September, October, February, or March, it will be quite enough to send a stout, hardy, well-bred horse two miles at a trot, or very slow canter, and another two miles at half speed, which would be about 6 minutes for the latter distance (taking into consideration the extra weight of the sweaters), and the pace may be slightly improved for the last half-mile. After this, he is trotted to his rubbing-down shed, the girths of the saddle are slackened, and he is covered over with more clothing for about ten minutes, or until the sweat begins to trickle freely down his legs, and drop from his fetlocks. If the trainer perceives by his laboured breathing that the horse is much distressed, he should lose no time in relieving him of the clothing, the hoods being first removed and the neck well scraped, wisped down, and dried ; particular care being taken to dry the space between the jaws.

The saddle and blanket across the chest are taken off, and after that the body clothing. Each part on being uncovered, is scraped and dried in succession. The horse should now get about a gallon of water to drink, and a suit of dry clothing, rather light than 
heavy, and suitable to the weather, being put on, he should be walked about for a few minutes, so that the trainer may see whether he will "break out" again or not. If this occurs, he should be stripped, dried, saddled, and ridden quietly about, in the direction of his stable, till he has cooled down. But if the animal shows no signs of breaking out, he should beled home to his stable without further delay.

During the colder months-November, December, and January - the distance may be increased.

With the clothing I have described, a five or six-mile trot, or alternate trots and canters, will be sufficient for ordinary horses possessed of no remarkable gameness or stoutness.

Light carcassed horses will not require sweating at all; as a four-mile gallop at half speed without clothing, or with only a hood, or one light suit, once a fortnight will be all that is generally required.

If, after a sweat, a horse refuses his corn, he should get some green food, such as carrots or lucern, during the day, a bran mash at night, no work next day beyond walking, and his regular gallops should not be commenced again until he has recovered his appetite and spirits. As a general rule, a horse should not be worked on the day following a sweat, which, for that reason, is usually given on a Saturday.

In the case of a lusty horse with doubtful forelegs, it would be dangerous to trust alone to exercise to get him fine enough, or even to sweating in the ordinary way, which, from the extra weight carried, would try his legs too much. Such a one will probably require physic once a month, and once a fortnight a sweat, 
which may be given at a trot, or by trotting and walking alternately, and later than usual in the morning, so that the heat of the sun may aid the wasting process without entailing extra work on the legs. Gross horses with infirm forelegs are always the most difficult to bring out; for the heavier they are above, the worse chance will their legs stand. On this account, before the trainer can venture to send them fast, he must get off some of the weight.

It is a matter of importance to have a light weight up when giving a horse a sweat; and, in order to obtain proper control, there is no objection to his using a curb, instead of a snaffle. If a lad much over 8 st. rides, the pace should not exceed that of a trot.

In England, trainers now rarely sweat their horses. As Tom Jennings, who trained Gladiateur, Fille de l'Air, Rayon d'Or, etc., once remarked to me, "If you send them fast enough, they'll want no sweating. The difficulty, then, will be to keep them big enough." This at Newmarket answers well, when the trainer has elastic turf, like that on the Limekilns, on which to gallop his horses, and when he can buy, without putting his hand into his own pocket, an unlimited number of yearlings to replace the older horses as they break down.

Remarks on Training Continued.-If, in the middle of the training, the horse appears at all feverish, or his legs inclined to inflammation from work and high feeding, he should be thrown cut of work for a week, bran-mashed for the first two or three days, have some green meat given, and an alterative ball administered. For three or four days after this, his 
corn should be diminished by one-half, and only walking exercise allowed.

During the third month of the preparation, the horse, if an Australian or English animal, may at first be sent a mile at about half speed, say in $2 \mathrm{~m} .45 \mathrm{~s}$, , the time and distance being gradually improved until he does $1 \frac{1}{4}$ miles in, say, $2 \mathrm{~m}$. $35 \mathrm{~s}$, which would be about conventional three-quarter speed. The short spin once a week may now be gradually increased to one of three quarters of a mile. During the last month of training, the spin may be discontinued and a long gallop substituted, or an extra day's rest, in the middle of the week, according as the horse is found to stand his work. The speed of the regular $1 \frac{1}{4}$ mile gallops may be gradually increased, up to the beginning of the last fortnight, to within 6 or $7 \mathrm{sec}$. of full speed; and no sweat should be given later than this. During the last fortnight, the trainer should be most careful not to overwork his horse though he ought to wait till then before fully extending him. Two Sundays' rest, another day's extra rest between the fast work, with perhaps a day's hacking, two long slow gallops, six or seven fast ones, to be run at nearly, if not quite, full speed, and gradually working up to the distance that has to be run; a slow canter for three quarters of a mile, on the day before the race; and the race day itself will be a judicious division of the last fortnight. The fast gallops should not be given by racing horses against each other; for a very little of that kind of work will go a long way.

I have endeavoured, by using approximate times for the gallops, to give a general idea of what would be 
advisable with a sound, stout, second-class Australian, which, with 9 st. 7 lbs. up could do, on a level course, his mile in $1 \mathrm{~m} .48 \mathrm{~s}$, or $1 \frac{1}{4}$ miles in about $2 \mathrm{~m} .18 \mathrm{~s}$. But there is such infinite variety in the way different horses stand training, that it would be fruitless to give more than a general outline of the system to be pursued, with some hints and general directions which I hope may prove useful. All the same, however well up a man without personal experience may be in book lore on training, the chances are that he will ruin a horse or two in his first essay ; but as soon as he gets some practical experience, he will quickly learn how to apply his book knowledge.

Training by short repeated gallops.-There are many horses whose legs would not stand the preparation I have described. With such animals, the trainer may adopt, with advantage, the system of short repeated gallops, instead of that of the ordinary long ones. For instance, in place of sending the horse a mile gallop, he might tell the riding lad to walk him round the course to the half-mile post, and gallop him at the speed ordered, then walk him round to the same place, and gallop him as before. In this case, the muscles will have performed the same work as they would have done, had the distance been one mile, and the suspensory ligaments would not have run a tithe of the danger of becoming sprained; for the time that these structures are peculiarly liable to injury is after the horse has begun to tire in his gallop (see Veterinary Notes for Horse Owners). At other times accidents rarely occur, except when a horse puts his foot on uneven ground, or hits himself. 
These repeated gallops may be commenced at a quarter of a mile, and be increased by degrees, say, in six weeks' time, up to three-quarters of a mile. At the shorter distances they may be given three times in a morning, and at the longer twice; and the pace should be gradually improved, as the horse's system becomes braced and strengthened by exercise.

Remarks on Training continued.-For a horse that can stand them, I think single gallops are, as a rule, best in India, taking into consideration the peculiarities of the climate, and the difficulty there exists in getting a sufficient number of riding lads.

One should never forget that many horses run best untrained. These are, generally, light carcassed impetuous ones, which a sight of a race-course would upset for a fortnight. Such animals should be well looked after in their stable, get lots of walking exercise and quiet hacking, and have a gallop only once in a waysay every ten days - and that away from a course.

Rogues or bolters should never be trained on a racecourse, but should get their work hacking, pig-sticking, or with the hounds. One can often get a long stretch of soft ground by the roadside or in the jungle, on which to extend a horse without letting him suspect that "business" is meant. I may remark that horses are extremely sharp in this respect, and know a great deal more about racing than we usually give them credit for.

At the risk of being laughed at, I positively assert that many horses know when they lose or win a race, and show this knowledge often most markedly by the way they look and carry themselves after running. I 
have frequently remarked that the once well-known Arab galloway, Caliph, very seldom on the day of a race required a setting muzzle; for he would, of his own accord, neither touch his hay, nor his bedding, and only just wet his lips in the morning, though he would take his allowance of corn all right. I believe the Arab Sunbeam had the same peculiarity. It may be asked how they knew they had to run on some particular day. Very easily, I should say, from the fixed routine they had been accustomed to at previous meetings-such as being plated, having their manes plaited, having a slack day on the previous one after several days of fast work, etc. - and from the appearance of the race-course, which made the fact manifest that races were about to come off.

Most platers, on coming to the track of a strange race-course will plainly show that they know what it is. Then again, how many old race-horses know when to make their effort on nearing the winning-post; though some of them would probably "shut up" were they called upon earlier by their jockeys. How well a horse knows whether his rider has spurs on or not! Some will be as sluggish as a cow if they are absent, though were the Latchfords on, they would be all life, even without being touched. Others will refuse to try if they get the slightest prick, and, even when the jockey is without spurs, they will require a few kicks in the ribs, just to show no punishment is meant, before they will consent to go kindly.

There is always a difficulty about riding boys in this country. In England, stable lads can either ride, or are capable of being taught; but among natives it is 
not the custom, and, as it is very difficult to get lads, one is frequently forced to send horses alone, or at most in pairs. I am aware of the difficulty of finding a boy who has even a little idea of pace. In default of having such a one, I strongly recommend the amateur trainer to time every gallop, as well as each quarter of a mile of it, so that he may be able to correct the lad as occasion may require. To do this, one will require a good stop watch; the best kind for this work being one which has a double second hand so arranged that one of its branches can be made to stop at any moment, and, by a second pressure rejoin its fellow, which in the meantime continues to go on, but which can be stopped together with the other at any moment. Thus, each quarter of a mile can be accurately timed, as well as the entire gallop. With such a watch, the time of the second horse as well as that of the first horse in a race can be ascertained with precision.

Young horses should generally have a horse to lead them in their gallops, and should occasionally be allowed to draw level and pass the other on nearing the winning-post. In doing this, the pace of the leader should be checked, so as to allow the change of position to be made without an effort on the part of the youngster, who, in this way, will gradually learn his business, and, towards the end of his training, will be accustomed either to wait or to lead.

When horses are trained for short distance races, as for half or three-quarters of a mile, they may be run much bigger than were they intended for longer ones; and the trainer should avoid ever sending them long gallops, except at a canter now and then, which will be 
less detrimental to their pace than gallops at, say, threequarter speed for a mile, or a mile and a quarter. They should have lots of walking and hacking. Three gallops a week over the short distance they will have to race, will usually be enough. Another point is that, for short races, horses should never be galloped on a heavy course, as it teaches them to dwell in their stride, and to lose the quick stroke in the gallop which is essential to speed. They should also be taught to start well and get quickly on their legs. To do this the rider must have hands good enough to catch his horse by the head, and send him "into his bridle" in a moment.

Trials.-In order to obtain a satisfactory trial, horses should only be tried when they are quite fit, which ought to be but a few days before the actual race comes off, unless the owner trains his animals specially for a trial, to see, for instance, if they be worth keeping for another season. The trial horse should be, in every case, equally well trained, and be one whose present (not past) public form is thoroughly well known to the trainer. Equally good jockeys should be put up, or, in default, equally bad, and the trial should be ridden out, as in a regular race, without favour or affection. Even with every precaution, trials are not always to be relied on, and a margin of $10 \mathrm{lbs}$. for mistakes would be little enough in the generality of cases ; for very many horses perform differently in public from what they do in private. Besides, with a lot of horses in a race, one can never tell how it will be run, or what accidents may happen. It is dangerous with horses that are at all shifty, to finish a trial at some point before the 
winning-post, on the course on which the race has to come off.

If an owner tries a lot of fresh horses, and finds but little difference between them, or at least, between the best three or four, he may be almost certain that there is not a race-horse among them. According to Admiral Rous there is an average of about three remarkable runners in 2,000. There being so many failures among even English thorough-bred stock, it would be unwise for Indian owners of small strings to be over sanguine respecting the subsequent career of their likely, though untried, maiden Australians, Arabs, or Country-breds. Trials between untrained horses are worth very little; because training makes a vast difference between animals of different stamps. Light carcassed, impetuous non-stayers, who would probably never be fit for anything but selling races, would, perhaps, in a trial for a short distance, beat with ease an equally untrained race-horse which might require months of galloping to get fit. Really valuable horses, which can race and stay, are the very kind that require a long time, and an enormous amount of work to develop their powers to the utmost; but impetuous non-stayers, that are often hardly worth their keep, will always be more or less in condition by dancing about, and fretting, whenever they are taken out of the stable.

I am very averse to trials, as a general rule; for they are liable to upset a horse in his work and to cause accidents. With the best arrangements, they are often very misleading as to the idea they give of actual form.

In the preceding pages, I have considered the work a 
horse may get, if there be five or six months to prepare him in before he runs. If, however, the time be limited to only two or three months, a dose of physic on commencing will be generally required; for one must hurry on the work, which, with high feeding, if physic be not given, is apt to upset a horse's system and make him feverish, thereby rendering his legs prone to inflammation. Pursuing the system I have already described, the horse will be put, without loss of time, into slow work, which may be increased up to a little beyond half speed by the time half the period allowed for training has elapsed. If the horse is well, and his legs fine and cool, no more medicine need be given, and the work can be continued as I have shown in the second preparation. But if the horse's system appear at all out of sorts, or his legs inclined to fill, an alterative or physic ball-as the case may require-should be given; and three or four days after the medicine has "set," work may be re-commenced.

It will be a great assistance to an amateur unaccustomed to training, to keep a diary in which to enter the distance and speed of the work done, and the amount of corn eaten, every day by each horse, with any remarks on their condition, etc., he may wish to note.

I have already gone fully into the subject of food, so shall not again notice it further than by saying that, in training, a horse's corn should be gradually increased up to the last two months, during which time he should have his full allowance, namely, as much as he can eat. If a horse's digestion gets upset by too much corn, it should be diminished, a bran mash may be 
given for a couple of nights, and some green meat, such as carrots or lucern, substituted for a part of the corn.

The amateur trainer will do well to study the marks of good condition in the horse. Until by practice he is able to recognise them, he need not hope for much success in his efforts; for to train well one must have an educated eye to detect the minute graduations of condition, and having acquired it, one will see at a glance what each horse lacks.

The most unerring sign of condition in an athlete is the fact of his being able to go through hard work without becoming thirsty. The horse trainer will also find that as a horse gets fit, the avidity with which he takes his water after his morning gallops will decrease; and that staleness is almost always accompanied by more or less thirst.

Training Ponies.-Many ponies of 14 hands, and even smaller, will stand as much training as big horses. The famous 13.1 Arab pony, Blitz, was a case in point. We shall generally find that the better bred (and consequently bigger, as a rule) a pony is, the more work will he bear. Blood English and Australian and highcaste Arab ponies may be trained according to the principles and routine which I have indicated for horses.

For ordinary Country-bred ponies, six weeks' training will generally be quite long enough, provided they commence in hard working condition. As a rule, they should not be galloped oftener than twice a week, nor farther than half a mile, except when the distance they have got to run is much longer, in which case they 
may be sent on an extra bit. Sweating and long slow gallops should be avoided, and I would advise that the pace of the work should be kept pretty brisk.

In some parts of India-as in Cachar-only ponies are used for racing, and are often asked to go long distances, frequently over a mile. Let us suppose a country-bred pony to be trained for a race of that length, and that he has six weeks in which to get fit; I would, then, recommend something like the following preparation :-

First fortnight.-A gallop at half speed, on Mondays and Thursdays, for a quarter of a mile, twice on the same morning, with a walk for a mile between the spins.

Second fortnight.- Single gallops on the same mornings, commencing at half a mile, and going up to three-quarters of a mile, improving the pace up to three-quarter speed.

Last fortnight.-Four gallops, a little better than three-quarter speed, for something under a mile.

On off days, the pony should have a fair amount of exercise, hacking, etc., which, I think, should not exceed 9 cr 10 miles a day.

If an owner has a real "glutton " for work, he may take liberties with him, but country-bred ponies usually are not of that sort.

Setting.-The degree of " setting," which term is used to express the routine employed in stinting a horse of his food and water before a race, will depend on the distance to be run, the time of day at which the horse is to come to the post, and on 
the condition and constitutional peculiarities of the animal itself. The longer the race is, the sharper should he be set. If it is to come off in the morning and the horse be gross, he should get, on the previous day, only about three pounds of hay or dried grass, given in quantities of one pound each, after his morning, midday, and evening feeds; the muzzle being put on to prevent him eating his bedding. The evening feed may be slightly decreased, and the early morning feed of one pound should be given three hours before the race comes off. In this case, no change in the system of watering on the day preceding the race is needed.

Water is very rapidly absorbed into the blood, and on that account, when taken in moderation, a couple of hours or so before a race, it does not act as a mechanical obstruction to the organs exerted in violent exercise, nor does it occupy the functions of the digestive apparatus in its assimilation, for a considerable time, as corn would do. For these reasons one need not stint a horse so sharply in the matter of water, as in that of food.

If the races be held in the evening - as they almost always are-the setting need not be so strict, and an allowance of, say, $6 \mathrm{lbs}$. of dried grass may be given the day before. The trainer will now be guided by the style of horse, whether to put on the muzzle the night before the race, or to wait till the next morning. In most cases I think it better to adopt the latter method; for if the muzzle be applied overnight, there is a great probability of the horse getting fidgeted by it, and thereby being prevented from having a good night's 
rest. Anyhow, on the morning of the race, he is given his usual one-pound feed, and is taken out for an hour and a half's walk, or he may get a very slow canter for three-quarters of a mile, and be sent the next quarter at nearly full speed just to open his pipes and to give him the idea that his day's work is finished. After that he may get about half his allowance of water, and nearly his full feed of corn, with a small handful of dried grass. The muzzle is now put on, and at noon he may get a couple of pounds of corn. If the race comes off about four o'clock, he should get nothing more; but if at a later hour, a double handful of corn may be given three hours, or three hours and a half, before the saddling bell rings.

If a muzzle does not irritate a horse, it is better to use one than to take up the bedding, without which most horses will not lie down during the day, and many will abstain from staling much longer than they ought to do. On the day of the race, the grooming should be got over quickly; for the horse should be disturbed and excited as little as possible. For the same reason, I would never plait the mane of an excitable horse. I may remark that the use of plaiting the mane is to prevent the hair flying about and getting entangled with the fingers of the rider, while he is holding the reins, especially when he wants to shorten his grip on them.

Having arrived at the race-course, the horse should be kept walking in the shade, if possible, and the saddling should be done quietly, and without any fuss. I think it is advisable for the owner to look after this operation himself, and to see that the weights, girths, stirrup leathers, \&c., are all right. The horse gets now, 
from a leather-covered soda-water bottle, just enough water to rinse his mouth out, the jockey is given a legup, the syce dusts his boots down, and off they start for the post, where, in case of accidents, a syce should always go, and should take a spare stirrup leather and girth ; for such things sometimes break at false starts. Besides this, the jockey may have to dismount in order to arrange some part of the gear, and might require the syce to hold his horse, or to lead him up to the starting. post in case he was fractious.

Treatment after running.-A horse should be watered immediately after a race, and, if he be much distressed, he may get $1 \frac{1}{2} \mathrm{oz}$. sweet spirits of nitre in a drench, or 2 drs. carbonate of ammonia in a ball. If he has not to run for five or six days, he may get a bran mash or two. But if a fortnight or more is to elapse before his next race, he may have an alterative ball, and be kept on green food for a couple of days or more. His legs and feet may, with advantage, be fomented after running.

Race-horses travelling by rail.-It may not be out of place for me here to remark that when racehorses are taken by rail, during the cold weather, their tails (when they are in the horse-boxes) should be pointed towards the engine, so as to obviate, as much as possible, the chance of the animals catching cold. 


\title{
CHAPTER VII.
}

\author{
RACE-COURSES.
}

ON KEEPING A GALLOPING TRACK IN ORDER-EFFECT OF GROUND ON HORSES-MEASURING COURSES-LENGTHS OF DIFFERENT COURSES IN INDIA.

THE climate and the hardness of the ground are the two great difficulties which a trainer has to contend against in India. When a race-course is on the ordinary soil we meet with in this Presidency, having generally a substratum of kunkur, nothing but constant manuring and picking up can keep it in order. This costs so much, that the Clerk of the Course (unless the Race Fund be particularly rich) may be well contented if he can keep a galloping track, even if only four yards broad, in good going order all the year round. Just before the close of the rains, he should take advantage of the softness of the ground to plough it up. It will cost about Rs. 30 a mile to plough and harrow a course 40 feet broad. If the ploughing be delayed, nothing but the pick-axe will touch hard soil. When arranging coolies for picking up ground, it is a good plan to have two men to each pick-axe, or hoe (phurwa), so that one may relieve the other. They will, alternately, pulverise the clods with a wooden batten (mungurree or tapee). The cost of labour may be calculated as follows: 
On the hardest kunkur soil, a coolie, using a pickaxe (gyntee), can pick up and pulverise about 30 square yards, 4 to 6 inches deep, a day; or, with a hoe, he can do about 40 square yards of ordinary hard, sunbaked soil; or 60 square yards of easy soil. The clods should be pulverised as the picking up proceeds; for if left for a few days exposed to the sun, they will become almost as hard as so many stones. The best pick-axes for this work are those supplied by Government to regiments among their entrenching tools. Litter or tan should now be put down without delay. It is no use applying them before the ground is thoroughly loosened; for, until it becomes so, manure would have as little chance of working into and amalgamating with it, as it would on a metalled road. On a track four yards broad, such as I have described, it would take 2,000 ( 1 maund = $82 \mathrm{lbs}$.) maunds of $\tan$, or 1,500 maunds of litter, to lay down a mile properly. The cartage of this will come to about Rs. 3 a hundred maunds, when brought from a distance of three miles. The spreading of the litter or tan will come to about eight annas a hundred maunds. Litter can sometimes be got from artillery, cavalry, or elephant lines, for the mere carting of it away; but when it is sold, its price will not usually exceed eight annas a cart-load of about 20 maunds. Old and thoroughly decomposed litter is the best. New litter always contains a large quantity of particles of undigested corn which have passed through in the dung of the horses. The presence of this grain will generally attract numerous field rats, that will burrow all over the course, and thus give a great deal of trouble before they can be exterminated, 
which is best done by filling the holes with water, and killing the rats as they come to the surface.

The Indian sun bakes the earth hard, and seems to burn up in a very short time whatever kind of manure is put on it; so that nothing but constant picking up and laying down litter, sand, or tan, at least twice a year, will keep a galloping track in anything like good order.

A track, 5 feet broad, will be found to be quite wide enough on which to work a horse by himself.

By constant manuring, a thin layer of good soil will in time be formed; but if the course be neglected for even a couple of years, it will become as hard as a turnpike road.

The beau idéal of a galloping track is an elastic one, that will neither jar the joints and suspensory ligaments by its hardness, strain the back tendons, or cause a horse to hit himself by its stickiness, like on soft clay, nor shorten the stride and make it dwelling by deadness, like on sand.

A heavy course is particnlarly trying to a horse with oblique, and a hard course to one with upright pasterns. Irregularities on the surface of the ground are a frequent cause of sprain to tendons and ligaments.

A galloping track such as I have mentioned, and $1 \frac{3}{4}$ miles round, will cost about Rs. 400 a year to keep in good going order.

The periphery of a race-course, for big horses, should not be less than $1 \frac{1}{4}$ miles. One of 5 furlongs will do for small ponies.

I may mention that a distance is 240 yards.

On a race-course, where horses are trained, one 
should erect a rubbing-down shed beyond the winning. post and on the inside of the course. These sheds are made of split bamboo and dry thatching grass (Hind. Phoos). A couple of stalls, roofed over in case of rain, with a small enclosure in front to keep off people troubled with curiosity, will cost about Rs. 16. Ghuramee (thatcher) is the name given to the labourers who do this chhuppur work.

'There should be, near each stand, a piece of ground carefully flagged and made level, on which to measure horses.

Race-courses are supposed to be measured on a line 5 feet from the inner edge all round; but practically the best plan is to measure close to the inside, and then add to the length obtained $10 \frac{1}{2}$ yards, under the assumption that the course is a circle, which is near enough for all practical purposes. This mathematical problem I leave to my readers to work out for themselves.

If horses are obliged to be galloped on the outside, on account of the inside being closed, the increased distance, once round, which might require to be done, in the event of a trial, may be readily calculated. For instance, say that the gallop is to be taken 25 feet from the inside, i.e., 20 feet outside the line on which the course was measured, then the increased distance would be four times $10 \frac{1}{2}$ yards, vi ., 42 yards : in fact, we add $10 \frac{1}{2}$ yards to the length of the course, for every 5 feet the galloping track is outside the line on which the course was measured.

A surveyor's large perambulator is more correct and expeditious than the ordinary chain. 
As a rule, courses in the morning give about a couple of seconds slower time for a mile, than they do in the evening.

I believe that the Bangalore course, for $1 \frac{1}{2}$ miles, is about six seconds slower than that of Madras.

The $1 \frac{1}{2}$ miles at Dehra Doon is very little slower than that on an ordinary flat track; but the mile is quite 2 sec. slower.

Races over $\frac{3}{4}$ mile at Lucknow, generally give bad timing, owing to the slight hill, for about half a mile, which leads up to that post.

The Calcutta, Sonepore, and Meerut courses are very fist.

\section{LENGTHS OF INDIAN RACE-COURSES.}

Miles Fur. Yds.

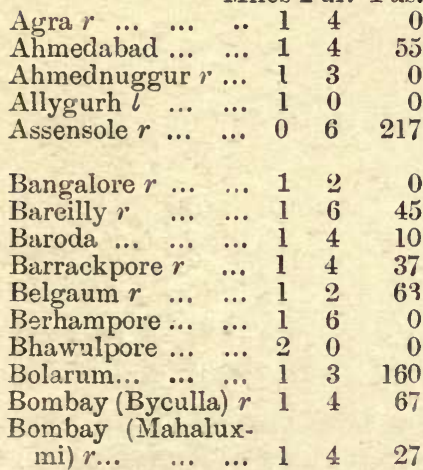

Bowenpilly, $r \quad(3$ miles from Secunderabad, monsoon

$\begin{array}{ccccc}\text { race-course) } & \cdots & \ldots & 1 \\ \text { Burdwan } r & \ldots & \ldots & 1\end{array}$

204

95

$\begin{array}{llllll}\text { Cachar } r & \ldots & \ldots & 0 & 5\end{array}$

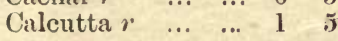
0 36
Miles Fur. Yds. Calcutta St. Leger $r \begin{array}{llll} & 1 & 6 & 132\end{array}$ $\begin{array}{llllll}\text { Cawnpore } l & \ldots & \ldots & 1 & 5 & 148\end{array}$ Chudderghat $r$ (8 miles from Secun$\begin{array}{llllll}\text { derabad) } & \ldots & \ldots & 1 & 3 & 142\end{array}$ $\begin{array}{lllllll}\text { Chupra } r & \ldots & \ldots & 1 & 1 & 4 & 146\end{array}$ $\begin{array}{lllllll}\text { Cuttack } \ldots & \ldots & \ldots & \ldots & 1 & 5 & 83\end{array}$

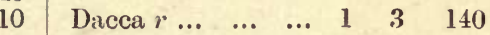

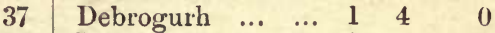

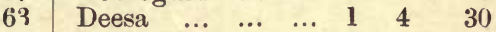

$\begin{array}{llllllll}0 & \text { Dehra } r & \ldots & \ldots & \ldots & 1 & 4 & 192\end{array}$

$\begin{array}{lllllllr}0 & \text { Dharwar } l & \ldots & \ldots & 1 & 1 & 58\end{array}$

$\begin{array}{llllllr}60 & \text { Dinagepore } & \ldots . & \ldots & 0 & 7 & 0\end{array}$

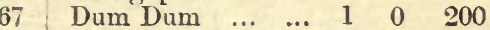
Do. Steeplechase $\quad 2 \quad 1 \quad 80$

Ferozepore $r$... $\quad \ldots \quad 1 \quad 1 \quad 6 \quad 0$

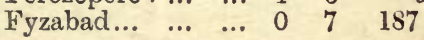

$\begin{array}{lllll}\text { Goruckpore } r & \ldots & 1 & 3 & 99\end{array}$ Hyderabad (Sincl) . $1 \quad 4 \quad 4 \quad 7$

$\begin{array}{lllll}J & J a c o b a b a d \\ r & \ldots & \ldots & 1 & 6\end{array}$ 2. 


\begin{tabular}{|c|c|c|c|c|c|c|c|c|c|c|}
\hline & & Mile & es 1 & ur. & Yds. & & Mil & & & Yds. \\
\hline Jamalpore & $\cdots$ & $\ldots$ & 1 & 0 & 0 & Muttra $\ldots \ldots$ & $\ldots$ & 1 & 4 & 0 \\
\hline Jessore ... & ... & $\ldots$ & 1 & 4 & 11 & Mysore ... ... & ... & 1 & 7 & 110 \\
\hline Jhelum $r$ & $\cdots$ & $\cdots$ & 1 & 2 & 0 & & & & & \\
\hline Jorehaut & ... & ... & 1 & 1 & 125 & Nusseerabad (R & aj- & & & \\
\hline Joudhpore & $\ldots$ & $\ldots$ & 1 & 4 & 98 & pootana) $r \ldots$ & $\ldots$ & 1 & 3 & 45 \\
\hline Jubbulpore $r$ & $\cdots$ & $\cdots$ & l & 0 & 126 & & & & & \\
\hline Jullundur $r$ & $\cdots$ & ... & & & 5 & $\begin{array}{ll}\text { Peshawur } l & \ldots \\
\text { Poona } r & . .\end{array}$ & $\begin{array}{l}\cdots \\
\cdots\end{array}$ & $\begin{array}{l}1 \\
1\end{array}$ & $\begin{array}{l}4 \\
4\end{array}$ & $\begin{array}{r}106 \\
47\end{array}$ \\
\hline Kamptee $r$ & $\cdots$ & $\cdots$ & 1 & 4 & 92 & Purneah ... ... & ... & 1 & 4 & \\
\hline r & & $\cdots$ & & & & Rajkote (Kattyw & ar) & 1 & 3 & \\
\hline Lahore $l \ldots$ & $\cdots$ & $\cdots$ & 1 & 6 & 20 & ore Beaulea & ah $r$ & 1 & $?$ & 0 \\
\hline cknow $l$ & $\cdots$ & $\cdots$ & 1 & 6 & 0 & Rawul Pindee $l$ & $\cdots$ & 1 & 3 & 9 \\
\hline adras $r$ & $\cdots$ & ... & 1 & 4 & 30 & Setapore $l$ & $\ldots$ & 1 & & \\
\hline at $r$ & $\cdots$ & $\cdots$ & 1 & 5 & 89 & Sialkote $r$ & $\ldots$ & 1 & & \\
\hline Mhow $r \ldots$ & $\cdots$ & $\therefore$ & 1 & 4 & 5 & Silligoree $\quad \ldots$ & $\ldots$ & 1 & 0 & 13 \\
\hline Midnapore & $\cdots$ & $\cdots$ & 1 & 1 & 116 & Simla (about) & ... & 0 & 7 & 0 \\
\hline ooltan ... & $\cdots$ & $\cdots$ & 0 & 6 & 134 & Sonepore $r \quad \ldots$ & $\cdots$ & 1 & 4 & 158 \\
\hline $\begin{array}{l}\text { Moiadabad } r \\
\text { Morar }\end{array}$ & $\ldots$ & $\ldots$ & 1 & $\begin{array}{l}4 \\
4\end{array}$ & 118 & Trichinopoly & & 1 & 2 & \\
\hline Mowl Alee & $r$ & $\left(4 \frac{1}{2}\right.$ & & & 10 & 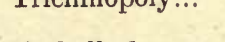 & & & & \\
\hline $\begin{array}{l}\text { miles from } \\
\text { derabad; } H\end{array}$ & $\begin{array}{l}\text { Secu } \\
\text { Hyde }\end{array}$ & & & & & Umballa $l \quad \ldots$ & $\cdots$ & 2 & 1 & \\
\hline $\begin{array}{l}\text { bad races } \\
\text { there) ... }\end{array}$ & s $h$ & & & & & Vizianagram $r$ & $\cdots$ & 1 & 3 & 10 \\
\hline Mozufferpore & $\ddot{e} \ddot{r}$ & $\cdots$ & 1 & $\begin{array}{l}4 \\
3\end{array}$ & $\begin{array}{r}00 \\
202\end{array}$ & Wellington $r$ & $\ldots$ & 0 & 5 & \\
\hline
\end{tabular}

The letters $r$ and $l$ distinguish right and left handed courses.

All large Stands ought to be inclined to the racecourse at an angle of about $30^{\circ}$, so as to enable everyone to have a good view. They ought to face the East, if for evening racing; and the West, if for meetings which are held in the morning, in order that the occupants may not suffer from the glare of the sun. The inclination I have mentioned, is that which has been given to the Cesarewitch Stand at Newmarket, and is the one recommended by my friend Mr. William Manning. 


\section{CHAPTER VIII.}

STEEPLECHASE COURSES.

IN order to fairly test the jumping as well as the galloping capabilities of horses, the fences ought not, on an average, to be further apart from each other than 400 yards. As remarked by that brilliant horseman, Mr. Bertie Short, the first third of the course should consist of broad, low, and somewhat easy obstacles, which would not be liable to bring disaster on the competitors before they had settled down to their work. The fences in the middle third should be such as to thoroughly test the jumping powers of the animals, so that the gallopers may not have it all their own way ; and those in the final third should become gradually more and more easy towards the finish, so that they may not be likely to bring down a tired horse which may happen to chance them a little. I may remark that such an arrangement can seldom be carried out in its entirety; although we may preserve its general character on a more or less circular line of country. Thus, supposing the course is two miles round, we may, to get three miles, make one half easy ; the other, stiff; the first and final miles being over the same ground. The fences should be as long as possible,especially the first and second; as very dangerous accidents are liable to occur, if the horses have not plenty of room when they are excited. After they have once 
settled down, they are not so likely to run out or go crooked as they were at first. Besides this, some are almost certain to "tail off."

On the majority of Indian steeplechase courses the ground for, say, twenty-five yards in front of each obstacle will require to be watered in order to effectually lay the dust; so that the horses behind the leaders may see what they are required to leap. The landing side should be made soft, for about the same distance, so as to save the horses' forelegs, and, also, to take the "bone" out of the ground in case any of the animals fall. The opposite extreme, of making the ground deep and "holding" on landing, should be carefully avoided. Stiff and solid fences, such as walls, should never be placed in a position which will cause their shadow to fall on the taking-off side. In other words, the horse which has to run in the afternoon, should meet no obstacle of this kind, when going in a westerly direction; for if he does so, he will be apt to jump as if the shadow represented a yawning drain, which, in such cases, he probably thinks it is ; and will, then, be liable to strike the fence and come down. The terrible accident which occurred at Dehra Doon to poor Jack Irving, who was one of the best jockeys I have ever seen, and which was ultimately the cause of his death, was caused in this manner. The same rule should be observed with regard to water-jumps; for, as remarked by Mr. Short, "the sun shining from the front on water is very dazzling to horses coming up fast."

The following are the usual kinds of fences met with on Indian steeplechase courses :- 
1. Hurdles, $3 \mathrm{ft}$. 6 in. high, and bushed with brushwood.

2. Bush fences, $3 \mathrm{ft}$. to $4 \mathrm{ft}$., and $8 \mathrm{ft}$. or $10 \mathrm{ft}$. broad at the base. Care should be taken that the material used does not contain long, sharp-pointed thorns, which often inflict severe injuries on the legs of horses that may happen to chance such obstacles.

3. Hedges, from $3 \mathrm{ft}$. to $4 \mathrm{ft}$. high. Quick-set hedges, which form the majority of the jumps on the Aintree course, over which the race for the Grand National is run, are seldom met with in India except at Dehra Doon, where they consist of rose bushes. I may remark that a weak hedge should never be stiffened by a rail, unless the wooden bar is placed in such a manner that the horse cannot help seeing it. Neglect of this precaution was the cause of the death at Liverpool of the famous gentleman rider "Mr. Edwards" (poor George Ede).

4. Walls. They are usually made of mud; and, if I may form an opinion, should not exceed $3 \mathrm{ft}$. 9 in. in height, if upright. The great fault made about mud walls in India is that they are often left in their ordinary brown condition, in which case they do not always stand out sufficiently sharply from their dingy surroundings to enable a horse coming at them to accurately measure his distance. At least, on the taking-off side, they should, if possible, be turfed over (with roots of doob or hurryalee), and kept watered for several days previously. We must remember that the afternoon glare on an Indian race-course; is often very deceiving to a horse's eyes. The wall, on the takingoff side, should have a slight slope, say ${ }_{1}^{3}$; in which 
case the wall may be made $4 \mathrm{ft}$. high as a maximum. Such a wall is quite formidable enough without having any drain in front of it. An obstacle like this should on no account be topped with brushwood or other covering ; for if this be done the horse will be very liable to chance the fence on account of the false impression its appearance is likely to give him. I have seen most regrettable accidents occur from horses being thus culpably misled by constructors of steeplechase courses. The stiffer a jump looks, the more likely is the animal to be careful when negotiating it.

5. Posts and rails, which may be made $3 \mathrm{ft} .6$ in. high. I have always insisted that the top bar should be made very thick, so as to plainly show the horses that they cannot chance it successfully. I think it is best to leave the post and rails unbushed.

The water-jump may be about $13 \mathrm{ft}$. broad, and may have a small hedge or bushed fence about $2 \mathrm{ft}$. high in front of it. It need not be more than $2 \mathrm{ft}$. deep. Its far side should slope up at an angle of about thirty degrees. Long ago, water-jumps with straight cut sides used to be a prolific cause of broken backs among steeplechase horses.

It frequently happens that, on filling an artificial water-jump, the water soaks through the soil, and renders the landing so soft, that a horse jumping on to it, at speed, would, probably, come down. Such a contingency may be obviated by putting down a few rows of kurbee or reeds, and covering them over with earth, so as to form a firm place for the horse to alight on.

7. An Irish bank, which may be $3 \mathrm{ft}$. 6 in. high, $6 \mathrm{ft}$. broad on the top, and may have sides sloping down at 
an angle of about forty-five degrees, with ditches of about $3 \mathrm{ft}$. broad on each side. If possible, this bank should be turfed over, as before described.

8. An in-and-out, or lane, which consists of two fences (hedges or walls) placed about $30 \mathrm{ft}$. apart.

The character of hedges, bush fences, or walls, may be varied by placing ditches on either side of them. Such a ditch should not be more than $4 \mathrm{ft}$. broad and about $2 \mathrm{ft}$. deep. When it is placed on the near side of the fence, it is advisable to make the ground, for, say, the last couple of feet, slope slightly up to the edge of the drain; so as to show the horse what he has to expect. In England, ditches have usually their sides more or less raised, on account of a portion of the mud, etc., when they are cleaned out from time to time, being thrown up on the edge of the drain.

The following might be taken as a fair average line of country for a $3 \frac{1}{2}$ miles steeplechase.

1. Flight of hurdles.

2. A broad bush fence, which may be safely chanced.

3. A hedge.

4. Water-jump.

5. Posts and rails.

6. Sloping wall, $4 \mathrm{ft}$. high.

7. Wall $3 \mathrm{ft.} 6 \mathrm{in}$. high, with a ditch in front of it.

8. An Irish bank.

9. An in-and-out, consisting of a wall $3 \mathrm{ft}$. high, with some brushwood on the top, and a $4 \mathrm{ft}$. drain in front of it. The second fence may be a hedge.

10. A wall $3 \mathrm{ft}$. high, with brushwood on the top.

11. Hedge with ditch on far side.

12 and 13. Hedges. 


\section{Flight of hurdles.}

The "run-in" may be about 500 yards long.

I may remark, that it is very inadvisable to start horses at a considerable distance from the first jump; for, by the time they will then arrive at it, they will, probably, be racing against each other, and will consequently take far longer to settle down to their work, than they would do were they started, say, 150 yards from the obstacle.

Stewards of a meeting at which steeplechases are run should be most particular to have the jumping events decided while there is plenty of daylight. 


\title{
CHAPTER IX.
}

\author{
BETTING.
}

PRINCIPLES OF BETTING AND BOOKMAKING-LOTTERIES-PARI ITTCELS AND TOTALISATORS-RACE POOLS.

Principles of betting and bookmaking.-The "odds" against an event occurring is the ratio which the number of the unfavourable ways the event may happen, bear to the favourable ones. Thus, it is 5 to 1 against any particular number (from 1 to 6 inclusive) being thrown with a single die, which, I need hardly say, has six faces. Regarding certainty as unity, we may represent the chance of an event occurring as a vulgar fraction, of which the-numerator is the favourable way or ways, and the denominator, the sum of all the ways, both favourable and unfavourable. Hence, in the case just cited, the chance of any particular number being thrown, is $\frac{1}{6}$.

Although the sum of the chances of any undecided event is, when correctly calculated, equal to unity, that of "price list" chances are larger; the difference between it and unity being the theoretical profit to the bookmaker. Thus, to take the following two lists :-
(1) 3 to 2 on $\mathrm{A}$.
(2) evens $X$.
3 to 1 against $\mathrm{B}$.
2 to 1 against $Y$.
3 to 1 against $\mathrm{C}$.
3 to 1 against $Z$. 
The sum of the list chances would be $\frac{1}{1} \frac{1}{0}$ for (1) and $\frac{13}{12}$ for (2); and consequently it would be possible to make a profit on a "book" with either of these lists. As I am not at present concerned with the actual practice of betting, I need not discuss such questions as to the probability of the "fielder" "getting round."

For (1) list of prices just quoted, the following would be a "round" book -

50 to 75 against A (2 to 3 against).
100 to 33 " B (3 to $1 \quad, \quad)$.
100 to 33 C (3 to $1 \quad, \quad)$.

If A won, the "bookie" would win $66-50=16$; if $\mathrm{B}$, $108-100=8$; and if $\mathrm{C}, 108-100=8$.

And for "list" (2):

75 to 75 against $X$ (evens).
100 to 50 " Y (2 to 1 against).
100 to 33 ", Z (3 to $1,, \quad)$.

In this case, if $\mathrm{X}$ won, he would gain $83-75=8$; if $\mathrm{Y}, 108-100=8$; and if $\mathrm{Z}, 125-100=25$.

The odds of one horse against another in the same race is the proportion which their respective chances bear to each other. Thus, if $\mathrm{A}$ be at even money ( $\frac{1}{2}$ chance) and $B$ at 2 to 1 ( $\frac{1}{3}$ chance), the correct betting on $\mathrm{A}$ against $\mathrm{B}$ (one to win) would be 3 to 2.

The combined odds of two or more horses in the same race is obtained by taking their combined chances. For example, if $\mathrm{A}$ was a 5 to 4 on, B 8 to 1 against, and C 17 to 1 against, their combined chance theoretically would be $\frac{5}{9}+\frac{1}{9}+\frac{1}{18}=\frac{13}{18}$; and then their combined odds, 13 to 5 on. 
$A$ double event bet is, also, calculated by taking the chances, which in this case are multiplied together. Thus, if it be 3 to 2 in favour of a certain occurrence taking place, and 10 to 1 against another event occurring, the chance of their both happening will be $\frac{3}{5} \times \frac{1}{11}=\frac{3}{55}$; and the odds 52 to 3 , or $17 \frac{1}{3}$ to 1 against it.

Lotteries.-In lotteries the number of tickets and their prices vary; although at the principal meetings they are generally fixed at a 100 , and Rs. 10 respectively.

The honorary secretary, or some other official, should, first of all, write down the tickets taken by single individuals, and then those taken conjointly; the practice being to throw with dice for tickets, for which the loser pays, although both he and the winner equally share the amount obtained for the chance of any horse which any of their tickets may draw. Not until all the tickets which can be disposed, either individually or conjointly, are written down, should sweeps be allowed to take place; for they always tend to check the other forms of ticket-taking.

A lottery may be made out on a large sheet of foolscap, on the first and second pages of which the tickets are written down. At the end of the second page there is a form for recording the result of the drawing; and on the third page one for showing the debit and credit of each person.

I shall now give an illustrative lottery paper for a race, in which we may assume that 5 horses, viz., Mr. Johnson's Sam, Mr. Williams' Jack, Mr. Payne's Lucy, Mr. Thompson's Ruby, and Mr. Smith's Brilliant, are declared to start, that there are 50 tickets at Rs. 10 each, and that Lucy won. From the total amount of 
the lottery, 5 per cent. is deducted for the benefit of the Race Fund.

Bombay Races, 189 -.

LOTTERY ON THE DERBY.

PRICE OF TICKETS, Rs. 10.

\begin{tabular}{|c|c|c|c|}
\hline No. & Names. & No. & Names. \\
\hline $\begin{array}{r}1 \\
2 \\
3 \\
4 \\
5 \\
6 \\
7 \\
8 \\
9 \\
10 \\
11 \\
12 \\
13 \\
14 \\
15 \\
16 \\
17 \\
18 \\
19 \\
20 \\
21 \\
22 \\
23 \\
24 \\
25\end{array}$ & 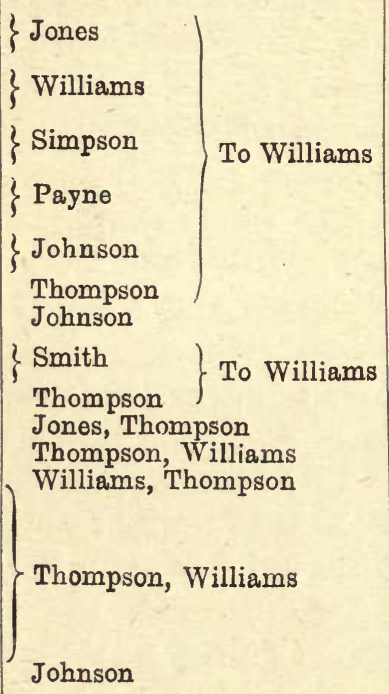 & $\begin{array}{l}26 \\
27 \\
28 \\
29 \\
30 \\
31 \\
32 \\
33 \\
34 \\
35 \\
36 \\
37 \\
38 \\
39 \\
40 \\
41 \\
42 \\
43 \\
44 \\
45 \\
46 \\
47 \\
48 \\
49 \\
50\end{array}$ & $\begin{array}{l}\text { Thompson, Jones } \\
\text { Smith, Thompson } \\
\text { Williams } \\
\text { Simpson, Williams } \\
\text { Thompson, Smith } \\
\text { Thompson, Williams } \\
\text { Williams, Thompson } \\
\text { Thompson, Smith }\end{array}$ \\
\hline
\end{tabular}

This form usually occupies the first and part of the second pages of the lottery paper. 
RESULT OF DRAWING.

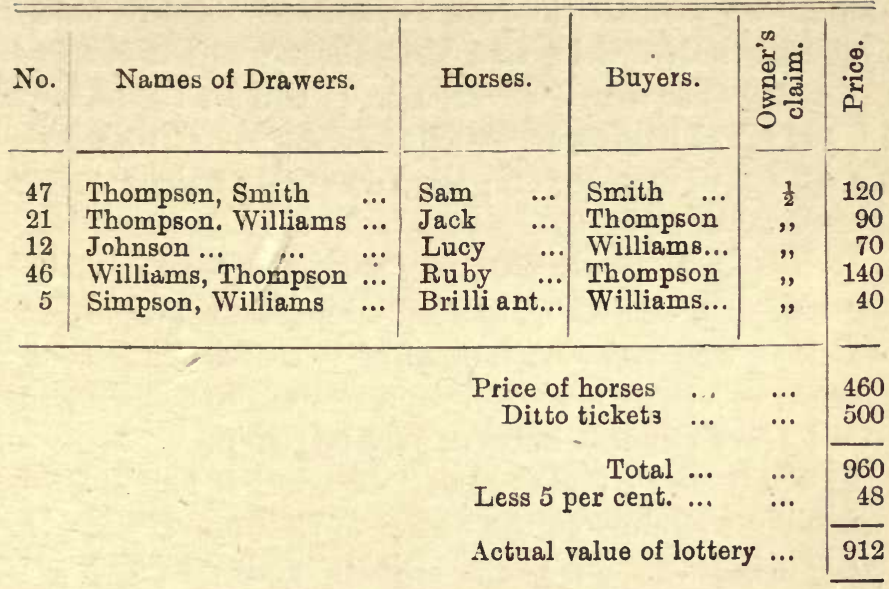

The above form should be at the end of the list of tickets. It is generally at the bottom of the second page.

\section{DEBITS AND CREDITS.}

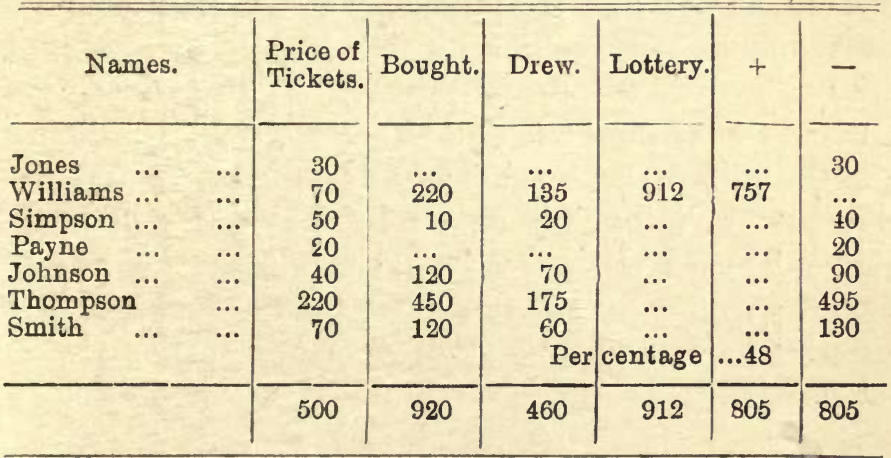

The above form is usually drawn out on the third page of the lottery paper. 
On the lottery paper which I have given as an illustration, we see that the Nos. 12,25 , and 36 were taken by single individuals, and that there was a sweep of two tickets per man for Nos. 1 to 11 and for 13, 14, and 15, the break having occurred by Johnson having taken No. 12 on first going off; the remaining tickets being taken conjointly.

By the C. T. C. Rules, an owner is entitled to claim one-half of his horse's chance (taking that proportion of risk as well as gain) immediately on its being sold. The owner's share is the only one allowed to be recorded on a lottery paper, whatever part be taken.

In the "Debits and Credits" we see that half of Sam is debited to Johnson, the owner of that horse.

By using the form of "Debits and Credits" we ensure correctness, which is proved, firstly, by the addition of the column under "Price of tickets" amounting to their gross value, and secondly, by the total sum under column "Bought" being exactly double that under "Drew"; for the purchaser of a horse's chance pays double the amount he is sold for, first to the drawer, and then into the lottery. The final step in proving the accounts, is to see that the total winnings, plus the percentage, is equal to the total losings. When this system is employed, a form like the following should be used to show the total debits and credits on each day's racing. I here assume that there were four lotteries held, and that twelve persons took part in them. 
Account of Lotteries held on 1st Day's Racing.

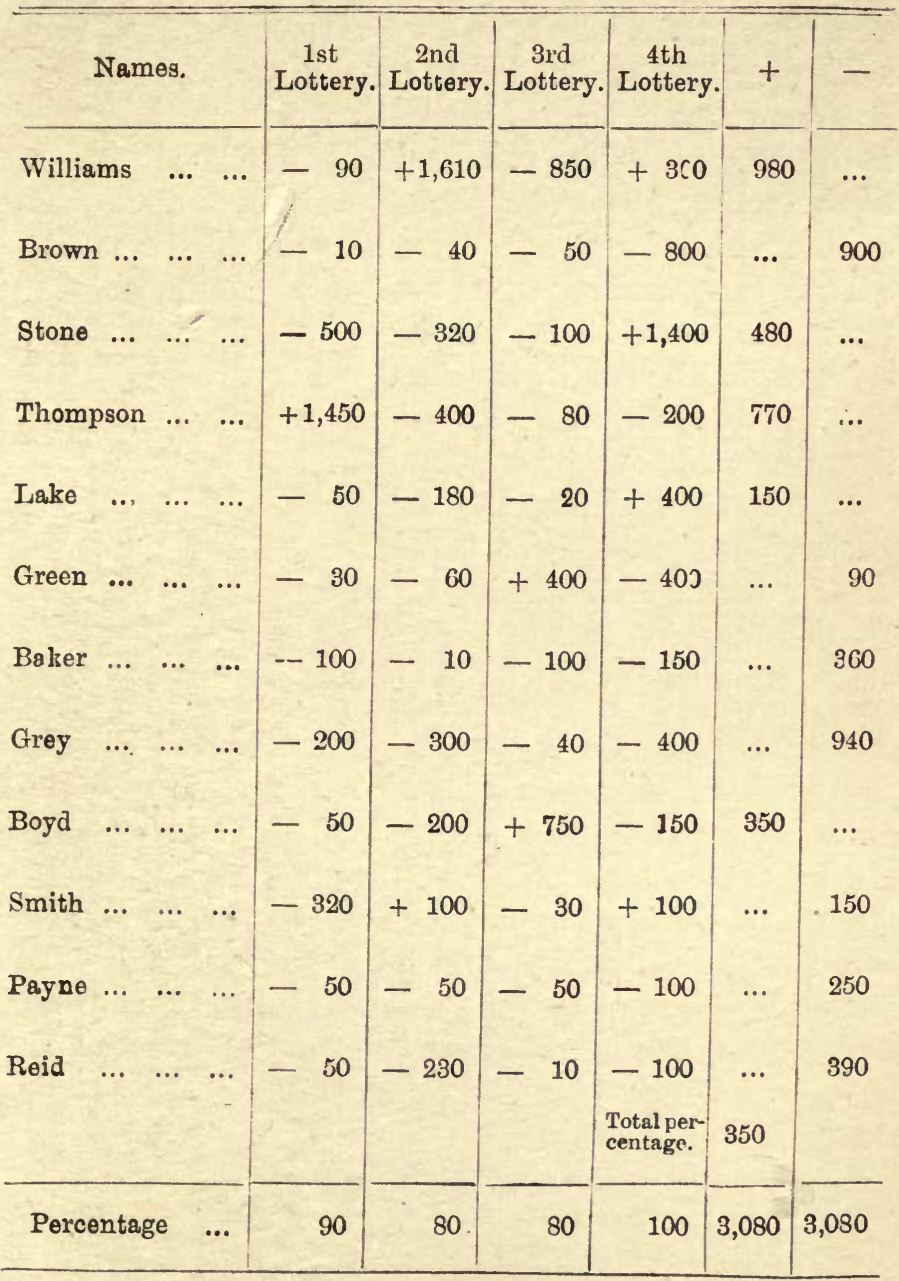


Nothing can be less liable to error than the system which I have described. Correctness is a most valuable quality when a mass of accounts has to be got through in a short time, which is always the case at a race meeting. This system's only fault is that, at a settling, if persons are not acquainted with its working, reference to the different debits and credits of individuals cannot be so readily made, and explanation given, as by another system which I shall now describe, and which is so selfevident in its working that I need only give the form for the accounts of each day's racing. Its only fault is that error cannot be readily checked. To save room, I shall give the form for only four lotteries; though of course it can be made out for any number.

In lottery accounts, the debits consist of price of tickets and purchase of horses; the credits, that of horses drawn, and lotteries or parts of lotteries won. By the following system (see next page) these items are arranged in the most simple manner for reference and computation :- 


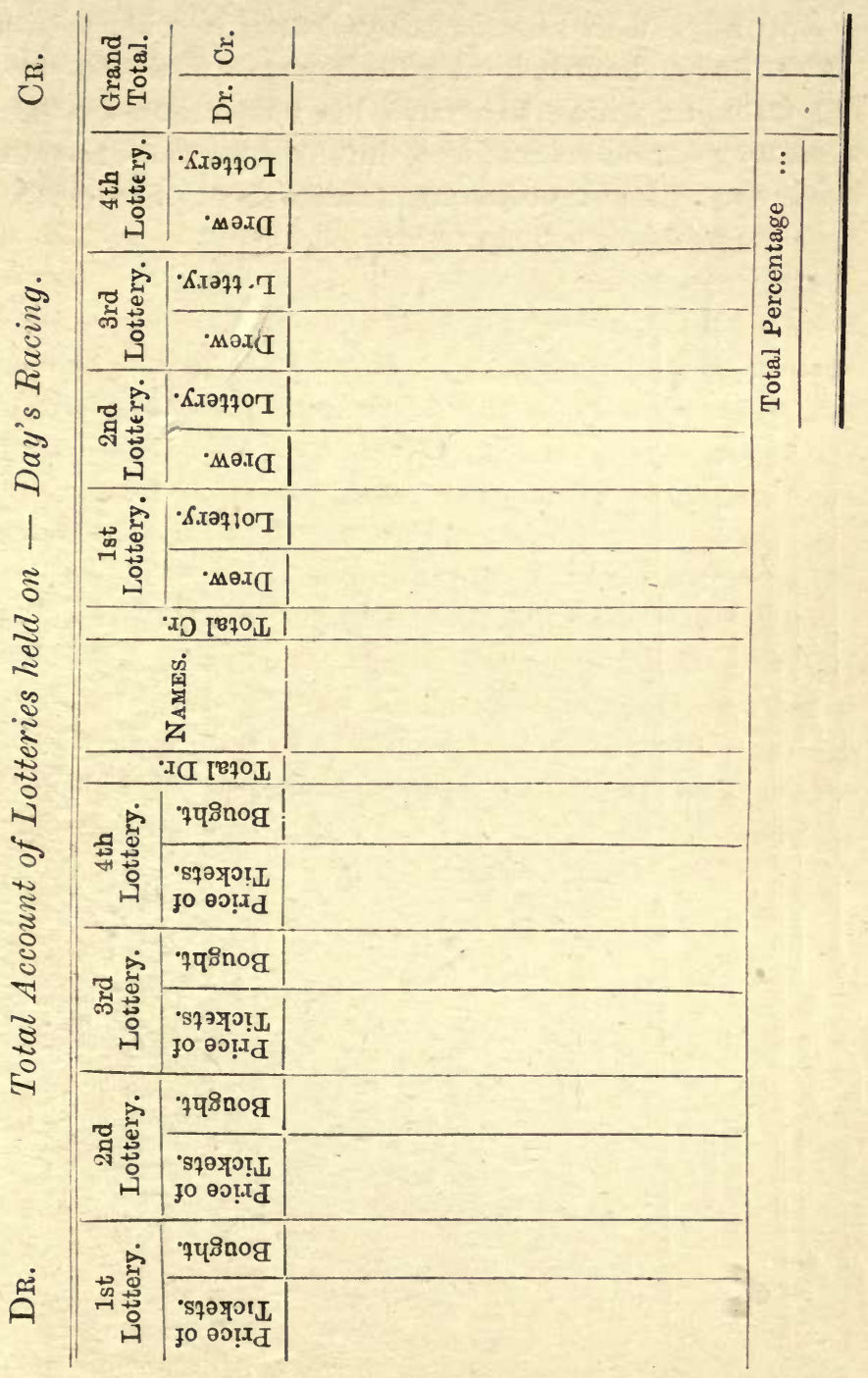


An owner who attends many Jotteries will find it convenient to have a lottery book, made in the following form, in which to record his transactions. The book may contain a couple of hundred pages, each one being about the size of a quarter of a sheet of foolscap.

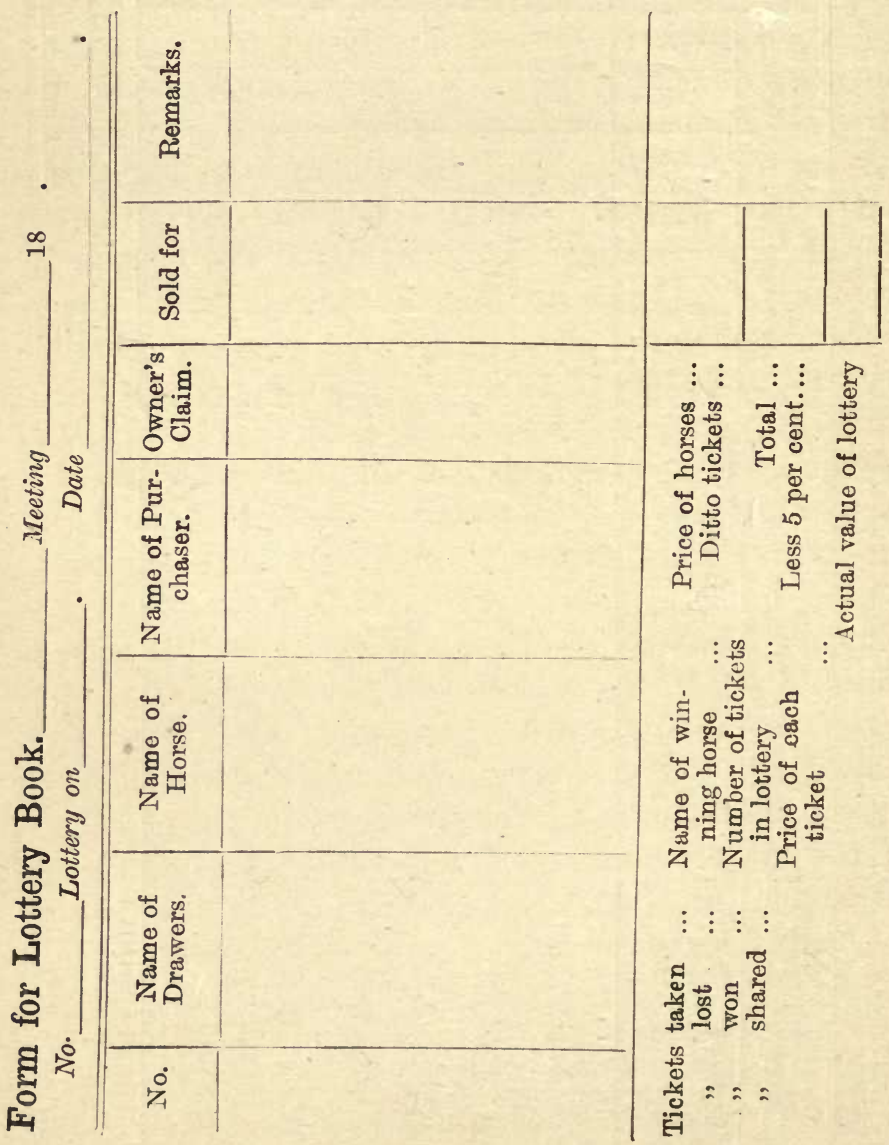


Formerly, the ledger system was in general use for keeping lottery accounts. It consisted of entering each person's name, who took part in the lotteries, in a ledger, giving one page to his debits, and the other to his credits. It is far too tedious; and by it accounts cannot be made up in sufficient time to allow of a settling immediately after a meeting is over. Every Honorary Secretary knows, if this be not done, how extremely difficult it is to subsequently square accounts satisfactorily. Among the residents of a station this remark does not apply; but at a large meeting, where the bulk of the plungers are here to-day and gone tomorrow, it is essential that everything should be settled as quickly as possible; for absentees find it hard to believe that they have won so little, or lost so much.

The lottery odds against a horse will be: Price of tickets + price of all the horses - discount - double price of the one particular horse, to that double price.

Thus, in the case we have already given, the odds against Jack are $500+460-48-180$ to 180 , viz., 732 to 180 , or about 4 to 1 .

Suppose, by a private arrangement the buyer of Lucy, who won the race, had given away one-fourth of her, then the quarter winnings would be thus calculated :-

Actual value of lottery $\quad \ldots \quad$... 912

Lucy's double price ... ... ... 140

4) 772

One-fourth share of winnings $\quad$.. 193 
Double lotteries are generally resorted to, when, from a paucity of horses in two races, speculation on either, separately, is checked. The chances of all the horses are then combined together, and the buyer of the chance which contained the names of the winners of both events takes the lottery. Let us suppose that two races-the Planter's Cup and Selling Stakes-had each three entries as follows:-

Planter's Cup.

Kingeraft.

Exeter.

Chorister.
Selling Stakes.

Lurline.

Butterfly.

Brandy.

The combined chances would then be :-

1. Kingeraft and Lurline.

2. Kingeraft and Butterfly.

3. Kingeraft and Brandy.

4. Exeter and Lurline.

5. Exeter and Butterfly.
6. Exeter and Brandy.

7. Chorister and Lurline.

8. Chorister and Butterfly

9. Chorister and Brandy.

These nine chances will be drawn for, and auctioned off, in the same manner as if they represented nine different horses entered for one particular race.

Pari Mutuels and totalisators.-The primitive way for arranging pari mutuels is as follows:-Near the Race Stand is fixed a long box divided into partitions, each of which has a slit like those in letter-boxes. On each partition is written the name of a race, in the order they are to be run. The person managing the Pari Mutuel is provided with cards printed in the following form :- 
MEERUT AUTUMN MEETING, 189-.

Tickets, Rs. 5 .

Name of race

Horse backed

No. of tickets

Signature of backer

Having received a card, the intending backer fills in according to his fancy, and places it, through the slit, into the partition set apart for the race on which he wishes to invest. This partition is closed on the horses arriving at the starting-post, after which no more cards can be put in. When the day's racing is finished, the amount invested on the losers in each event is divided among those who backed the winners of those respective races, after deducting a percentage, usually 10 per cent., for the benefit of the Race Fund. Let us assume that in one of the races the winner was backed by $\mathrm{A}$ for Rs. 10, by B for Rs. 5, and by C for Rs. 15, and that the other horses in the same race had been backed for Rs. 170. The total here would be Rs. 200, from which to calculate a percentage of Rs. 20 at 10 per cent. Deducting this Rs. 20 from Rs. 150 (amount lost), would leave Rs. 150 to be divided between A, B, and C, and they would get respectively Rs. 50, Rs, 25, and Rs. 75 . 
The totalisator is an instrument by which the operator can record, for public view, the number of tickets taken on each horse; the total number being automatically shown. The tickets bear the number of the horse and the name of the race, so that all the backer has to do is to pay his money and take his ticket. Every machine should be in electrical communication with the judge or other official, who should be able to effectively lock it the moment the starter's flag falls. Having frequently seen the ordinary form of machine " manipulated," I must say that I prefer to it the kind used in South Africa. In it a book of tickets (somewhat like a cheque book), numbered in succession, is placed before each number. The tickets on being purchased, are torn out of these books in the sight of all men, and given to the buyers. The public can thus see whether or not anyone attempts to take tickets after the race, and the numbers taken remain on record until all the winners are paid.

Race Pools may be got up by any number of persons who bid for choice of horses entered for a race, the buyer of the winner of which takes the several amounts bid for the other horses. Say, for instance, that the horses Lancer, Gaylad, Breeze, and Phantom were entered for a certain race; the auctioneer would then ask, "How much for first choice?" Suppose A bid Rs. 50, B bid Rs. 70, and D finally got it for Rs. 500: $\mathrm{D}$ would then have the choice of any one of the four horses. Let us say that he took Gaylad. The second choice for Lancer, Breeze, and Phantom would, in the same manner, be put up to auction: and suppose A got it for Rs. 400 and took Lancer; also that B got 
Breeze for Rs. 80, and that C bought Phantom for Rs. 120, the pool would thus stand:-

$\begin{array}{lllllll}\text { D pays for Gaylad } & \ldots & \ldots & \ldots & \ldots & \text { Rs. } & 500\end{array}$

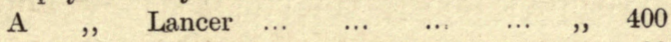

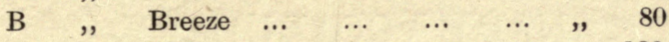

$\begin{array}{lllllll}\text { C } & \text { " Phantom } & \ldots & \ldots & \ldots & \text {, } & 120\end{array}$

If Gayland wins, D will win $\quad \ldots \quad \ldots \quad, \quad 600$

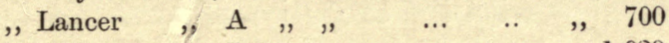

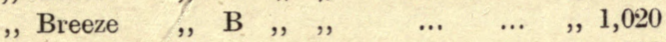

"Phantom ", C , , , $\quad \ldots \quad \ldots \quad$, 


\section{HINDUSTANEE STABLE AND VETERI- NARY VOCABULARY.}

THE following, with the exception of names of diseases, colours, and some technical expressions, are words which any syce will understand and which are in common use in the stable. In order to render the pronunciation easy to those unacquainted with the language, I have written the vowels as they are pronounced in the following words:-

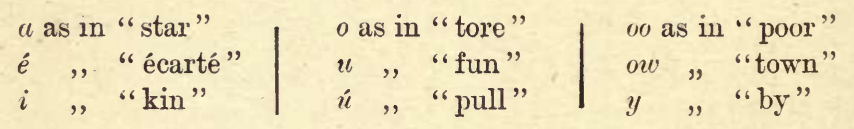

n should be pronounced like the French nasal n, as in "mon." The Hindee letters $t$, d, and $\mathrm{r}$ are pronounced hard as in English, and the th, dh, and rh like what these letters would sound if aspirated; $\mathrm{kh}$ and gh stand for these two guttural letters in Arabic.

\section{PARTS, ETC., OF THE HORSE.}

Abdomen, Pét.

Acid, n., 'Tézab.

Aconite (A. ferox), Mahoor.

$\Lambda$ ged (horses ten years old and

upwards), Mulé punj.

Aloes, Músubbur; élwa.

Alum, Phitkurree.

Amble, to, Ruhwar chulna.

Anasarca, Tubuk.

Anise-seed, Sownf.

Antimony, black, Súrma.

Anvil, blacksmith's, Nihai.

S̈undan.
Aphthæ, Unchluer.

Arab horse, Tazee, or urubee ghora.

Areca-nut, Súparee.

Arsenic, red, Mynsil.

" white, Sunkheea.

Artery, Shiryan.

yellow, Hurtal.

Asafoetida, Heeng.

Asthma, Duma.

Axletree, Dhúree.

Back, Peeth.

Backband, Barkush. 
Backbone, Reerh.

Back tendon, Ghúr-nuss.

Bag (for grain, etc.), Bora.

Ball (physic), Duwa kee golee.

Balling iron, Daroo-kush.

Bandage, Puttee.

, (wet), Pochura.

Barbs, or paps, Unchtur.

Barley, Jouv.

Bars (of the hoof), Dohree-pútlee.

Bar-shoe, Gol-nal.

Bay, Kúmyt.

, with legs which are black up to the knees, Seeah zanoo kúmyt.

, with belly and inside of legs light coloured, Kéhur.

Beans, Sém.

Bearing rein, Gol bay.

Bedding (straw), Bichalee.

Belly, Pét.

Belly band, Pétee.

Bile, Pitta.

Bit (curb), Duhana.

Bite, to, Katna.

Biter (a horse), Kuttur.

Black, Múshkee; kala.

Bladder, Phúknee.

Blanket, Kummul.

Bleed, to, Fusd kholna.

Blind, Andha.

,' of one eye, Kana.

Blinkers, Putta.

Blister, Chhala.

Blood, Khoon.

Blue stone, Neela tooteea.

Bobtailed horse, Bunda, or lundoora ghora.

Body (of a carriage), Howda.

Body piece(clothing), Gurdunnee

Boil, n., Phora.

Bolt, to (off the course), Phutjana.

Bone, Huddee.

Borax, Sohaga.

Bots (eggs), Leek.

," (larva), Bur.

Brain, Mughz; bhéja.
Bran, Chokur.

Breast-piece, Chhatee bund.

Breast-plate, Pésh.bund.

Breechen, Púshtung.

Breeding district, Khét.

Bridle, Lugum.

Brittle feet, Súmkhara.

Bronchitis, $K u f$.

Brook (steeplechase), Nala.

Broom, Jharoo.

Brow-band, Kun-sirra.

Brown, or dark bay, Téleeya lúmyt; lukhowree kúmyt. Natives call light brown, kumyt (bay), and dark brown, méshkee (black).

Bruise, n., Chot.

Brush, n., Koochee.

," to, Néwur lugna.

Buck, to, Kandhee murna.

Bucket, Baltee.

Buckle, Buksooa.

Butteris (shoeing), Súm turash.

Calkin, Khoonta.

Camphor, Kafoor.

Canker of the foot, Kufgeera.

Cannon bone, Nullee.

Canter, to, Poya chulna.

Capped elbow, Kheesa.

," hock, Kühneed.

,, knee, Zanooc.

Caraway seeds, Ajwyn.

Carbonate of solla, Kharsujec.

Carrots, Gajur.

Cartilage, Kurree leuddee

Caster (horse), Nuzuree ghora.

Castor oil; Réndee ka tél.

Cataract, Moteea-bind.

Catarrh, Zukam; surdhee.

Catechu, Kuth.

Caustic, Tooteea.

Chaff, Bhoosa.

Chalk, Khuree mittee.

Chamois leather, Sabur.

Cheek, Gal.

Chest, Chhatee; seena. 
Chestnut (all over), Surung.

, with dark mane and tail, Kúmyt. dark, Mowha súrung.

, with light mane and tail, Chowdur Súrung.

Chisel, cold, Chhénee.

Clean, Saf.

Cleft of the frog, Putlee kice ghaee.

Clench of a nail, Príchee. , to (a nail), Mékh ko puchee kurna.

Clip (of a shoe), Thokur; killif.

Clothing, light, Thunda kupra.

," warm, Gurm kupra.

Clyster pipe, Pichlaree.

Cold (adj.), Thunda.

Coldin the head, Zukam; surdhee.

Cold chisel, Chhénee.

Colic, Kúrkúree.

Collar (harness), Hulka.

Colours, racing, Ghurdowree Kupra.

Colt, Buchhéra.

Comb, Kunghee.

Condiment, Musula.

Constipation, $K u b z$.

Consumption, Khushlibél.

Copper, acetate of, Jungal.

Corn (injury to foot), Chhala.

Corn (grain), Dana.

Corners of the mouth, Buchh.

Coronet, Bhown, ur súm kee mughzee.

Corrosive sublimate, Ruskapoor.

Cough, Khansee.

Country-bred horse, Désee ghora

Cowdung, Gobur.

Cowkick, to, Kainchee marna

Cracked heels, Chheewur.

Cream-coloured (horse), Doodheeya shirgha.

Crib-biter, Howapeené-wala.

Croton bean, Jumalgota.

oil, Jumalgoté lia tel.

Crupper, Dúmchee.
Crust of the hoof, Shakh.

Curb (a bit), Duhana.

Curb (an injury), Bujr huddee.

Curb-chain, Duhané liee zunjeer.

Currycomb, Khurara.

Cyst, Jowa.

Dandriff, Roosee.

Defect (in a horse), $A y b$.

Diarrhoea, Dust.

Digest, to (food), Huzm kurna.

Dirty, Mylc.

Dismount, to, Uturna.

Ditch, Khaee.

Dock (under the tail), Sughiree.

Door, Durwaza.

Double bank (steeplechase), Dum duma.

Drench, to, Duwa pilana..

Drink, to, Peena.

Drive, to, Hankna.

Dropped hip, Kum koola.

Dropsy, Tubuk.

Dull, to be, Sust hona.

Dun, light, all over, Shirgha.

,, with dark mane and tail, summund.

, with black stripe down the back, Sélee summund.

,, with dark points and black horizontal stripes on forearms, Kúla.

,, with zebra marks, Kéhuree Kúla.

,, with legs black up to the knees, Seeah zanoo summurd. Dung, Leed.

Dysentery, Péchish; Khoonee dust.

Ear, Kan.

Eat, to, Khana.

Elbow, Aglee Kohnee.

Elephantiasis, Feel-pa.

English horse, Bilayutee ghora.

Enteritis, Boghma.

Entire (as a horse), Andoo. 
Epilepsy, Mirgee.

Eye, $A$ n $k h$.

Eyelash, Buronee.

Eyelid, Puluk.

Farcy, Bél.

Farrier, Saloturee.

Fast (swift), 'T'́z.

Fat, n., Churbee.

, adj., Mota; furba.

Feather in the hair, Bhounree

Feeder, a bad, Kum khor.

Felloe, Putee.

Fetlock, Múttha.

Fever, Tup; búkhar.

Fibre (of muscle, etc.), Résh $\alpha$

Fill, to (as a leg), Py ajana.

Filly, Buchhéree.

Fire, n., $A g$.

,, to, Daghna.

Fistula, Nasoor.

Fit (in training), Taiyar.

Five year old, Punjsala.

Flank, Kohk.

Flat (race), Sufjart.

Flat-feet, Chúpatee súm.

Flatulency, Badee.

Fleam, Nushtur.

Flour (coarse), Ata.

", (fine), Mydu.

", (very fine), Soojee.

Foal of one month, Kurra.

," of four months, Sinaya.

", of eight months, Wastat.

, to be in, Gabhin.

Foam from the mouth, $K u f$.

Foment, Sénlina.

Foot, Pyr.

Foot and mouth disease, Kúrpuka; khuirha.

Foot-board, Paondan.

Forage, Chara.

,, daily allowance of, Ratib.

Forearm, Bazoo; dund.

Forehead, Matha; péshanee.

Fore-leg, Hath.

Fore-lock, Chotee.
Forge, Mistree-khana.

Four year old, Charsala.

Frog, Pútlee.

Fullering (of a shoe), Punalee.

Gallop, to, Dowrna; surput phénkna.

Garron, Dugga.

Geld, to, Akhta kurna.

Gelding, Akbta.

Ginger (dry), Sonth.

Girth, Tung.

(green), Udruk.

Girth-gall, Zér tung zukhm.

Girth-tug, Chheep.

Glanders, Khunak; seembha.

Gloves of hair for grooming, Huthee.

Go-down (of water, etc.), Ghoont. Goose-rumped, Tubur goon.

Gram, Chuna.

(Madras), Kúlthee.

Granulate, to, Angoor bhurna.

Granulations, Angoor.

Grass, Ghas.

Grass-cutter, Ghuseeara.

Grass lands (preserved), Rukh.

Graze, to, Churna.

," to send to, Churana.

Grey or white, with dark mane and tail, Subza.

" flea-bitten, Mugsee.

„ dappled, Gúldar subza.

" iron, Neela subza.

" nutmeg, Lal subza.

Grey, with skin black and white in patches, Sunjaf.

Grind coarsely, to, Dulna.

, finely, to, Peesna.

Groom, Saees. to, Malish kurnu.

Gullet, Hulk. This word is, also, applied to the windpipe.

Gums, Musooré.

Hair (of the mane and tail), Bal. ", (of the body), Roan; rom. 
Half-bred (horse), Doghla.

Halter, Núkta.

Hames, Huslée.

Hammer, shoeing smith's, Huthowree.

Handful (double), Unjul. (single), Mútthee.

Hand-rub, to, Hath sé mulna. Hard-mouthed (horse), Moohzor. Harness, Saz.

" (d) uble), Joree ku saz.

" (single), Ekla saz.

" (tandem), Agul pichul saz.

Haw (of the eye), Butana.

Head, Sir.

Head-collar, Núkta.

Head-groom, Jumudar saees.

Head-rope, Agaree.

Head-stall (of a bridle), Sirduwalee.

Heart, Dit.

Hedge, Bar.

Heel (of the hoof), Khoontee.

Heel-rope, Pichliaree.

Hidebound, Chirm khúshk.

High-couraged, Jan baz.

Hill pony, 'Tanghun.

Hind leg, Paon.

Hind quarters, Putha.

Hip, Koola.

Hobbles, casting, Gr̆hur puchluar; lungur.

" (for the hind legs),

Hock, Koonch. Mújuma.

Hoe, Phurwa.

Hole (of stirrup leather), Ghur. Hollow-backed horse, Kíuchiee, or zeen púsht ghora.

Holsters, líuboor.

Honey, Shuhud.

Hood (clothing), Kunsilla.

Hoof, Suim.

Hoof ointment, Sim roghun.

Horse, Ghora.
Horse with four white stockings and blaze, Puchkuleeyan.

Horse, to ("to come in season"), Gurm hojana; bégluna; alung hona.

Horse-fly, Dans.

Hot, Gurm.

Hoven, Badee.

Hurdle, Phoos kee tuttee.

Indian hemp (dried flowers), Ganja.

(leaves), Bhung; subzee.

(resin), Churus.

Indigestion, Bud-huzmee.

Inflar mation, Julun; sozish.
,

"

9 of the feet, Sum ka tup. of the liver, Kuléjé liee beemaree. of the lungs, Phephré kee beemaree.

Intestines, Ant, unturee.

Iron, sulphate of, Huree kusees.

Jade (horse), Kluullur.

Jaundice, Y urkan; kunvulbad

Jaw, Jubra.

Jib, to, Urh-jana.

Jockey, Coachwan.

Joint, Jor, ganth, giru.

Jump, to, kooduce; phanduce.

Keeper (on reins), Muchllee.

Kerosine oil, Mittee ki tél.

Kick, to, P'ishituk marna; lat chulana.

Kick, to (with both feet at once), Dúluttee marna.

Kicker, Luttur.

Kidney, Gúrda.

Knee, Ghútua; zanoo.

Knife, Chhiree.

Lame, Lungra. 
Iame chronically, Kühna lung.

Laminitis, Súm ka tup.

Lampas, I'alooa.

Lard, Soour liee churbee.

Lead a horse, to, Tililume.

Leading rein, Baydoree.

Leather, Chumra.

Leech, Jonk.

Lime, Choona.

Linseed, Ulsee; teesee. oil, Clsee ka tél, or teesce kic tel.

Lip, Honth

Lip-strap, Buhadúree.

Litter (manure), Klaad.

Liver, Kuléja.

Iivery stables, Uryurra.

Loins, Kumr.

Paralysis of the, Kumree.

Loodianah fever, Gutheea; bhugona; zuhurbad.

Lotion, Doné kee duva.

Lukewarm, Sheer gurm.

Lunge a horse, to, Kawa dína. Lungs, Pliéplıra.

Madness, Deewangee.

Maggots, Kecré.

Maize, Mukuce.

Mane, Yal.

Mange, Khújlee; kharish.

Mare, Ghoree; madwan.

Mark in the tceth, Dunt kee seeahee.

Martingale, Zérbund.

Matter (pus), Peeb.

Megrims, Mirgee.

Melanosis, Bamunee.

Membrane, Jlitlee.

Mercury, Puru.

Mill, hand, Chukkee.

Millet, Bujra, ju'vur.

Moon-bliudness, futturendlice; shub-kurce.

Mount, to, Suever hone.

Mouse-coloured (horse), Sor r.

Mouth, Moonh.
Mucus (from the eyes), keechur. ," (, ", nose), Néta; rént.

kihar.

Muscle, Gosht,

Mustard, Rai.

oil, Surson ka tél.

Muzzle (of face), Toothun. (,, wire, etc.), Chheeka.

Nail, Prég; mékh.

Nave (of a wheel), Nabh.

Navicular disease, Surrun bad (?).

Neatsfoot oil, Paé ka tél.

Neck, Gurdun.

Neigh, Hinhinana.

Nerve, Usub.

Nitre, Shora.

Nose, Nuk.

Nose bag, Tubra.

Nose band, Nasbund.

Nostrils, Nuthna.

Nut (of a screw), Dibree.

Nux vomica, Kúchla.

Oakgalls, Majoo.

Oats, Jy.

Oil, Tél.

Ointment, Murhum.

Once round (race-course), Poora chutkitur.

One-eyed, Kura.

Ophthalmia, Ankh úthnu.

Opium, Afeem.

Pad (harness), Chal.

Pain, Durd.

Palate, Taloo.

Pancreas, Libba.

Panel (of a saddle), Guddee.

Pant, to, Hampma.

Paraffine oil, MLittec lice tél.

Parrot-mouthed, Toté dulurn.

Pastern, Gamchee.

Iaw, to from impatience), Tapnu. 
Paw, to (strike out with the foreleg), Tap marna.

Pepper, black, Gol mirch. red, Lal mirch.

Periosteum, Huddee kee jhillee.

Pestle and mortar, Hawun dista. Physic, Duwa.

" to, Duva déna.

," to (purge), Julab déna.

Pickaxe, Gyntee.

Picker (hoof), Súm-Khúdnee.

Piebald, "Kala abluk.

Pincers, Zumboor; sunrsee.

Pinch (of salt, etc.), Chuithee.

Pleuro-pneumonia (cattle), Pheepree.

Plunge, to, Lumbeean kurna.

Pneumonia, Phéphrékce beemaree

Pole (of a carriage), Bum.

Pony, yaboo; tattoo.

Poppy heads, Posta.

Pores of the skin, Musam.

Port of a bit, Jeebhee.

Posts and rails, Jungla.

Pot (cooking), Dégchee.

Poultice, Luibdee.

Powder (dry medicine), Súfoof. (medicine wrapped up in paper), Púreea.

Prance, to, Nachna.

Proud flesh, Bud gosht.

Pulse (artery), Nubz.

Pumiced feet, Chúpatee súm.

Punch, Súmba ; pogur.

Pupil of the eye, Ankh kee pútlee.

Pus (matter), Peeb.

\section{Quarter-ill (cattle), Gutheea;} golee.

Quiet (as a horse), Ghúreeb.

Race, Bazee; shurt.

Race course, Chutkur; ghuirdowr Race-horse, Ghúrdowree ghora ; shurtee ghora.

Rasp, Rét.

Rear, to, Alif hona.
Reins, Ras.

Removing (shoes), Khol-bundee. Resin, Ral.

Retention of urine, Péshab-bund. Rheumatism, Baee.

Ribs, Puslee.

Rice (cooked), Bhat.

", (in husk), Dhan.

" (uncooked), Chawul.

Rice-water, Kanjee.

Ride, Suwaree kurna.

Rig, a, Ek andeea.

Rinderpest, Mata; chéchulk; dévee Ring(ofmartingale,etc.), Chhulu , (of metal), Kari.

Ringbone (on fore-feet), Chukrawul.

(on hind-feet), Pústuk.

Ringworm, Dad.

Roan, Gurra.

Roar, to (disease), Shérdumee kurna.

Roaring, Shérdumee.

Rock salt, Numuk sung.

Roller (band), Furakhee.

Rope, Russee.

Rosette, Kurn-phool.

Rough rider, Chabúk suwar.

Rowel, Phirkee.

Rubber (towei), Jharun.

Rump, Pútha.

Run away, to, Bhag-jana.

Saddle, Zeen.

", to, Zeen bandhna.

Saddle-cloth, Tuh-roo; urukgeer; numda; myl khora.

Saddle-covering, Zeen-posh ; bogh-bund.

Saddle-dressing, Moomroghun . Saddle-flaps, Dawun.

Saddler, Zeen saz; zeen ka mochee. Saddle-stand, Ghoree.

Sal ammoniac, Nouscedur.

Saliva, Ral.

Salt, Numuk.

Saltpetre, Shora. 
Salts (Epsom), Júlabee numuk. Sandcrack, Shikak súm.

Scales, Turazoo.

Scissors, Kainchee.

Scrotum, Fotr.

Selling race, Leelamee bazee.

Sesamum oil, Til ka tél, or jinjilee ka tél.

Shaft (of a carriage), Dund $\alpha$.

Shaft-tugs, Choongee.

Sheaf (of straw, etc.), Poola.

Sheath, Ghilaf.

Shoe, Nal.

Shoeing, Nal-bundee.

Shoeing smith, Nal-bund.

Shoe with calkins, Khoonteedar nal.

clips, Thokurdar nat.

Shoulder, Plur ; Kandhee.

Shy, to, Bhurukna.

Sickle, Durantee.

Sieve, Chhulnee.

Sinew, $P y$; nuss; putth $\alpha$.

Skeleton, Thuthuree.

Skewbald, Lal abluk.

Skin, Chumra.

Skittish, Chunchul.

Slight-built, Chhuréra budun.

Sling, Jhola.

Slow (as a horse), Dheema; mutha.

Snaffle, Kuzaee.

Snort, to, Furfur kurna.

Soap, Sabun.

Soap-nut, Reeta.

Sole of the foot, Dilla; tulwa.

Sore back, Peeth lugna.

,, mouth, Buchka.

,, throat, Gulsooa.

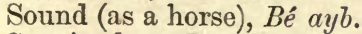

Spavin, bog, Motra. bone, Hudd $a$.

Speck (in the eye), Chicent.

Spinal cord, Huram mughz.

Spleen, Tillee.

Splint (bone), Bél huddee, bér huddee.
Splinter (of bone, etc.), Kirich. Spoke of a wheel, Duree.

Sprain, Moch.

Sprain a tendon or ligament, to, Py ajana.

Spud (for rooting up grass), Kúrpa.

Spur, Kanta ; múmréz.

Stable, Istubbul; than ; tubéla.

Stack (of hay, etc.), Gurree.

Star on forehead, Sitarapéshanee.

Steeplechase, Tuttee bazee.

Stifle, Külaba.

Stirrup, Rikab.

Stirrup-leather, Rikab duwal.

Stirrup-lock, Champ.

Stomach, Koth $a$.

Stomachic, Pachuk.

Strangles, Húbuk.

Strap, Tusma.

Straw, Púwal.

, (a single), Tinka.

, (for bedding), Bichalee.

Strawberry roan, with white legs and muzzle, and coat ticked ont with white, Cheena.

Stringhalt, Jhumuk-bad.

Stripe down back, like that of a donkey, Sélee.

Stud-bred, a, Lumburee ghora.

Stumble, to, Thokur khana.

Sugar-cane, Gunna; ookh; eekh.

Sugar of lead, Suféda.

Sulphate of copper, Neela tooteea.

Sulphur, Gunduk.

Suppression of urine, Péshabbund

Surcingle, Bala tung.

Surfeit (skin disease), Gurmee dané.

Sweat, Puseena.

Sweat-scrapers, Puseena-kush.

Sweet oil, Meetha tél.

Swelling, Wurum; soojun.

Synovia, Jor ka tél.

Tack (small nail), Birinjee.

Tail, Dúm. 
Tan, Bukla.

Tape, Feeta.

Temple (of head), Kun-puttee.

Tendon, $P_{y}$; nuss; putth .

Tetanus, Chandnee kee beemaree; pista duhun.

Thick (as gruel, etc.), Garha.

Thigh, Ran.

Thorough-bred, Useel.

Thorough-pin, Bhubhootura.

Three year old, Do-ék.

Throat, Gula.

Throat-lash, Gultunnee.

Thrush (disease), Russ. to have, Russ uturna.

Tire of a wheel, Hal.

Tired (fatigued), Thuk gya.

Toe of the foot, Thokur; pés (more correctly, pésh).

Tongue, Jeebh.

Tongue of a buckle, Buksooa kee sooee.

Tooth, dant.

," milk, Doodh ka dant.

, molar, Darh.

, (nippers), Dant.

", permanent, Pukka dant; pukka darh.

Tow, Sun.

wolf's, Chor dant.

Trace (harness), Jot.

Trace-bearer, Manik jot.

Trot, to, Dúlkee chulna.

Trough (feeding), Kuthra.

Trowel (for rooting up grass), Kúrpa.

Tumour, Rusaowlee.

Turpentine (crude), Gunda biroza.

(oil of), Gunda birozé

,

ka tél; tarpeen ka tél.

Tush, Nésh; koontee.

Twitch, Kúchmal; Poozmal.

Two year old, Nakund.

Tympanitis, Badee.

Underbred, Kumzat.
Unsound, Aybee.

Unsoundness, $A y b$.

Upright pasterns, Múrgh-pa.

Urethra, Nézé ka soorakh.

Vagina, Choot.

Vein, Rug; wureed.

Venice turpentine, Gunda biroza.

Verdigris, Jungat.

Vertebra, Munka.

Veterinary manual, Furus nama

Veterinary Surgeon, Saloturee sahib.

Vicious (as a horse), Budzat.

Vinegar, Sirla.

Walk, to (as a horse), Kudum kudum chulna.

Walk a horse, to, Rowl kurna.

Wall, Deewal.

Wall of the hoof, Shahk.

Wall-eyed (one eye), Takee.

,, (both eyes), Súlymanee.

Wart, Mussa.

Water, Panee.

," boiling, Khowlta pance; josh panee.

Wax, Moom.

Weave, to (a stable trick), Jhoomna.

Weaver, Jhoomnéuvala.

Weighing-room, Tol ghur.

Weight cloth, Seesa-guddee.

Wheat, Géhoon.

Wheel (of a carriage), Puhiya. Whip, Chabúk.

White, with white mane and tail, and black skin, Súrkh $a$.

, , , pink skin, Núkra.

," , dark mane and tail, Subza.

N.B. Suféd is the common word for w'ite.

Windgall, Byza.

Window, Kirkee.

Windpipe, Hulk. 
Wind-sucker, Howa peené wala.

Winkers, Putta.

Winning-post, Jeet kee lukree.

Wisp, Koocha.

Withers, Mudow.

Womb, Kolk.

Worm in the eye, Moonja.

Worms (round), Kénchooa.
Worms (thread), Chünchina. Wound, Zukhm.

Yard, Néza.

Yearling, Surloo.

Zinc, sulphate of, Suféd tooteca.

\section{IDIOMS AND PIIRASES.}

The abscess has come to a head Phor puli gya.

The horse has a sore back ... Ghoré kee peeth lugee hy.

Myhorseisblown ... ... Hamaréghoréka dum phoolgya hai.

The horse bolted off the course... Ghora chukkur sé phut gya.

My horse bores to the right ... Humaraghora dahinékobagkurta

Where was that horse bred? ... Wuh kis khét ka ghora hy?

The horse is not properlybroken in Ghoré ka mooh kuchcha hy.

Thehorsehascut himself brushing Ghoré ko névur luga hy.

The horse has a cataract in his Ghoré kee dahinee ankh mén off eye

The horse is in hard condition ...

The horse is a crib-biter (or windsucker) ... moteea-bind hy.

Ghora ka budun gutheela hy.

Ghora howa peeta.

Wash the horse's $\ddot{d o c k}$ and sheath Ghoré kee saghiree aur fota dho. The horse looks dull $\quad . . \quad \quad$... Ghora síst maloom déta hy.

He fell off the horse $\quad .$. ... Wuh ghoré pur sé gira.

The horse's leg is filled ... .... Ghoré ko py agyee.

Put the shoe firmly on ... .... Nal jikkur ké bandho.

The mare is in foal ... ... Ghoree gabhin hy.

Froment the horse's leg with hot Ghoré ké pyr kn gurm pance se water for half an hour

Slacken the girths

Tighten the girths $\quad \ldots . \quad \ldots$ Tung kuso. adhé ghunté tuki sénko.

Give your horse two or three Apné ghoré ko do teen ghoont go-downs of water

The horse chucks his head (when being ridden) ... ... ...

The horse has cracked heets $\quad \ldots$. Ghoré kee gamchee mén chheewur ho gya. 
He hogged the mane of his pony Usné apné tattoo kee yal ko bubree keeya.

Hold my horse

The jockey was not able to hold the horse

IJengthen the stirrups one hole...

Shorten the stirrups two holes ... The horse's hoof slopes too much; take more off the toes

The horse has hurt his leg

Don't jerk the reins ...

The horse has clean legs...

The horse has got lockjaw

Make much of your horse

He can't master the horse

Humara ghora thamo.

Coachwan ghore ko muheen rok sukka.

Rikab ko ék ghur aur lumba kuro.

Rikab ko do ghur churhao.

Ghoré ka súm zeeada sulamee hy, punjé ké neeché sé aur cheelo

Ghoré ké pyr ko chot lugee.

... Ras ko jhutka mut do.

... Ghoré ké hath pyr durust hyn.

... Ghoré ko chandné né mara.

... Apné ghoré ko dilasa do.

That horse is difficult to mount

The mare has a light mouth

How old is that horse? ...

The horse has ophthalmia

Ghora is sé nuheen dubta.

Tell me the good and bad points of that horse

The horse pulls a great deal ... The grey horse refused the water-

$\begin{array}{lllll}\text { jump } & \ldots & \ldots & \ldots & \ldots\end{array}$

Your horse is a roarer $\quad . . \quad \ldots$

He has a strong seat $\quad \ldots \quad \ldots$

He has a weak seat $\quad \ldots . \quad \ldots$

Ride the horse at a smart walk...

Take the horse once round at half speed

The horse has sprained his leg ...

I will give the horse a sweat tomorrow morning

The horse goes tender on the near foreleg

The horse has thrush

Don't put on the bandages too

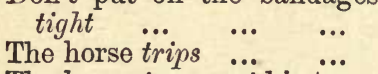

The horse turns out his $\ldots$

The horse is a weaver ...

The horse's wind is good

The horse's wind is bad ...

Wisp down the horse ....

The horse's withers are galled
Wuh ghora bud rikab hy.

Madwan ka moonh nurm hy.

Us ghoré kee úmr kya hy?

Ghoré kee ankh úthee.

Us ghoré ké ayb aur húnur hum sé kuho.

Ghora buhut moonh zor hy.

Subza ghora naté sé phut gya.

Túmhara ghora shérdumee kurta.

Uska asun kura hy.

Uska asun dheela hy.

Ghoré ko chutuk sé kudum kudum chullao.

Ghoré ko ék chukkur ath anné ka do.

Ghore ké pyr men moch aya.

Hum kul fujjur ghoré sé pusseena nikaléngé.

Ghora apné bayan hath ko kuchh manta hy.

Ghoré ké súm mén rus útura hy.

Puttee zeeada tung mut bandho.

Ghora thokur khata.

Ghoré ké pyr mén tao hy.

Ghora humésha jhoomta.

Ghore ka dum khoob achcha hy.

Ghore ka dum juldee toot jata.

Ghoré ké kooncha maro.

Ghoré ka mudow sooja hy. 
CALCUTTA TURF CLUB WEIGHTS

FOR

AGE AND CLASS. 

JANUARY.

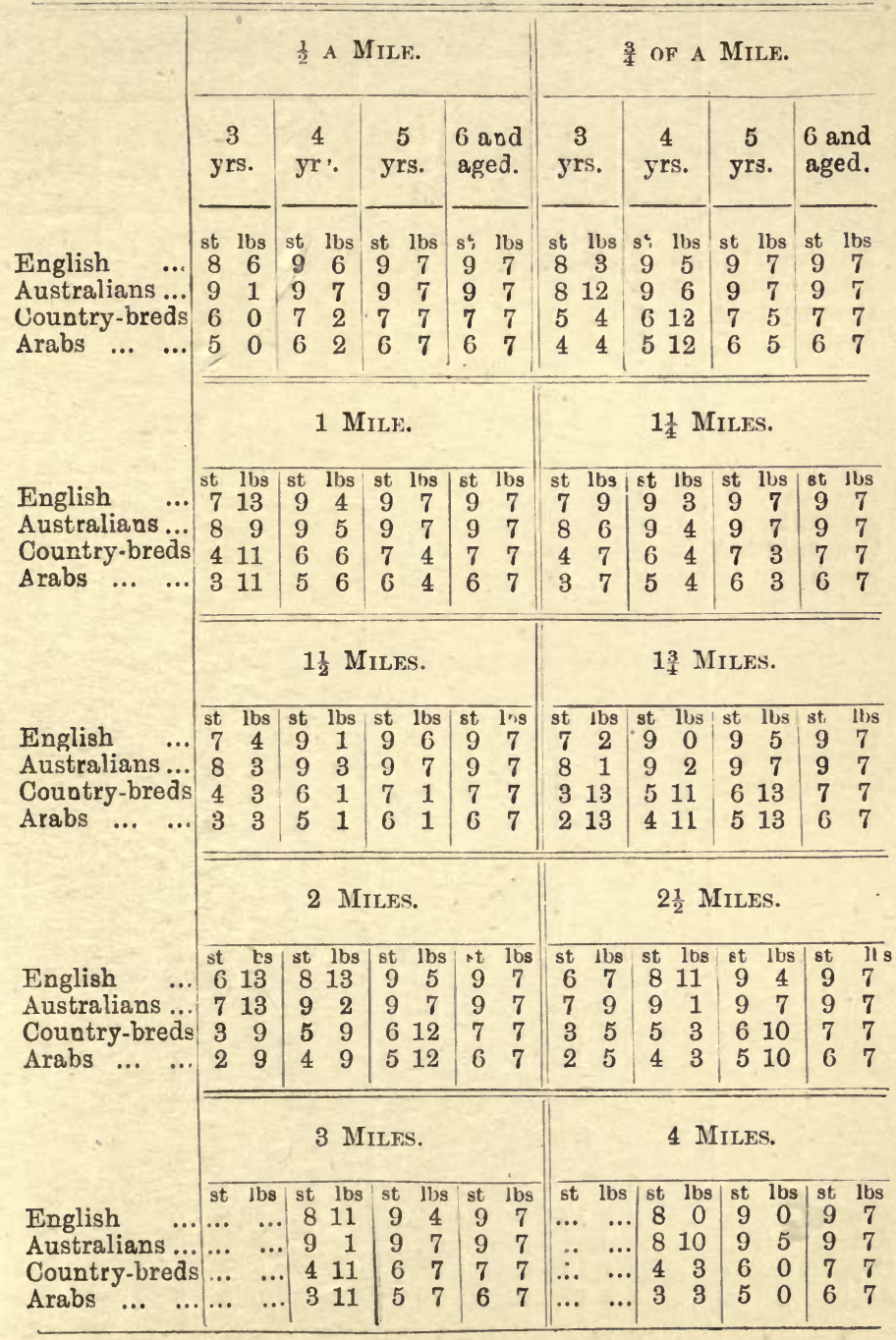


FEBRUARY.

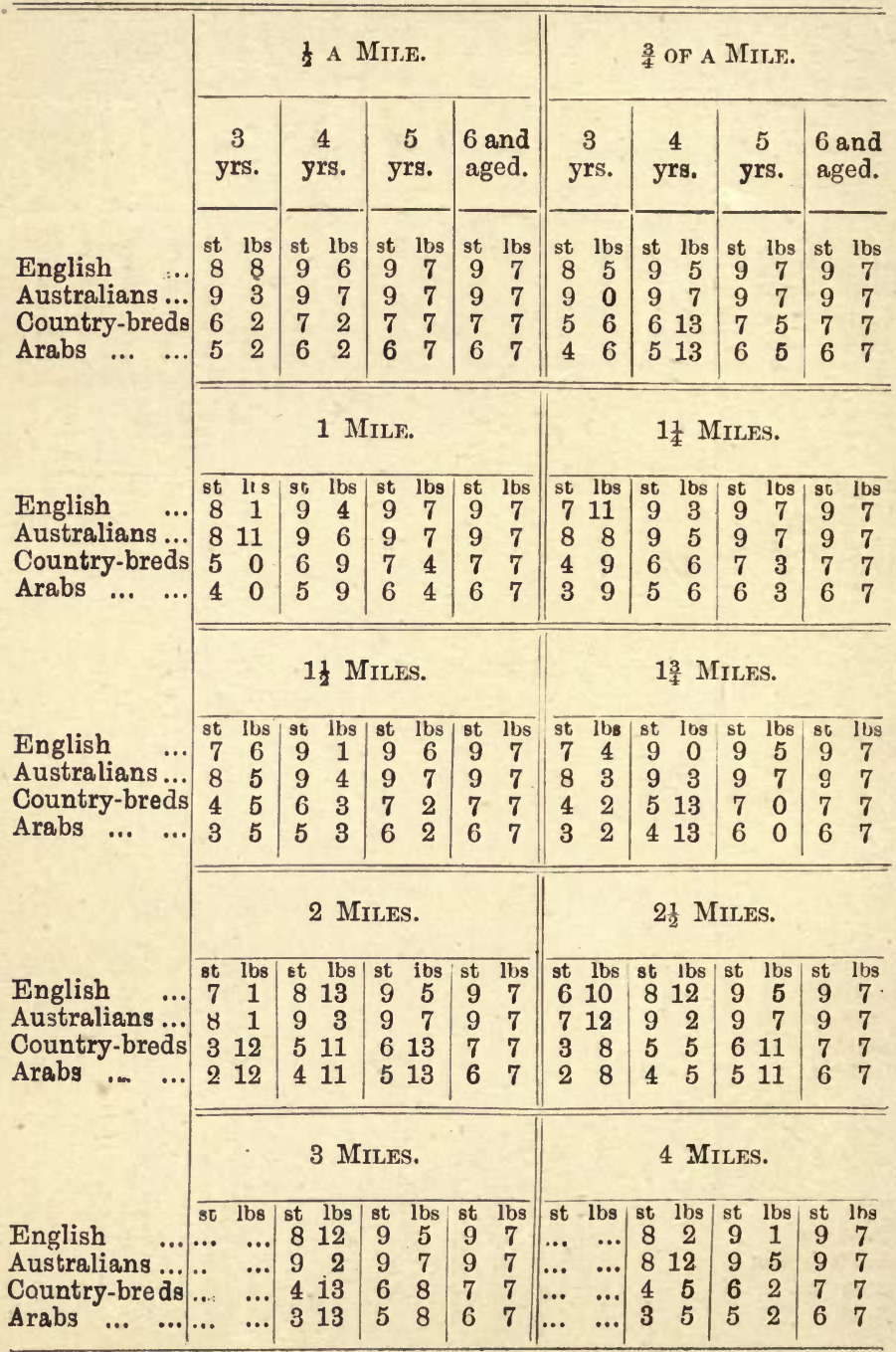


MARCH.

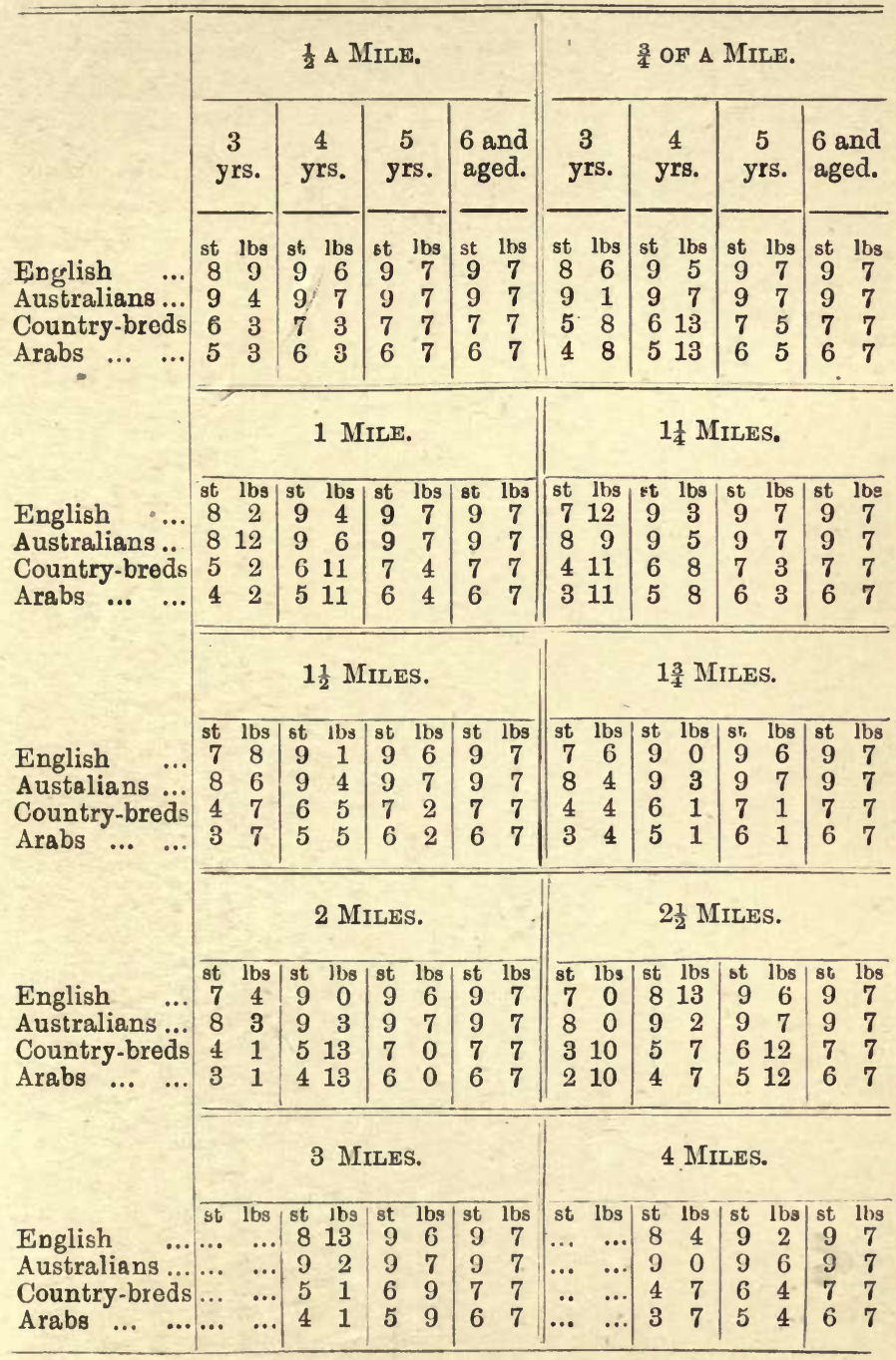


APRIL.

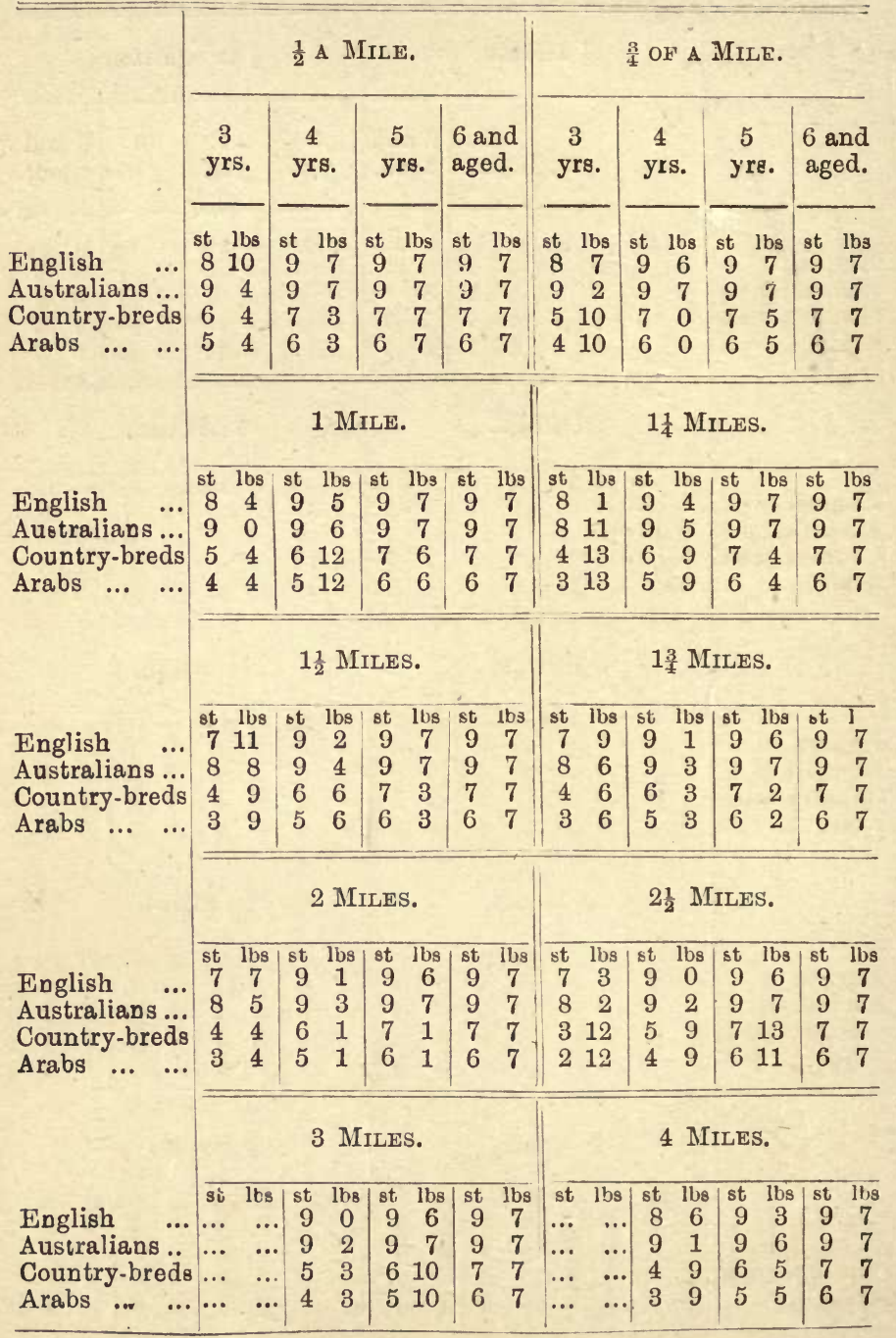


WEIGHTS FOR AGE AND CLASS.

MAY.

\begin{tabular}{|c|c|c|c|c|c|c|c|c|}
\hline \multirow[b]{3}{*}{\begin{tabular}{l|l} 
& \\
English & $\ldots$ \\
Australians & $\ldots$ \\
Country-breds \\
Arabs $\quad \ldots$ &..
\end{tabular}} & \multicolumn{4}{|c|}{$\frac{1}{2}$ A MILE. } & \multicolumn{4}{|c|}{$\frac{3}{4}$ OF $\triangle$ MILE. } \\
\hline & \multirow{2}{*}{\begin{tabular}{cc}
\multicolumn{2}{c}{3} \\
jre. \\
st & lbs \\
8 & 10 \\
9 & 4 \\
6 & 5 \\
5 & 5
\end{tabular}} & \multirow{2}{*}{\begin{tabular}{cc}
\multicolumn{2}{c}{4} \\
yrs. \\
st & $1 \mathrm{bs}$ \\
9 & 7 \\
9 & 7 \\
7 & 4 \\
6 & 4
\end{tabular}} & \multirow{2}{*}{\begin{tabular}{|c|c|}
\multicolumn{2}{c|}{5} \\
yrs. \\
st & $1 \mathrm{bs}$ \\
9 & 7 \\
9 & 7 \\
7 & 7 \\
6 & 7
\end{tabular}} & $\begin{array}{l}6 \text { and } \\
\text { aged. }\end{array}$ & $\begin{array}{c}3 \\
\text { yrs. }\end{array}$ & \multirow{2}{*}{\begin{tabular}{cc}
\multicolumn{2}{c}{4} \\
yrs. \\
st & lbs \\
9 & 6 \\
9 & 7 \\
7 & 1 \\
6 & 1
\end{tabular}} & \multirow{2}{*}{\begin{tabular}{cc}
\multicolumn{2}{c}{5} \\
$y \leq s$. \\
st & $1 b s$ \\
9 & 7 \\
9 & 7 \\
7 & 5 \\
6 & 5
\end{tabular}} & $\begin{array}{l}6 \text { and } \\
\text { aged. }\end{array}$ \\
\hline & & & & $\mid$\begin{tabular}{cc|} 
st & $1 \mathrm{bs}$ \\
9 & 7 \\
9 & 7 \\
7 & 7 \\
6 & 7
\end{tabular} & $\left|\begin{array}{cc}\text { st } & \mathrm{lbs} \\
8 & 9 \\
9 & 3 \\
5 & 11 \\
4 & 11\end{array}\right|$ & & & $\begin{array}{lc}s^{2} & 11 s \\
9 & 7 \\
9 & 7 \\
7 & 7 \\
6 & 7\end{array}$ \\
\hline & \multicolumn{4}{|c|}{1 Mile. } & \multicolumn{4}{|c|}{$1 \frac{1}{4}$ MiLES. } \\
\hline $\begin{array}{l}\text { Englisi } \\
\text { Australians ... } \\
\text { Country-breds } \\
\text { Arabs } \quad . . \quad \quad \ldots\end{array}$ & $\begin{array}{rr}\mathrm{sc} & \mathrm{lbs} \\
8 & 7 \\
9 & 2 \\
5 & 6 \\
4 & 6\end{array}$ & $\left|\begin{array}{cc}\text { st } & 1 b_{s} \\
9 & 5 \\
9 & 7 \\
6 & 12 \\
5 & 12\end{array}\right|$ & $\begin{array}{|cc|}\text { st } & \text { lbs } \\
9 & 7 \\
9 & 7 \\
7 & 4 \\
6 & 4\end{array}$ & $\left|\begin{array}{cc|}\text { st } & \text { lbs } \\
9 & 7 \\
9 & 7 \\
7 & 7 \\
6 & 7\end{array}\right|$ & $\mid \begin{array}{rr}\text { st } & \text { lbs } \\
8 & 4 \\
8 & 13 \\
5 & 1 \\
4 & 1\end{array}$ & $\begin{array}{cc}\text { sc } & \text { l's } \\
9 & 4 \\
9 & 6 \\
6 & 10 \\
5 & 10\end{array}$ & $\begin{array}{cc}\text { st } & \text { lbs } \\
9 & 7 \\
9 & 7 \\
7 & 4 \\
6 & 4\end{array}$ & $\begin{array}{cc}\text { st } & \text { its } \\
9 & 7 \\
9 & 7 \\
7 & 7 \\
6 & 7\end{array}$ \\
\hline & \multicolumn{4}{|c|}{$1 \frac{1}{2}$ Miles. } & \multicolumn{4}{|c|}{$1 \frac{3}{4}$ MILES. } \\
\hline 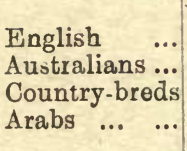 & $\begin{array}{rr}\text { st } & \mathrm{lb} \\
8 & 0 \\
8 & 10 \\
4 & 11 \\
3 & 11\end{array}$ & $\mid$\begin{tabular}{cc|}
$\mathrm{si}$ & $10 \mathrm{~s}$ \\
9 & 3 \\
9 & 5 \\
6 & 7 \\
5 & 7
\end{tabular} & $\begin{array}{|cc|}\text { st } & \text { lbs } \\
9 & 7 \\
9 & 7 \\
7 & 3 \\
6 & 3\end{array}$ & $\begin{array}{|cc|}\text { st } & 1 \mathrm{bs} \\
9 & 7 \\
9 & 7 \\
7 & 7 \\
6 & 7\end{array}$ & $\mid$\begin{tabular}{rr|} 
st & lbs \\
7 & 11 \\
8 & 8 \\
4 & 8 \\
3 & 8
\end{tabular} & \begin{tabular}{cc|} 
st & lbs \\
9 & 2 \\
9 & 4 \\
6 & 4 \\
5 & 4
\end{tabular} & $\begin{array}{|cc|}\text { st } & 1 \mathrm{lb} \\
9 & 6 \\
9 & 7 \\
7 & 2 \\
6 & 2 \\
\end{array}$ & 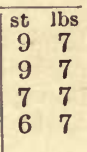 \\
\hline & \multicolumn{4}{|c|}{2 Miles. } & \multicolumn{4}{|c|}{$2 \frac{1}{2}$ Miles. } \\
\hline $\begin{array}{l}\text { English } \\
\text { Australians .... } \\
\text { Country-breds } \\
\text { Arabs ... } \quad . .\end{array}$ & $\begin{array}{rr}\text { st } & 1 \mathrm{~b} \\
7 & 10 \\
8 & 7 \\
4 & 6 \\
3 & 6\end{array}$ & $\left|\begin{array}{cc}\text { st } & \text { lhs } \\
9 & 1 \\
9 & 4 \\
6 & 2 \\
5 & 1\end{array}\right|$ & $\begin{array}{|cc|}\text { st } & \text { lbs } \\
9 & 6 \\
9 & 7 \\
7 & 1 \\
6 & 1\end{array}$ & $\begin{array}{|cc|}\text { st } & \text { lbs } \\
9 & 7 \\
9 & 7 \\
7 & 7 \\
6 & 7\end{array}$ & $\left|\begin{array}{cc}\text { st } & \text { lbs } \\
7 & 6 \\
8 & 4 \\
4 & 0 \\
3 & 0\end{array}\right|$ & $\begin{array}{|rr|}\text { st } & \text { lbs } \\
9 & 0 \\
9 & 3 \\
5 & 11 \\
4 & 11\end{array}$ & $\begin{array}{|cc|}\text { st } & \text { lbs } \\
9 & 6 \\
9 & 7 \\
6 & 13 \\
5 & 13\end{array}$ & \begin{tabular}{|cc} 
st & lbs \\
9 & 7 \\
9 & 7 \\
7 & 7 \\
6 & 7
\end{tabular} \\
\hline & \multicolumn{4}{|c|}{3 Miles. } & \multicolumn{4}{|c|}{4 Miles. } \\
\hline $\begin{array}{l}\text { English } \\
\text { Australians } \ldots \\
\text { Country-breds } \\
\text { Arabs } \quad . .\end{array}$ & 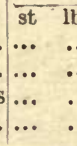 & \begin{tabular}{c|cc} 
& st & lbs \\
. & 9 & 0 \\
. & 9 & 3 \\
. & 5 & 5 \\
. & 4 & 5
\end{tabular} & $\begin{array}{cc}\text { st } & 1 \mathrm{bs} \\
9 & 6 \\
9 & 7 \\
6 & 11 \\
5 & 11\end{array}$ & $\begin{array}{|cc|}\text { st } & \text { lbs } \\
9 & 7 \\
9 & 7 \\
7 & 7 \\
6 & 7\end{array}$ & $\left|\begin{array}{cc}\text { st } & 10 \mathrm{~s} \\
\ldots & \ldots \\
\ldots & \ldots \\
\cdots & \ldots \\
\ldots & \ldots \\
\ldots & \ldots\end{array}\right|$ & $\begin{array}{|cc|}\text { st } & \text { lbs } \\
8 & 8 \\
9 & 3 \\
4 & 11 \\
3 & 11\end{array}$ & $\begin{array}{|cc|}\text { st } & 1 \mathrm{lbs} \\
9 & 4 \\
9 & 7 \\
6 & 6 \\
5 & 6\end{array}$ & $\begin{array}{ll}\text { st } & \text { lbs } \\
9 & 7 \\
9 & 7 \\
7 & 7 \\
6 & 7\end{array}$ \\
\hline
\end{tabular}


JUNE.

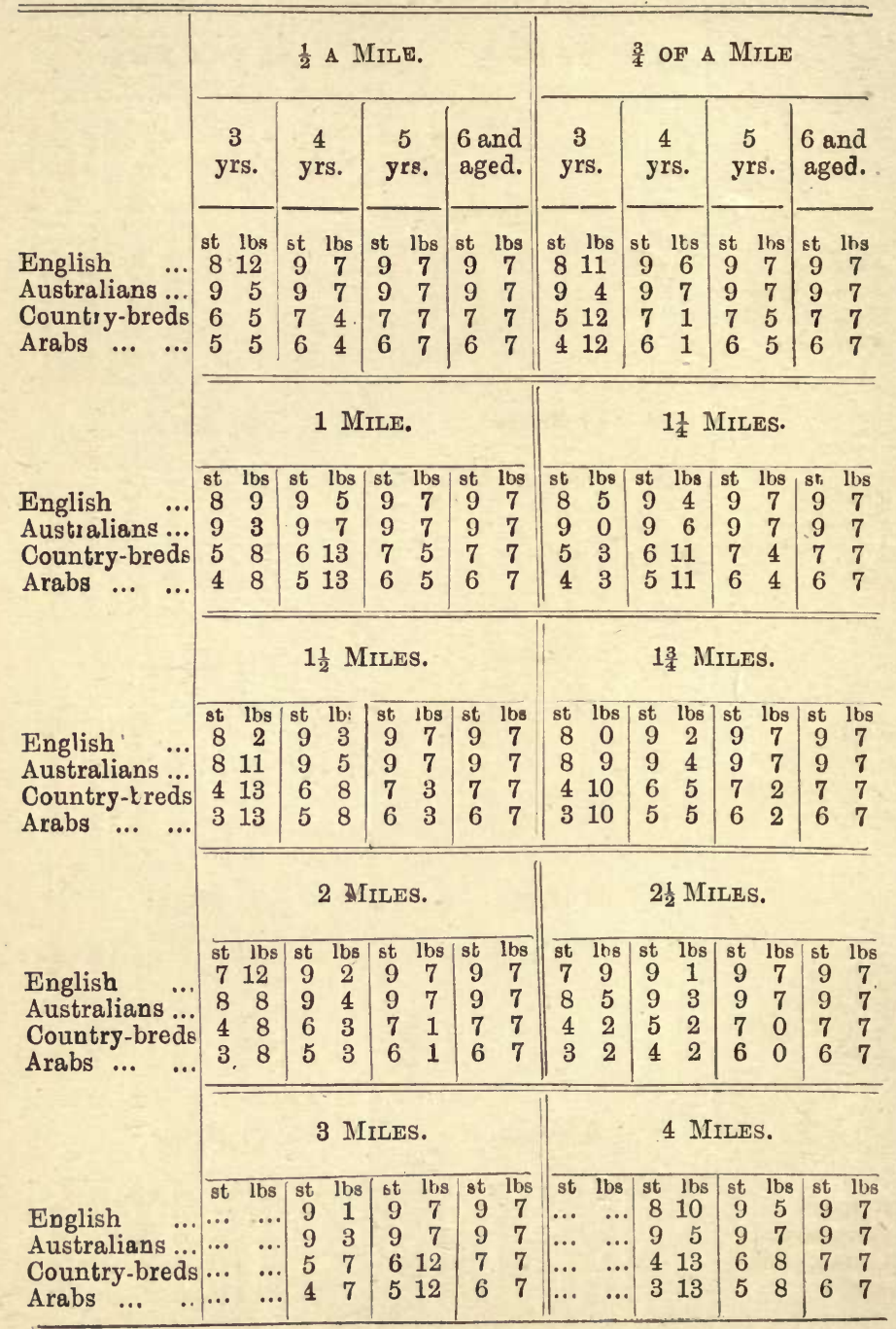


IULY.

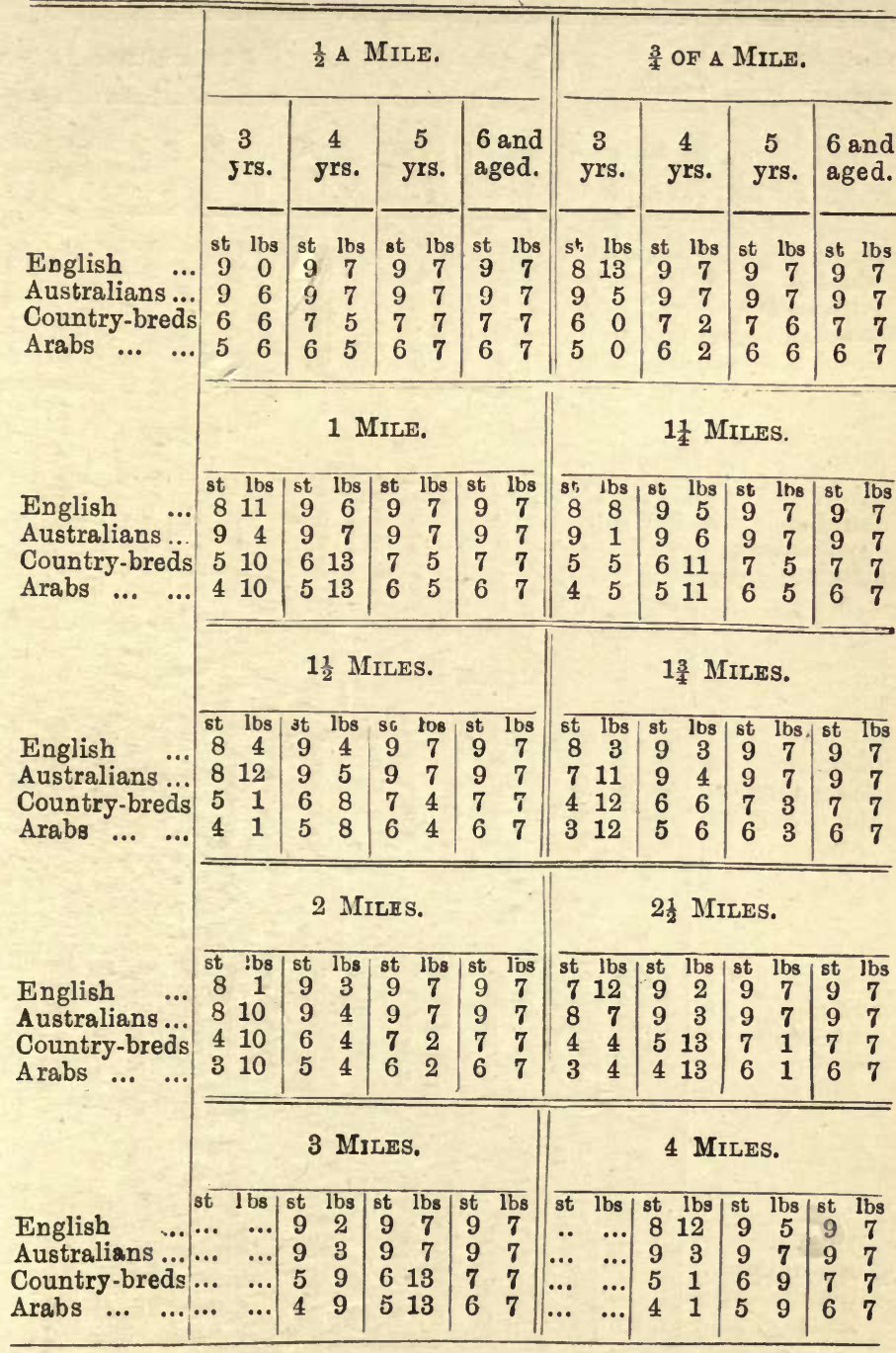


AUGUST.

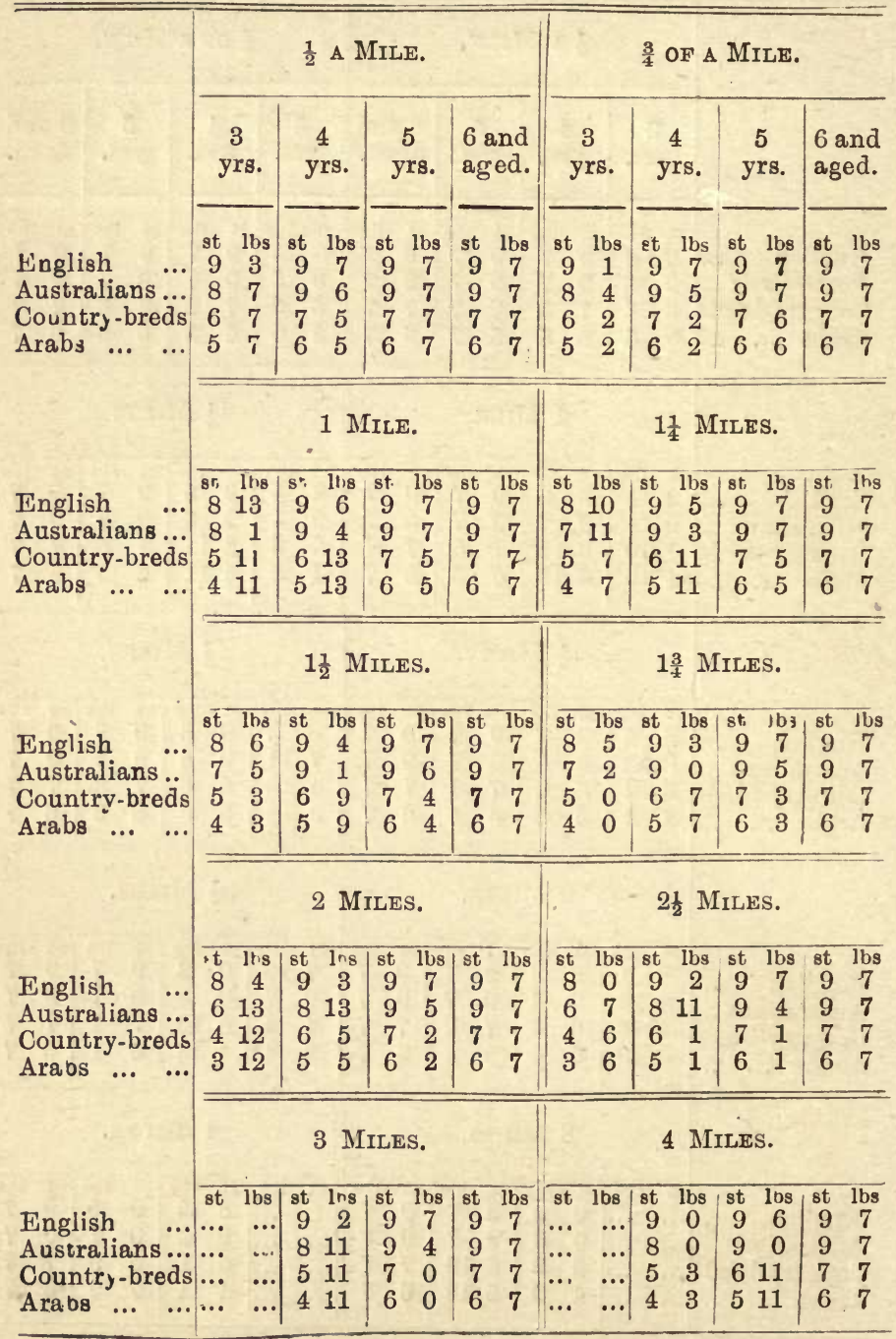


SEPTEMBER.

$\frac{1}{2}$ A MILE.

\begin{tabular}{|c|c|c|c|}
\hline 3 & 4 & 5 & 6 and \\
\hline yrs. & yrs. & yis. & \\
\hline lbs & st lbs & st lbs & st lbs \\
\hline
\end{tabular}

English

st lbs st lbs st lbs st lbs Australians... Country-breds Arabs ... ...

$\frac{3}{4}$ OF A MiLe.

$\begin{array}{llllllllllllllllllll}8 & 8 & 9 & 6 & 9 & 7 & 9 & 7 & 8 & 5 & 9 & 5 & 9 & 7 & 9 & 7\end{array}$

$\begin{array}{llllllllllllllllll}6 & 8 & 7 & 5 & 7 & 7 & 7 & 7 & 6 & 3 & 7 & 3 & 7 & 6 & 7 & 7\end{array}$

$\begin{array}{llllllllllllllllll}5 & 8 & 6 & 5 & 6 & 7 & 6 & 7 & 5 & 3 & 6 & 3 & 6 & 6 & 6 & 7\end{array}$

1 Mile.

$1 \frac{1}{4}$ MiLes.

English

st lbs st lbs st lbs st lbs st lbs st lbs st lbs 8 si lbs Australians ... Country-breds Arabs ... ...

\begin{tabular}{rr|rr|rr|rrrrr|rrrrrrr}
9 & 0 & 9 & 6 & 9 & 7 & 9 & 7 & 8 & 11 & 9 & 5 & 9 & 7 & 9 & 7 \\
8 & 2 & 9 & 4 & 9 & 7 & 9 & 7 & 7 & 12 & 9 & 3 & 9 & 7 & 9 & 7 \\
5 & 12 & 7 & 0 & 7 & 5 & 7 & 7 & 5 & 9 & 6 & 12 & 7 & 5 & 7 & 7 \\
4 & 12 & 6 & 0 & 6 & 5 & 6 & 7 & 4 & 9 & 5 & 12 & 6 & 5 & 6 & 7
\end{tabular}

$1 \frac{1}{2}$ Miles.

13 Miles.

English

st los st lbs st lbs st lbs

Australians ... 8

Country-breds

Arabs ... ...

\begin{tabular}{rr|rr|rr|rr|}
8 & 7 & 9 & 4 & 9 & 7 & 9 & 7 \\
7 & 6 & 9 & 1 & 9 & 6 & 9 & 7 \\
5 & 5 & 6 & 10 & 7 & 4 & 7 & 7 \\
4 & 5 & 5 & 10 & 6 & 4 & 6 & 7
\end{tabular}

\section{Miles.}

$2 \frac{1}{2}$ MILEs.

English st $1^{\text {hs }}$ |st lbs $\mid$ st lbs lst lbs Australians ... Country-breds Arabs ... ...

\begin{tabular}{|cc|cc|cc|cc|cc|cc|cc|cc}
\hline st & 1 rs & st & lbs & st & lbs & st & 1 lbs & st & 1bs & st & lbs & st & 1bs & st & 1 lbs \\
8 & 5 & 9 & 3 & 9 & 7 & 9 & 7 & 8 & 2 & 9 & 2 & 9 & 7 & 9 & 7 \\
7 & 1 & 8 & 13 & 9 & 5 & 9 & 7 & 6 & 10 & 8 & 12 & 9 & 5 & 9 & 7 \\
4 & 12 & 6 & 6 & 7 & 2 & 7 & 7 & 4 & 8 & 6 & 3 & 7 & 2 & 7 & 7 \\
3 & 12 & 5 & 6 & 6 & 2 & 6 & 7 & 3 & 8 & 5 & 3 & 6 & 2 & 6 & 7 \\
\hline
\end{tabular}

3 Miles.

4 Miles.

English

st lbs st lbs st lbs st lbs Australians . \begin{tabular}{ll|lllllll}
... & ... & 9 & 2 & 9 & 7 & 9 & 7
\end{tabular} Country-breds

\begin{tabular}{rr|rr|rr|rr|rr|rr|rr|rr}
$\ldots$. & $\ldots$ & 9 & 2 & 9 & 7 & 9 & 7 & $\ldots$ & $\ldots$ & 9 & 1 & 9 & 6 & 9 & 7 \\
$\ldots$ & $\ldots$ & 8 & 12 & 9 & 5 & 9 & 7 & $\ldots$ & $\ldots$ & 8 & 2 & 9 & 1 & 9 & 7 \\
$\ldots$ & $\ldots$ & 5 & 13 & 7 & 1 & 7 & 7 & $\ldots$ & $\ldots$ & 5 & 5 & 6 & 13 & 7 & 7 \\
$\ldots$ &.. & 4 & 13 & 6 & 1 & 6 & 7 & $\ldots$ & $\ldots$ & 4 & 5 & 5 & 13 & 6 & 7
\end{tabular}
Arahs 
OCTOBER.

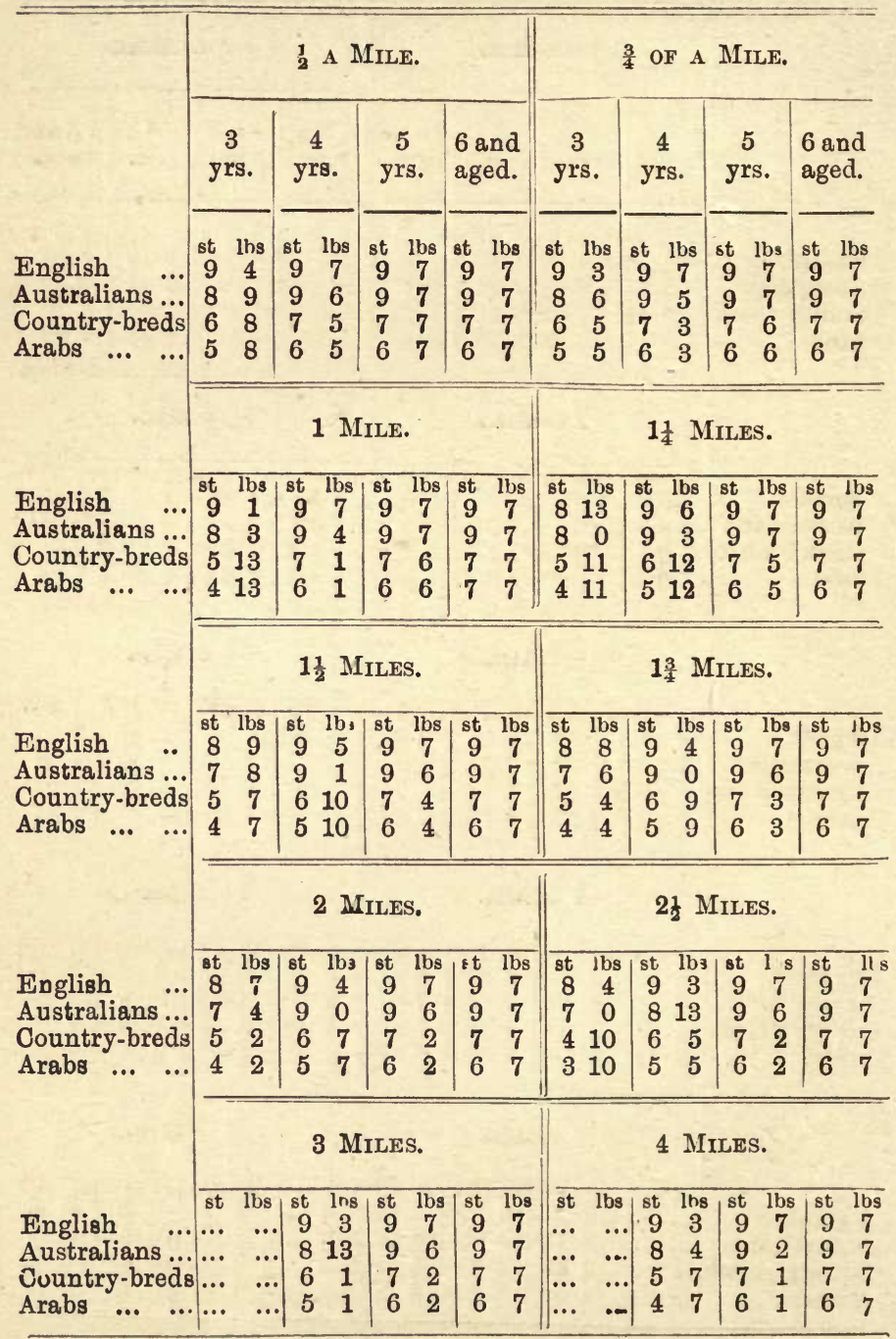


WEIGHTS FOR AGE AND CLASS.

NOVEMBER.

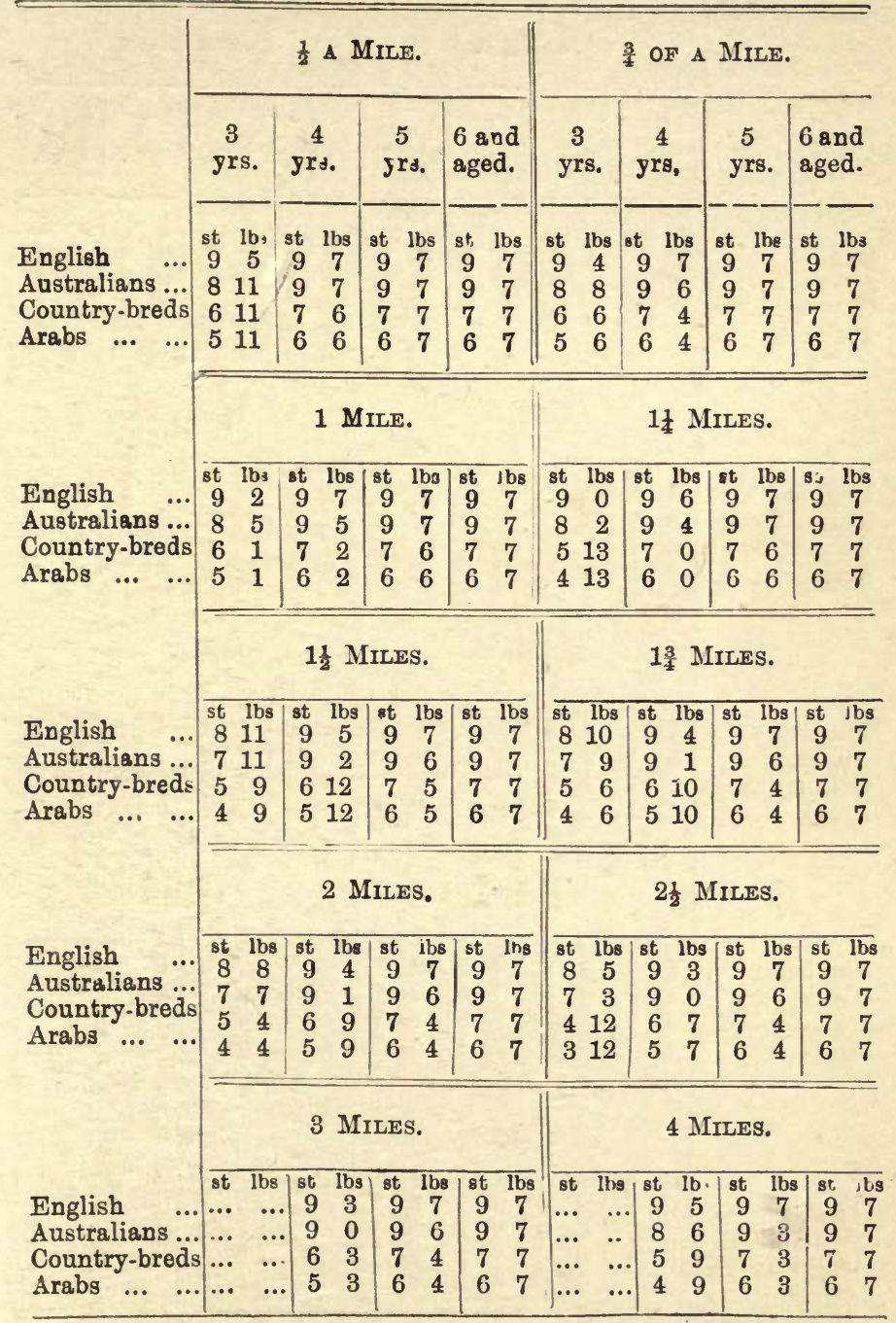


DECEMBER.

\begin{tabular}{|c|c|c|c|c|c|c|c|c|}
\hline & \multicolumn{4}{|c|}{$\frac{1}{2}$ a MILE. } & \multicolumn{4}{|c|}{$\frac{3}{4}$ of A MiLe. } \\
\hline & $\begin{array}{c}3 \\
\text { yrs. }\end{array}$ & $\begin{array}{c}4 \\
\text { yrs. }\end{array}$ & $\begin{array}{c}5 \\
\text { yrs. }\end{array}$ & $\begin{array}{l}6 \text { and } \\
\text { aged. }\end{array}$ & $\begin{array}{c}3 \\
\text { yrs. }\end{array}$ & yrs. & $\begin{array}{c}5 \\
-\mathrm{yrs} .\end{array}$ & $\begin{array}{l}6 \text { and } \\
\text { aged. }\end{array}$ \\
\hline $\begin{array}{ll}\text { English } & \ldots \\
\text { Australians } & \ldots \\
\text { Country-bre } & \\
\text { Arabs } & . .\end{array}$ & $\begin{array}{cc}\text { st } & \text { lbs } \\
9 & 6 \\
8 & 13 \\
6 & 13 \\
5 & 13\end{array}$ & $\begin{array}{cc}\text { st } & \text { lbs } \\
9 & 7 \\
9 & 7 \\
7 & 6 \\
6 & 6\end{array}$ & $\begin{array}{cc}\mathrm{t} & \mathrm{lbs} \\
9 & 7 \\
9 & 7 \\
7 & 7 \\
6 & 7\end{array}$ & $\begin{array}{cc}\text { st } & \mathrm{lbs} \\
9 & 7 \\
9 & 7 \\
7 & 7 \\
6 & 7\end{array}$ & $\begin{array}{cc}\text { st } & \text { lbs } \\
9 & 5 \\
8 & 10 \\
6 & 7 \\
5 & 7\end{array}$ & $\begin{array}{rr}\text { st } & \text { lbs } \\
9 & 7 \\
9 & 6 \\
7 & 5 \\
6 & 5\end{array}$ & $\begin{array}{cc}\text { st } & \text { lbs } \\
9 & 7 \\
9 & 7 \\
7 & 7 \\
6 & 7\end{array}$ & $\begin{array}{cc}\text { st } & \text { lbs } \\
9 & 7 \\
9 & 7 \\
7 & 7 \\
6 & 7\end{array}$ \\
\hline & \multicolumn{4}{|c|}{1 Mile. } & \multicolumn{4}{|c|}{$1 \frac{1}{4}$ Miles. } \\
\hline $\begin{array}{l}\text { English } \\
\text { Australians } \ldots \\
\text { Country-bre is } \\
\text { Arabs ... } \quad . .\end{array}$ & $\begin{array}{|cc|}\text { st } & \text { lbs } \\
9 & 3 \\
8 & 7 \\
6 & 4 \\
5 & 4\end{array}$ & \begin{tabular}{cc|} 
st & lbs \\
9 & 7 \\
9 & 5 \\
7 & 3 \\
6 & 3
\end{tabular} & $\left|\begin{array}{cc}\text { st } & \text { lbs } \\
9 & 7 \\
9 & 7 \\
7 & 7 \\
6 & 7\end{array}\right|$ & \begin{tabular}{|cc} 
st & lbs \\
9 & 7 \\
9 & 7 \\
7 & 7 \\
6 & 7
\end{tabular} & $\begin{array}{|cc|}\text { st } & \text { lbs } \\
9 & 1 \\
5 & 4 \\
6 & 2 \\
5 & 2\end{array}$ & $\begin{array}{|cc|}\text { st } & \text { lbs } \\
9 & 6 \\
9 & 4 \\
7 & 2 \\
6 & 2\end{array}$ & $\begin{array}{|cc|}\text { st } & \text { lbs } \\
9 & 7 \\
9 & 7 \\
7 & 7 \\
6 & 7\end{array}$ & \begin{tabular}{|cc} 
st & lbs \\
9 & 7 \\
9 & 7 \\
7 & 7 \\
6 & 7
\end{tabular} \\
\hline & \multicolumn{4}{|c|}{ 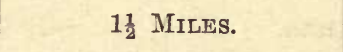 } & \multicolumn{4}{|c|}{13 Miles. } \\
\hline $\begin{array}{l}\text { English } \\
\text { Australians ... } \\
\text { Country-breds } \\
\text { Arabs ... ... }\end{array}$ & $\begin{array}{|rr|}\text { s } & 1 \mathrm{lbs} \\
8 & 13 \\
8 & 1 \\
5 & 11 \\
4 & 11\end{array}$ & $\left|\begin{array}{cc}\text { st } & \text { Jbs } \\
9 & 5 \\
9 & 3 \\
7 & 0 \\
6 & 0\end{array}\right|$ & $\left|\begin{array}{cc}\text { st } & \text { lbs } \\
9 & 7 \\
9 & 7 \\
7 & 6 \\
6 & 6\end{array}\right|$ & $\begin{array}{|cc|}\text { st } & 1 b s \\
9 & 7 \\
9 & 7 \\
7 & 7 \\
6 & 7\end{array}$ & $\begin{array}{lr}\text { st } & 1 \mathrm{~b}: \\
8 & 11 \\
7 & 12 \\
5 & 9 \\
4 & 9\end{array}$ & $\begin{array}{|cc|}\text { st } & 1 \mathrm{~b}_{3} \\
9 & 4 \\
9 & 2 \\
6 & 12 \\
5 & 12\end{array}$ & $\left|\begin{array}{cc|}\text { st } & 1 \mathrm{~b} 3 \\
9 & 7 \\
9 & 6 \\
7 & 6 \\
6 & 6\end{array}\right|$ & $\mid \begin{array}{cc}\text { st } & \text { lbs } \\
9 & 7 \\
9 & 7 \\
7 & 7 \\
6 & 7\end{array}$ \\
\hline & \multicolumn{4}{|c|}{2 Miles. } & \multicolumn{4}{|c|}{$2 \frac{1}{2}$ Miles. } \\
\hline $\begin{array}{ll}\text { English } & \ldots \\
\text { Australians } & \ldots \\
\text { Country-bre } 3 \mathrm{~s} \\
\text { Arabs }\end{array}$ & \begin{tabular}{cc|} 
st & lbs \\
$\varepsilon$ & 10 \\
7 & 10 \\
5 & 7 \\
4 & 7
\end{tabular} \mid & $\left|\begin{array}{cc}\text { st } & \text { lbs } \\
9 & 4 \\
9 & 1 \\
6 & 11 \\
5 & 11\end{array}\right|$ & $\left|\begin{array}{cc}\text { t } & \text { lbs } \\
9 & 7 \\
9 & 6 \\
7 & 6 \\
6 & 6\end{array}\right|$ & $\begin{array}{|cc|}\text { st } & 178 \\
9 & 7 \\
9 & 7 \\
7 & 7 \\
6 & 7\end{array}$ & $\begin{array}{|cc|}\text { st } & 1 \mathrm{bs} \\
8 & 7 \\
7 & 6 \\
5 & 1 \\
4 & 1\end{array}$ & $\begin{array}{|cc|}\text { st } & \text { lbs } \\
9 & 3 \\
9 & 0 \\
6 & 9 \\
5 & 9\end{array}$ & $\left|\begin{array}{cc}\text { st } & \text { lhs } \\
9 & 7 \\
9 & 6 \\
7 & 6 \\
6 & 6\end{array}\right|$ & \begin{tabular}{|cc} 
st & l., \\
9 & 7 \\
9 & 7 \\
7 & 7 \\
6 & 7
\end{tabular} \\
\hline & \multicolumn{4}{|c|}{3 Miles. } & \multicolumn{4}{|c|}{4 Miles. } \\
\hline $\begin{array}{l}\text { English } \\
\text { Austral ans... } \\
\text { Country-breds } \\
\text { Arabs ... ... }\end{array}$ & \begin{tabular}{|cc} 
st & lus \\
$\ldots$ & $\cdots$ \\
$\ldots$ & $\cdots$ \\
$\ldots$ & $\cdots$ \\
$\ldots$ & $\cdots$
\end{tabular} & $\mid \begin{array}{cc}\text { st } & \mathrm{lb} \\
9 & 3 \\
9 & 0 \\
6 & 6 \\
5 & 6\end{array}$ & $\begin{array}{|cc|}\text { st } & \mathrm{Jbs} \\
9 & 7 \\
9 & 6 \\
7 & 6 \\
6 & 6\end{array}$ & \begin{tabular}{|cc} 
st & lbs \\
9 & 7 \\
9 & 7 \\
7 & 7 \\
6 & 7
\end{tabular} & $\begin{array}{cc}\text { st } & \text { lbs } \\
. . & \ldots \\
\ldots & \ldots \\
. . & \ldots \\
. . & \ldots\end{array}$ & $\begin{array}{rr}\text { st } & \text { lbs } \\
9 & 6 \\
8 & 8 \\
5 & 12 \\
4 & 11\end{array}$ & \begin{tabular}{|cc} 
st & lbs \\
9 & 7 \\
9 & 4 \\
7 & 5 \\
6 & 5
\end{tabular} & $\begin{array}{rr}\text { st } & \text { lb } \\
9 & 7 \\
9 & 7 \\
7 & 7 \\
6 & 7\end{array}$ \\
\hline
\end{tabular}




\section{EXTRACT FROM C.T.C. RULES OF RACING.}

"19 . . European and North-American horses shall be classed with English ; African and South American horses with Australasian; Persian borses with Arab; other Asiatic horses with Country-bred ...

"20. The age of a horse of the English, Country-bred and Arab class, shall be reckoned from the 1st January; and of the Australian class, from the 1st of August.

"Appendix A. (i.) As 6 st. is the lowest weight which a horse can carry, lower weights are only inserted to show the relative weights of the different classes.

"(ii.) Weight for age for 'English and Australasian horses is the scale reduced $4 \mathrm{lbs}$.; for Country-bred and Arab horses, the scale raised $24 \mathrm{lbs}$. and $38 \mathrm{lbs}$. respectively.

"(iii.) When English and Australian horses run together without any other class in a weight for class race, the weight in the scale is reduced $4 \mathrm{lbs}$.; and when Country-bred and Arab horses run together without any other class it is raised $28 \mathrm{lbs}$.

"(iv.) When horses of only one class run in a weight for age and class weight, the weight to be carried is weight for age, unless otherwise specified.

"(v.) Welter weight is obtained by adding 2 st. to the scale of weight read in connection with these instructions.

"(vi.) A two year old, if an English, Country-bred, or Arab, must carry the weight of a three year old in 
January ; if an Australian, the weight of a three year old in August.

"(vii.) A three year old English, Country-bred, or Arab horse, running in a race exceeding $2 \frac{1}{2}$ miles, must carry the weight of a four year old in January; and a three year old Australian horse must carry the weight of a four year old in August." 


\section{Messrs. Hurst \& Blackett beg to announce that they are now publishing the following Works by Captain M. Horace Hayes, F.R.C.V.S.}

\section{Points of the Horse.}

\section{A familiar Treatise on Equine Conformation. BY}

\section{Capt. M. HORACE HAYES, F.R.C.Y.S.}

This Edition has been thoroughly revised and contains numerous additions, including specially written Chapters on the Breeds of English and Foreign Horses.

Illustrated by 200 reproductions of Photographs of Typical "Points" and Horses, and 205 Drawings by J. H. OSwALD BRown.
SECOND EDTION.
Revised and Enlarged.
Super-Royal 8vo., Cloth, Gilt Top, 34s.

" Capt. Horace Hayes, the best of writers upon horses, has issued a second edition-considerably altered and enlarged, and magnificently illustrated-of his admirable work upon the 'Points of the Horse,' which is, in fact, a complete work on horses, their races and peculiarities."-Athencum.

\section{Illustrated Horsebreaking.}

BY

\section{Capt. M. HORACE HAYES, F.R.C.Y.S.}

This Edition has been entirely re-written, the amount of the letterpress more than doubled, and 75 reproductions of Photographs have been added.

SECOND EDITION. Imperial 16mo., Buckram, 21s.

"A valuable addition to the literature of a subject which this author may really be said to have made his own. We do not know another who so happily combines absolute practical knowledge with an attractive literary style."Referee. 


\section{Veterinary Notes for Horse $=0$ wners.}

An Illustrated Manual of Horse Medicine and Surgery, written in simple language, with over 200 Illustrations.

By Capt. M. H. HAXES, F.R.C.Y.S.

FIFTH EDITION. Revised throughout, considerably enlarged, and incorporates the substance of the Author's "Soundness and Age of Horses."

Large Crown 8vo., Buckram, 15s.

"It is superfluous to commend a book that is an established success, and that has gone on from edition to edition extending its usefulness."-Army and Navy Gazette.

\section{Training and Horse Management in India.}

By Capt. M. H. HAYES, F.R.C.X.S. FIFTH EDITION. Crown 8vo., Cloth, 6s.

" We entertain a very high opinion of Capt. Hayes' book on 'Horse Training and Management in India,' and are of opinion that no better guide could be placed in the hands of either amateur horseman or veterinary surgeon newly arrived in that important division of our Empire."-Veterinary fournal.

\section{Infective Diseases of Animals.}

\section{Belng Part I. of the Translation of Friedberger and Frohner's} Pathology of the Domestic Animals.

Translated and Edited by Capt. M. H. HAYES, F.R.C.Y.S. With a Chapter on Bacteriology by DR. G. NEwMAN, D.P.H.

Demy 8vo., 10s. 6d. Nett.

"The plan of the work is excellent, and the arrangement all that could be desired; while the translation has been aptly done, and the awkwardness of rendering the original German into English, so common in translations, has been avoided. Dr. Newman's notes on bacteriology form an acceptable addition to the volume. This is a work which no veterinary practitioner who is anxious to be thoroughly up-to-date in his professional knowledge can afford to be without."-Glasgow Herald.

\section{The Horsewoman.}

\section{A Practical Guide to Side-Saddle Riding.}

By Mrs. HAYES. Edited by Capt. M. H. HAYES.

With 4 Collotypes from Instantaneous Photographs, and 48 Drawings after Photographs, by J. H. OsWALD BRown.

With Numerous Illustrations. Large Crown 8vo., Cloth Gilt, 10s. 6d.

"This is the first occasion on which a practical horseman and a practical horsewoman have collaborated in bringing out a book on riding for ladies. The result is in every way satisfactory, and, no matter how well a lady may ride, she will gain much valuable information from a perusal of "The Horsewoman. " 1 "Field.

LONDON: HURST AND BLACKETT, LIMITED. 


\section{NEW AND IMPORTANT WORK.}

In One Volume, demy 8 vo, extra cloth, Illustrated by numerous Maps and Plans. Price I 2s. nett.

\section{The Egyptian Campaigns,}

I882=1885. New and Revised Edition continued to 1899 .

By CHARLES ROYLE,

Late R.N.; Barrister-at-Law, Judge of the Egyptian Court of Appeal, Cairo.

\section{NEW WORK ON MADEIRA.}

In Two Volumes, demy 8vo, with 76 Full-page Illustrations and Maps. Price 20s. nett.

\section{The Madeira Islands.} BY ANTHONY J. DREXEL BIDDLE.

Containing The History of the Madeiras, Information for the Traveller and Visitor, and a Description of the Natives; their Characteristics, Religion, Laws and Customs, \&c.

MR. W. ROSSETTI'S NEW WORK. In One Volume, crown 8vo, Illustrated. Price 6s.

Præraphaelite Diaries and Letters. Containing Letters of Dante Gabriel Rossetti ; Diary of FORD MADOX BROWN; the P.R.B. Journal, by W. RossetTi.

Edited by WILIIAM MICHAEL ROSSETTI. 
MR. TIGHE HOPKINS' LATEST SUCCESS.

In One Volume, crown 8 vo, extra cloth. 6 .

\section{An Idler in Old France}

\section{By TIGHE HOPKINS,}

Author of "The Dungeons of Old Paris," "Nell Haffenden," Etc.

\section{NEW WORK BY ARTHUR H. BEAVAN.}

In One Volume, crown 8vo, with a specially designed Cover by Albert A. Turbayne, and 5 Portraits. $6 \mathrm{~s}$.

\section{James and Horace Smith}

(JOINT AUTHORS OF "REJECTED ADDRESSES").

A FAMILY NARRATIVE, BASED UPON HITHERTO UNPUBLISHED PRIVATE DIARIES, LETTERS, AND OTHER DOCUMENTS.

\section{By ARTHUR H. BEAVAN,}

Author of "Marlborough House and Its Occupants," Etc.

Now Ready, at all Booksellers and Libraries. In One Volume, crown 8vo, cloth, with 58 Illustrations. Price 2s. 6d.

\section{China and the Chinese.}

Translated and Edited from the French of EDMUND Plauchut.

\section{By Mrs. ARTHUR BELL (N. D'Anvers),}

Author of "Elementary History of Art," "Science Ladders Series," Etc. 
NEW AND IMPORTANT BOOK OF TRAVEL.

In One Volume, demy $8 \mathrm{vo}$, with 56 Illustrations, from Photographs by the Author, a Frontispiece by R. Talbot Kelly, R.B.A., and 2 Maps. Price I6s.

\section{FROM SPHINX TO ORACLE.}

Through the Libyan Desert to the Oasis of Jupiter Ammon.

BY

ARTHUR SILVA WHITE, Hon. F.R.S.G.S.

Author of "The Development of Africa," Etc.

NEW WORK BY J. H. E. SECRETAN.

In One Volume, large crown $8 \mathrm{vo}$, with 24 Illustrations. Price 6s.

\section{TO KLONDYKE AND BACK.}

A Journey down the Yukon from its Source to its Mouth.

WITH HINTS TO INTENDING PROSPECTORS.

By J. H. E. SECRETAN, of Ottawa.

NEW WORK BY W. A. PICKERING, C.M.G.

In One Vol., demy 8vo, extra cloth, with 25 Illustrations, from Photographs and Sketches by the Author. Price r6s.

\section{PIONEERING IN FORMOSA. By W. A. PICKERING, C.M.G.}

Late Protector of Chinese in the Straits Settlements. 
NEW WORK bY FRANOIS HINDES GROOME. In One Volume, demy 8vo. Price r 2s.

\section{GYPSY \\ FOLK = TALES.}

BY

FRANCIS HINDES GROOME,

Author of "In Gypsy Tents," "Two Suffolk Friends," Etc.

MR. OSCAR BROWNING'S NEW WORK.

In One Vol., crown 8vo, with a Portrait of Charles XII. 6s.

CHARLES XII. of SWEDEN BY OSCAR BROWNING.

NEW WORK BY T. H. S. ESCOTT.

In One Volume, large crown 8vo, extra cloth. Price 6s.

PERSONAL FORCES OF THE PERIOD.

By T. H. S. ESCOTT,

Author of "England: Its People, Polity, and Pursuits," "Social Transformations of the Victorian Age," Etc.

NEW WORK BY DR. PARKER. NOW READY, AT ALL BOOKSELLERS AND LIBRARIES.

In One Volume, crown 8vo. Price 3s. $6 \mathrm{~d}$.

\section{CHRISTIAN PROFILES}

IN A PAGAN MIRROR.

BY JOSEPH PARKER, D.D.,

MINISTER OF THE CITY TEMPLE, LONDON. 


\section{BOOKS FOR THE COUNTRY AND SEASIDE.}

Each in One Volume, crown 8vo. Price 3s. 6d.

\section{Folly and Fresh Air.}

BY EDEN PHILLPOTS.

Author of "The Human Boy," "My Laughing Philosopher," \&c. Illustrated by J. Leys Pethybridge.

\section{From Veldt Camp Fires.}

STORIES OF SOUTHERN AFRICA.

By H. A. BRYDEN.

Author of "An Exiled Scot," "Gun and Camera in Southern Africa," \&c.

\section{THE KISS OF ISIS.}

BY CAPTAIN ARTHUR HAGGARD.

Author of "Only a Drummer Boy," "With Rank and File," \&c.

\section{London at the End of the Century.} By ARTHUR W. À BECKETT,

Author of "The Member for Wrottenborough," "The Modern Adam," \&c.

The Professional and other Psychic Stories.

Edited by A. GOODRICH FREER (MISS X),

Author of "Essays in Psychical Enquiry," "The Alleged Haunting of $\mathrm{B}-$ House," \&c.

The Second Thoughts of an Idle Fellow.

BY JEROME K. JEROME,

Author of "Three Men in a Boat," \&c., \&c.

LONDON : HURST AND BLACKETT, LIMITED. 
NEW AND POPULAR EDITION of

\section{Edna Lyall's Novels.}

Each One Vol., crown 8vo, 3s. 6 d.

DONOYAN : A MODERN ENGLISHMAN.

WE TWO.

KNIGHT ERRANT.

IN THE GOLDEN DAYS.

WON BY WAITING.

A HARDY NORSEMAN.

TO RIGHT THE WRONG.

UNIFORM WITH THE ABOVE.

Dr. Geo. Macdonald's Novels.

Each One Vol, crown 8vo, 3s. 6 d.

DAYID ELGINBROD.

ROBERT FALCONER.

SIR GIBBIE.

ALEC FORBES OF HOWGLEN.

SALTED WITH FIRE.

LONDON : HURST AND BLACKETT, LIMITED. 


\section{POPULAR WORKS BY POPULAR AUTHORS}

THE NEW FICTION, and other Essays on Literary Subjects. By H. D. TraILL, Author of "The New Lucian," "The Life of Sir John Franklin," etc. One Vol., crown 8vo. Price 6s.

IN CAMP AND CANTONMENT. Stories of Foreign Service. By Edith E. Cuthell, Author of "Only a Guardroom Dog," "The Wee Widow's Cruise," etc. One Vol., crown 8vo. Price 3s. 6d.

LADY HAMILTON AND LORD NELSON. By John Cordy Jeaffreson. New and Revised Edition. Containing Additional Facts, Letters and other Materials. With Portrait of Lady Hamilton. One Vol., large crown 8vo, gilt top. Price 6s.

FAMOUS BRITISH WARSHIPS AND THEIR COMMANDERS. By WALTER WOOD. Author of "Barrack and Battlefield." With Portrait of Admiral Viscount Nelson. One Vol., large crown 8vo. Price 6s. THE TAME FOX, and other Sketches. By Finch Mason. With 6 Full-page Coloured Illustrations. One Vol., large crown 8vo. Price 7 s. 6 d.

BARRAOK AND BATTLEFIELD. Tales of the Service at Home and Abroad. By Walter Wood. One Vol., large crown 8vo, gilt top. Price 6s.

THE REAL LORD BYRON. By JOHN CORDY JEAFFRESON. One Vol, crown 8vo. With Portrait of Lord Byron by T. Phillips, R.A., engraved on steel. Price 5 s.

FIFTY YEARS OF MY LIFE IN THE WORLD OF SPORT AT HOME AND ABROAD. By SIR John Dugdale Astley, Bart. One Vol., crown 8vo with Portrait. Price 6s. Also in small crown 8vo, cloth. Price 2s. 6d.

THE LAST OF THE BUSHRANGERS. An Account of the Capture of the Kelly Gang. One Vol., crown 8vo, with 8 Full-page Illustrations. Price 3 s. $6 \mathrm{~d}$.

LONDON : HURST AND BLACKETT, LIMITED. 
NEW AND POPULAR NOVELS. NOW READY AT ALL BOOKSELLERS AND LIBRARIES.

Each in One Yolume, croxn 8xo. Price 6s.

\section{BEQUEATHED.}

By BEATRICE WHITBY, Author of "The Awakening of Mary Fenwick," "Part of the Property," \&c.

\section{THE DISHONOUR OF FRANK SCOTT}

By M. HAMILTON, Author of "A Self-denying Ordinance," "McLeod of the Camerons," \&c.

A MARTIAL MIND.

By ANNE ELLIOT, Author of "Dr. Edith Romney," "The Winning of May," \&c.

\section{AYLWIN.}

By THEODORE WATTS-DUNTON, Author of "The Coming of Love ; Rhona Boswell's Story"

THE FORSAKEN WAY.

$A$ Romance. By PHILIP LAFARGUE, Author of "Stephen Brent," "The Salt of the Earth," \&c.

A KISS FOR A KINGDOM;

Or, a Venture in Vanity. By BERNARD HAMILTON Author of "The Light."

\section{TRICKS AND TRIALS.}

By CHRISTABEL COLERIDGE, Author of "The" Main Chance," "Waynflete," \&c.

\section{RISING FORTUNES :}

The Story of a Man's Beginnings. By JOHN OXENHAM, Author of "God's Prisoner," \&c.

\section{THE LORD OF THE HARVEST.}

By M. BETHAM-EDWARDS, Author of "A Storm-rent Sky," "Kitty," "Dr. Jacob."

\section{THE PORT GUARD SHIP:}

$A$ Romance of the Modern Navy. By FRED T. JANE, Author of "Blake of the Rattlesnake," "His Lordship the Passen and We," \&c.

LONDON : HURST AND BLACKETT, LIMITED. 


\section{BEATRICE WHITBY'S NOVELS EACH IN ONE VOLUME, CROWN 8vo-3s. 6d.}

\section{THE AWAKENING OF MARY FENWICK}

"We have no hesitation in declaring that "The Awakening of Mary Fenwlck" is the best novel of its kind that we have seen for some years. The story is extremely simple. Mary Mauser marries her husband for external, and perhaps rather inadequate, reasons, and then discovers that he married her because she was an heiress. She feels the indignity scately, and does not scruple to tell him her opinion-her very candid opinion-of his behaviour. Mary Fenwick and her husband live and move and make as believe in them in a way which fow but the great masters of fiction have been able to compass. $-\Delta$ then 2 um.

\section{ONE REASON WHY}

- The governess makes a re-entry into flction under the auspices of Beatrice Whitby in "One Reason Why." Readers generaliy, however, will take a great deal more interest, for once, in the children than in their instructress. "Bay "and "Ellie" are charmingly natural additions to the children of novel-land; 80 much 80 , that there is a period when one dreads a death-bed ecene for one of them-a fear which is happily unfulelled. Craphic.

\section{PART OF THE PROPERTY}

- The book is a thoroughly good one. The theme is fairly familiar-the rebellion of a spirited girl against a match which has beon arranged for her without her knowledge or consent; her resentment of being treated, not 28 \& woman with a heart and will, but as "part of the proporty;" and her flnal discovery, which is led up to with real dramatic skill, that the thing against which her whole nature had risen in revolt has become the one desire of her heart, - Spectator.

\section{IN THE SUNTIME OF HER YOUTH}

The careless optimism of the head of the family would be incredible, if we did not know how men exist full of responsibilities yot free from solieitudes, and who tread with a janty step the very verge of ruin; his inconsolable widow would be equally improbabie, if we did not meet every day with women who devote themselves to such idols of clay. There is interest in it from first to last, and its pathos is relieved by touches of true inmour.'-Illustrated London Newos.

\section{MARY FENWICK'S DAUGHTER}

This is one of the most deiightful novels we have read for a long time. "Bab" Ferwick is an "ont of door" kind of girl, full of spirit, wit, go, and sin, both original and acquired. Her lover, Jack, is all that a hero should be, and great and magnanimous as he is, finds some difficulty in forgiving the insouciante mistress all her little sins of omission and commission. The whole is admirable - - Black and White.

\section{A MATTER OF SKILL}

'The title otory, showing how a stately girl is captured after a good deal of' trouble, by whort and commonplace young man, is very amueing; and there are other sketches in which it is interesting to follow the wiles of Mother Eve ere ahe has come to years of disoretion.-Academy.

\section{SUNSET}

"We weleome suoh a story as "Sunset." It is slightly sentimental as one would guese from its title, but never mawlish, and it is illumined by flashes of humour, as well as by nome oocasional refleotions that exhibit a close acquaintance with human nature.'-The Times. 
HURST AND BLACKETT'S HALF-A-GROWN SERIES,

IN RED CLOTH.

LIFE OF MARIE ANTOINETTE. By Charles Duke YoNGE.

NATHALIE. By Julia Kavanagh.

THE CRESCENT AND THE CROSS. By ELIOT WARBURTON.

ST. OLAVE'S. By the Author of "Janita's Cross."

THE OLD COURT SUBURB. BY LEIGH HUNT.

ON THE SCENT. By Lady M. Majendie.

ADAM GRAEME OF MOSSGRAY. By MRS. OLIPHANT. BARBARA'S HISTORY. BY AMELIA B. EDWARDS.

THE LAIRD OF NORLAW. By MrS. OLIPHANT.

NO CHURCH. BY F. W. ROBINSON.

LORD BRACKENBURY. By Amelia B. Edward, LL.D.

A ROSE IN JUNE. By Mrs. Oliphant.

PHCEBE, JUNiOR. By Mrs. Oliphant.

THROUGH THE LONG NIGHT. By MRS. E. LYNN LiNTON.

MARQARET AND HER BRIDESMAIDS. By the Author of "The Valley of a Hundred Fires."

THE VALLEY OF A HUNDRED FIRES. By the Author of "Margaret and Her Bridesmaids."

LONDON : HURST AND BLACKETT, LIMITED. 


\section{EDITIONS OF \\ 'JOHN HALIFAX, GENTLENAN'}

\section{ILLUSTRATED EDITION}

Illustrations by HUGH RIVIERE, large crown 8 vo, extra cloth, gilt top, price 6s.

\section{STANDARD EDITION}

Crown 8vo, cloth, with frontispiece by SIR JoHN MILLAIS, Bart., price 5s.

\section{TEWKESBURY EDITION}

Crown 8vo, cloth, with portrait of Author by Professor Herkomer, cloth, price 3s. 6 d.

\section{POPULAR EDITION}

Crown 8vo, cloth, price 2s.

\section{PEOPLE'S EDITION}

In medium 8vo, cloth, price $1 \mathrm{~s}$.

In paper cover, price $6 \mathrm{~d}$. 


\section{MRS. CRAIK'S NOVELS Each in One Volume, Crown Octavo, 3s. $6 d$.}

\section{JOHN HALIFAX, GENTLEMAN.}

- The new and chesper edition of this interesting work will doubtless meet with great raccess. John Halifax, the hero of this most beautif ul story, is no ordinary hero, and this his history is no ordinary book. It is a full-length portrait of \& true gentiemen, one of natare' own nobility. It is also the history of a home, and a thoroughly English one. The work abounds in incident, and is full of graphic power and true pathos. It is book that few will read without becoming wiser and better."-Scotsman.

\section{A LIFE FOR A LIFE.}

"We are always glad to weicome this author. She writes from her own convictions, and she has the power not only to conceive clearly what it is that she wishes to say, bat to express it in language effective and vigorous. In 'A Life for a Life' she is fortunate in a good sabject, and she has produced a work of strong effect. The reader, having read the book through for the story, will be apt (if he be of our persuasion) to return and read again many pages and passages with greater pleasure than on a flrst perusal. The whole book is replete with a graceful, tender delicacy; and in addition to its other merits, it is written in good careful English." -A thenæum.

\section{CHRISTIAN'S MISTAKE.}

"A more charming story, to our taste, has rarely been written. Within the compase of a single volume the writer has hit off a circle of varied characters, all true to naturonome true to the highest natare-and she has entangled them in a story which keeps a: in suspense till the knot is happily and gracefuliy resolved; while, at the same time, a pathetio interest is sustained by an art of which it would be difflicult to analyse the secret. It is a choice gift to be able thus to render human nature so traly, to penetrate its depth: with such a searching sagacity, and to illuminate them with a radiance so eminentiy the writor'B own."-The Iimes.

\section{A NOBLE LIFE.}

"This is one of those pleasant tales in which the author of 'John Halifax' operks out of a generous heart the purest truths of life."-Examiner.

"Few men, and no women, will read 'A Noble Lifo' without flnding themselves the better." - Spectator.

"A atory of poworful and pathetio interest. -Daily Neros.

\section{THE WOMAN'S KINGDOM.}

"'The Woman's Kingdom' sustain the author's reputation as a writer of the purest and noblest kind of domestic stories. The novelist'e lesson is given with admirsbio foroe and sweetness "-Athen sum.

"The Woman' Kingdom ' is remarkable for its romantio interest. The character are masterpieces. Edna is worthy of the hand that drew John Halifax" - Post.

\section{A BRAVELADY.}

"A very good novel, showing a tender eympathy with human nature, and permeated by a pure and noble spirit."-Examiner.

"A most charming story." - Standard.

"Wo earnestly recommend this novel It is a special and worthy opecimen of the athor's remarkable powers. The reader's attention never for a moment flaga."-Past.

\section{MISTRESS AND MAID.}

"A good, wholesome book, as plessant to read as it is instructive." $-A$ thenoesm.

"This book is written with the same true-hearted esrnestness as 'John Halifax. The opirit of the whole work is excelleut "-Examiner.

"A charming tale charmingiy told."-Standard.

\section{LONDON : HURST AND BLACKETT, LIMITED.}




\section{MRS. CRAIK'S NOVELS Each in One Volume Crown Octavo, 3s. 6 d.}

\section{YOUNG MRS. JARDINE.}

"' 'Toung Mrs. Jardine' is a protty story, witten in pure English."-The Times.

"There is much good feeling in this book. It is pleasant and wholesome." $-A$ thenerum.

" $\mathrm{A}$ book that all shouid read. Whilat it is quite the equal of any of its predecessor: in elevation of tbought and style, it is perhaps their superior in interest of plot and dramatic intensity. The characters are admirably delineated, and the dialogue in natural and cies." - Morning Post.

\section{HANNAH.}

"A powerful novel of social and domestio life. One of the most successful efforts of a meccessful novelist,"-Daily Neros.

"A very plessant, healthy story, well and artistically told. The book is sure of a wide drole of resderi. The character of Hannah is one of rare beanty." -Standard.

\section{NOTHING NEW.}

" 'Nothing New' displays all those superior merits which have made 'John Halifax' one of the mont popular works of the day." - Post.

"The reader will find these narrative calculated to remind him of that truth and mergy of hnman portraiture, that spell over human affections and emotions, which have itamped this anthor as one of the first novelists of our day." -John Bull.

\section{THE UNKIND WORD.}

"The anthor of 'John Halifax' has written many fascinating storles, but we can eall to mind nothing from her pen that has a more enduring charm than the graceful sketches in this work. Such a charscter as Jessio stands out from a crowd of heroines as the type of all that is truly noble, pure, and womanly."-United Service Magazine.

\section{STUDIES FROM LIFE.}

"These studies are truthful and vivid pictures of life, often earnest, always full of right feeling, and occasionally lightened by tonches of qulet genial humour. The volnme is remarksble for thought, sound sense, shrewd observation, and kind and sympathetio foeling for sll things good and beantiful."-Post.

\section{A WOMAN'S THOUGHTS ABOUT WOMEN.}

"A book of sound counsel. It is one of the most sensible works of its kind, well written truo-hearted, and altogether practical. Whoever wishes to give advice to a young lady may thank the anthor for means of doing so."-Examiner.

"These thoughts are worthy of the earnest and enlightened mind, the all-ombracins charity, and the well-osrned roputation of the author of "John Halifax." "- Standard

"This excellent book is charscterised by good sense, good trste, and feeling, and is Fritten in an earnest, philanthropic, as woll as practical spirit." - Post.

\section{HIS LITTLE MOTHER.}

"' His Little Mother' is the story of a sister'B self-sacriflce from her chlldhood untti her early death, worn out in her brother's and his children's service. It is a pathetie story as the suthor telis it. The beanty of the girl's devotion is desoribed with many tender touches, and the question of short-sighted though loving foolishness is kept in the background. The volume is written in a pleasant informal manner, and contains many tender generous thoughts, and not a few practical ones. It is a book that will be read with inbrest, and that cannot be lightly forgotten."-St. James's Garelte. 


\section{Winoer the Ipecial Datronage of ther Inajesty.}

Published annually, in December, in One Volume, royal 8vo, the Arms engraved, bound with gilt edges, 3Is. 6 d.

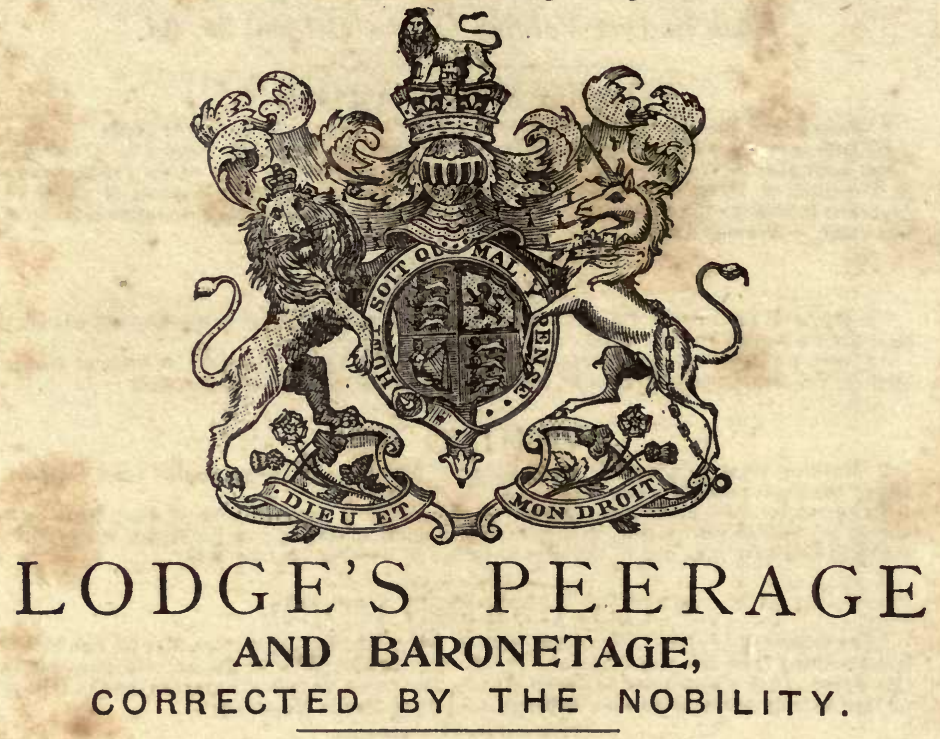

\section{LIST OF THE PRINCIPAL CONTENTS.}

Historical View of the Peerage.

Parliamentary Roll of the House of Lords.

English, Scotch, and Irish Peers, in their orders of Precedence.

Alphabetical List of Peers of Great Britain and the United Kingdom, holding superior rank in the Scotch or Irish Peerage.

Alphabetical List of Scotch and Irish Peers, holding superior titles in the Peerage of Great Britain and the United Kingdom.

A Collective List of Peers in their order of Precedence.

Table of Precedency among Men.

Table of Precedency among Women.

The Queen and the Royal Family.

Peers of the Blood Royal

The Peerage, alphabetically arranged.

Families of such Extinct Peers as have left Widows or Issue.

Alphabetical List of the Surnames of all the Peers.
The Archbishops and Bishops of England and Ireland.

The Baronetage, alphabetically arranged.

Alphabetical List of Surnames assumed by members of Noble Families.

Alphabetical List of the Second Titles of Peers, usually borne by their Eldest Sons.

Alphabetical Index to the Daughters of Dukes, Marquises, and Earls, who, having married Commoners, retain the title of Lady before their own Christian and their Husbands' Surnames.

Alphabetical Index to the Daughters of Viscounts and Barons, who, having married Commoners, are styled Honourable Mrs.; and, in case of the husband being a Baronet or Knight, Hon. Lady.

A List of the Orders of Knighthood.

Mottoes alphabetically arranged and translated.

"This work is the most perfect and elaborate record of the living and recently deceased members of the Peerage of the Three Kingdoms as it stands at this day. It is a most useful publication. We are happy to bear testimony to the fact that scrupulous acoursey is a distinguished feature of this book."-Times. 

RETURN TO the circulation desk of any

University of California Library

or to the

NORTHERN REGIONAL LIBRARY FACILITY

Bldg. 400, Richmond Field Station

University of California

Richmond, CA 94804-4698

ALL BOOKS MAY BE RECALLED AFTER 7 DAYS

2 -month loans may be renewed by calling

(415) 642-6233

$\mathrm{Re}$

1-year loans may be recharged by bringing books to NRLF

Renewals and recharges may be made 4 days prior to due date

DUE AS STAMPED BELOW

\section{DEC? 251989 \\ FEB 18 1993}

MAY 052001 
321

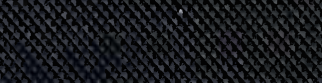

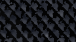

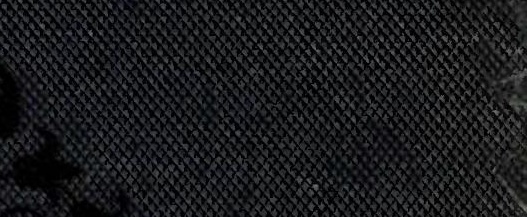

